ANDREI NARDELLI

THE SHAFT FRICTION DEGRADATION OF PILES UNDER CYCLIC AXIAL LOADING IN WIND TURBINE FOUNDATIONS

São Paulo 

THE SHAFT FRICTION DEGRADATION OF PILES UNDER CYCLIC AXIAL LOADING IN WIND TURBINE FOUNDATIONS

\begin{abstract}
Dissertation presented to the Graduate Program in Civil Engineering of the School of Engineering of the University of São Paulo as a fulfillment of the requirements for the degree of Master of Science.
\end{abstract}

Concentration area:

Geotechnical Engineering

Advisor: Prof. Dr. Marcos Massao Futai

São Paulo 
Autorizo a reprodução e divulgação total ou parcial deste trabalho, por qualquer meio convencional ou eletrônico, para fins de estudo e pesquisa, desde que citada a fonte.

Este exemplar foi revisado e alterado em relação à versão original, sob responsabilidade única do autor e com a anuência de seu orientador.

São Paulo, 27 de julho de 2019

Assinatura do autor:

Assinatura do orientador:

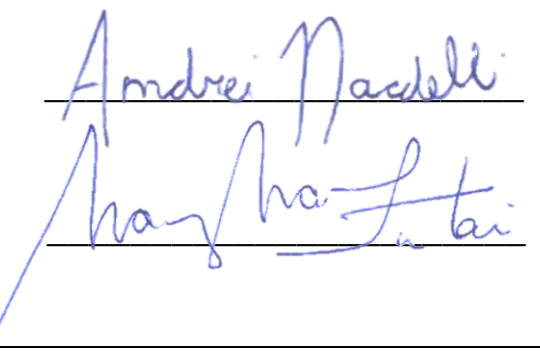

Catalogação-na-publicação

\section{Nardelli, Andrei}

The shaft friction degradation of piles under cyclic axial loading in wind turbine foundations / A. Nardelli -- versão corr. -- São Paulo, 2019.

$182 \mathrm{p}$.

Dissertação (Mestrado) - Escola Politécnica da Universidade de São Paulo. Departamento de Engenharia de Estruturas e Geotécnica.

1.Wind turbine foundations 2.Soil-structure interaction 3.Cyclic loading 4.Pile-soil interface 5.Shaft friction degradation I.Universidade de São Paulo. Escola Politécnica. Departamento de Engenharia de Estruturas e Geotécnica II.t. 


\section{ACKNOWLEDGMENT}

I would like to express my deepest gratitude to my supervisor, Professor Marcos Massao Futai, for his encouragement and guidance during the past two years. I would like to acknowledge the committee members of this dissertation, Professor Cristina de Hollanda Cavalcanti Tsuha and Professor Marcio de Souza Soares de Almeida for their contributions. I am also very thankful to the Geotechnical Engineering Research Group (GeoInfraUSP) whose support has enabled me to grow professionally and overcome several challenges. I would like to thank all my GeoInfraUSP colleagues for their assistance and friendship.

I would like to express my thanks to the Brazilian Association of Wind Energy for sharing the Brazilian wind farm statistics database. I am also very grateful to all the wind energy companies and foundation designers who actively participated in this research: Alupar, Atlantic Energias Renováveis, Casa dos Ventos Energias Renováveis, Companhia Hidrelétrica do São Francisco CHESF, CPFL Renováveis, CTE Wind Brazil, Cubico Brazil, Eletrosul Centrais Elétricas, Enel Green Power Brazil, Engie, Queiroz Galvão Energia, Renova Energia, Votorantim Energia and Professor Jarbas Milititsky.

Finally, I would like to express my sincere thanks to my dear girlfriend and family, colleagues and friends for their encouragement, friendship and love.

The author acknowledges the financial support by the National Council for Scientific and Technological Development (CNPq; grants 405759/2013-4 and 302470/2017-4), the Department of Economic Development, Science, Technology and Innovation of São Paulo (SDECTI) and the São Paulo Research Foundation (FAPESP; grants 2015/10223-2 and 2017/07341-9). 

"Caminante, son tus huellas el camino y nada más;

Caminante, no hay camino, se hace camino al andar. $\mathrm{Al}$ andar se hace el camino, y al volver la vista atrás se ve la senda que nunca se ha de volver a pisar.

Caminante no hay camino sino estelas en la mar." 



\section{ABSTRACT}

\section{NARDELLI, A. The shaft friction degradation of piles under cyclic axial loading in wind}

turbine foundations. 2019. 182 p.. Dissertation (Master of Science in Geotechnical Engineering). School of Engineering, University of São Paulo, São Paulo, Brazil, 2019.

Onshore wind turbine foundations are mainly subjected to large overturning moments. The wind action imposes cyclic and dynamic loading conditions which occur in extreme and service scenarios. Deep foundations, when used, transfer this large overturning moment through a pile group which combines the axial and lateral resistance of all piles. Several authors noticed that cyclic axially loaded piles could have their resistance reduced due to shaft friction degradation. Considerable efforts have been made to understand this degradation phenomenon. However, the design and performance of cyclic axial loaded piles require greater advances. Therefore, this research sought to assess the shaft friction degradation of axially loaded piles in wind turbine deep foundations, especially for those located in Brazil. Several issues related to the main objective of this study had to be addressed because onshore wind turbine foundations are an area of recent research, especially in Brazil.

The first stage of this research explored the key aspects of onshore wind turbine foundations in Brazil and compared them with the worldwide status. The main reason to explore this subject is that several authors consider onshore wind turbine foundations a well-understood topic; however, limited data from actual situations have been published, especially in developing countries where wind energy projects have recently started. Thus, a survey on Brazilian energy companies and foundation designers was conducted, and the first Brazilian database of wind turbine foundations was created. This database contains data from more than three thousand Brazilian wind turbine foundations. The key aspects, types and dimensions of these foundations were summarized. Worldwide, concrete gravity foundations are the most commonly used foundation type for onshore wind turbines. In Brazil, $43.3 \%$ of the wind turbines had shallow foundations, essentially concrete gravity, and $56.7 \%$ had deep foundations, mostly continuous flight auger piles. The foundation type was chosen according to the local foundation expertise and geotechnical conditions, which included soil type, water table level, soil layer resistance, the extent of porous soil layers and bedrock depth

This first stage of the research identified that Brazilian wind turbine foundations are significantly different from other countries. Approximately $70 \%$ of Brazilian wind turbine deep foundations used continuous flight auger piles, most of them embedded in sandy soils. Therefore, experimental investigations of the sand-concrete interface response under 
monotonic and cyclic loading are essential. The second and third stages of this research sought to investigate the sand-concrete interface response based on this recent insight.

The second stage assessed the sand-concrete interface response through monotonic interface direct shear tests under different confinement conditions. The role of surface structural characteristics, confinement condition, sand mean diameter, particle morphology, sand gradation and relative density were evaluated. A nonlinear conceptual model of the interfacial-to-internal friction angle ratio was proposed according to normalized roughness and normalized waviness. Additionally, multiple regression was used to estimate the sandconcrete interface strength by the effect of constant normal stiffness. The results were essential to understand and to predict the sand-concrete interface response of concrete piles under static axial loading.

The third stage explored the shaft friction degradation of cyclic axial loaded piles through sand-concrete and sand-steel cyclic interface direct shear tests. In geotechnical engineering practice, field and experimental tests are usually performed to evaluate the number of cycles until failure occurs under constant cyclic amplitude. According to this approach, cyclic failure can either occur quickly or not at all. From a practical viewpoint, the cyclic test times are unpredictable, which makes these tests difficult to plan and to perform. Therefore, a new approach based on increasing cyclic amplitude is proposed to overcome the conventional method. A simple cumulative damage model established a relationship between the cyclic loaded tests under constant and increasing cyclic amplitudes. The new approach provides additional insights into the cyclic interfacial response, such as the effect of previous cycles, the cyclic amplitude at failure and the displacement development throughout cycling. This new approach can be effortlessly extended to other experimental and field investigations. From a practical viewpoint, this new approach can reduce the cost and duration of projects.

The author believes that this dissertation brought breakthroughs to the wind energy companies and to the geotechnical engineering community. However, further studies on onshore wind turbine foundations are still required.

Keywords: Wind turbine foundations. Soil-structure interaction. Cyclic loading. Pile-soil interface. Shaft fiction degradation. 


\section{RESUMO}

NARDELLI, A. Degradação do atrito lateral de estacas em fundações de torres eólicas submetidas ao carregamento cíclico axial. 2019. 182 p.. Dissertação (Mestre em ciências em Engenharia Geotécnica). Escola politécnica, Universidade de São Paulo, São Paulo, Brasil, 2019.

As fundações de torres eólicas onshore são submetidas a grandes momentos de tombamento. A ação do vento impõe carregamentos cíclicos e dinâmicos que ocorrem em condições operacionais e extremas. Fundações profundas, quando usadas, transferem esse momento de tombamento através de um grupo de estacas que, por sua vez, são submetidas a esforços axiais e laterais. Muitos estudos observaram que estacas submetidas ao carregamento cíclico axial estão sujeitas à degradação do atrito lateral. A fim de compreender essa degradação, diversas pesquisas foram realizadas. No entanto, o dimensionamento e desempenho de estacas submetidas ao carregamento cíclico axial requer maiores avanços. Dessa forma, esta pesquisa buscou avaliar a degradação do atrito lateral em estacas de torres eólicas, principalmente aquelas localizadas no Brasil. Da mesma forma, foram abordados assuntos relacionados ao objetivo principal deste estudo uma vez que pesquisas sobre fundações de torres eólicas onshore ainda são incipientes, especialmente no Brasil.

A primeira etapa da pesquisa explorou as principais características das fundações de torres eólicas onshore no Brasil e comparou-as com a prática internacional. Investigou-se este assunto uma vez que diversos autores consideram as fundações de torres eólicas onshore um tópico já compreendido; entretanto, a quantidade de informações e dados publicados são ínfimos, especialmente em países em desenvolvimento onde os projetos eólicos iniciaram recentemente. Por essa razão, realizou-se uma pesquisa com as empresas e projetistas do setor a fim de criar o primeiro banco de dados brasileiro sobre fundações de torres eólicas onshore. Esse banco de dados possui mais de três mil fundações cadastradas. Os principais aspectos, tipos e dimensões dessas fundações foram apresentados. Internacionalmente, o tipo de fundação mais empregado para torres eólicas onshore são fundações superficiais de gravidade. No Brasil, $43.3 \%$ das torres eólicas apresentam fundações superficiais, essencialmente fundações de gravidade, e $56.7 \%$ das torres eólicas apresentam fundações profundas, principalmente por grupo de estacas hélice continua. $\mathrm{O}$ tipo da fundação foi determinado com base na expertise local e condições geotécnicas, incluindo o tipo de solo, nível de água, resistência do solo, espessura de camadas porosas e profundidade do topo rochoso. 
Identificou-se, através da primeira etapa, que as fundações de torres eólicas onshore no Brasil são significantemente diferentes de outros países. Aproximadamente $70 \%$ das fundações profundas são por grupo de estacas hélice contínua, sendo na maior parte em contato com solos arenosos. Desta forma, há necessidade de realizar investigações experimentais da interface areia-concreto. A segunda e terceira etapas desta pesquisa concentraram-se no comportamento estático e cíclico da interface areia-concreto.

A segunda etapa avaliou o comportamento estático da interface areia-concreto através de ensaios de cisalhamento direto em diferentes condições de confinamento. Foram avaliadas as influências das características da superfície sólida, diâmetro médio dos grãos, morfologia dos grãos, distribuição granulométrica e densidade relativa. Um modelo não linear do ângulo de atrito na interface de acordo com a rugosidade e ondulação normalizadas foi proposto. Além disso, empregou-se uma regressão múltipla para estimar a resistência da interface areiaconcreto de acordo com a constante de rigidez. Os resultados foram essenciais na compreensão e previsão do comportamento estático da interface de estacas de concreto.

A terceira etapa explorou a degradação do atrito lateral em estacas através de ensaios de cisalhamento direto cíclicos na interface areia-concreto e areia-aço. Usualmente, campanhas experimentais são conduzidas para avaliar o número de ciclos até ruptura com uma amplitude cíclica constante. A ruptura geotécnica pode ocorrer rapidamente ou nunca ocorrer; e, desta maneira, a duração dos ensaios é imprevisível, dificultando planejamento e execução das obras. Por essa razão, uma nova abordagem foi proposta baseada em amplitudes cíclicas crescentes. Um modelo de dano acumulado estabeleceu a relação entre os ensaios com amplitude cíclica constante e cíclica. A nova abordagem fornece informações adicionais do comportamento cíclico da interface, como o efeito de ciclos anteriores, amplitude cíclica na ruptura e o acúmulo de deslocamento permanente. Essa nova abordagem pode ser facilmente aplicada em outras investigações experimentais e provas de cargas cíclicas. Do ponto de vista prática, essa abordagem pode reduzir o custo e tempo de projetos, além de melhorar a previsão do desempenho dessas fundações.

Espera-se que essa pesquisa tenha trazido avanços para as empresas do setor e comunidade geotécnica. Contudo, novas pesquisas sobre fundações de torres eólicas onshore ainda são necessárias.

Palavras-chave: Fundações de torres eólicas. Interação solo-estrutura. Carregamento cíclico. Interface estaca-solo. Degradação do atrito lateral. 


\section{LIST OF ABBREVIATIONS}

AAP

ABEE

BNDS

CCA

CFAP

CLSM

CIDST

CNL

$\mathrm{CNPq}$

$\mathrm{CNS}$

CPT

$\mathrm{DF}$

DMT

DSA

FAPESP

FEM

FIT

FOS

ICA

IDST

IEC

IQR

LVDT

MASW

PAC

PIT

PIV

PMT

PROINFA

$\mathrm{RCS}$

RCS1

Alluvial Anker Pile

Brazilian Association of Wind Energy

National Development Bank

Constant Cyclic Amplitude

Continuous Flight Auger Pile

Confocal Laser Scanning Microscopy

Cyclic Interface Direct Shear Tests

Constant Normal Load

National Council for Scientific and Technological Development

Constant Normal Stiffness

Cone Penetration Test

Deep Foundation

Flat Dilatometer Test

Design Scan Arm

São Paulo Research Foundation

Finite Element Method

Feed-In Tariffs

Factor of Safety

Increasing Cyclic Amplitude

Interface Direct Shear Test

International Electrotechnical Commission

Interquartile Range

Linear Variable Differential Transformers

Multi-Channel Analysis of Surface Waves

Governmental Acceleration Program

Pile integrity test

Particle Image Velocimeter

Pressuremeter Test

Alternative Sources Incentive Program

Rough Concrete Surface

Rough Concrete Surface of very coarse sand 


\begin{tabular}{|c|c|}
\hline $\mathrm{RCS} 2$ & Rough Concrete Surface of fine sand \\
\hline REMI & Refraction MicroTremor \\
\hline RGB & Red-Green-Blue \\
\hline RQD & Rock Quality Designation \\
\hline RWCS & Rough-Wavy Concrete Surface \\
\hline RWCS1 & Rough-Wavy Concrete Surface of $2.5 \mathrm{~mm}$ \\
\hline RWCS2 & Rough-Wavy Concrete Surface of $5.0 \mathrm{~mm}$ \\
\hline RWCS3 & Rough-Wavy Concrete Surface of $7.5 \mathrm{~mm}$ \\
\hline RWCS4 & Rough-Wavy Concrete Surface of $10.0 \mathrm{~mm}$ \\
\hline SASW & Spectral Analysis of Surface Waves \\
\hline SCS & Smooth Concrete Surface \\
\hline SDECTI & $\begin{array}{l}\text { Department of Economic Development, Science, Technology and Innovation } \\
\text { of São Paulo }\end{array}$ \\
\hline SF & Shallow Foundation \\
\hline SLS & Serviceability Limit State \\
\hline SM & Silty Sand \\
\hline $\mathrm{SP}$ & Poorly graded Sand \\
\hline SP\#16 & Very coarse sand \\
\hline SP\#100 & Fine sand \\
\hline SPT & Standard Penetration Test \\
\hline SRT & Soil reinforcement technique \\
\hline SS & Steel Surface \\
\hline SW & Well-graded Sand \\
\hline ULS & Iltimate Limit State \\
\hline USCS & Unified Soil Classification System \\
\hline WL & Water Level \\
\hline
\end{tabular}




\section{LIST OF NOTATIONS}

$\begin{array}{ll}\alpha_{\mathrm{i}} \text { and } \beta_{\mathrm{i}} & \text { power function fitting parameters under increasing cyclic amplitude } \\ \alpha_{\mathrm{c}} \text { and } \beta_{\mathrm{c}} & \text { power function fitting parameters under constant cyclic amplitude } \\ \alpha, \zeta \text { and } \lambda & \text { multiple regression fitting parameters }\end{array}$

$\mathrm{A}, \mathrm{B}$ and $\mathrm{C} \quad$ fitting parameter of the $\kappa$ model parameter

$\mathrm{A}(\gamma)$ and $\mathrm{m}(\gamma)$ fitting parameters as function of strain level

$\mathrm{A}_{\mathrm{e}} \quad$ evaluation area

c' effective cohesion

$\mathrm{C}_{\mathrm{u}} \quad$ uniformity coefficient

$\mathrm{C}_{\mathrm{c}} \quad$ curvature coefficient

CSR cyclic stress ratio

d pile diameter

D cumulative damage value

$\mathrm{D}_{\tau} \quad$ degradation factor

$\mathrm{D}_{\mathrm{R}} \quad$ relative density

$\mathrm{D}_{50} \quad$ mean particle diameter

$\Delta \sigma \quad$ difference between the maximum and initial normal stress

$\Delta \sigma / \sigma_{\mathrm{i}} \quad$ normalized normal stress variation

$\Delta \mathrm{Z} \quad$ vertical distance

$\delta^{\mathrm{b}} \quad$ unsaturated interface shear strength angle

$\delta_{\mathrm{v}} \quad$ volumetric change

$\delta_{\mathrm{p}} \quad$ peak interface friction angle

$\delta_{\mathrm{pp}} \quad$ post-peak interface friction angle

$\delta / \varphi \quad$ interfacial-to-internal friction angle ratio

$\delta / \varphi_{\mathrm{p}} \quad$ peak interfacial-to-internal friction angle ratio

$\delta / \varphi_{\mathrm{pp}} \quad$ post-peak interfacial-to-internal friction angle ratio

E elastic modulus

e void ratio

$\mathrm{e}_{\max } \quad$ maximum void ratio

$\mathrm{e}_{\min } \quad$ minimum void ratio

f frequency

$\varphi_{\mathrm{p}} \quad$ peak soil internal friction angle 


\begin{tabular}{|c|c|}
\hline$\varphi_{\mathrm{pp}}$ & post-peak soil internal friction angle \\
\hline $\mathrm{G}_{\max }$ & static shear modulus \\
\hline $\mathrm{G}$ & dynamic shear modulus \\
\hline $\mathrm{G}_{\mathrm{s}}$ & specific gravity \\
\hline$\gamma$ & shear strain \\
\hline $\mathrm{H}_{\mathrm{r}}$ & rib height \\
\hline$\kappa$ & cumulative damage model fitting parameter \\
\hline $\mathrm{k}$ & stiffness \\
\hline $\mathrm{J}$ & dimensionless parameter as function of relative density \\
\hline $\mathrm{L}$ & evaluation length \\
\hline$\mu$ & coefficient of friction \\
\hline $\mathrm{N}$ & number of interface shear tests performed \\
\hline $\mathrm{N}_{\mathrm{f}}$ & number of cycles at the last stage of cycling \\
\hline $\mathrm{n}_{\mathrm{i}}$ & number of cycles performed in certain cyclic amplitude \\
\hline $\mathrm{N}_{\mathrm{s}}$ & number of cycles per stage \\
\hline $\mathrm{N}_{\mathrm{SPT}}$ & blows count on the standard penetration test \\
\hline $\mathrm{N}_{\mathrm{t}}$ & total number of cycles \\
\hline $\mathrm{N}_{\mathrm{t}, \mathrm{i}}$ & total number of cycles under increasing cyclic amplitude \\
\hline $\mathrm{N}_{\mathrm{t}, \mathrm{c}}$ & total number of cycles under increasing cyclic amplitude \\
\hline $\mathrm{N}_{\mathrm{t}, \mathrm{c}, \mathrm{i}}$ & $\begin{array}{l}\text { cycles to failure under a constant cyclic amplitude at a certain cyclic } \\
\text { amplitude }\end{array}$ \\
\hline$\eta$ & cumulative damage model fitting parameter \\
\hline$v$ & poisson ratio \\
\hline OCR & over consolidation ratio \\
\hline $\mathrm{p}_{\mathrm{a}}$ & atmospheric pressure \\
\hline $\mathrm{p}^{\prime}$ & average effective stress \\
\hline q & bearing capacity \\
\hline $\mathrm{Q}_{\text {mean }}$ & mean load \\
\hline$Q_{\text {cyclic }}$ & cyclic load amplitude \\
\hline$Q_{\max }$ & maximum static shaft load \\
\hline $\mathrm{r}$ & pile radius \\
\hline $\mathrm{R}_{\mathrm{a}}$ & average roughness parameter \\
\hline $\mathrm{R}_{\max }$ & maximum roughness parameter \\
\hline
\end{tabular}




\begin{tabular}{|c|c|}
\hline $\mathrm{R}_{\mathrm{n}}$ & normalized roughness parameter \\
\hline RQD & rock quality designation value \\
\hline$\rho_{\mathrm{cs}}$ & cyclic slip displacement \\
\hline$\sigma$ & normal stress \\
\hline$\sigma_{\mathrm{i}}$ & initial normal stress \\
\hline$\tau$ & shear stress \\
\hline$\tau_{\text {cric }}$ & shear stress at critical voids developed under CNS conditions \\
\hline$\tau_{\text {cric k }=0}$ & shear stress at critical voids developed under CNL conditions \\
\hline$\tau_{\mathrm{cyc}}$ & cyclic shear stress \\
\hline$\tau_{\text {mean }}$ & mean shear stress \\
\hline$\tau_{\max \text { static }}$ & maximum shear stress under monotonic loading \\
\hline$\tau_{\text {mean }}$ & normalized mean shear stress \\
\hline$\tau_{\max \text { static }}$ & 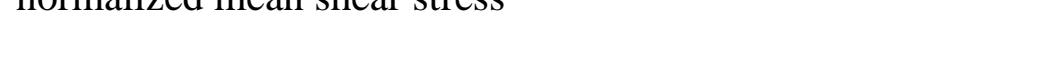 \\
\hline$\tau_{c y c}$ & normalized cyclic shear stress \\
\hline$\tau_{\text {max static }}$ & \\
\hline$\tau / \sigma$ & stress ratio \\
\hline$\theta$ & current volumetric water content \\
\hline$\theta_{\mathrm{r}}$ & residual volumetric water content \\
\hline$\theta_{\mathrm{s}}$ & saturated volumetric water content \\
\hline $\mathrm{u}_{\mathrm{a}}$ & pore-air pressure \\
\hline $\mathrm{u}_{\mathrm{w}}$ & pore-water pressure \\
\hline $\mathrm{W}$ & height of waviness \\
\hline $\mathrm{W} / \mathrm{L}$ & normalized waviness \\
\hline$\xi_{\mathrm{p}}$ & peak interface dilation angle \\
\hline $\mathrm{Z}$ & profile height \\
\hline
\end{tabular}





\section{CONTENTS}

1 INTRODUCTION

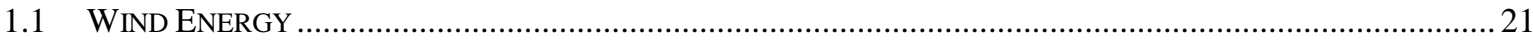

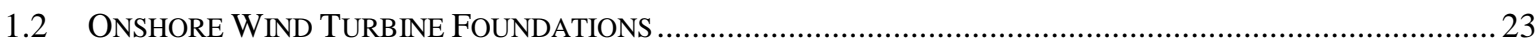

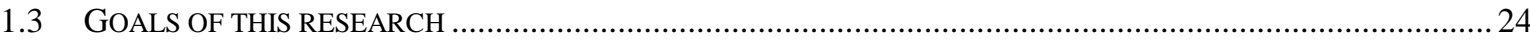

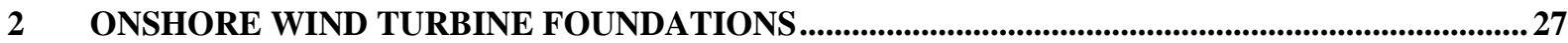

2.1 ASSESSMENT OF ONSHORE WIND TURBINE FOUNDATIONS: THE BRAZILIAN CASE ..............................227

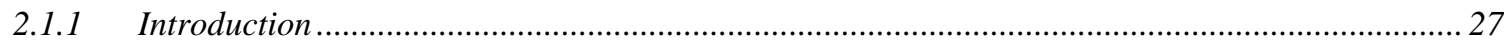

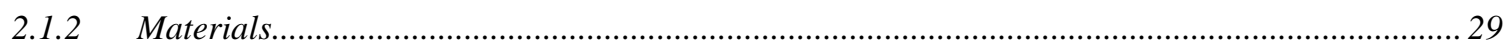

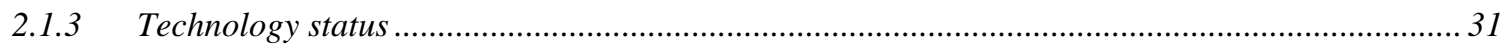

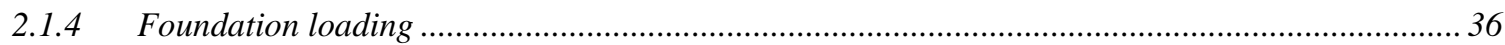

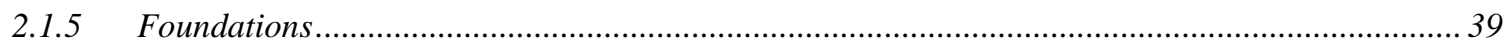

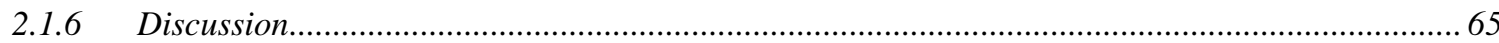

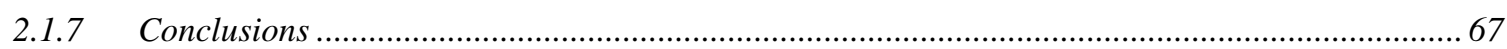

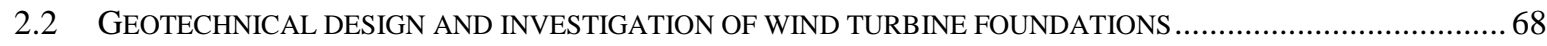

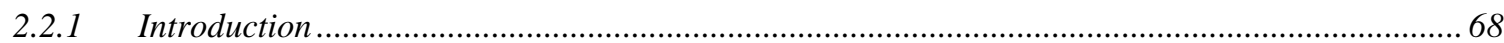

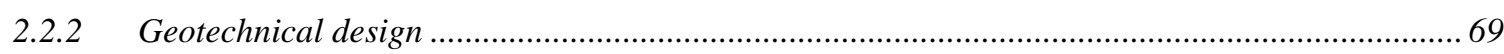

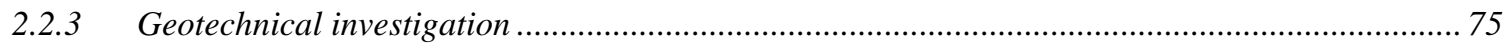

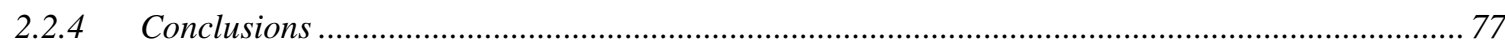

3 LITERATURE REVIEW: SOIL-STRUCTURE INTERFACE.....................................................79

3.1 SOIL-STRUCTURE INTERFACE UNDER MONOTONIC LOADING ........................................................... 79

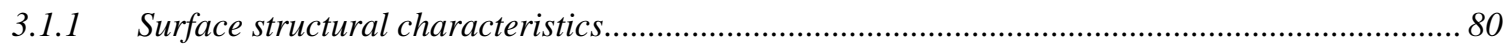

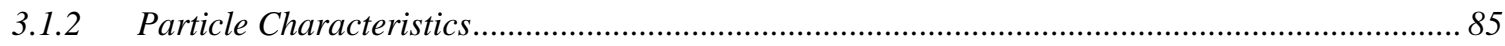

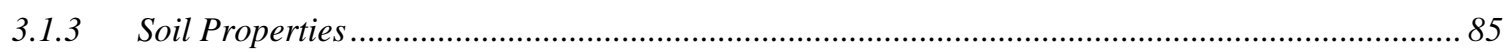

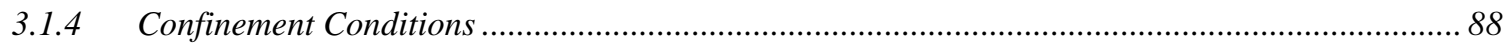

3.1.5 Soil Moisture Content ............................................................................................................ 90

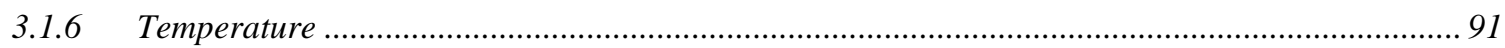

3.2 SOIL-STRUCTURE INTERFACE UNDER CYCLIC LOADING ............................................................ 91

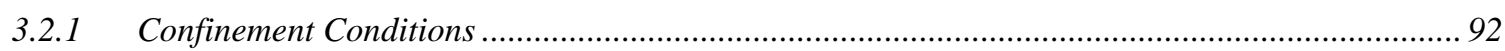

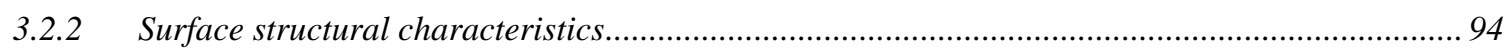

3.2.3 Particle Characteristics and Soil Properties ..................................................................... 95

3.2.4 Amplitude, Frequency and Number of cycles ........................................................................ 96

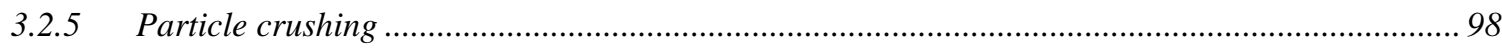

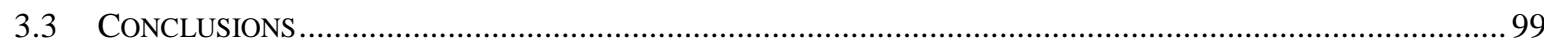

4 SAND-CONCRETE INTERFACE BEHAVIOR AND STRENGTH ........................................101

4.1 SAND-CONCRETE INTERFACE: EXPERIMENTAL INVESTIGATION........................................................ 101 


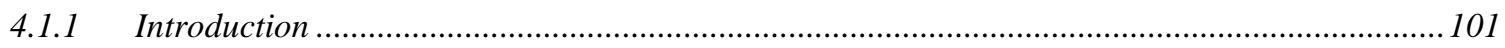

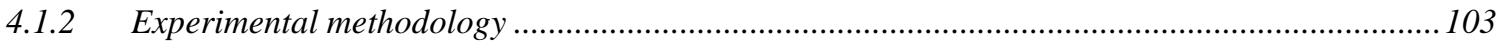

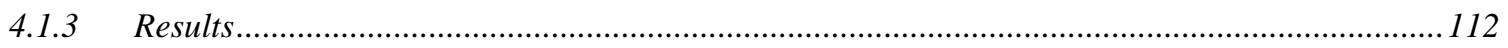

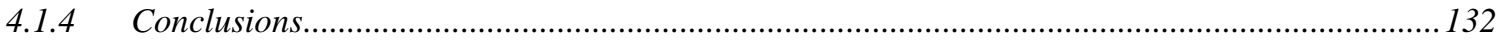

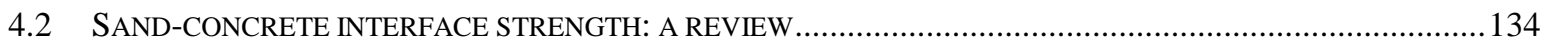

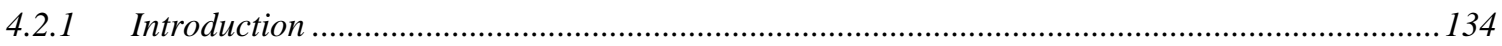

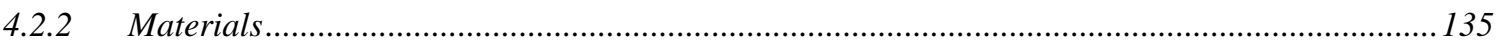

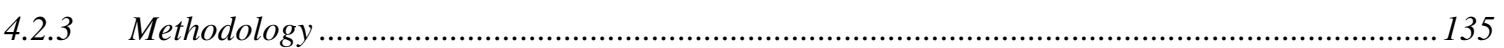

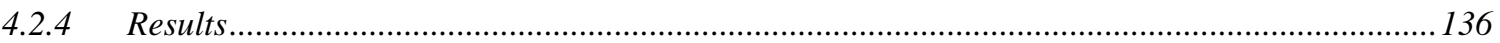

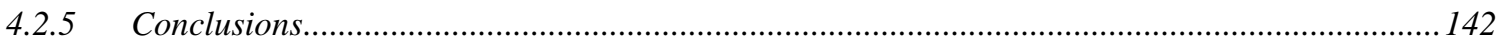

5 CYCLIC SAND-SOLID INTERFACE RESPONSE ...........................................................................145

5.1 A NEW APPROACH TO THE DESIGN OF CYCLIC AXIAL LOADED PILES.............................................. 145

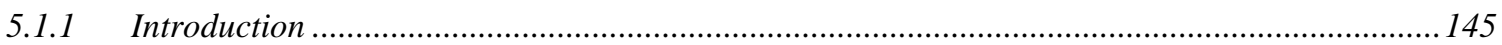

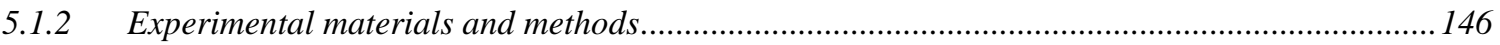

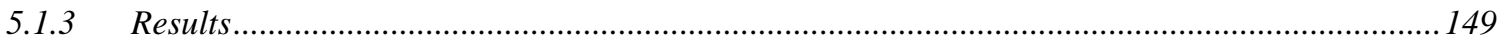

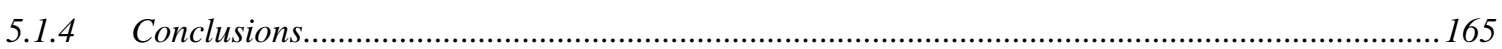

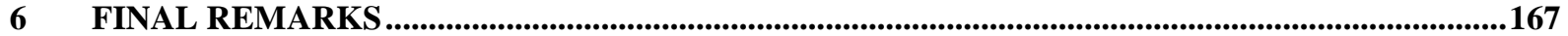

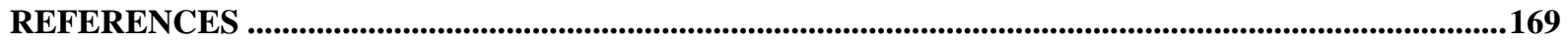




\section{INTRODUCTION}

\subsection{Wind Energy}

In the last decade, the world's total wind energy installed capacity has significantly increased, reaching $486.7 \mathrm{GW}$ in 2016 (GWEC, 2017). The majority of the wind energy installed capacity is located in China (34.9\%), United States (16.5\%) and Germany (10.4 \%) (GWEC, 2018). Wind energy is already the second largest form of power generation in the European Union (EU) (Wind Europe, 2017). Additionally, 40\% of Denmark's electricity demand and between 20 to $35 \%$ of the demand in Portugal, Ireland, and Spain are estimated to be supplied by wind power (GWEC, 2016; U.S. Department of Energy, 2017).

According to the Brazilian Electricity Regulatory Agency (ANEEL), Brazil's wind energy installed capacity comprises $7.1 \%$ of the total installed capacity of $151 \mathrm{GW}$ (Brazilian Wind Energy Association, 2017). In 1992, Brazil's first wind turbine (1.0 MW) was installed in Fernando de Noronha. In 2001, Brazil's wind energy potential was estimated at $143 \mathrm{GW}$, considering the wind quality at 50 meters in height (Cresesb, 2001). Until 2004, there was only 27.1 MW of wind energy installed capacity in Brazil. Thus, the Brazilian government conducted policy incentives to expand renewable energy generation. The Alternative Sources Incentive Program (PROINFA) conducted Feed-In Tariffs (FIT) policies, and later, long-term auctions supported by the National Development Bank (BNDES) credit lines (GWEC and Brazilian Wind Energy Association, 2011; Aquila et al., 2017). In the United States, for example, favorable tax policies, such as production tax credit and accelerated tax depreciation, have supported the growth of wind energy projects (U.S. Department of Energy, 2017). In Great Britain, the feed-in tariffs will be the next subsidy mechanism to support low carbon generation projects (Royal Academy of Engineering, 2014). Currently, Brazil is in the eighth position in the world ranking regarding wind energy installed capacity (GWEC, 2018).

In recent decades, wind turbine sizes have significantly increased. The first wind turbines had 0.05 MW capacity and a rotor diameter of 15 meters (EWEA, 2011). Typical current international wind turbines capacities are 2.0 MW and 4.0 MW for onshore and offshore wind farms, respectively (IEA-ETSAP and IRENA, 2016). Currently, 8.0 MW wind turbines are commercially available with a rotor diameter of 164 meters (Royal Academy of Engineering, 2014; IEA-ETSAP and IRENA, 2016). Very large-scale wind turbines in the range of 10 to $20 \mathrm{MW}$ with a rotor diameter of 250 meters and a hub height of 150 meters may be feasible in the near future (EWEA, 2011). 
The typical onshore capacity factor ranges from 20 to $30 \%$ for China and India, 25 to $35 \%$ for Europe and 30 to $45 \%$ for North America (IEA-ETSAP and IRENA, 2016). In Brazil, the average capacity factor in 2016 was $40.7 \%$, which is well above the global average (Brazilian Wind Energy Association, 2017). The northeast Brazilian region is known for having highly consistent wind, and consequently, high capacity factors. According to the U.S. Department of Energy (2017), a gradual improvement in capacity factor is expected, as wind turbines with taller towers and greater rotor diameters are being installed.

Wind farms can be classified as onshore or offshore depending on the site location (Figure 1.1). However, only 3.05\% of the world wind installed capacity comes from offshore wind farms, most of them established in United Kingdom (35.85\%) and Germany (28.56\%) (GWEC, 2017). There is a high investment cost associated with the offshore projects due to the construction, operation and transmission (Royal Academy of Engineering, 2014; GWEC, 2016; IEA-ETSAP and IRENA, 2016). Additionally, it is commonly attributed to the offshore wind farms to be more efficient due to the stronger winds and fewer obstacles (Royal Academy of Engineering, 2014; IEA-ETSAP and IRENA, 2016). This preconception of superior wind quality and greater energy production may not be entirely true (Enevoldsen and Valentine, 2016). Enevoldsen and Valentine (2016) noticed that offshore wind farms do not produce more energy per installed MW when compared to onshore wind farms. In the United States, for example, the highest average annual wind speed at 80 meters is located in Interior and Great Lakes regions, and not along the coastlines (U.S. Department of Energy, 2017). As a consequence of the noise and visual impacts which directly affect social acceptance (Kaldellis et al., 2016), onshore wind farms are usually located in the countryside.
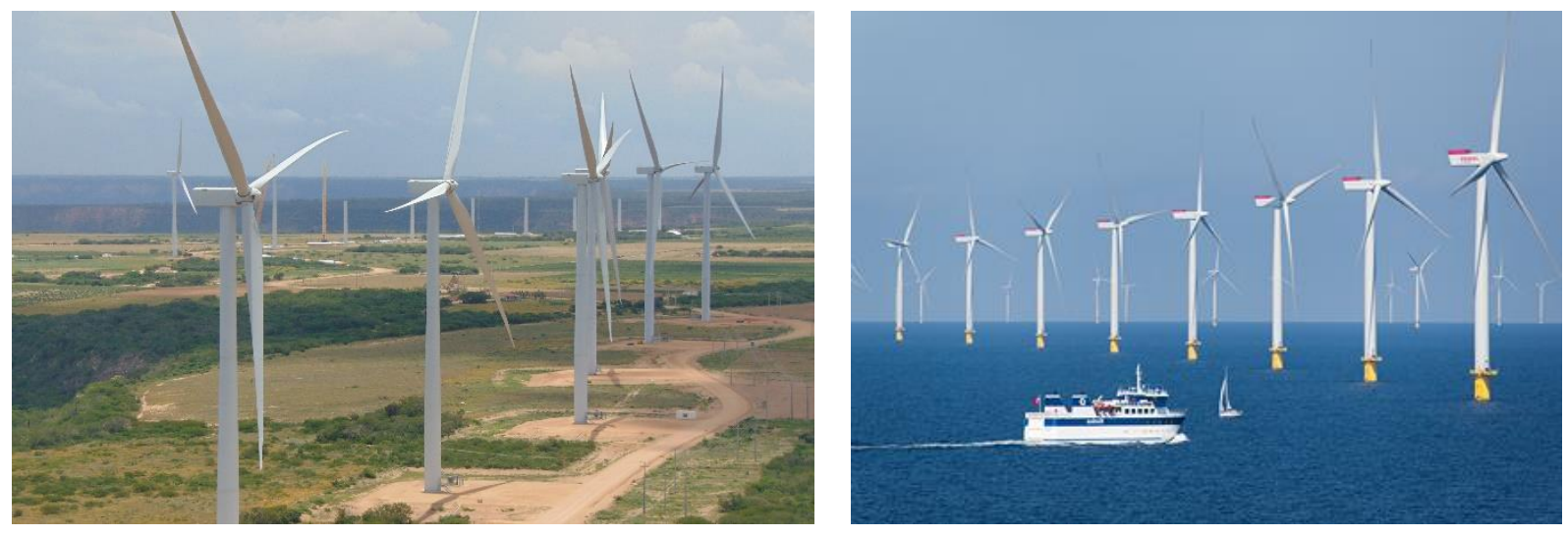

Figure 1.1: Ventos do Araripe III onshore wind farm in Brazil (Casa dos Ventos, 2019) and Anholt offshore wind farm in Denmark (Siemens, 2013). 


\subsection{Onshore Wind Turbine Foundations}

The main components of the wind turbines are the foundation, grid connection cables, tower, nacelle, generator and rotor blades. The foundation is a crucial component that transfers permanent and variable loads from the structure to the ground throughout the wind turbine lifespan. As a result of structure weight and slenderness, wind turbine foundations are mainly subjected to large overturning moments due to the presence of considerable horizontal loads. The wind imposes cyclic and dynamic loading conditions that occur in extreme and service scenarios. The wind action causes a frequency of less than $0.1 \mathrm{~Hz}$ on wind turbines, while the rotor frequency is between $0.17 \mathrm{~Hz}$ and $0.33 \mathrm{~Hz}$ (Pytlik, 2016). The number of cycles that the foundation will be subject to over a 20-year lifespan ranges from $10^{7}$ to $10^{9}$ (Pytlik, 2016). This type of loading can cause fatigue and differential settlement in the structure and foundation which can significantly impact the operation and wind turbine lifespan.

Deep foundations, when used as onshore wind turbine foundations, transfer the overturning moment and the vertical and horizontal forces through a pile group. According to Vesic (1977), upon horizontal forces, pile groups act as a structural system combining the axial and lateral resistance of all piles. As a consequence of the pile cap high stiffness, the piles are usually considered to be axially and laterally loaded (DNV/Ris $\varnothing, 2002)$.

Different simplified models have been proposed to evaluate single piles under static axial loading. These models are based on the load transfer functions (e.g., Coyle and Reese, 1966; Randolph and Wroth, 1978), load transfer diagrams (e.g., Aoki, 1987) and on the mechanics of elastic continuous (e.g., Poulos and Davis, 1980). All these models consider two sources of capacity: shaft resistance; and base resistance. For the onshore wind turbine deep foundations, the pile design and performance are a complex issue due to the presence of cyclic loading.

Several authors noticed that cyclic axially loaded piles could have their resistance reduced due to shaft friction degradation. Considerable efforts have been made to understand this degradation phenomenon, also referred to as skin friction fatigue. The load transfer on the pile-soil system occurs at their interface, which is a stress-concentration zone. Due to the several difficulties to conduct full-scale experiments, small scale investigations are conducted through model pile tests, simple shear tests, interface direct shear tests and so forth. These investigations aim to understand the behavior of the stress-strain relationship between soilsolid interfaces throughout each cycle. In geotechnical engineering practice, cyclic stability diagrams are widely used to describe the shaft friction degradation of piles under cyclic axial 
loading. Field and experimental tests are usually performed to evaluate the number of cycles until failure under a constant cyclic amplitude. Through this approach, cyclic failure can either occur quickly or not at all. From a practical viewpoint, cyclic test times are practically unpredictable, which makes these tests difficult to plan and to perform them. As several tests are required to develop one cyclic stability diagram, these investigations are often expensive and time consuming. The design of axially loaded piles still requires greater advances. Further attention must be given to this issue, especially in developing countries, where wind projects have recently emerged. These countries exhibit distinguished soils and different foundation expertise; hence, distinct effects of the shaft friction degradation are expected.

This research sought to assess the shaft friction degradation of axially loaded piles in wind turbine deep foundations located in Brazil. However, it was first necessary to assess the wind turbine foundations used in Brazil to identify what types of pile-soil interfaces are established. Continuous flight auger piles embedment in sandy soils were noticed to be the most common case for wind turbines deep foundations in Brazil. Therefore, experimental investigations into the sand-concrete interface under monotonic and cyclic loading were performed. The interfacial response was assessed through monotonic and cyclic interface direct shear tests. A new approach based on increasing cyclic amplitudes is proposed to the design of cyclic axial loaded piles. The results provided new breakthroughs into the design and performance of axial loaded piles embedment in sandy soils.

\subsection{Goals of this research}

The main objective of this research was to assess the shaft friction degradation of axially loaded piles using cyclic interface direct shear tests, aiming at their application to wind turbine deep foundations, especially those located in Brazil. Several tasks were required, and each of these tasks constituted a dissertation chapter.

Chapter 2: Several questions emerged regarding the current status of wind turbine foundations worldwide and in Brazil. In Brazil, there has been an absence of database or studies about the subject - to the best of the author's knowledge. Thus, a survey into Brazilian energy companies and foundation designers was conducted, and the first Brazilian database of wind turbine foundations was developed. A review of scientific articles, governmental reports and guidelines was performed to assess the current status of wind turbine foundations worldwide.

Chapter 3: A literature review of the soil-solid interface under monotonic and cyclic loading was conducted to comprehend the current state-of-knowledge. No attempt was made 
to establish an unquestionable truth. However, this section had a major role in supporting the experimental tasks of this research.

Chapter 4: The sand-concrete interface strength and behavior under monotonic loading was assessed through interface direct shear tests. The effects of surface structural characteristics, initial relative density, sand mean diameter and confinement condition were analyzed. Additionally, a literature review of published data was performed to assess sandconcrete interface strength for other conditions, such as different particle morphologies and sand gradations.

Chapter 5: Sand-concrete and sand-steel cyclic interface direct shear tests were performed to assess the shaft friction degradation. As several cyclic load tests are usually required, a new approach based on increasing cyclic amplitude is proposed to overcome the conventional time consuming method. 


\section{ONSHORE WIND TURBINE FOUNDATIONS}

The key aspects of onshore wind turbine foundations were explored in this chapter which is composed of two subsections. The first subsection (2.1) exhibits the results of a Brazilian wind turbine foundations database. This database was based on a survey of Brazilian energy companies and foundation designers. The results obtained were compared with onshore wind turbine foundations worldwide. The first subsection was recently submitted to a high-impact journal, and it is currently under review.

The second subsection (2.2) assesses the geotechnical design and investigation of onshore wind turbine foundations. A review of scientific articles, governmental reports and guidelines were conducted to establish the main aspects of these foundations in Europe and the United States. The geotechnical design and investigation of Brazilian wind turbine foundations were evaluated through several design reports obtained from the database. The second subsection composed an article which was accepted to the IX Seminar of Foundations and Geotechnical Engineering (SEFE 9) (2019).

\subsection{Assessment of onshore wind turbine foundations: the Brazilian case}

\subsubsection{Introduction}

In the last decade, the world's wind energy installed capacity has grown significantly, reaching $539.6 \mathrm{GW}$ by the end of 2017 (GWEC, 2018). The majority of this installed capacity is located in China (34.9\%), the USA (16.5\%) and Germany (10.4\%) (IRENA, 2016; GWEC, 2018). Currently, wind energy corresponds to approximately $4.6 \%$ of the total electricity generated worldwide (U.S. Department of Energy, 2017; EPE, 2018). Brazil occupies the eighth position in the world ranking of installed capacity with $12.76 \mathrm{GW}$ and leads Latin America (GWEC, 2018).

In Brazil, hydropower is the leading source of electricity generation, supplying over $65 \%$ of electricity (EPE, 2018). However, expanding the immense hydropower installed capacity is currently an obstacle. Therefore, due to the great wind potential, wind energy installed capacity has recently advanced to assure electric energy diversification, security and expansion. In 2012, Brazil had only $2.5 \mathrm{GW}$ of wind energy installed capacity. In 2016, Brazil increased its wind power capacity by $23.1 \%$ due to the installation of $2.0 \mathrm{GW}$ of new wind farms. Brazil's wind energy installed capacity already composes $7.1 \%$ of $151 \mathrm{GW}$ total Brazilian installed capacity (Brazilian Wind Energy Association, 2018a). Emphasizing the role of the Brazilian government in expanding wind energy generation through policy 
incentives is important. The Alternative Sources Incentive Program (PROINFA) implemented feed-in tariffs (FIT), and later, long-term auctions supported by National Development Bank (BNDES) credit lines (GWEC and Brazilian Wind Energy Association, 2011; Aquila et al., 2017). Brazil is forecast to have a wind energy installed capacity of $16.4 \mathrm{GW}$ by 2020 . No wind turbine was installed offshore in Brazil up to 2018; however, a few projects are under development, and the first offshore wind farm is expected to be operating by 2022 (Luna, 2018).

Wind farms consist of an ensemble of wind turbines. The main components of these wind turbines are the foundation, grid connection cables, tower, nacelle, generator and rotor blades. The foundation is a crucial component that transfers permanent and variable loads from the structure to the ground throughout the lifespan of a wind turbine. As a result of structure height and slenderness, wind turbine foundations are mainly subjected to large overturning moments due to the presence of considerable horizontal loads, primarily caused by wind (IEC 61400-1, 2005). The wind imposes cyclic and dynamic loading conditions that occur in extreme and service scenarios. With the progressive increases in turbine size, tower height and rotor diameter, the overturning moment at the foundation will significantly increase, which can increase the tower and foundation costs (IRENA, 2016). Although the foundation is a key component of a wind turbine, wind farm locations are mostly based on energy assessments, and as a result, construction sites are often geotechnically unfavorable (Pham et al., 2018). Horgan (2013) identified five influential foundation design variables, which include surface roughness, soil type, construction materials, generating capacity and tower height. According to Hassanzadeh (2012), the type and size of a wind turbine foundation are chosen according to the geotechnical conditions of the site, rated power of the wind turbine and type of tower.

Currently, offshore wind turbine foundations are an area of intense research (Andersen et al., 2012; Negro et al., 2014; Abhinav and Saha, 2017). Several authors have described onshore wind turbine foundations as a well-understood area (Horgan, 2013; Royal Academy of Engineering, 2014). However, limited data on onshore wind turbine foundations have been published, especially in developing countries where wind energy projects have recently started. Additionally, several studies conducted onshore wind turbine foundation analysis and comparisons based on ordinary assumptions about real foundations (Horgan, 2013; Mohamed and Austrell, 2017). Several life-cycle assessments have been conducted based on limited wind turbine foundation samples (Crawford, 2009; Martínez et al., 2009; Guezuraga et al., 2012). 
Onshore wind turbine foundation databases have never been published and explored, even in developed countries where wind energy is well established. The wind energy industry could profit from this information for improving the planning phase, encountering technical issues, meeting future research needs, and guiding long-term national strategic planning and appropriate national standards. This subsection investigated the status of onshore wind turbine foundations in Brazil in comparison with the current worldwide status. A significantly large Brazilian wind turbine foundation database was required for appropriate statistical and spatial representativeness. This database was developed by the Geotechnical Engineering Research Group (GeoInfraUSP) of the University of São Paulo as one of its infrastructure research areas. The main aspects concerned were the technology status of wind turbines, including rated power, rotor diameter, hub height and tower type; foundation loading, and characteristics of the foundations, such as types, dimensions and geotechnical aspects.

\subsubsection{Materials}

This paper assessed the onshore wind turbine technology status and foundations worldwide based on available scientific literature, reports, online public information, standards and guidelines. An overview of the onshore wind turbine foundation types has been performed for certain countries, including the United States, France and northern European countries.

The Brazilian Association of Wind Energy (ABEE) provided a database with Brazilian wind farm statistics, which included wind turbine rated power, rotor diameter and tower height, for almost all wind turbines located in Brazil. A survey of Brazilian energy companies and foundation designers was conducted, and the first Brazilian database of wind turbine foundations was created. Many of the largest Brazilian wind energy companies provided useful data between 2017 and 2018. The names of companies and wind farms have been anonymized due to our confidentiality agreement. The database contains data from 24 different wind energy companies, encompassing 284 wind farms, 3,031 wind turbines and $6,798 \mathrm{MW}$ of installed capacity, which represents approximately $52 \%$ of the Brazilian total installed capacity. The commercial operation years of these wind projects were mainly from 2012 to 2018, except for one wind project from 2008 and two from 2006. The wind farms were mainly found in the following states: Bahia, Rio Grande do Sul, Piauí, Rio Grande do Norte, Ceará and Pernambuco. These states are mainly located on the northeast and south coasts of Brazil, which have strong and constant wind conditions. Additionally, these 
Brazilian states have the largest wind energy installed capacity among the twelve Brazilian states with wind farms (Fig. 2.1).

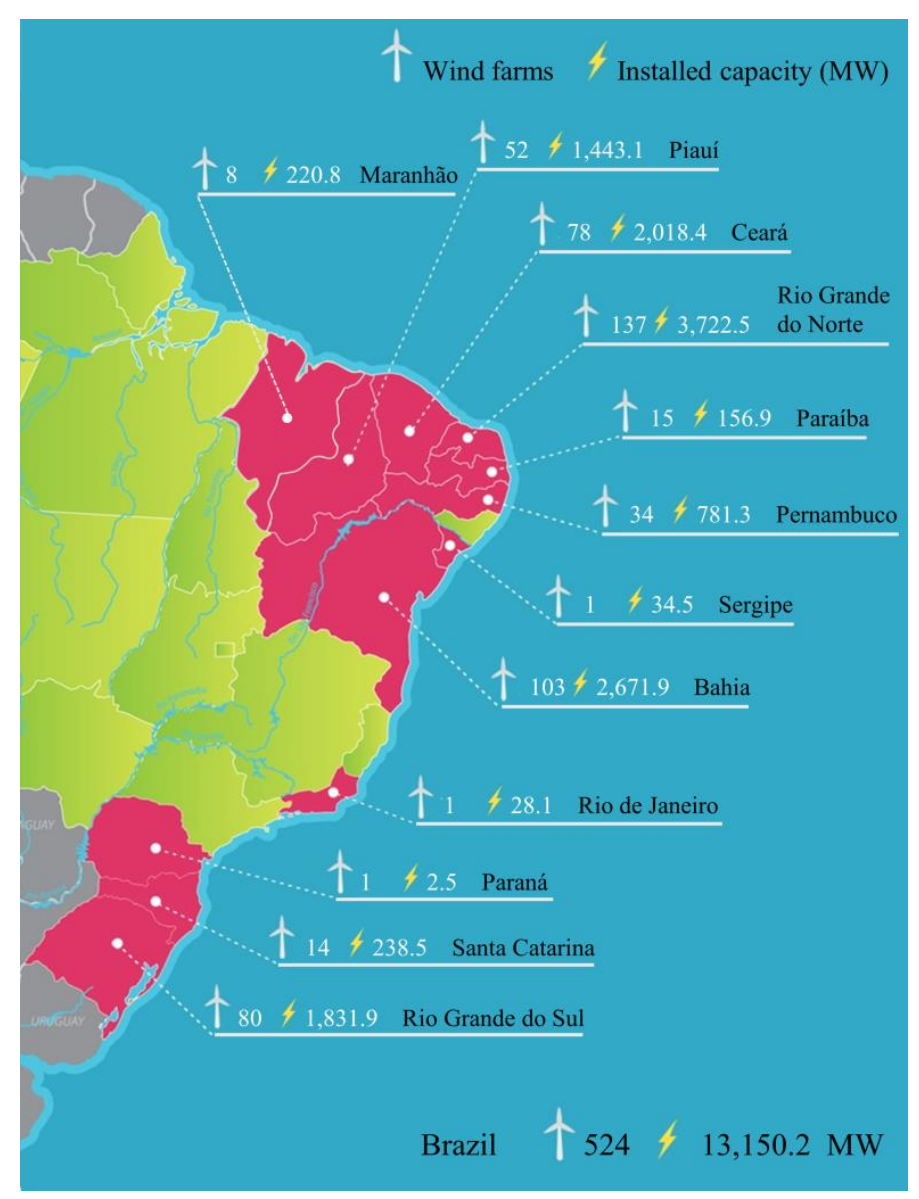

Figure 2.1: Map of Brazilian wind energy installed capacity by state in April 2018. Artwork and data source (Chaussê, 2014; Brazilian Wind Energy Association, 2018b).

This database was created based mainly on foundation projects, foundation design reports and geotechnical investigation reports. Wind turbine geotechnical investigations were mostly based on the standard penetration test (SPT), which was performed once per wind turbine foundation and when necessary combined with rock core drilling tests. Occasionally, the geotechnical survey included laboratory tests and geophysical methods. More advanced in situ investigations, such as the cone penetration test (CPT), pressuremeter test (PMT) and flat dilatometer test (DMT), were not conducted, at least for the samples acquired. Plate load tests were occasionally conducted for shallow foundations. When deep foundations were used, dynamic or static pile load tests were usually performed on one pile per foundation and according to the Brazilian standards. Additionally, the survey acquired data on wind projects with different levels of information. Therefore, the analysis used different amounts of data, i.e., a distinct number of wind turbines, which is constantly specified. 


\subsubsection{Technology status}

Technology status: worldwide

Typical onshore wind turbine capacity is $2 \mathrm{MW}$, ranging from $1 \mathrm{MW}$ to $3 \mathrm{MW}$ (IEAETSAP and IRENA, 2016). The European market has the highest average turbine capacity, approximately 2.4 MW (Hernández et al., 2017). However, these averages vary substantially by country and region (GWEC, 2016). In 2016, for example, Sweden, Finland and Austria had average turbine capacities above 3.0 MW, while Italy, Portugal, the United Kingdom and Spain had averages below 2.2 MW (Wind Europe, 2017). Three main reasons were identified: regulatory restrictions on tip height, duration of projects, and wind regimes. Onshore wind turbine capacities above $5 \mathrm{MW}$ are still marginal, representing only $0.3 \%$ of the installed capacity in the world in 2015 (Hernández et al., 2017). By 2025, the average rated power of newly installed wind turbines is forecast to be $3.6 \mathrm{MW}$ in Denmark, 3.5 MW in Germany, 2.6 MW in the United States, 2.4 MW in India and 2.5 MW in China (IRENA, 2016). A survey of 163 experts in Europe verified that the upper boundaries of wind turbine rated power are not expected to be pushed much further (Agora Energiewende, 2017). The continuous shift towards less attractive sites and low generator-to-rotor ratios are possible reasons.

In 2015, the average rotor diameter and hub height of new installations were 100 meters and 85 meters, respectively (Hernández et al., 2017). Over the years, the average turbine capacity, rotor diameter and hub height of onshore wind turbines have steadily increased (GWEC, 2016). In the United States, for example, the average turbine capacity and rotor diameter have significantly increased in recent years, reaching an average rated power and rotor diameter of newly installed wind turbines of 2.15 MW and 108 meters, respectively, in 2016. In turn, the average hub height in 2016 was 83 meters, and this value had remained almost constant since 2011 (U.S. Department of Energy, 2017).

The wind turbine rated power, the quality and characteristics of the wind resource, the hub height and the rotor diameter play major roles in the amount of electricity generated by a wind turbine (IRENA, 2016). In recent years, the average specific power $\left(\mathrm{W} / \mathrm{m}^{2}\right)$ has decreased due to the greater increase in the rotor diameter compared to the growth in the turbine capacity (U.S. Department of Energy, 2017; Agora Energiewende, 2017). Capacity factors are expected to increase as a result of the greater swept rotor area available for each watt of rated power and of higher hub heights (IRENA, 2016; GWEC, 2016; U.S. Department of Energy, 2017). Note that wind turbines in high wind speed locations, Class I, have progressively lost share in favor of wind turbines in medium and low wind speed locations, 
Classes II and III, respectively (GWEC, 2016). For example, Class III turbines have increasingly dominated the U.S. wind market (U.S. Department of Energy, 2017).

Wind turbine towers are made mostly from steel (Royal Academy of Engineering, 2014; Agora Energiewende, 2017). Tubular steel towers are suitable for heights up to 100 meters (Agora Energiewende, 2017). Therefore, as wind turbine hub heights increase, the use of concrete and hybrid steel-concrete towers will become more frequent (Hernández et al., 2017; Rebelo et al., 2014). The use of a hybrid solution takes advantage of lowering the center of gravity of the tower and easing the assembly of the steel segments (Rebelo et al., 2014).

\section{Technology status: Brazil}

To evaluate the technology status of wind turbines in Brazil, acquiring data on wind turbine rated power, rotor diameter and tower height was necessary. The Brazilian Association of Wind Energy provided a database with information on almost all wind turbines located in Brazil. This subsection presents the results of this database, which was provided through June of 2017. Five stages of wind farms were considered: in operation; ready to operate; in trials; under construction; and engaged. The database verified that 5,054 wind turbines were in operation in Brazil by the end of the 2017 first semester and that 271 wind turbines were already in trials or ready to operate. These numbers are expected to increase due to the installation of 1.006 wind turbines under construction and 1.654 wind turbines already engaged, which will be operating by 2020 .

Figure 2.2a-c show the wind turbine rated power, rotor diameter and hub height according to the year of installation. Usually, wind farms have several wind turbines with the same rated power, rotor diameter or hub height values. A few remarkable dates are emphasized due to their importance: PROINFA started in April 2002 to assure electricity energy diversification and expansion; a Governmental Acceleration Program (PAC) to boost infrastructure started in January 2007; and December 2009 saw the first auction exclusively for wind energy (Ferreira et al., 2014). Wind turbine rated power was verified to range mostly from 1,5 MW to 3,0 MW, while the average rated power for wind turbines in operation, trials and ready to operate was approximately 2,0 MW (Fig. 2.2a). Since 2009, "wind energy auctions included a stipulation prohibiting the import of wind turbines with a nominal capacity below 1,5 MW" (GWEC and Brazilian Wind Energy Association, 2011). The rated power annual average and annual cumulative average have been constantly increasing. Wind turbines under construction or already engaged, for example, had an increase in rated power, with an average value of 2.3 MW (Fig. 2.2a). However, since 2014, a constant maximum 
rated power value of 3.0 MW and an increase in the minimum value of wind turbine rated power were observed (Fig. 2.2a). The wind turbine rotor diameter mostly ranged from 80 to 125 meters (Fig. 2.2b). For example, for the wind turbines in operation, trials and ready to operate, the average rotor diameter was 96 meters. The annual average rotor diameter and annual cumulative average have also been constantly increasing. The wind turbines under construction or already engaged, for example, had an increase in rotor diameter, with an average value of 112 meters. Since 2014, a constant maximum rotor diameter value of 125 meters and an increase in the minimum value of the wind turbine rotor diameter were observed (Fig. 2.2b). The wind turbine hub height mostly ranged from 80 to 125 meters (Fig. 2.2c). For example, for the wind turbines in operation, trials and ready to operate, the average hub height was 88 meters. However, the hub height annual cumulative average remained almost constant since 2011, except for the annual average fluctuation. Additionally, the wind turbine hub height range remained almost constant between 80 and 125 meters (Fig. 2.2c). The average international values of rated power, rotor diameter and hub height were similar to those presented in Figure 2.2a-c. Similarly, increases in the average rated power and rotor diameter in recent years were verified, while the average hub height was held almost constant.

Figure 2.2d-f compare the results for the ABEE database, i.e., Figure 2.2a-c data, and the wind turbine foundation database of the rated power, rotor diameter and hub height. The wind turbine foundation database exhibited a median rated power of $2.1 \mathrm{MW}$ with $50 \%$ of the values between 2.0 and $2.7 \mathrm{MW}$, a median rotor diameter of 110 meters with $50 \%$ of the values between 97 and 122 meters, and a median hub height of 89 meters with $50 \%$ of the values between 80 and 100 meters. In general, the wind turbine foundation database had a statistical distribution slightly superior to that of ABEE database. This result was expected since the wind turbine foundation database mainly contained data from 2012 to 2018, which explains the higher observed values than those in the ABEE database, especially regarding wind turbine rated power and rotor diameter. 


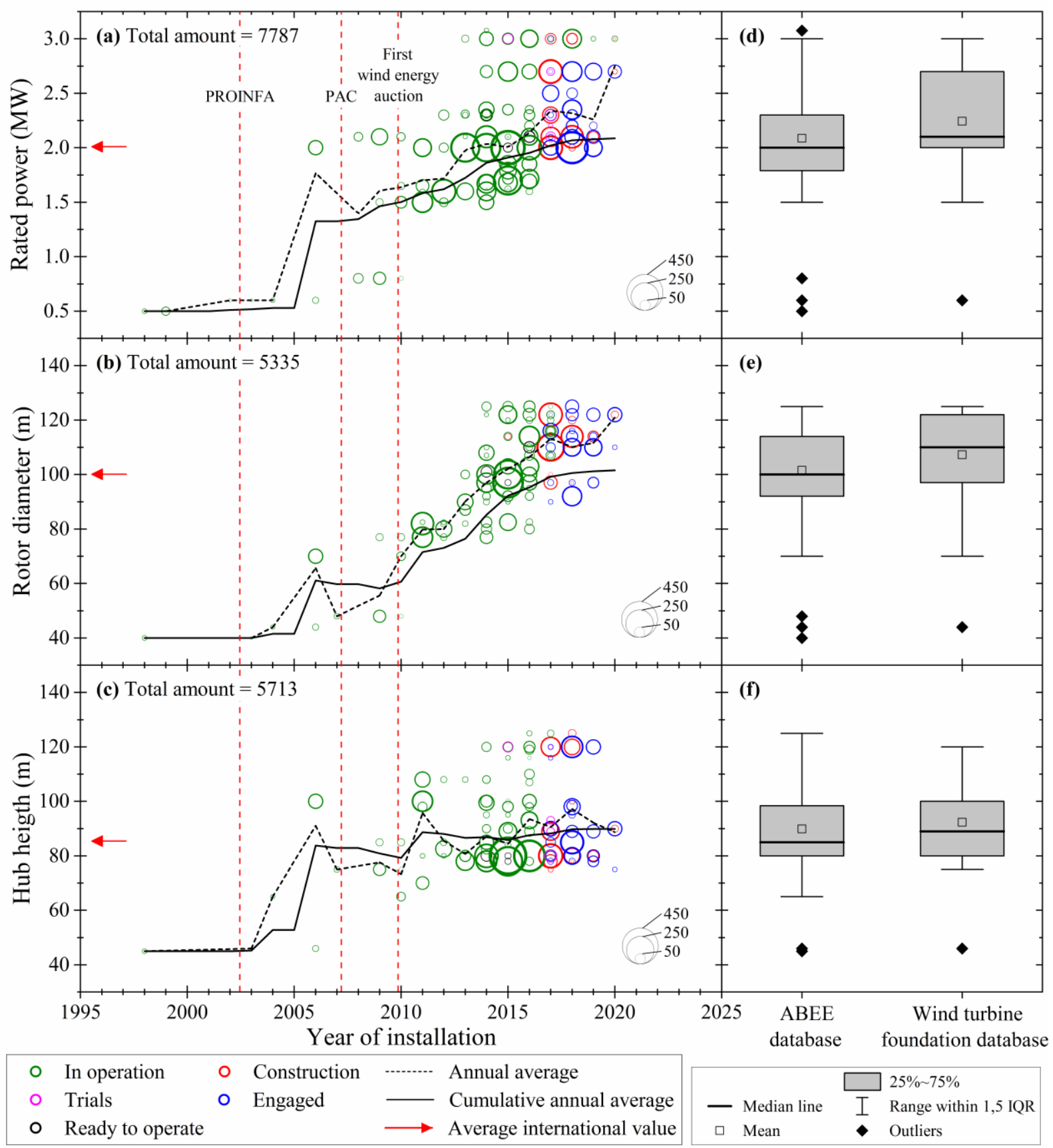

Figure 2.2: Bubble charts for wind turbines: (a) rated power, (b) rotor diameter and (c) hub height according to the year of installation for five wind farm statuses. The size of each circle indicates the amount of wind turbine data. Additionally, box plots for the ABEE database and wind turbine foundation database of (d) rated power, (e) rotor diameter and (f) hub height.

Figure 2.3 shows the correlation between the rotor diameter and rated power of wind turbines. Wind turbines under construction and engaged had average values of rotor diameter and rated power superior to those of wind turbines in operation. An upward relationship between rotor diameter and rated power was verified. However, no relationship between hub height and rated power, R-squared of 0.237 , and hub height and rotor diameter, R-squared of 0.148 , was verified. 


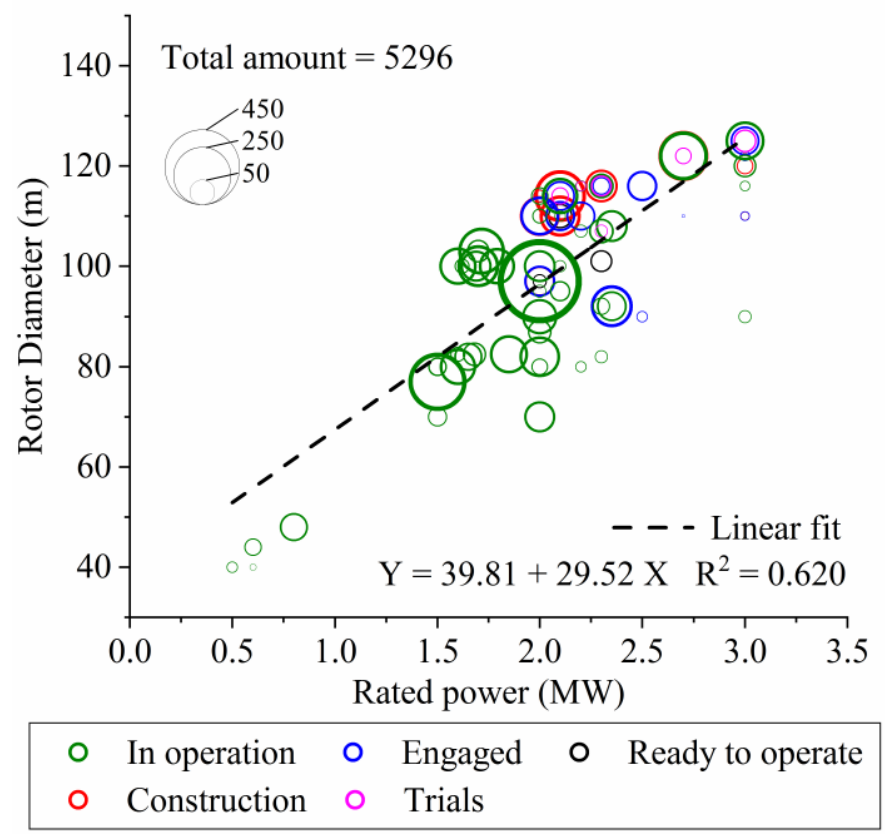

Figure 2.3: Correlation between wind turbine rotor diameter and rated power for five wind farm statuses. The size of each circle indicates the amount of wind turbine data.

According to the wind turbine foundation database, approximately $73.6 \%$ of the wind towers in the sample were made of steel, while $26.4 \%$ were made of concrete (Fig. 2.4a). No hybrid steel-concrete towers were identified in the sample. The difference between steel and concrete towers regarding wind turbine rated power, rotor diameter and rotor diameter was analyzed (Fig. 2.4b). Concrete towers were used when the hub height exceeded 100 meters. Figure 2.4b also highlights that steel and concrete towers exhibited the same ranges of rated power and rotor diameter. No significant influence of the International Electrotechnical Commission (IEC) class on the tower type was noticed. 
(a)

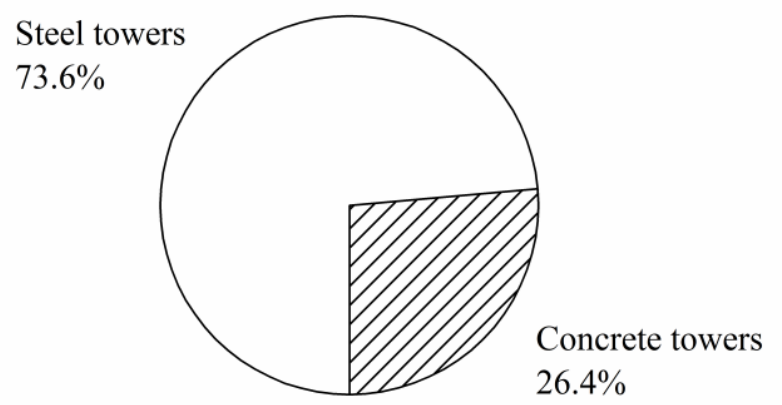

(b)

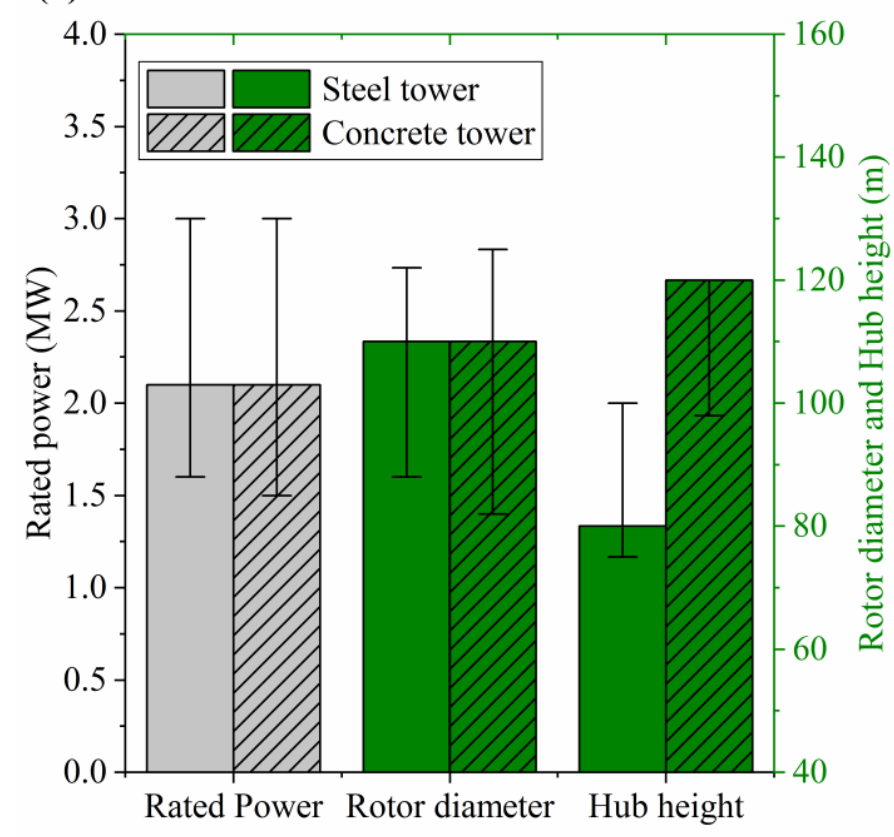

Figure 2.4: Wind turbine towers: (a) types of wind towers in Brazil among 2,537 wind turbines in the sample; (b) minimum, median and maximum values of rated power, rotor diameter and hub height for 1,866 steel and 672 concrete towers in the sample.

\subsubsection{Foundation loading}

\section{Foundation loading: worldwide}

Several load combinations must be regarded, including normal and extreme conditions and temporary conditions, e.g., fault situations, installation and transportation (DNV/Ris $\emptyset$, 2002). The normal condition concerns long-term structural loading, while extreme conditions are rare but represent a critical design condition (Germanischer Lloyd, 2010). The design load cases are specified according to the wind scenario, electrical condition and another external scenario (IEC 61400-1, 2005). For example, IEC 61400-1 establishes several environmental scenarios, such as normal and extreme wind speed, extreme wind shear, extreme normal and coherent gusts, extreme direction change and normal turbulence (IEC 61400-1, 2005). Extreme wind speeds are usually treated as the stationary wind speed during a 10-minute interval or a wind gust during a short period of time, e.g., over 3 to 10 seconds, for a 50-year 
recurrence period (DNV/Ris $\varnothing$, 2002; Germanischer Lloyd, 2010). The design loads are usually provided by the wind turbine manufacturer (Tinjum and Christensen, 2010).

Wind turbines are usually classified into three main classes according to the wind speed and turbulence parameters (IEC 61400-1, 2005). For example, Class 1 wind turbines are designed to withstand 10 minutes of $50 \mathrm{~m} / \mathrm{s}$ extreme reference wind speed with a 50 -year recurrence period at hub height. For Class II and Class III wind turbines, the extreme reference wind speed values are $42.5 \mathrm{~m} / \mathrm{s}$ and $37.5 \mathrm{~m} / \mathrm{s}$, respectively. These characteristic values are used to cover most applications; however, they do not represent any specific site (Germanischer Lloyd, 2010). In cases where a special design is necessary or a cost-optimal design process is conducted, site-specific design loads are performed (DNV/Ris $\varnothing, 2002$; Germanischer Lloyd, 2010). The presence of wind turbines influences the wind flow locally, increasing the turbulence intensity. Therefore, wherever wind turbines are installed behind other turbines at distances of less than 10 to 20 rotor diameters, the wake effects need to be considered (DNV/Risø, 2002; Germanischer Lloyd, 2010).

As wind turbine increases, the forces and the overturning moment at the base also increase. Morgan and Ntambakwa (2008), for example, noticed a linear increase of the extreme overturning moment at the base as wind turbine rated power increased. Shrestha and Ravichandran (2016) determined an overturning moment at the base of 237.37 MN.m for a 130-meter hybrid tower, considering a wind speed of $160 \mathrm{mph}$. According to Rebelo et al. (2014), the overturning moment at the base more than doubles from a 2.0 MW to a $3.6 \mathrm{MW}$ wind turbine with a 100-meter rotor diameter and more than quadruples to a 5.0 MW wind turbine with a 150-meter rotor diameter. Additionally, the wind tower material plays an important role in the magnitude of the efforts. While steel tower foundation design is governed by wind action, concrete and hybrid towers are significantly influenced by seismic forces in the foundation design, increasing the overturning moment at the base up to 3.3 times (Rebelo et al., 2014). When earthquakes are excluded from designs, concrete and hybrid wind tower foundations use approximately the same amounts of concrete as steel wind tower foundations (Rebelo et al., 2014). In addition to the influence of the wind turbine rated power, rotor diameter and hub height, the environmental conditions govern the wind turbine loading (DNV/Risø, 2002).

\section{Foundation loading: Brazil}

Wind turbine foundations have to resist large overturning moments, which are directly influenced by the wind action depending on each site. Therefore, the wind turbine IEC class 
directly influences the overturning moment at the base. Additionally, the wind turbine rated power, rotor diameter, hub height and tower type, such as steel and concrete towers, may influence the magnitude of the foundation loading and thus the foundation design. The effects of the rated power, rotor diameter, hub height and tower type on the overturning moment at the base were analyzed (Fig. 2.5). Foundation loads were obtained from the wind turbine manufacturer technical reports, which considered several scenarios and load combinations. Therefore, Brazilian design load cases adhere to the same requirements considered worldwide. In turn, Brazil has minor earthquake and blizzard issues.

Figure 2.5a displays the influence of the rated power for steel and concrete towers on the overturning moment at the base. A great spread in the overturning moment at the base was observed, and a slightly upward trend was identified. As expected, the wind turbine IEC class significantly influenced the overturning moment at the base. Class II wind turbines exhibited higher overturning moments at the base than Class III wind turbines. The concrete towers exhibited larger overturning moments at the base, regardless of the rated power. Figure $2.5 \mathrm{~b}$ displays the effects of the rotor diameter and hub height on the overturning moment at the base for steel and concrete towers. A wide range of overturning moments at the base was observed for the range of wind turbine rotor diameters, while larger overturning moments at the base were identified only for concrete towers. Additionally, a wide range of overturning moments at the base was identified for the range of wind turbine hub heights of 75 to 95 meters. Concrete towers, which had higher hub height values, exhibited larger overturning moments at the base. High hub height values led to the use of concrete towers (Fig. 2.4b); thus, this type of tower subjected the wind turbine foundation to the larger overturning moment at the base. 
(a)

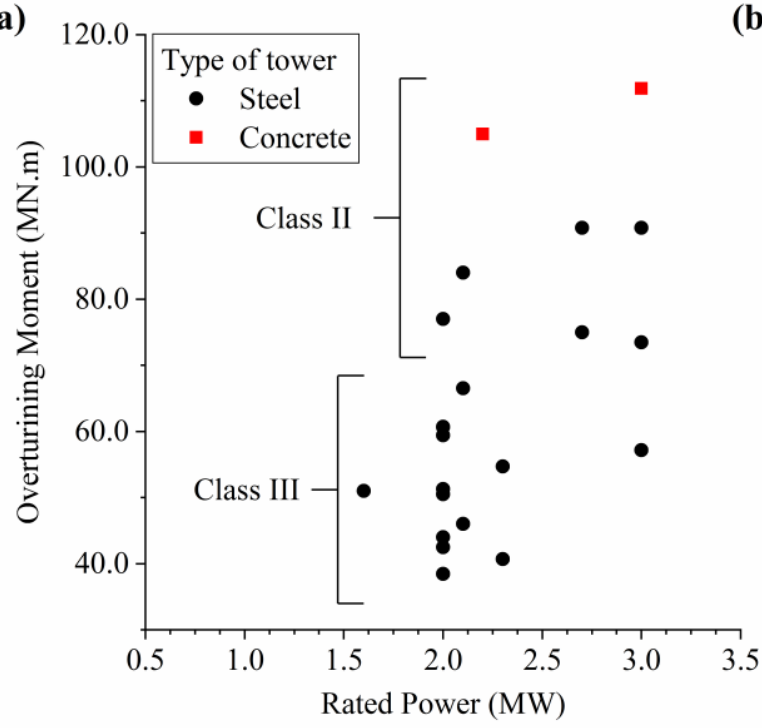

(b)

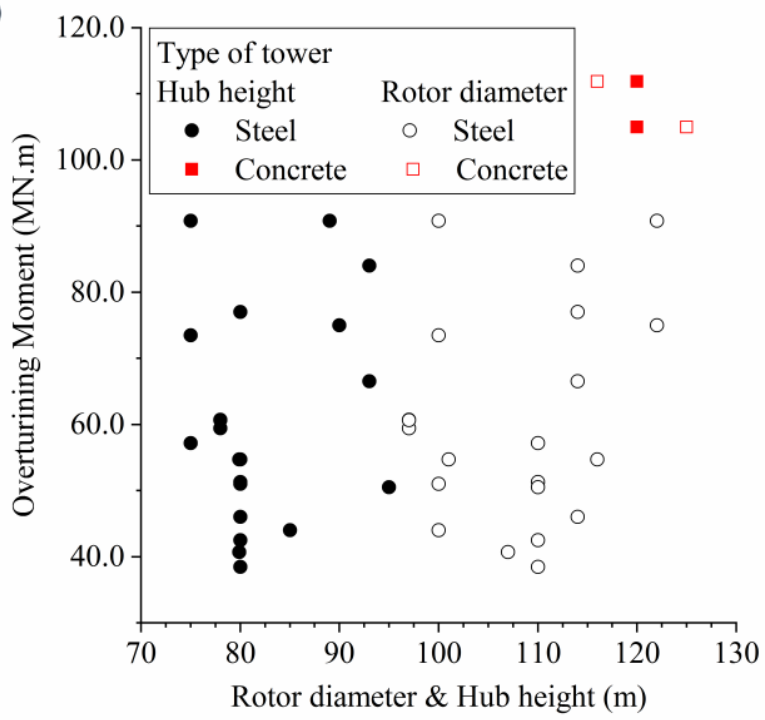

Figure 2.5: The effects of (a) rated power and (b) rotor diameter and hub height on the overturning moment at the base for 93 concrete and 1422 steel towers.

\subsubsection{Foundations}

\section{Foundations worldwide}

Basically, an onshore wind turbine foundation can be described as a concrete foundation (IEA-ETSAP and IRENA, 2016). The type of foundation, shallow or deep, is mostly dependent on the nature of the soil (Germanischer Lloyd, 2010). The typical wind turbine foundation is a reinforced concrete raft of circular outline that settles over bedrock or over a soil with appropriate geotechnical properties, such as stiff clays, gravel, or dense sand (DNV/Risø, 2002; Pham et al., 2018). If the bearing capacity of the soil is insufficient or improvement is uneconomical, shallow foundations are impractical, and deep foundations are used.

Two companies, SIC (2017) and Peiko (2017), exhibited available data on onshore wind turbine foundations of northern European countries, such as Norway, Sweden and Finland. This particular database provided information about 26 onshore wind farms, totaling 549 wind turbines and 1,750.8 GW. Wind turbine foundation types consisted of $49.0 \%$ rock anchor foundations, $47.0 \%$ concrete gravity foundations, and only $4.0 \%$ piled foundations. In addition, the wind turbine rated powers and hub heights did not influence the foundation types. The ranges of turbine capacities and hub heights were 2.0 to $3.6 \mathrm{MW}$ and 85 to 142 meters for concrete gravity foundations, respectively, and 2.3 to $3.6 \mathrm{MW}$ and 87 to 142 meters for rock anchor foundations, respectively.

In France, data for more than 50 wind farms, totaling 350 wind turbines and approximately $1.0 \mathrm{GW}$ of installed capacity, were acquired from a global design and 
consultancy company. More than $85 \%$ of the wind turbines were verified to be supported by shallow foundations. Additionally, $10 \%$ of the wind turbine foundations used controlled modulus column rigid inclusions, and 5\% used deep foundations.

Several wind farms in the United States used rock anchor foundations, such as Kingdom Community Wind (Lowell, VT), Bull Hill Wind Towers (Eastbrook, ME), Record Hill Wind Towers (Roxbury, ME), Rollins Wind Towers (Lee, ME), and Brodie Mtn Wind (Hancock, MA) (Shrestha, 2015). However, octagonal shallow foundations were the most frequently used foundation type for onshore wind turbines in the United States (Tinjum and Christensen, 2010). Regarding deep foundations, Patrick and Henderson's tensionless pier were extensively used in the United States for shore-based wind turbine foundations (Tinjum and Christensen, 2010).

\section{a) Shallow foundations: worldwide}

A shallow foundation consists of a slab with a large surface area, which distributes the efforts to the soil below, and a central reinforced pedestal, which connects the foundation to the wind tower. Occasionally, reinforced beams or ribs are used above or below the slab to provide greater structural stiffness to the foundation. Due to the foundation weight and backfill soil above it, shallow wind turbine foundations are also considered gravity foundations. The construction material is almost exclusively reinforced concrete (Svensson, 2010). Shallow foundations may have different plan shapes, including circles, octagons and squares, and distinct geometries, such as cylindrical or square prisms. Less concrete is used as the foundation shape is optimized, such as octagon or circle shapes; however, these shapes require $20 \%$ to $30 \%$ more steel than the square shape (Horgan, 2013).

Typically, gravity foundations have a diameter between 12 and $20 \mathrm{~m}$, central pedestal diameter of 4.5 to $5.5 \mathrm{~m}$, thickness of $0.7 \mathrm{~m}$ at the edge and 2.5 to $3.5 \mathrm{~m}$ at the center, embedment of 2.4 to $3.5 \mathrm{~m}$ beneath the ground level, content of 120 to 460 cubic meters of concrete and 125 to $360 \mathrm{kN}$ of reinforcing steel (Tinjum and Christensen, 2010; Lang, 2012; Berndt, 2015; Ntambakwa et al., 2016). Figure 2.6 shows the required concrete volume for gravity foundations as a function of the wind turbine rated power. As the wind turbine rated power increases, the wind turbine foundation is likely to use a larger concrete volume. Additionally, similar positive trends are noticed for Australian and United States projects. 


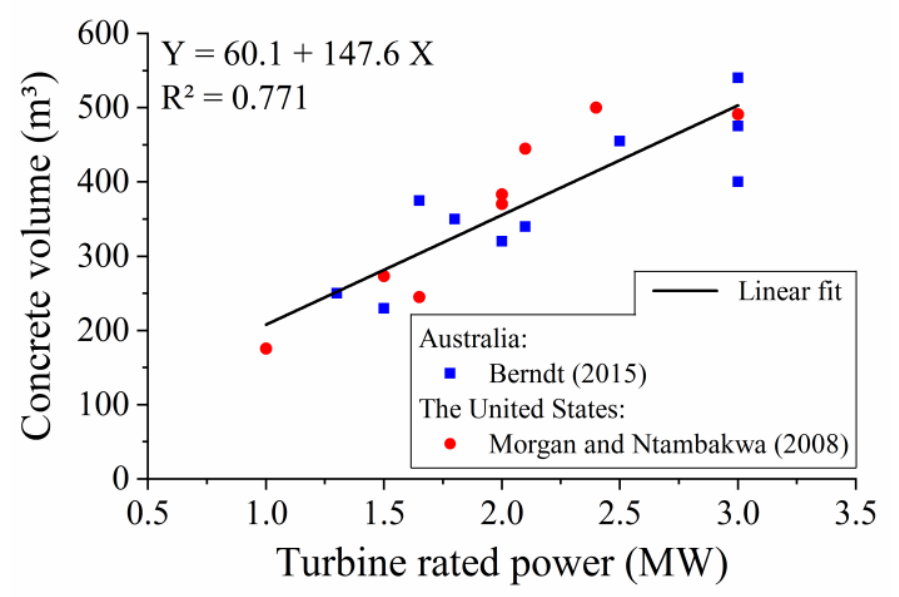

Figure 2.6: Concrete volume versus wind turbine rated power for gravity foundations (Berndt, 2015; Ntambakwa et al., 2016).

The water table level also plays an important role in the foundation characteristics. DNV/Ris $\varnothing$ (2002) emphasizes the importance of considering the water level (WL) depth in relation to the foundation base. The presence of the WL above the foundation base reduces the effective weight of the submerged portion of the foundation, reducing the overall vertical load and increasing the eccentricity (Tinjum and Christensen, 2010). The foundation diameter is increased by approximately $15 \%$ to $20 \%$ when the WL is at the ground surface compared with a WL deep below the surface (Mohamed and Austrell, 2017). In certain soils, cyclic degradation with multiple instances of zero pressure could lead to breakdown of the in situ soil structure and subsequent serviceability problems in the presence of water (Morgan and Ntambakwa, 2008).

For sites with poor geotechnical conditions, soil improvements can be made to ensure that the foundation can withstand the loads. The soil properties that are usually improved are stiffness, shear strength and soil homogeneity. Several soil improvement techniques can be performed, such as soil preloading, dynamic compaction, jet-grouting, rammed aggregate piers and rigid inclusions. The use of dynamic compaction is limited to coarse-grained soils and can be effective up to depths approximately 7.0 to 10.0 meters (Tinjum and Christensen, 2010). Rammed aggregate piers are used where soft or loose upper soil layers underlie a more competent material to pier lengths up to 7 meters (Tinjum and Christensen, 2010). Rigid inclusions are high modulus concrete or grout columns installed through soil strata with poor geotechnical proprieties. The rigid inclusions are typically installed beneath a mattress of granular material above which the shallow foundation is settled. Although no structural link with the shallow foundation is made, rigid inclusions can reduce the total and differential 
settlements and improve the bearing capacity (Pham et al., 2018). Shrestha and Ravichandran (2016) noted that rigid inclusions were the most economical choice for a certain site condition, 8 meters of soft to firm clay overlying the cooper marl, when comparing shallow and deep foundations. As the number of rigid inclusions increased, the soil settlement, foundation rotation, axial forces and bending moments on the inclusions decreased (Pham et al., 2018). However, after a certain number of inclusions, the addition of inclusions had a negligible contribution in reducing the settlement (Shrestha and Ravichandran, 2016).

Another method that is not truly a soil improvement technique is to simply exchange the soil below the foundation for crushed stone, soil-cement stabilization or compacted local soil, for example. These methods are convenient when a thin poor soil layer near the ground level lies beneath an appropriate soil (Svensson, 2010). Over-excavation and replacement can be economical up to a depth of 3.0 meters below the foundation base depending on the soil and groundwater level (Tinjum and Christensen, 2010).

Frequently, when bedrock is near the ground level, rock anchored foundations are used (Ismael, 1982). The overturning resistance comes from a combination of the bearing pressure beneath the cap and the tension of steel bars grouted into boreholes and post-tensioned (Morgan and Ntambakwa, 2008). The rock classification, rock quality designation (RQD), joint spacing and orientation, and stratification are the main rock properties related to rock anchor capacity (Tinjum and Christensen, 2010).

\section{b) Deep Foundations: worldwide}

Deep foundations are used when large highly porous soil layers are near the ground level, competent soil or rock is deeply buried and soil improvements are uneconomical (Morgan and Ntambakwa, 2008; IRENA, 2017). A deep wind turbine foundation consists of a pile group assembled by a pile cap (Shrestha, 2015). The pile cap, also called the raft, provides structural stiffness to the pile group and acts as the connection between piles and the wind tower. The piles, which are drilled or driven through low-strength soil layers, transfer the load from the wind turbine to competent soil or rock layers through axial and lateral pile resistances (DNV/Risø, 2002; Berndt, 2015). However, the interaction between axial pile resistance and lateral pile resistance is commonly disregarded (DNV/Ris $\varnothing, 2002$; Frank et al., 2005).

Pile foundations have been widely used in wind turbines because they can decrease the foundation size and construction cost (Lang, 2012). The number, distribution, length, and diameter of the piles have significant influences on the foundation performance. However, 
steel reinforcement of the concrete structures is required, which increases the construction cost due to the concentration of efforts, especially axial force and bending moment, on the top of piles (Pham et al., 2018). The pile raft is the most effective solution for reducing the total and differential foundation settlement (Pham et al., 2018). Increasing the number of piles has a positive effect in terms of reducing settlement. In turn, due to the pile cap rotation movement, peripheral piles are subjected to greater bending moments and axial forces.

Another type of wind turbine deep foundation that has been widely used in the United States is Patrick and Henderson's tensionless pier, as previously mentioned. This foundation consists of a post-tensioned concrete annulus with a diameter of approximately 5.0 meters and depths of 8.0 to 12.0 meters (Tinjum and Christensen, 2010).

\section{Foundations in Brazil}

The following analysis used data from the first Brazilian database of wind turbine foundations. Wind turbine foundations were composed of $43.3 \%$ shallow foundations (SFs) and $56.7 \%$ deep foundations (DFs). Figure 2.7 shows the percentages of foundation types. Clearly, concrete gravity SFs and continuous flight auger pile (CFAP) DFs prevailed with approximately $40.0 \%$ each. Root pile DFs were used in $12.6 \%$ of the cases, while $7.5 \%$ of the wind turbines had other types of foundations, such as rock anchored SFs and steel driven pile DFs. These results were significantly different from international practice, which used a great proportion of SFs.

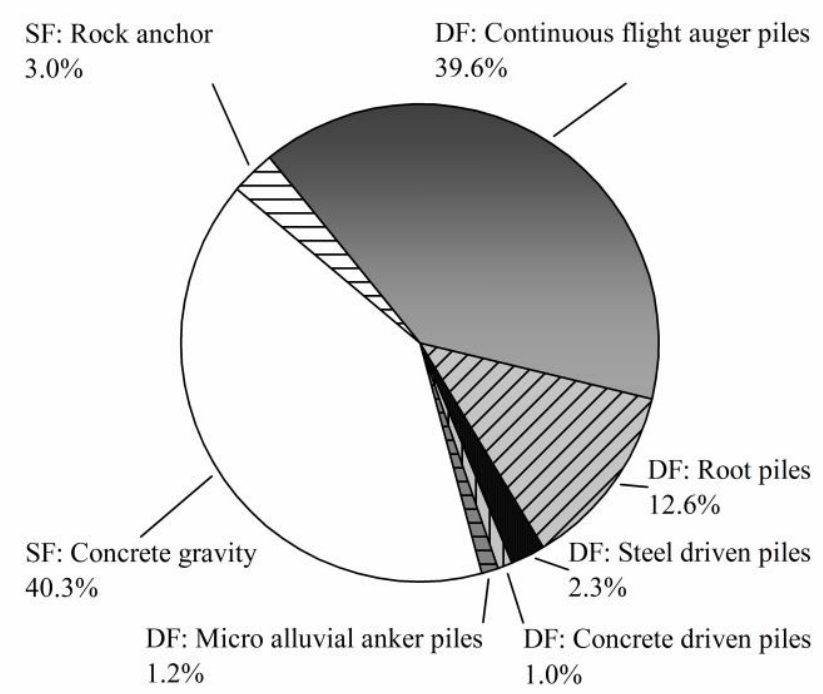

Figure 2.7: Types of wind turbine foundations for 3,031 wind turbines. 
Wind turbines with concrete towers exhibited larger overturning moments at the base; however, they were not influenced by the type of wind turbine foundation. Wind turbines with steel towers had $50.9 \%$ SFs and $49.1 \%$ DFs, of which $70.9 \%$ were CFAP DFs. Wind turbines with concrete towers showed $49.1 \%$ SFs and $50.9 \%$ DFs, of which $87.6 \%$ were CFAP DFs. Although the tower type did not influence the foundation type, it clearly influenced the foundation's dimensions (Table 2.1). The wind turbine SFs with concrete towers exhibited larger diameters and greater amounts of concrete than the wind turbine SFs with steel towers. The average increases in SF diameter and concrete volume were approximately $15 \%$ and $28 \%$, respectively. For CFAP DFs, the wind turbines with concrete towers had higher values of pile cap diameter, pile cap concrete volume and number of piles than wind turbines with steel towers. The CFAP DF pile cap diameter and concrete volume had average increases of approximately $12 \%$ and $48 \%$, respectively. In addition, CFAP DFs with concrete towers used, on average, nine piles more than the wind turbines with steel towers.

Table 2.1: The effect of the tower type on shallow and deep foundation characteristics.

\begin{tabular}{llcc}
\hline \multirow{2}{*}{ Foundation } & \multicolumn{2}{c}{ Tower type } \\
& & Steel & Concrete \\
\hline \multirow{3}{*}{ SFs } & Number of data & 950 & 330 \\
& Diameter $(\mathrm{m})$ & $16.7(1.4)$ & $19.2(1.2)$ \\
& Concrete volume $\left(\mathrm{m}^{3}\right)$ & $321.7(65.1)$ & $412.9(62.7)$ \\
\hline \multirow{3}{*}{ CFAP DFs } & Number of data & 649 & 300 \\
& Raft diameter $(\mathrm{m})$ & $15.5(1.6)$ & $17.3(0.5)$ \\
& Raft concrete volume $\left(\mathrm{m}^{3}\right)$ & $320.7(44.2)$ & $475.4(44.0)$ \\
& Number of piles & $23.3(6.3)$ & $32.2(5.5)$ \\
\hline
\end{tabular}

Note: Average values and standard deviations, in parentheses, are presented.

\section{a) Shallow foundations: Brazil}

As previously mentioned, SFs accounted for $43.3 \%$ of the onshore wind turbine foundation samples. However, different types of SFs and several soil reinforcement techniques (SRTs) were used to improve the foundation performance. Table 2.2 displays the SF types and SRTs used for 1,313 wind turbines. The concrete gravity SFs with no SRTs made up $74.8 \%$ of the SF samples, while the concrete gravity SFs with SRTs accounted for $10.7 \%$ of the samples. Rock anchored SFs composed $7.0 \%$ of the SF samples. Additionally, $7.5 \%$ of wind turbine SFs did not specify whether SRTs were used. Regarding the plan shape of SFs with or without SRTs, $88.4 \%$ of them had a circular plan shape, of which $5.0 \%$ were hollow inside, and $11.6 \%$ had a square plan shape. All the rock anchored SFs had circular plan shapes; however, $81.5 \%$ of them were hollow inside. 
SRTs for SFs were used when certain subsoil layers exhibited poor geotechnical properties and geotechnical improvements were practical and economical. The main geotechnical properties improved were stiffness, shear strength and soil homogeneity. The SRTs were usually used through two approaches: all wind turbine SFs in a wind farm required SRTs, or a few wind turbine SFs in a wind farm required SRTs to replicate the same SF in all wind turbines. The thickness and type of SRT depended on site conditions for each wind turbine. The SRTs used were soil-cement stabilization, crushed stone or cyclopic concrete and stabilization grouting. The soil-cement stabilization and crushed stone or cyclopic concrete techniques had a median thickness of 1.00 meter and a standard deviation of 0.75 meter, ranging from 0.25 to 3.50 meters. The jet-grouting technique usually used 13 to 29 holes that were 6 to 12 meters in depth and 3 inches in diameter.

Table 2.2: Types of SFs for 1,313 wind turbines of the sample.

\begin{tabular}{lcc}
\hline SFs & \multicolumn{2}{c}{ Total number $(\%)$} \\
\hline No reinforcement & $982(74.8 \%)$ & \\
Soil reinforcement & $140(10.7 \%)$ & \\
$\quad$ Soil-cement stabilization & $56(4.3 \%)$ \\
Crushed stone/cyclopic concrete & $17(1.3 \%)$ \\
$\quad$ Stabilization grouting & $67(5.1 \%)$ \\
Rock anchored & $92(7.0 \%)$ \\
No available information & $99(7.5 \%)$ & \\
\hline
\end{tabular}

Table 2.3 shows the statistical results for SF dimensions and material amounts for SFs without SRTs, SFs with SRTs and rock anchored SFs. Approximately $30.0 \%$ of SFs without SRTs exhibited concrete towers, while $18.8 \%$ of SFs with SRTs had concrete towers. Rock anchored SFs used only steel towers. As previously mentioned, the type of tower influenced the SF dimensions and material amounts (Table 2.1). The average diameter of SFs was approximately 17.00 meters; however, the statistical distributions of SF diameters differed according to the SF type. SFs without SRTs had a wide statistical distribution of foundation diameters ranging from 13.50 to 20.75 meters. Rock anchored SFs exhibited a narrow statistical distribution of foundation diameters ranging from 13.50 to 17.00 meters. The tower type and amount of data possibly influenced these extreme values observed. The average SF height was approximately 2.60 meters, ranging mainly from 2.00 to 3.00 meters. The statistical distributions of SF diameters were similar for different SF types. Therefore, no significant influence of the SF type on the foundation diameter and height was identified. 
The concrete volume used in SFs ranged from $210.5 \mathrm{~m}^{3}$ to $485.0 \mathrm{~m}^{3}$, with an average value of approximately $345.0 \mathrm{~m}^{3}$. SFs with SRTs exhibited a higher statistical distribution of concrete volume than SFs without SRTs and rock anchored SFs. A wide range of steel amounts was used in wind turbine SFs, ranging from 18,115 to $51,289 \mathrm{~kg}$. SFs without SRTs had a median steel amount value of $28,500 \mathrm{~kg}$, while SFs with SRTs and rock anchored SFs exhibited median steel amounts of $36,551 \mathrm{~kg}$ and $42,674 \mathrm{~kg}$, respectively. The reinforcement ratio, i.e., the ratio between steel amount and concrete volume, was also determined. The reinforcement ratio ranged from $68.4 \mathrm{~kg} / \mathrm{m}^{3}$ to $126.3 \mathrm{~kg} / \mathrm{m}^{3}$ with an average value of approximately $98.7 \mathrm{~kg} / \mathrm{m}^{3}$.

In general, the lower parts of the statistical distributions up to the median values were similar for rock anchored SFs and SFs with and without SRTs. The higher parts of the statistical distributions could have been influenced by the sample size and tower types. SFs with SRTs and rock anchored SF samples accounted for only 138 and 92 wind turbines, respectively, while SFs with SRTs and rock anchored SF samples had $18.8 \%$ and $0.0 \%$ concrete towers, respectively. Therefore, the SF type did not significantly influence the foundation diameter, concrete volume or steel amount.

Additionally, rock anchored SFs usually had 16 to 32 anchors that were 4 to 9 meters in depth and 6 inches in diameter. All SFs were embedded in soil and used backfill to increase the overturning resistance, regardless of the SF type. The median backfill weight was 4471 $\mathrm{kN}$ with a standard deviation of $1614 \mathrm{kN}$ and ranged from $1600 \mathrm{kN}$ to $7722 \mathrm{kN}$. 
Table 2.3: Statistical results for foundation dimensions and material amounts for 1,313 wind turbine SFs.

\begin{tabular}{|c|c|c|c|c|}
\hline & & SFs without SRTs & SFs with SRTs & Rock anchored SFs \\
\hline \multirow{2}{*}{$\begin{array}{l}\text { Tower type } \\
\text { (\%) }\end{array}$} & Steel & 72.2 & 81.2 & 100.0 \\
\hline & Concrete & 29.4 & 18.8 & 0.0 \\
\hline \multirow{5}{*}{ Diameter (m) } & Minimum & 13.50 & 16.10 & 13.50 \\
\hline & Median & 17.00 & 17.30 & 17.00 \\
\hline & Standard deviation & 1.84 & 1.63 & 1.92 \\
\hline & Maximum & 20.75 & 17.60 & 17.00 \\
\hline & Amount of data & 963 & 138 & 92 \\
\hline \multirow{5}{*}{ Height (m) } & Minimum & 1.80 & 2.20 & 2.60 \\
\hline & Median & 2.60 & 2.55 & 2.80 \\
\hline & Standard deviation & 0.40 & 0.25 & 0.20 \\
\hline & Maximum & 3.20 & 3.00 & 3.00 \\
\hline & Amount of data & 1083 & 138 & 92 \\
\hline \multirow{5}{*}{$\begin{array}{l}\text { Concrete } \\
\text { volume }\left(\mathrm{m}^{3}\right)\end{array}$} & Minimum & 210.5 & 265.0 & 210.5 \\
\hline & Median & 340.0 & 380.0 & 362.6 \\
\hline & Standard deviation & 78.9 & 67.9 & 58.3 \\
\hline & Maximum & 485.0 & 440.3 & 362.6 \\
\hline & Amount of data & 1048 & 138 & 92 \\
\hline \multirow{5}{*}{$\begin{array}{l}\text { Steel amount } \\
(\mathrm{kg})\end{array}$} & Minimum & 18,115 & 18,115 & 18,809 \\
\hline & Median & 28,500 & 42,674 & 36,551 \\
\hline & Standard deviation & 10,300 & 10,736 & 6,684 \\
\hline & Maximum & 51,289 & 51,289 & 36,551 \\
\hline & Amount of data & 850 & 90 & 92 \\
\hline \multirow{5}{*}{$\begin{array}{l}\text { Reinforcement } \\
\text { ratio }\left(\mathrm{tf} / \mathrm{m}^{3}\right)\end{array}$} & Minimum & 0.0684 & 0.0684 & 0.0802 \\
\hline & Median & 0.0969 & 0.0969 & 0.1008 \\
\hline & Standard deviation & 0.0119 & 0.0127 & 0.0077 \\
\hline & Maximum & 0.1263 & 0.1263 & 0.1079 \\
\hline & Amount of data & 850 & 90 & 92 \\
\hline
\end{tabular}

The influence of the wind turbine characteristics on the foundation dimensions and material amounts was analyzed for SFs in Figure 2.8. The SF type had no significant effect, as similar results were obtained for each SF type; thus, the linear correlations were determined considering all SFs. Positive trends in SF diameter, concrete volume and steel amount were observed with the wind turbine rated power, rotor diameter and hub height. However, low correlation factors were obtained, especially for the rotor diameter. The wind turbine hub height had moderate correlation factors. Overall, the SF diameter had higher correlation factors with technology status than with SF material amount. Additionally, Australian and United States wind projects exhibited similar results for concrete volume versus rated power.

Figure 2.9a shows the influence of SF diameter on the concrete volume and steel amount. The foundation diameter had significant effects on the concrete volume and steel amount, with moderate correlation factors of 0.620 and 0.612 , respectively. The concrete volume and steel amount increased with the SF diameter, as expected. For example, a 13 meter diameter SF would require $208 \mathrm{~m}^{3}$ of concrete and 15,114 $\mathrm{kg}$ of steel, while a 21 meter diameter SF would require $480 \mathrm{~m}^{3}$ of concrete and $51,450 \mathrm{~kg}$ of steel. The rates of increase in concrete volume and steel amount per meter of SF diameter were approximately $34 \mathrm{~m} / \mathrm{m}$ and 
$4,542 \mathrm{~kg} / \mathrm{m}$, respectively. No significant influence of the SF type was noticed on the SF diameter and material amount relationship. Figure $2.9 \mathrm{~b}$ displays the steel amount and concrete volume relationship. A reinforcement ratio of $98.7 \mathrm{~kg}$ of steel per $\mathrm{m}^{3}$ of concrete was observed. Additionally, concrete and steel towers had similar reinforcement ratios.
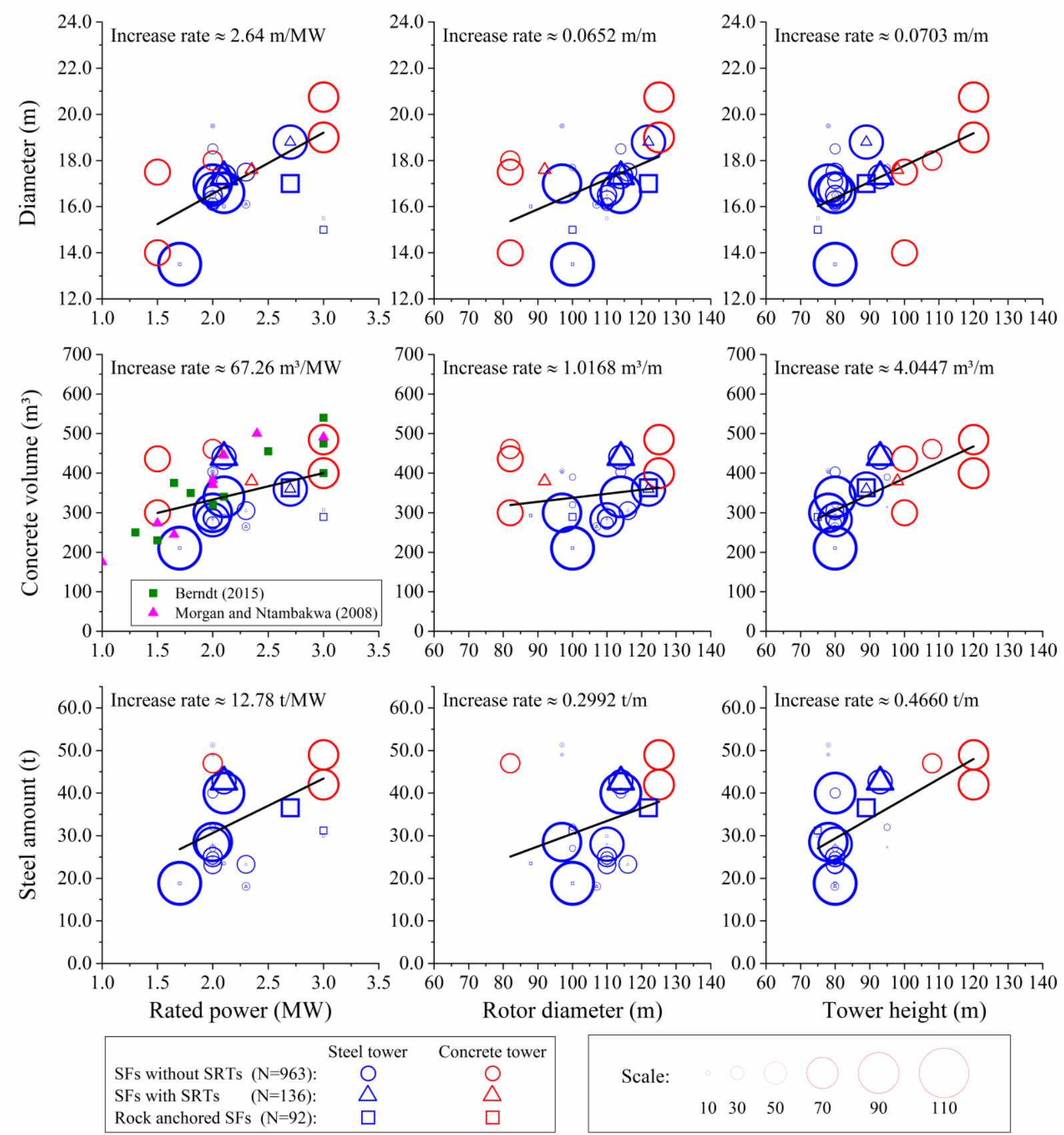

Figure 2.8: Effects of the wind turbine technology status on the diameter, concrete volume and steel amount of 1,191 wind turbine SFs. The circle size indicates the number of wind turbines. 

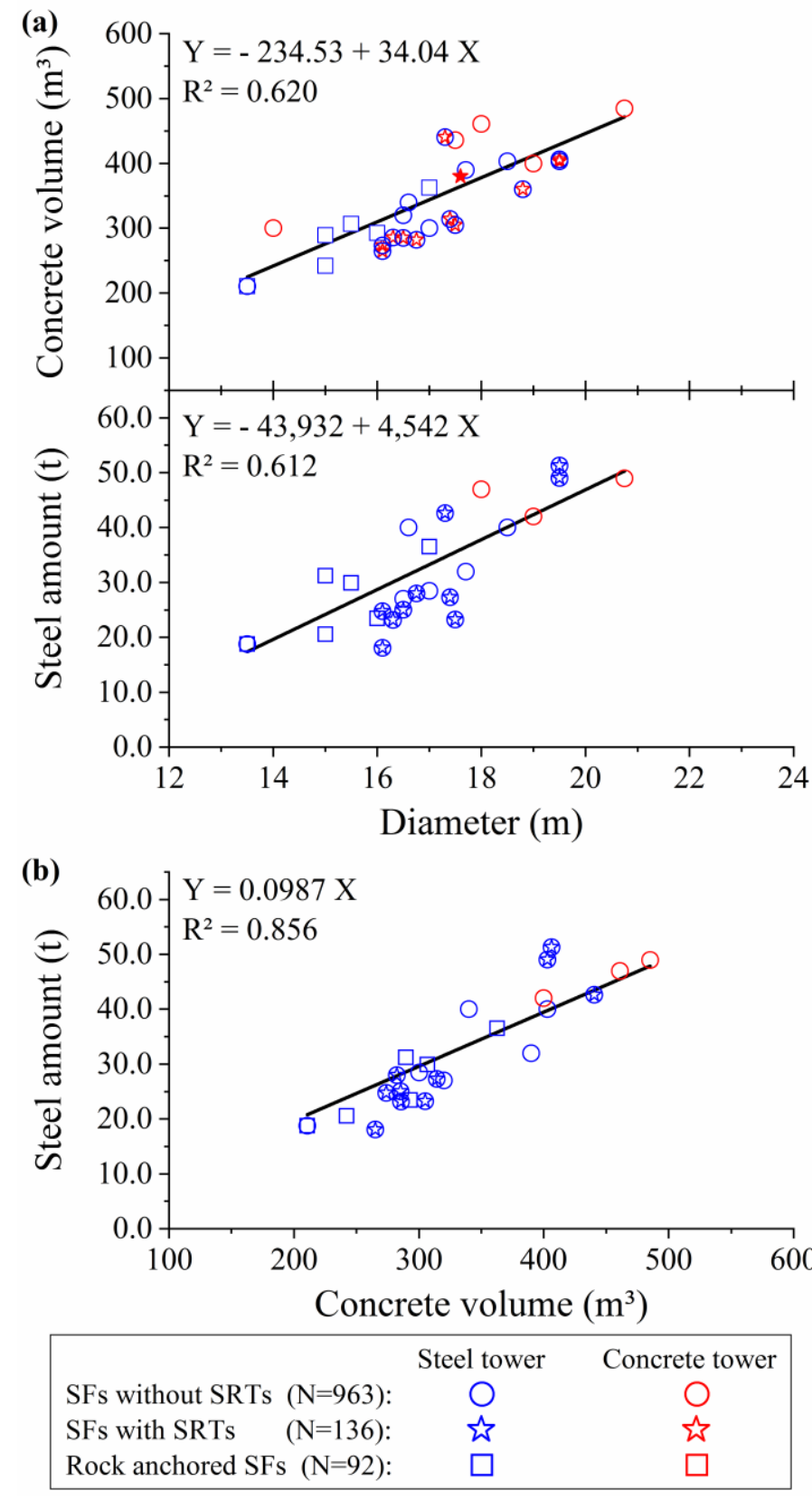

Figure 2.9: Influence of the SF diameter on (a) concrete volume and steel amount for 1,191 wind turbine SFs. (b) the reinforcement ratio of wind turbine SFs.

Table 2.4 displays the subsoil types, such as soil, rock or weathered rock, above which wind turbine SFs were settled. For SFs with SRTs, the subsoil type was such that the foundation would settle if no SRT was used. Wind turbine SFs were typically settled above soil layers (42.2\%), rock layers $(36.5 \%)$ and weathered rock layers $(21.3 \%)$.

SFs without SRTs were predominantly settled above soil and rock levels, with a great share of them settled above sandy soils and sandstone. SFs with SRTs were predominantly employed to improve soil and weathered rock layers, with a great share of them conducted in sandy soils and weathered calcilutite rock. Rock anchored SFs were mainly settled above 
rock, especially migmatite and phyllite, and a minor proportion of rock anchored SFs were settled above a thin soil layer overlying a rock layer. In general, different types of SFs were used depending on the ground type, such as soil, weathered rock and rock; in turn, in a few cases, different types of SFs were used for the same ground type, evidencing the existence of other variables.

A significant difference between the SPT impenetrable depth for SFs with or without SRTs and rock anchored SFs was identified (Fig. 2.10). Usually, the SPT impenetrable depth was related to the presence of weathered rock or rock layers. Figure 2.10 shows that the wind turbine SFs without SRTs had a wide range of SPT impenetrable depths with a median value of 3.5 meters. Wind turbine SFs with SRTs had a median SPT impenetrable depth of 5.0 meters, with $50 \%$ between 3.0 and 6.0 meters. In turn, rock anchored SFs were close to the ground level and had a narrow range of SPT impenetrable depths with 75\% less than 3.5 meters. Additionally, 573 wind turbine SFs had water table level data; however, $97 \%$ of them did not identify the WL.

Table 2.4: Subsoil types, in percentage, above which wind turbine SFs were settled for 365 SFs without SRTs (Type 1), 108 SFs with SRTs (Type 2) and 81 rock anchored SFs (Type 3).

\begin{tabular}{lrrrr} 
Subsoil type & $\begin{array}{c}\text { Type } 1 \\
(\%)\end{array}$ & $\begin{array}{c}\text { Type } 2 \\
(\%)\end{array}$ & $\begin{array}{c}\text { Type } 3 \\
(\%)\end{array}$ & \multicolumn{1}{c}{$\begin{array}{c}\text { Total } \\
(\%)\end{array}$} \\
\hline Soil & 41.9 & 52.8 & 29.6 & 42.2 \\
Sand & 5.8 & 6.5 & 6.2 & 6.0 \\
Clayey/silty sand & 18.1 & 31.5 & 13.6 & 20.0 \\
Clay & 1.9 & 1.9 & & 1.6 \\
Sandy/silty clay & 13.4 & 9.3 & & 10.6 \\
Silt & & & 1.2 & 0.2 \\
Clayey/sand y silt & 2.7 & 3.7 & 8.6 & 3.8 \\
\hline Rock & 38.6 & 3.7 & 70.4 & 36.5 \\
Sandstone & 24.9 & 0.9 & & 16.6 \\
Metasandstone & 6.3 & 0.9 & & 4.3 \\
Migmatite & & & 35.8 & 5.2 \\
Quartzite & 6.6 & & 1.2 & 4.5 \\
Phyllite & & & 32.1 & 4.7 \\
Others & 0.8 & 1.9 & 1.2 & 1.1 \\
\hline Weathered rock & 19.5 & 43.5 & & 21.3 \\
Sandstone & 6.6 & 8.3 & & 6.0 \\
Metasandstone & 3.6 & & & 2.3 \\
Claystone & 4.1 & 6.5 & & 4.0 \\
Calcilutite & 1.1 & 26.9 & & 6.0 \\
Others & 4.1 & 1.9 & & 3.1 \\
\hline Total: absolute values & 365 & 108 & 81 & 554 \\
\hline & & & & \\
\hline
\end{tabular}




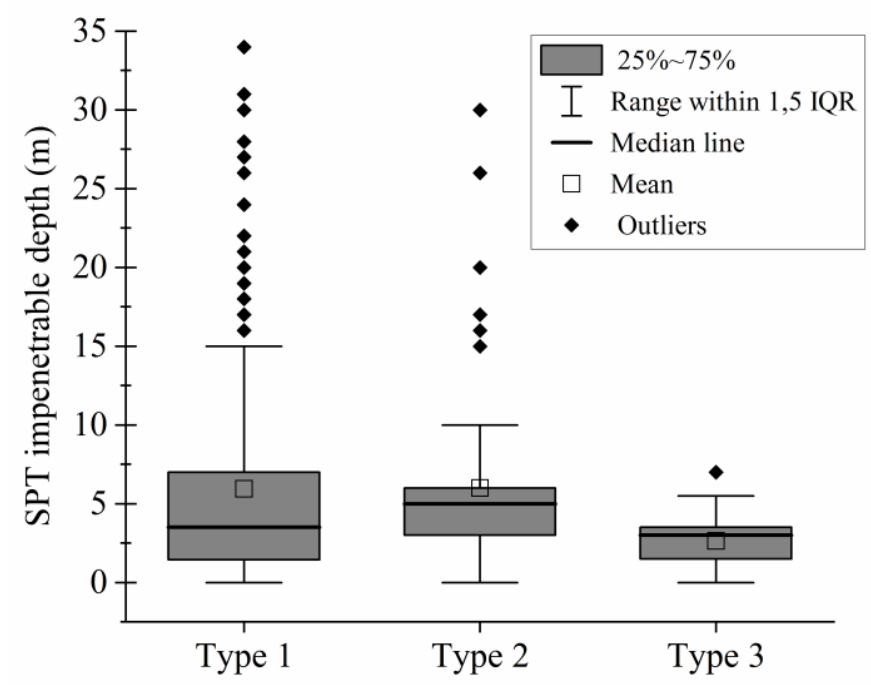

Figure 2.10: The SPT impenetrable depths for 464 SFs without SRTs (Type 1), 134 SFs with SRTs (Type 2) and 81 rock anchored SFs (Type 3).

The resistance and deformability of the ground layer above which SFs were settled also directly affected the foundation performance. The SFs were mainly designed based on SPT results. The SF design used a median admissible stress of $350 \mathrm{kPa}$, ranging mainly from 200 to $350 \mathrm{kPa}$. Figure 2.11a shows a box chart of the $\mathrm{N}_{\text {SPT }}$ values at the bases of SFs with or without SRTs. For clarity, the $\mathrm{N}_{\text {SPT }}$ results for the SFs with SRTs refer to the $\mathrm{N}_{\text {SPT }}$ values

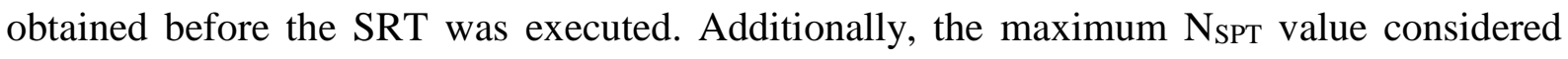
was 50. For the SFs settled above the soil layers, a significant difference in the N was observed. The SFs without SRTs had $75 \%$ of their N median value of 40 . In turn, SFs with SRTs had $75 \%$ of their NSPT values lower than 33 , while the median value was 19 . For the SFs settled above weathered rock layers, no significant difference in NSPT results was observed. Most of the NSPT values obtained were limited to 50, while lower values were statistically considered outliers. In general, lower $\mathrm{N}_{\text {SPT }}$ values led to the necessity of SRTs. SFs with SRTs settled above soil layers used $60 \%$ soil-cement stabilization and $24 \%$ crushed stone or cyclopic concrete techniques; in turn, SFs with SRTs settled above weathered rock layers used $70 \%$ stabilization grouting and 30\% soil-cement stabilization methods.

Figure $2.11 \mathrm{~b}$ and $\mathrm{c}$ show the effects of the $\mathrm{N}_{\mathrm{SPT}}$ value and overturning moment at the base on the SF diameter for different types of layers. A large number of wind turbines exhibited the same overturning moment at the base, since wind farms usually used one wind turbine type, and the foundation loading was provided by the wind turbine manufacturer. As the foundation loading increased, the SF diameter increased (Fig. 2.11b, c). Additionally, the 
same foundation diameter was used for several wind turbine sites in a wind farm; however, these sites exhibited different $\mathrm{N}_{\mathrm{SPT}}$ values at the SF base. The foundation diameters of SFs without SRTs decreased as the minimum $\mathrm{N}_{\text {SPT }}$ values increased (Fig. 2.11b). Therefore, the lowest $\mathrm{N}_{\text {SPT }}$ value of a wind farm site was critical to the foundation design. In turn, SFs with SRTs exhibited a wide range of low $\mathrm{N}_{\mathrm{SPT}}$ values, and no clear trend was observed (Fig. 2.11c). Nevertheless, these low N SPT values were improved through SRTs. A coupled effect of foundation loading and low $\mathrm{N}_{\text {SPT }}$ values of a wind farm site on the SF diameter was observed. In general, high foundation loading and low N NPT values led to large SF diameters, while low foundation loading and high $\mathrm{N}_{\text {SPT }}$ values resulted in low SF diameters (Fig. 2.11b). Additionally, wind turbines settling above clayey soils exhibited lower foundation diameters than wind turbines settling above sandy soils; however, wind turbines settling above sandy soils provided a greater amount of data and thus a wider range of N $\mathrm{N}_{\text {SPT }}$ values. 

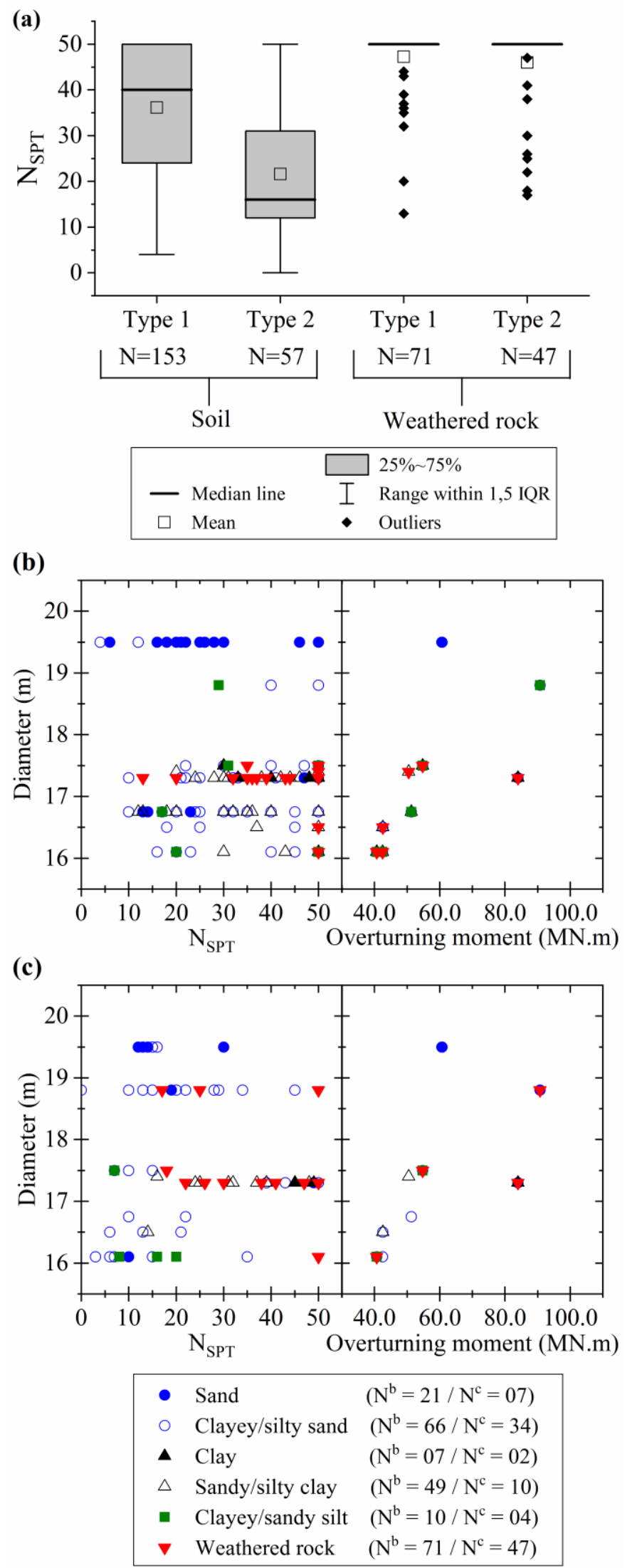

Figure 2.11: Wind turbine SFs settled above soil and weathered rock layers: (a) $\mathrm{N}_{\text {SPT }}$ results for SFs with or without SRTs; (b) $\mathrm{N}_{\mathrm{SPT}}$ versus diameter and overturning moment at the base for SFs without SRTs and different subsoil types; (c) $\mathrm{N}_{\text {SPT }}$ versus diameter and overturning moment at the base for SFs with SRTs and different subsoil types. 
Figure 2.12a shows a box chart of the RQD values obtained at the SF base. SFs exhibited RQD values ranging from $0 \%$ to $100 \%$. SFs without SRTs had $75 \%$ of their RQD values lower than $46 \%$ and a median RQD value of $20 \%$. SFs with SRTs had all RQD values below $12 \%$. Rock anchored SFs had $75 \%$ of their RQD values higher than $20 \%$ and a median RQD value of $60 \%$.

Figure 2.12b shows the influence of RQD value and overturning moment at the base on the SF diameter for SFs settled above rock layers. In general, high foundation loading led to a large SF diameter. Rock anchored SFs exhibited the same range of foundation loading as SFs with and without SRTs; however, rock anchored SFs had a lower statistical distribution of foundation diameters than SFs with and without SRTs. This outcome was expected as the use of rock anchor bolts reduced the required foundation diameter. Additionally, wind turbine sites exhibited a wide range of RQD values from $0 \%$ to $100 \%$ (Fig. 2.12b). As the same foundation diameter was usually used for several wind turbine sites in a wind farm, the RQD value did not exhibit a clear influence on the foundation diameter. The foundation loading and the SF types, however, had significant influences on the foundation diameter. 


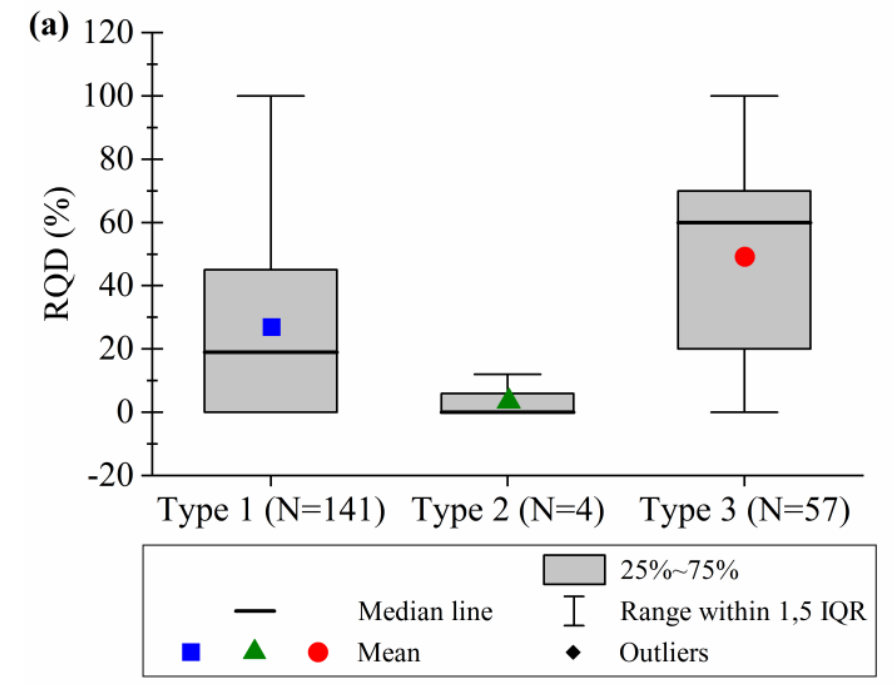

(b)

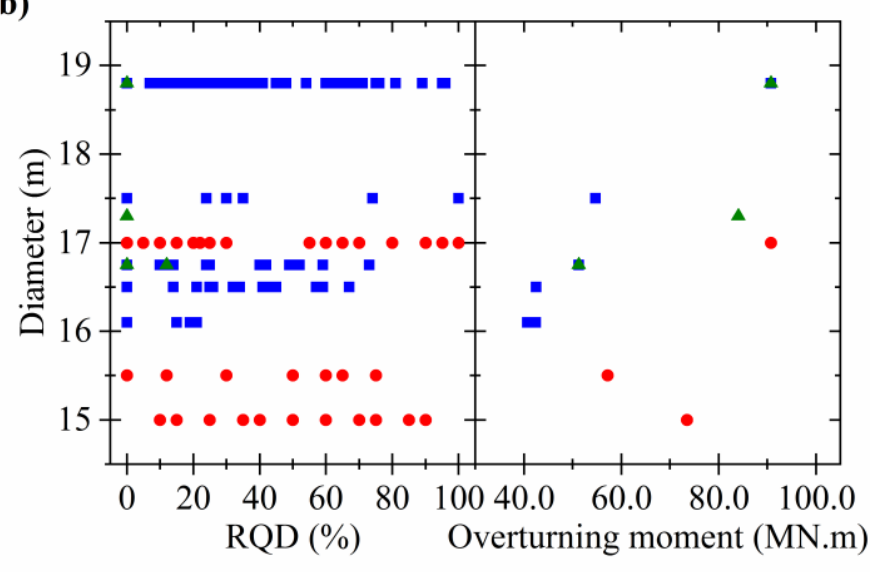

- SFs without SRTs $\quad(\mathrm{N}=141)$

- SFs with SRTs $\quad(\mathrm{N}=004)$

- $\quad$ Rock anchored SFs $(\mathrm{N}=057)$

Figure 2.12: Wind turbine SFs settled above rock layers: (a) RQD values for SFs without SRTs (Type 1), SFs with SRTs (Type 2), and rock anchored SFs (Type 3); (b) SF diameter according to the RQD value and overturning moment at the base for different SF types.

\section{b) Deep foundations: Brazil}

DFs were used for 1,718 wind turbines, which represents $56.7 \%$ of the samples. Many types of piles were used in these DFs, including CFAPs, root piles, steel driven piles, concrete driven piles and alluvial anker piles (AAPs). The next subsections present the characteristics of and geotechnical investigation data about these types of DFs. The CFAPs were predominant in the DF samples (70\%), followed by root pile DFs $(22.2 \%)$. Steel driven piles and concrete driven piles were used in $4.1 \%$ and $1.7 \%$ of wind turbine DFs, respectively. AAPs, as locally named, are small-diameter self-drilled grouted piles. AAPs were used in $2.0 \%$ of wind turbine DFs. 
Limited data were acquired for certain types of DFs, and the following results had to be cautiously analyzed. All pile caps had circular plan shapes. However, approximately 30\% of the pile caps were hollow inside and usually filled with backfill soil. Table 2.5 shows the characteristics of the pile cap and pile group for wind turbine DFs. As previously mentioned, although the tower type, concrete or steel, did not influence the foundation type, it clearly influenced the foundation dimensions (Table 2.1). Therefore, the results of Table 2.5 had to consider this effect. CFAP DFs had similar percentages of steel and concrete towers in the wind turbine foundation database, which considered all wind turbine foundations (Fig. 2.4a). Root pile DFs, concrete driven pile DFs and AAP DFs exhibited mainly steel towers, while steel driven piles had mainly concrete towers.

The average pile cap diameter was approximately 16.0 to 17.0 meters, ranging mainly from 13.0 to 19.0 meters, which were similar to those of SFs. CFAP DFs exhibited a pile cap diameter statistical distribution similar to that of SFs (Table 2.3). In turn, root pile DFs had a lower statistical distribution of pile cap diameter than CFAP DFs and SFs. Steel driven pile DFs had the highest statistical distribution of pile cap diameter, while AAP DFs exhibited the lowest pile cap diameters, with a maximum pile cap diameter of 11.3 meters. In general, DF pile cap diameters were higher for concrete towers than for steel towers. For example, root pile DFs, which had mainly steel towers, had a maximum pile cap diameter of 17.0 meters, while steel driven pile DFs, which had mainly steel towers, had a minimum pile cap diameter of 16.5 meters. CFAP DFs, which had steel and concrete towers, had a wide range of pile cap diameters. The average pile cap height was approximately 2.80 meters, ranging mainly from 2.50 to 3.25 meters (Table 2.5). No significant difference in the pile cap height between DFs was observed. Additionally, SFs had similar values of pile cap height to DFs (Table 2.3).

Table 2.5 shows the material amounts, i.e., steel and concrete, required for the pile caps of DFs. A wide range of concrete volume values was observed, ranging from $172.0 \mathrm{~m}^{3}$ to $700.0 \mathrm{~m}^{3}$. The steel amounts required for DFs also had a wide statistical distribution, ranging from 12.690 tons to 56.685 tons. CFAP DFs had a statistical distribution of concrete volume and steel amount similar to that of SFs (Table 2.3). Root pile DFs and AAP DFs had the lowest statistical distribution of concrete volume and steel amount of the pile cap, while steel driven piles had the highest statistical distribution of material amounts. The tower type and consequently the pile cap diameter influenced the amount of material used in the pile cap, as seen in Table 2.5. For example, DFs that exhibited a great proportion of concrete towers, e.g., steel driven pile DFs and CFAP DFs, had a superior statistical distribution of foundation diameter and, as a result, great material amount. Figure 2.13a shows the influence of the pile 
cap diameter on the concrete volume and steel amount for wind turbine DFs. Great concrete volume and steel amount are required as the pile cap diameter increases. Therefore, steel driven pile DFs, which used large pile cap diameters, required large amounts of material, while root pile DFs and AAP DFs, which had low pile cap diameters, used less material (Fig. 2.13a). Additionally, the material amount required for the pile cap DFs was slightly superior to those observed for SFs, while a similar trend was observed; however, a notable difference was identified when considering the total material amount for pile cap plus pile group. For example, CFAP DFs had a median increase of $26.9 \%$ in the concrete volume when considering the pile cap and pile group, with this value ranging from $14 \%$ to $86 \%$.

Figure $2.13 \mathrm{~b}$ shows the concrete volume and steel amount relationship of the pile cap DFs. As the concrete volume increased, the steel amount increased. The reinforcement ratio was similar for all DF types, with an average value of $95.2 \mathrm{~kg}$ of steel per $\mathrm{m}^{3}$ of concrete. This value was nearly the same as that for SFs, which had an average value of $98.6 \mathrm{~kg}$ of steel per $\mathrm{m}^{3}$ of concrete. In Table 2.5, the pile cap reinforcement ratio values were near these values, with the exception of steel and concrete driven pile DFs, which had inferior and superior values, respectively.

The backfill weights of DFs ranged from $1,300 \mathrm{kN}$ to $6,800 \mathrm{kN}$, which is similar to the range for SFs (Table 2.5). CFAP DFs had a wide statistical distribution of backfill weight as a great amount of data was available. AAP DFs, which had the lowest pile cap diameter, exhibited the lowest backfill weight among deep and shallow foundations. Root pile DFs and steel driven pile DFs exhibited a median backfill weight of approximately 4,000 kN.

Table 2.5 also displays the number and diameter of piles used on DFs. DFs used between 14 and 48 piles per foundation. CFAP DFs and root pile DFs exhibited an average of approximately 30 piles per foundation, with average pile diameters of 60 and 40 centimeters, respectively. Steel and concrete driven pile DFs and AAP DFs had on average approximately 38 piles per foundation. Steel driven pile DFs used structural $\mathrm{H}$-shaped piles, while concrete driven pile DFs and AAP DFs exhibited pile diameters of 50 and 30 centimeters, respectively. The piles of all types of foundations were vertically installed, with the exception of AAPs, which were inclined 12 degrees from the vertical. 
Table 2.5: Statistical results of pile cap and pile group characteristics for wind turbine DFs.

\begin{tabular}{|c|c|c|c|c|c|c|}
\hline & & CFAPs & Root Piles & $\begin{array}{c}\text { Steel Driven } \\
\text { Piles } \\
\end{array}$ & $\begin{array}{c}\text { Concrete } \\
\text { Driven Piles }\end{array}$ & AAPs \\
\hline \multirow{2}{*}{$\begin{array}{l}\text { Tower } \\
\text { type }(\%)\end{array}$} & Steel & 68.4 & 99.0 & 36.5 & \multirow[t]{2}{*}{100.0} & 100.0 \\
\hline & Concrete & 31.6 & 1.0 & 63.5 & & \\
\hline \multirow{5}{*}{$\begin{array}{l}\text { Pile cap } \\
\text { diameter } \\
(\mathrm{m})\end{array}$} & Minimum & 13.60 & 13.00 & 16.50 & \multirow{4}{*}{16.30} & 10.70 \\
\hline & Median & 17.00 & 14.80 & 20.00 & & 10.70 \\
\hline & Standard deviation & 1.66 & 1.38 & 1.70 & & 0.30 \\
\hline & Maximum & 19.50 & 17.00 & 20.00 & & 11.30 \\
\hline & Amount of data & 812 & 254 & 63 & 19 & 35 \\
\hline \multirow{5}{*}{$\begin{array}{l}\text { Pile cap } \\
\text { height }(\mathrm{m})\end{array}$} & Minimum & 2.00 & 2.60 & 2.50 & \multirow{4}{*}{2.50} & 2.80 \\
\hline & Median & 2.75 & 2.80 & 3.50 & & 3.00 \\
\hline & Standard deviation & 0.47 & 0.22 & 0.50 & & 0.10 \\
\hline & Maximum & 3.80 & 3.75 & 3.50 & & 3.00 \\
\hline & Amount of data & 812 & 254 & 63 & 19 & 35 \\
\hline \multirow{5}{*}{$\begin{array}{l}\text { Pile cap } \\
\text { concrete } \\
\text { volume } \\
\left(\mathrm{m}^{3}\right)\end{array}$} & Minimum & 216.0 & 216.0 & 432.0 & \multirow{4}{*}{298.5} & 172.0 \\
\hline & Median & 351.0 & 290.0 & 700.0 & & 172.0 \\
\hline & Standard deviation & 76.1 & 58.1 & 129.0 & & 10.2 \\
\hline & Maximum & 535.0 & 362.6 & 700.0 & & 194.0 \\
\hline & Amount of data & 812 & 191 & 63 & 19 & 35 \\
\hline \multirow{5}{*}{$\begin{array}{l}\text { Pile cap } \\
\text { steel } \\
\text { amount } \\
(\mathrm{kg})\end{array}$} & Minimum & 17,800 & 17,800 & 37,720 & \multirow{4}{*}{40,463} & 12,690 \\
\hline & Median & 32,130 & 36,530 & 53,956 & & 14,762 \\
\hline & Standard deviation & 10,948 & 7,732 & 7,724 & & 3,987 \\
\hline & Maximum & 56,685 & 36,530 & 53,956 & & 21,342 \\
\hline & Amount of data & 605 & 170 & 63 & 19 & 24 \\
\hline \multirow{5}{*}{$\begin{array}{l}\text { Pile cap } \\
\text { reinforce- } \\
\text { ment ratio } \\
\left(\mathrm{tf} / \mathrm{m}^{3}\right)\end{array}$} & Minimum & 0.0824 & 0.0824 & 0.0771 & \multirow{4}{*}{0.1356} & 0.0738 \\
\hline & Median & 0.0915 & 0.1007 & 0.0771 & & 0.0858 \\
\hline & Standard deviation & 0.0105 & 0.0090 & 0.0053 & & 0.0232 \\
\hline & Maximum & 0.1227 & 0.1108 & 0.0894 & & 0.1241 \\
\hline & Amount of data & 605 & 170 & 63 & 19 & 24 \\
\hline \multirow{5}{*}{$\begin{array}{l}\text { Backfill } \\
\text { weight } \\
(\mathrm{kN})\end{array}$} & Minimum & 1,532 & 2,118 & 3,080 & \multirow{4}{*}{5,178} & \multirow{4}{*}{1,360} \\
\hline & Median & 2,306 & 3,750 & 4,432 & & \\
\hline & Standard deviation & 1,414 & 798 & 650 & & \\
\hline & Maximum & 6,800 & 4,471 & 4,432 & & \\
\hline & Amount of data & 706 & 179 & 63 & 19 & 13 \\
\hline \multirow{5}{*}{$\begin{array}{l}\text { Number of } \\
\text { piles }\end{array}$} & Minimum & 14.0 & 20.0 & 28.0 & 30.0 & 36.0 \\
\hline & Median & 28.0 & 30.0 & 38.0 & 38.0 & 40.0 \\
\hline & Standard deviation & 7.5 & 6.7 & 7.3 & 3.9 & 2.9 \\
\hline & Maximum & 42.0 & 48.0 & 38.0 & 38.0 & 44.0 \\
\hline & Amount of data & 1136 & 381 & 63 & 30 & 35 \\
\hline \multirow{5}{*}{$\begin{array}{l}\text { Piles } \\
\text { diameter } \\
(\mathrm{m})\end{array}$} & Minimum & 0.50 & \multirow{4}{*}{0.40} & & \multirow{4}{*}{0.50} & \multirow{4}{*}{0.30} \\
\hline & Median & 0.60 & & Structural H & & \\
\hline & Standard deviation & 0.06 & & shape & & \\
\hline & Maximum & 0.70 & & & & \\
\hline & Amount of data & 1201 & 381 & 63 & 30 & 35 \\
\hline
\end{tabular}



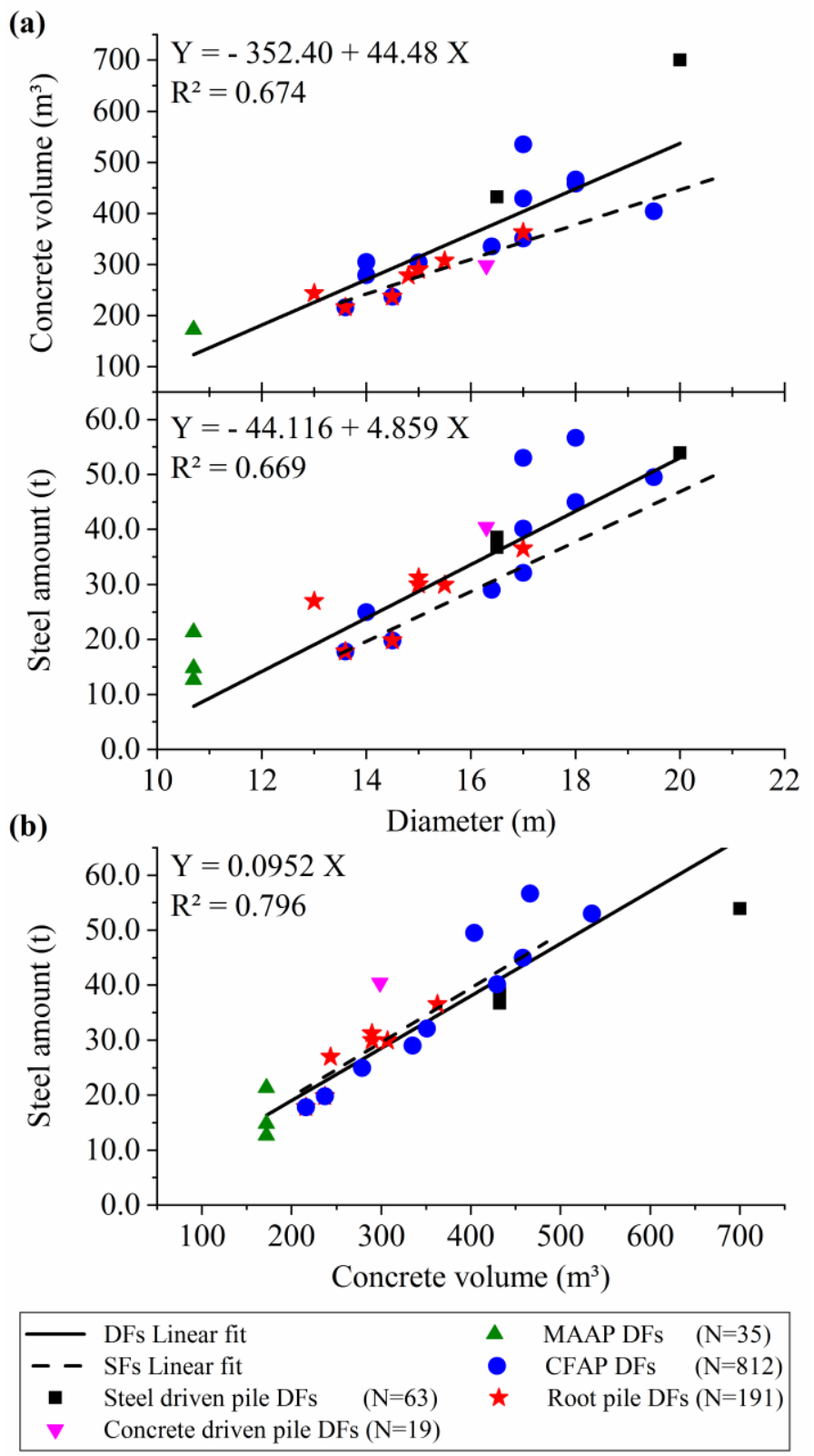

Figure 2.13: Influence of the pile cap diameter on (a) concrete volume and steel amount of wind turbine DFs; (b) the reinforcement ratio of DFs.

Figure 2.14 shows the statistical results of the pile length, pile toe depth and SPT impenetrable depth for all types of pile foundations. Different amounts of data were available for pile length, pile toe depth and SPT impenetrable depth (Fig. 2.14). The median pile lengths of DFs ranged from 11.0 to 15.0 meters. CFAPs had a median pile length of 12.8 meters. Steel and concrete driven piles exhibited median pile lengths of 15.0 and 13.5 meters, respectively. Root piles had the lowest median pile length of 11.0 meters. AAPs had a median pile length of 14 meters. CFAPs, AAPs and steel and concrete driven piles exhibited similar spreads of pile lengths, ranging mainly between 10.0 and 20.0 meters. Root piles, in turn, had a narrow statistical distribution, ranging mainly from 10.0 to 12.0 meters. Approximately 23 
steel driven pile DFs and 11 concrete driven pile DFs had information about the differences in maximum and minimum piles lengths in the same foundation. The median difference in driven pile length for the same DF was approximately 2.5 to 3.5 meters with a standard deviation of 1.60 meters, ranging from 1.0 to 7.0 meters.

Figure 2.14b displays the pile toe depths of CFAPs, root piles and driven piles. In general, the pile toe depths were equal to the pile length plus 2.0 to 3.0 meters, as the pile cap bases were usually set 2.0 to 3.0 meters under the ground level. Figure $2.14 \mathrm{c}$ shows the SPT impenetrable depths of CFAPs, root piles and driven piles. As previously mentioned, the SPT impenetrable depth was usually related to the presence of weathered rock or rock layers. The median SPT impenetrable depth of CFAPs was 16.0 meters and ranged mostly from 8.0 to 24.0 meters. The CFAP lengths were restricted by the SPT impenetrable depth since the pile toe depths were inferior to the SPT impenetrable depth. This result was expected since the drilling process by continuous flight hollow stem auger is limited by high-strength layers. Root piles, in turn, exhibited a median SPT impenetrable depth of 5.0 meters, ranging mostly from 0.0 to 13.0 meters. Root piles were used when the SPT impenetrable depth was close to the ground level, which inhibited the use of CFAPs; therefore, root piles were installed through weak rock and rock layers. Steel driven piles exhibited a wide statistical distribution of SPT impenetrable depths, while concrete driven piles had a narrow statistical distribution due to the amount of data (Fig. 2.14c). Clearly, driven piles had high SPT impenetrable depths, with a median value of approximately 35.0 meters.

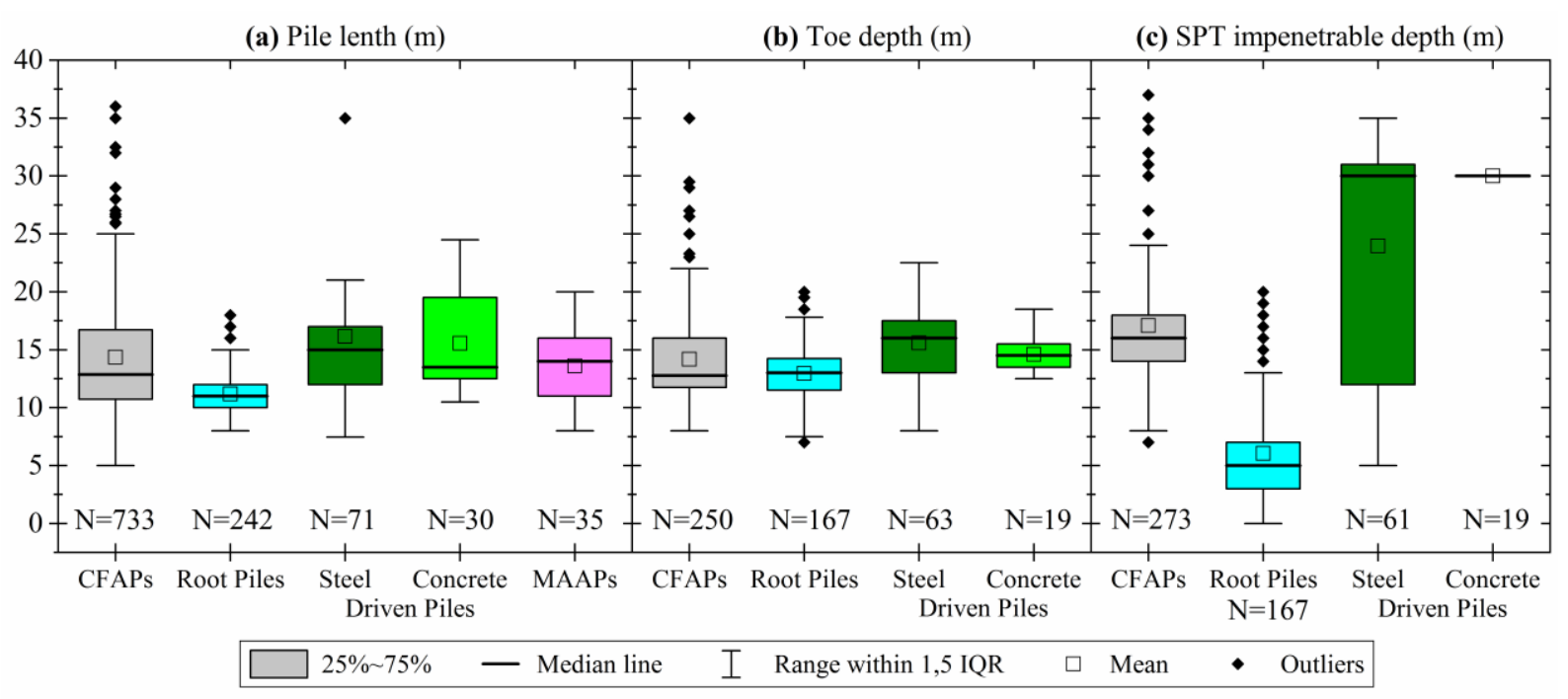

Figure 2.14: Statistical results of pile length, toe depth and SPT impenetrable depth for wind turbine DFs. 
Figure 2.15 shows the percentage of soil investigations that identified the presence of a WL. Additionally, Figure 2.15 displays the WL depth of wind turbine sites for which the WL was identified. In general, the presence of the WL was similar to all wind turbines in a wind farm.

Almost no soil investigation identified the presence of the WL for SFs and root pile DFs (Fig. 2.15). In turn, for CFAP DFs, approximately $68.3 \%$ of the soil investigations identified the presence of a WL, which exhibited a median depth of 3.1 meters, with $50 \%$ of the values between 1.8 and 4.8 meters. For driven pile DFs, almost all soil investigations identified the presence of a WL, which had a median depth of 1.25 meters. The presence and depth of the WL clearly limited the pile cap base depth. CFAP DFs had a median pile cap base depth of 2.0 meters, ranging from 1.3 meters above the ground level to 3.8 meters depth. Driven pile DFs exhibited a median pile cap base depth of 1.5 meters and ranged mostly from 1.0 meter to 2.5 meters.

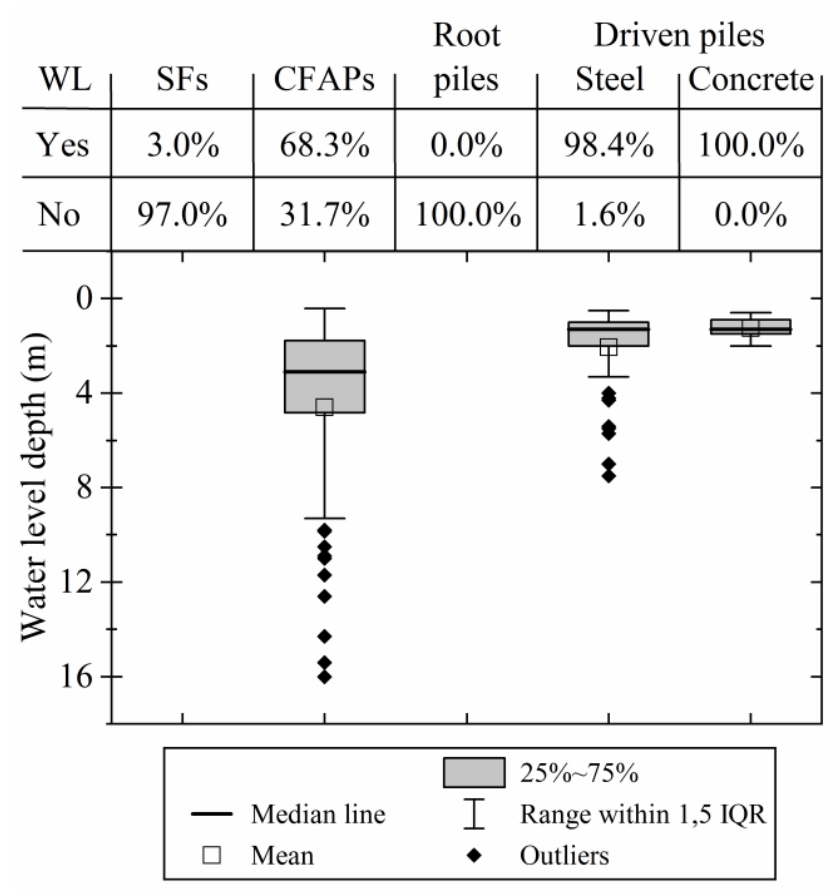

Figure 2.15: WL depths of wind turbine foundations.

The subsoil types, i.e., soil, weathered rock or rock, in contact with the pile top, pile shaft and pile toe were analyzed (Table 2.6). Concerning the pile shaft, the length of the subsoil layers in contact with the pile shaft of each DF was analyzed. The database acquired geotechnical investigation data for 556 wind turbine DFs. The geotechnical investigation data were mainly composed of 307 CFAP DFs, which represents $25.6 \%$ of the CFAP DFs, and 167 
root pile DFs, which represents $65.7 \%$ of the root pile DFs. Steel and concrete driven pile DFs had geotechnical investigation data for 63 and 19 wind turbines, respectively.

The results indicate that the pile tops were mostly embedded in soil layers, which were identified in more than $85.0 \%$ of the wind turbine DFs (Table 2.6). The pile tops were mainly in contact with sandy soils. CFAPs had a minor share of pile tops embedded in clayey soil layers (29.0\%). Root pile DFs exhibited minor percentages of pile tops settled in silty soils (21.0\%), backfill (14.3\%) and rock layers (11.4\%). The results obtained for the pile tops, which are equivalent to the pile cap bases, were significantly different from those for SFs, which had a significant share of SFs settled above rock layers $(36.5 \%)$ and weather rock layers $(21.3 \%)$ (Table 2.4).

The pile shafts were mostly embedded in soil layers, with the exception of root pile DFs (Table 2.6). More than $85.0 \%$ of the pile shafts of CFAPs and steel and concrete driven piles were in contact with sandy soil layers. Steel driven piles had a minor share of pile shafts embedded in weathered rock layers (13.4\%). Root pile shafts, in turn, were mostly embedded in rock layers (58.8\%), especially sandstone, phyllite and migmatite, followed by soil layers $(30.9 \%)$ near the ground level.

The pile toes of CFAP DFs and steel and concrete driven pile DFs were mostly embedded in soil layers, especially sandy soils. CFAP DFs exhibited $24.8 \%$ of pile toes embedded in rock or weathered rock layers, mostly sandstone. CFAP toes were limited by the drilling process in these layers. Steel and concrete driven pile toes were in $36.5 \%$ of the cases embedded in sandstone rock layers. The root pile toes, in turn, accounted for $89.2 \%$ of the cases embedded in rock layers, especially sandstone, phyllite and migmatite. 
Table 2.6: Subsoil types in contact with the pile tops, pile shafts and pile toes for wind turbine DFs.

\begin{tabular}{|c|c|c|c|c|c|c|c|c|c|c|c|c|}
\hline \multirow[b]{2}{*}{ Subsoil type } & \multicolumn{4}{|c|}{ Pile top (\% wind turbines) } & \multicolumn{4}{|c|}{ Pile shaft (\% pile length, meters) } & \multicolumn{4}{|c|}{ Pile toe (\% wind turbines) } \\
\hline & CFAPs & $\begin{array}{l}\text { Root } \\
\text { piles }\end{array}$ & $\begin{array}{c}\text { Steel } \\
\text { driven } \\
\text { piles }\end{array}$ & $\begin{array}{c}\text { Concrete } \\
\text { driven } \\
\text { piles }\end{array}$ & CFAPs & $\begin{array}{l}\text { Root } \\
\text { piles }\end{array}$ & $\begin{array}{c}\text { Steel } \\
\text { driven } \\
\text { piles }\end{array}$ & $\begin{array}{c}\text { Concrete } \\
\text { driven } \\
\text { piles } \\
\end{array}$ & CFAPs & $\begin{array}{l}\text { Root } \\
\text { piles }\end{array}$ & $\begin{array}{c}\text { Steel } \\
\text { driven } \\
\text { piles }\end{array}$ & $\begin{array}{c}\text { Concrete } \\
\text { driven } \\
\text { piles }\end{array}$ \\
\hline Soil & 99.7 & 85.6 & 98.4 & 100.0 & 93.8 & 30.9 & 85.9 & 100.0 & 75.2 & 7.8 & 63.5 & 100.0 \\
\hline Sand & 32.6 & 2.4 & 77.8 & 89.5 & 43.2 & 0.8 & 68.1 & 48.7 & 40.8 & 1.2 & 50.8 & 10.5 \\
\hline Clayey/silty sand & 32.6 & 46.1 & 15.9 & 5.3 & 42.0 & 13.4 & 16.2 & 49.0 & 31.2 & 1.2 & 11.1 & 89.5 \\
\hline Clay & 1.6 & 0.6 & & & 0.5 & 0.2 & & & & & & \\
\hline Sandy/silty clay & 29.0 & 1.2 & 4.7 & 5.2 & 3.7 & 2.2 & 1.6 & 2.3 & 0.4 & 0.6 & 1.6 & \\
\hline Silt & & 3.0 & & & & 1.0 & & & & & & \\
\hline Clayey/sandy silt & 3.3 & 18.0 & & & 4.4 & 11.0 & & & 2.8 & 4.8 & & \\
\hline Backfill & 0.6 & 14.3 & & & & 2.3 & & & & & & \\
\hline Rock & & 11.4 & 1.6 & & 2.0 & 58.8 & 0.7 & & 11.6 & 89.2 & 36.5 & \\
\hline Sandstone & & & 1.6 & & 2.0 & 16.8 & 0.7 & & 11.6 & 28.7 & 36.5 & \\
\hline Phyllite & & 5.4 & & & & 13.0 & & & & 15.0 & & \\
\hline Migmatite & & 4.2 & & & & 18.2 & & & & 25.1 & & \\
\hline Others & & 1.8 & & & & 10.8 & & & & 20.4 & & \\
\hline Weathered rock & 0.3 & 3.0 & & & 4.2 & 10.3 & 13.4 & & 13.2 & 3.0 & & \\
\hline Sandstone & 0.3 & 2.4 & & & 3.8 & 8.7 & 13.4 & & 12.4 & 1.2 & & \\
\hline Siltstone & & & & & 0.3 & 0.4 & & & 0.4 & & & \\
\hline Claystone & & & & & 0.1 & 0.3 & & & 0.4 & 0.6 & & \\
\hline Others & & 0.6 & & & & 0.9 & & & & 1.2 & & \\
\hline Total: absolute values & 307 & 167 & 63 & 19 & 2918 & 1876 & 859 & 242 & 250 & 167 & 59 & 19 \\
\hline
\end{tabular}

Figure 2.16 shows a box chart of the $\mathrm{N}_{\mathrm{SPT}}$ and RQD values of the pile tops, pile shafts and pile toes for wind turbine DFs. For clarity, the $\mathrm{N}_{\mathrm{SPT}}$ values shown for the pile shaft refer to the average shaft value for each DF. CFAPs and driven piles exhibited significantly low pile top $\mathrm{N}_{\text {SPT }}$ values (Fig. 2.16a, c and d), with $75 \%$ of the $\mathrm{N}_{\text {SPT }}$ values lower than 14 . CFAPs and steel driven piles had a median $\mathrm{N}_{\text {SPT }}$ value of 9, while concrete driven piles exhibited a median N NPT value of 11. These values were lower than the pile cap values of SFs with SRTs, which had $75 \%$ of $\mathrm{N}_{\text {SPT }}$ values higher than 13 (Fig. 2.11a). In turn, root pile tops exhibited a median $\mathrm{N}_{\mathrm{SPT}}$ value of 18, ranging mostly from 10 to 28 (Fig. 2.16b). When the root pile tops were settled above a rock layer, a median RQD value of $0 \%$, with $75 \%$ of RQD values less than 20\%, was obtained (Fig. 2.16b). The statistical distributions of root pile top $\mathrm{N}_{\mathrm{SPT}}$ and RQD values were similar to those of SFs with SRTs settled above soil and rock layers (Figs. 2.11a and 2.12a).

The average pile shaft $\mathrm{N}_{\mathrm{SPT}}$ values for CFAPs and driven piles are also shown in Figure 2.16. These DFs usually exhibited a linear increase in NSPT values with depth. The median pile shaft $\mathrm{N}_{\mathrm{SPT}}$ average value for CFAPs and concrete driven piles was 30 , while steel 
driven pile DFs exhibited a median value of 27. Additionally, a narrow statistical distribution of the average pile shaft $\mathrm{N}_{\mathrm{SPT}}$ values was observed, ranging mostly from 25 to 35 (Fig. 2.16a, c and d). The root pile shafts were usually embedded in initial layers of soil, which had $\mathrm{N}_{\text {SPT }}$ data, and then weathered rock and rock layers, which had RQD data (Table 2.6). Therefore, the average pile shaft $\mathrm{N}_{\mathrm{SPT}}$ or RQD values were not determined.

Additionally, Figure 2.16 shows the $\mathrm{N}_{\text {SPT }}$ and RQD values of DF pile toes. When the pile toes were embedded in soil layers, CFAPs and steel driven pile toes had a median $\mathrm{N}_{\text {SPT }}$ value of approximately 43, with $75 \%$ of $\mathrm{N}_{\mathrm{SPT}}$ values superior to 35 (Fig. 2.16a and d). Concrete driven pile toes had mostly $\mathrm{N}_{\mathrm{SPT}}$ values of approximately 50 (Fig. 2.16c). When CFAP toes were embedded in weathered rock or rock layers, the $\mathrm{N}_{\text {SPT }}$ and RQD values were 50 and $0 \%$, respectively (Fig. 2.16a). Steel driven pile toes, when embedded in rock layers, had a median RQD value of 50, with $50 \%$ of the RQD values between $20 \%$ and $70 \%$ (Fig. 2.16d). The root pile toes were usually embedded in rock layers, which had a median RQD value of $35 \%$ and a wide statistical distribution of the RQD values, with $50 \%$ of the RQD values between $0 \%$ and $75 \%$ (Fig. 2.16b). 
(a) Continuous flight auger piles

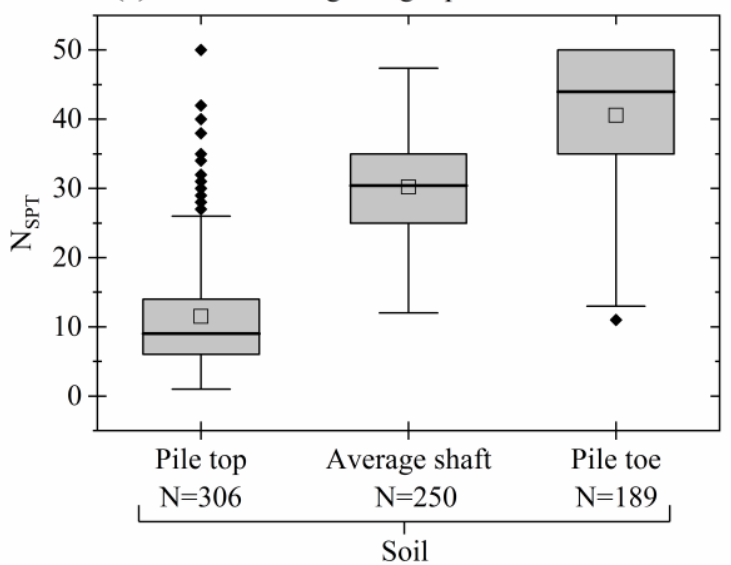

(c) Concrete driven piles

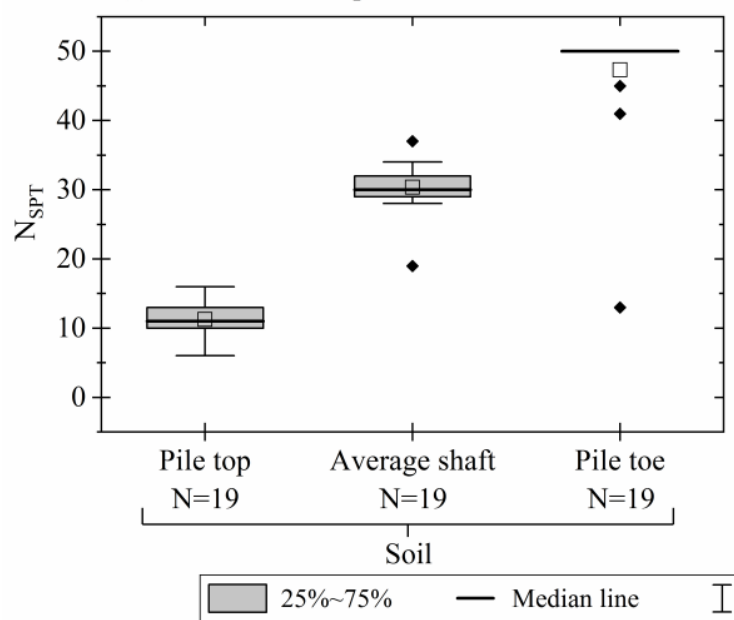

(b) Root piles $^{2}$

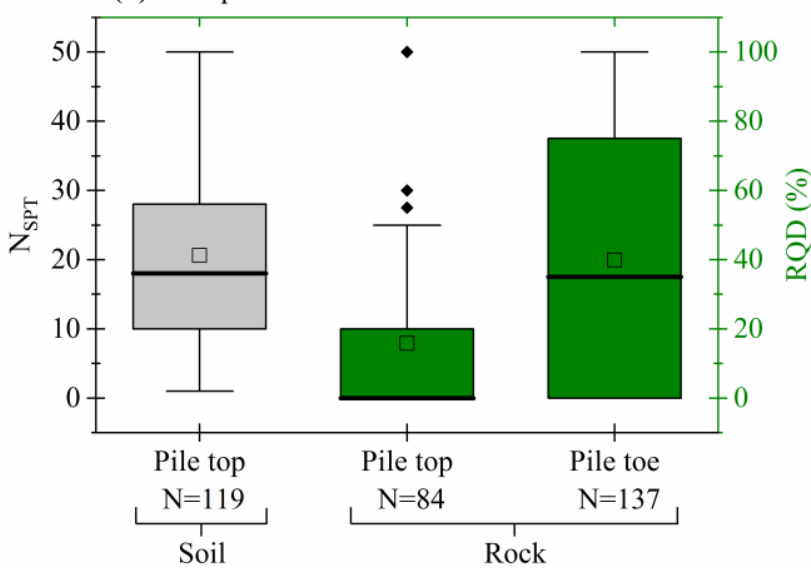

(d) Steel driven piles

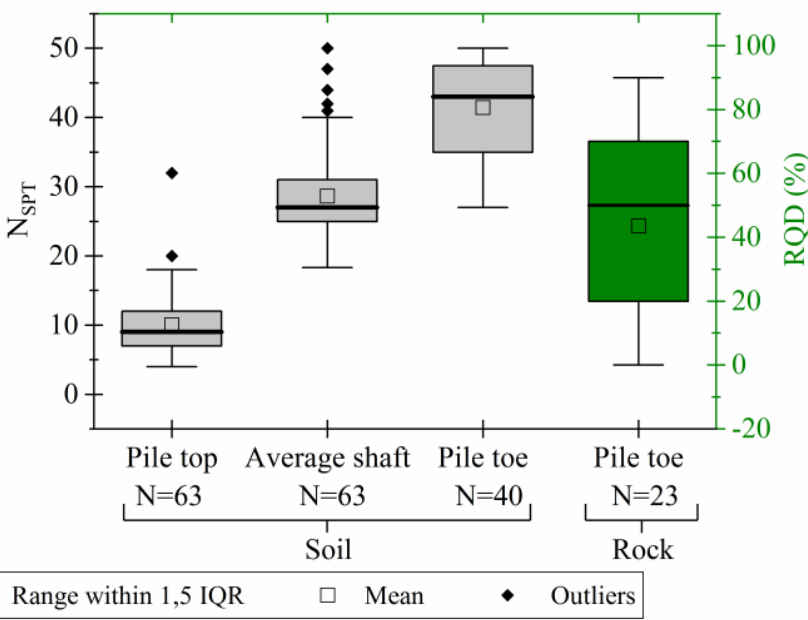

Figure 2.16: The $\mathrm{N}_{\mathrm{SPT}}$ and RQD results of pile top, average pile shaft and pile toe for (a) CFAP DFs; (b) root piles; (c) concrete driven piles; and (d) steel driven piles. Notes: 1 CFAP toe embedded in weathered rock and rock had $\mathrm{N}_{\mathrm{SPT}}$ and RQD values of 50 and $0 \%$, respectively, and 2 root pile toes embedded in soil and weathered rock had $\mathrm{N}_{\text {SPT }}$ values of 50 .

\subsubsection{Discussion}

The results indicated that different types of foundations were used according to several subsoil conditions and not only the soil type. These subsoil conditions determined the feasibility of the wind turbine foundation in terms of design and executability. The foundation loading, in turn, mainly affected the foundation size.

Approximately $43 \%$ of the onshore wind turbines in Brazil used SFs. Shallow foundations were mainly used when subsoil conditions provided appropriate geotechnical properties near the ground level. Geotechnical conditions were usually characterized by no water table presence and appropriate soil resistance near the ground level, which increased with depth. The subsoil resistance and type, such as soil, weathered rock or rock, and the SPT impenetrable depth determined whether soil improvements or rock anchors were required. Soil improvement techniques were used to increase the resistance of thin porous layers near 
the ground level. Soil-cement stabilization was mainly used for soil improvement, while stabilization grouting was mainly used for weathered rock improvement. Rock anchors were used when bedrock was near the ground level. The SF type and foundation loading had marked influences on the foundation diameter of SFs settled above rock layers, while the NSPT value and foundation loading affected the foundation diameter of SFs settled above soil and weathered rock layers.

Deep foundations were used in 57\% of the onshore wind turbines in Brazil. Different types of piles were used depending on the geotechnical conditions. Continuous flight auger pile DFs were usually used under certain conditions, which were characterized by the presence of a water table and very poor soil resistances near the ground level, which slowly increased with depth through a pile length of approximately 13 meters. Root pile DFs were used under different subsoil conditions, which were characterized by the absence of a water table and the presence of weak weathered rock and rock layers near the ground level, within a depth of 5 meters. Therefore, the root piles shaft were mostly in contact with weathered rock or rock layers, unlike CFAPs. Concrete and steel driven pile DFs were characterized by the presence of a water table near the ground level and the presence of porous soil layers, whose resistance slowly increased with depth through a pile length of approximately 13 to 15 meters. All piles were vertically installed, except the AAPs, which were inclined 12 degrees from the vertical.

Continuous flight auger and driven pile lengths were usually restricted by the presence of strong layers, such as weathered rock and rock layers, due to drilling and driving process restrictions. In turn, root piles were used when weathered rock and rock layers were close to the ground level. This result was expected since root piles are small-diameter bored piles whose resistance is manly beneficial for shaft-rock friction. The geotechnical conditions and pile installation process clearly influenced a certain pile preference. Additionally, a large proportion of wind turbines used continuous flight auger pile DFs due to the great local acceptance of this type of pile foundation.

Several geotechnical conditions influenced the foundation type, including ground type, WL depth, soil layers resistances, extent of porous soil layers and bedrock depth. However, occasionally, different types of foundations were used despite similar geotechnical conditions. For example, SFs, rock anchored SFs and root pile DFs occasionally had similar geotechnical conditions. Two main reasons were identified: a certain type of foundation prevailed among others on a wind farm as the same foundation was used for several wind turbines, and a certain foundation type was preferred according to the local foundation expertise. 


\subsubsection{Conclusions}

The current status of onshore wind turbine foundations in Brazil was investigated and compared with the worldwide status. The main aspects concerned were the technology status of wind turbines, including rated power, rotor diameter and hub height, and the characteristics of the foundations, such as types, loading, dimensions and geotechnical aspects. The following conclusions were drawn.

- The technology status analyses identified that Brazilian wind turbines had characteristics, i.e., wind turbine rated power, rotor diameter and hub height, similar to those of most wind turbines worldwide. New wind farms tended to use greater wind turbine rated power and larger rotor diameter, while a moderate increase in the wind turbine hub height was expected. Concrete towers, which represented $26.4 \%$ of wind turbines in Brazil, were used when the hub height exceeded 100 meters.

- Foundation loading, i.e., the overturning moment at the base, directly influenced the size of the wind turbine foundation, while the foundation type was not affected. Foundation loading was significantly influenced by the tower material, concrete or steel, and the wind turbine IEC class. Concrete towers or Class II wind turbines exhibited higher overturning moments at the base than steel towers or Class III wind turbines, respectively. A marked spread in foundation loading with wind turbine rated power, rotor diameter and hub height was identified; however, a slight upward trend was noticed. This positive trend was also indirectly verified by the correlation of wind turbine technology status with foundation diameter and material amount.

- As concrete towers increased the foundation loading, the tower type influenced the shallow and deep foundation dimensions and material amounts. Concrete towers required greater foundation diameters and material amounts than steel towers. Additionally, deep foundations required a greater number of piles when concrete towers were used.

- The types of foundations used in onshore wind turbines differed in each country. In Brazil, for example, deep foundations are widely used, especially groups of continuous flight auger piles and then root piles. The type of onshore wind turbine foundation was chosen according to several factors. The geotechnical conditions, including soil type, water table level, soil layers resistances, extent of porous soil layers and bedrock depth, had a major role in the foundation type. Additionally, the local foundation expertise and acceptance clearly influenced a certain foundation type. 
For example, note that a great share of wind turbines used continuous flight auger pile DFs, which are widely used for conventional structures in Brazil.

- Usually, a unique foundation type was chosen for all wind turbines in a wind farm. In places, the wind turbines could be relatively far apart; therefore, considerable variability of the geotechnical aspects was noticed, and in a few cases, more than one type of foundation was required.

- Unexpectedly, no significant differences in raft diameters or material amounts were observed between shallow and deep foundations. In turn, rock anchored shallow foundations, root piles and alluvial anker pile deep foundations used smaller pile cap diameters and material amounts than the other types. However, no significant difference in the reinforcement ratios of shallow and deep foundations was observed.

Commonly, wind farm construction sites are geotechnically unfavorable. Further research in the literature on onshore wind turbine foundations is required, especially because limited data on actual situations and conditions have been published; wind energy has recently advanced in developing countries that have distinct geotechnical conditions and different local foundation expertise and acceptance. Additionally, future research should address numerical analysis, risk and reliability and life-cycle assessments of these different wind turbine foundation types.

\subsection{Geotechnical design and investigation of wind turbine foundations}

\subsubsection{Introduction}

Renewable energies play a major role in the achievement of sustainable development. Hence, several nations are conducting incentives policies for the development of renewable energies, such as wind energy. The majority of the wind energy installed capacity is located in China (34.9\%), United States (16.5\%) and Germany (10.4\%) (GWEC, 2018). Brazil is currently in the eighth place of world ranking regarding wind energy installed capacity (GWEC, 2018).

Wind farms locations are mostly based on energy assessments and as a result, construction sites are often geotechnicaly unfavorable (Pham et al., 2018). Geotechnical design and investigation have a crucial role in wind project deployment, as well as in their life extension and repowering. For example, Ziegler et al. (2018) conducted a survey with experts in the field about lifetime extension and repowering of onshore wind turbines in Europe. The major technical concerns of these experts were missing documentation and access to design information. 
Geotechnical design and investigation of onshore wind turbine foundations are often considered a well-understood area, as several international guidelines and standards are available. However, limited information has been published about the geotechnical design and investigation of these foundations in developing countries where wind energy projects have recently started. These countries, such as Brazil, have distinct geotechnical conditions and different foundation expertise and acceptance (Subsection 2.1). Therefore, further research in the literature is required.

This subsection explored the key aspects regarding the geotechnical design and investigation of onshore wind turbine foundation worldwide and in Brazil. International standards, guidelines and scientific reports were used to assess these aspects worldwide. Brazilian geotechnical design and investigation were evaluated through a large database, containing more than three thousands of Brazilian wind turbine foundations (Subsection 2.1). This database was acquired by a survey to Brazilian wind energy companies. The names of the wind farms were anonymized due to our confidentiality agreement.

\subsubsection{Geotechnical design}

\section{Geotechnical design: worldwide}

Eurocode 7 (EN 1997-1, 2004; EN 1997-2, 2007) and DNV/Ris Ø (2002) are usually used as guidelines for the geotechnical design of onshore wind turbine foundations. A deterministic design is usually performed, assuming a quasi-static load and considering partial safety factors as a semi-probabilistic approach (Andersen et al., 2012). According to several guidelines, partial factors shall be applied in the characteristics values of loads and material strengths due to the probability of the load occurring and the uncertainties about the material strengths (DNV/RisØ, 2002; EN 1997-1, 2004; IEC 61400-1, 2005; Germanischer Lloyd, 2010).

The Ultimate Limit States (ULSs) and Serviceability Limit States (SLSs) which are established by Eurocode 7 (EN 1997-1, 2004) and IEC 61400-1 (2005), are the most common approach (DNV/Ris Ø, 2002; Germanischer Lloyd, 2010). The ULSs include extreme scenarios, such as earthquakes and severe wind conditions in non-operating or operating conditions. ULSs are associated with the collapse or structural failure, e.g. plastic yield, instability, buckling, and overturning (DNV/Ris Ø, 2002; EN 1997-1, 2004; Germanischer Lloyd, 2010). The SLSs correspond to conditions beyond the specified service requirements for structure or structural member, e.g. cracks, permanent deflections and vibrations (DNV/Ris Ø, 2002; EN 1997-1, 2004; Germanischer Lloyd, 2010). The characteristic loads of 
the ULS and SLS are determined for 1 and 50 years recurrence period, respectively (IEC 61400-1, 2005; DNV/Ris Ø, 2002; Germanischer Lloyd, 2010). According to the DNV/Ris $\emptyset$ (2002), these values were chosen by convenience and tradition and do not imply an exact design lifetime. Usually, the designed service life of wind turbines is 20 years (Ziegler et al., 2018).

Several analyses must be conducted to attend the ULSs of wind turbine foundations, including overturning, maximum pressure on soil bearing capacity, foundation slip and subsoil collapse. Regarding the SLSs, restrict tolerances to foundation settlement, eccentricity and tilt are specified. As the loads are highly eccentric on the foundation, second-order effects should be checked (EN 1997-1, 2004). Wind turbines manufacturers establish specifications of horizontal and rotational foundation stiffness. In order to perform these analyses, soilstructure interaction is frequently modelled as a support face of compression-only springs under the foundation through Finite Element Methods (FEMs) (Frank et al., 2005). The stiffness of those springs is defined according to the subsoil characteristics and geometry of the foundation (Horgan, 2013; Rebelo et al., 2014). When performing natural frequency analyses, the foundation shall be replaced by torsion and displacement springs at the tower base (Germanischer Lloyd, 2010). The wind turbine natural frequency should consider the mass and stiffness properties of the turbine, tower and foundation to avoid resonance between natural and turbine operational frequencies (ASCE/AWEA, 2011).

\section{a) Shallow foundations geotechnical design: worldwide}

Gravity foundations are always an alternative when strong and stiff soil or rock are near the ground level. Eurocode 7 (EN 1997-1, 2004) establishes several design verifications, such as loss of overall stability, bearing resistance failure, sliding, combined failure in the ground and in the structure, structural failure and excessive settlements. The foundation design is mainly governed by the overturning moment, minimum rotational stiffness requirement and maximum allowable bearing pressure. Economy and durability are essential criteria for the wind turbine foundation design (Morgan and Ntambakwa, 2008). The first step in the design is to fix a required performance and determine foundation geometry and embedment depth. Direct methods, which include analytical and semi-empirical approaches, and indirect methods can be used in the design of shallow foundations (Frank et al., 2005).

Foundation stability refers to the foundation resistance to excessive movement, such as rotation or translation, under extreme loads (Morgan and Ntambakwa, 2008). The overturning stability is usually assured and then horizontal stability is evaluated. The foundation stability 
is commonly solved by limiting equilibrium methods or allowable stress design (DNV/Ris $\emptyset$, 2002; Morgan and Ntambakwa, 2008). According to DNV/Ris $\emptyset$ (2002), the foundation stability is usually the most decisive factor to determine foundation area, embedment depth and weight. Mohamed and Austrell (2017) noticed that the unit weight of the backfill soil has a significant influence on the foundation stability, especially when the water level is near the ground surface.

Bearing capacity formulas for idealized conditions are acceptable to the foundation design (DNV/Ris $\varnothing, 2002)$. Closed-form solutions, such as the well-known TerzaghiMeyerhof equation, are used to determine the bearing capacity (ASCE/AWEA, 2011; Ntambakwa et al., 2016). According to Mohamed and Austrell (2017), the soil resistance parameters, such as friction angle and cohesion, and water level depth, have a strong effect on the allowable bearing capacity value. These authors noticed that increasing soil resistance parameters and embedment depth are a good solution to decrease the foundation area.

Foundation sliding is unlike to be a problem for large shallow foundation although passive resistance of the surrounding soil is disregarded (Tinjum and Christensen, 2010).

The foundation stiffness which depends on the soil-foundation-structure interaction is crucial for predicting the dynamic structural response (DNV/Ris $\varnothing, 2002$; Ntambakwa et al., 2016). Additionally, a "no gapping" verification under operational loads is often performed to ensure adequate foundation stiffness and limit cyclic loading which can contribute to cyclic degradation of supporting soils (ASCE/AWEA, 2011; Ntambakwa et al., 2016). The wind turbine manufacturers usually specify a minimum value of foundation rotational stiffness (ASCE/AWEA, 2011). Commonly, linear-stiffness springs which depend on the strain level, are used to determine the rotational stiffness (DNV/Ris Ø, 2002).

Foundation settlement is usually a minor concern of onshore wind turbine foundations since the contact pressure from vertical loads is quite low, typically ranging from 50 to $75 \mathrm{kPa}$ (Tinjum and Christensen, 2010). However, the foundation must attend the specified limits of differential settlement. Short-term recoverable elastic, long-term plastic and consolidation, and differential settlements should be addressed (Morgan and Ntambakwa, 2008). Typically, the total settlement of granular soils is based on the application of extreme loads, while the settlement of fine soils is based on the elastic and long-term consolidation settlement under operational loads (Ntambakwa et al., 2016). The maximum differential settlement is usually on the order of $3.0 \mathrm{~mm} / \mathrm{m}$ to $4.5 \mathrm{~mm} / \mathrm{m}$ (Ntambakwa et al., 2016). In the absence of specified limits, a maximum inclination of $3.0 \mathrm{~mm} / \mathrm{m}$ is recommended (ASCE/AWEA, 2011). 


\section{b) Deep foundations geotechnical design: worldwide}

The pile group resistance is not necessarily the sum of axial and lateral resistance of all the piles in the group due to the overlap of plastified soil zones (DNV/Ris $\varnothing, 2002)$. This overlap depends on the piles spacing, pile diameter, and soil characteristics and proprieties. According to the DNV/Ris $\varnothing$ (2002) and Germanischer Lloyd (2010), the pile group effect shall be considered for close spaced piles. According to the EN 1997-1 (2004), special attention must be given to the situation where tensile piles interact in a group. One tension pile reduces the effective vertical stresses of the surrounding piles, reducing the foundation capacity. Therefore, conservative assumptions are usually made as a result of the limited knowledge of the pile group behavior (DNV/Ris $\varnothing, 2002)$.

The distribution of axial forces through the piles depends on the foundation geometry, loading, pile cap stiffness and piles responses. Piles are often assumed to be fixed to the pile cap, and the pile cap is often assumed as a rigid cap (DNV/Ris $\varnothing, 2002)$. Piles are subjected to compression and tension, lateral and bending loadings due to the overturning moment at the foundation. Germanischer Lloyd (2010), for example, suggests that piles should be inclined to sustain horizontal forces and torsional loading. Besides the maximum static pile load, the load capacity of piles under dynamic and cyclic loading shall be taken into account (Germanischer Lloyd, 2010; Puech and Garnier, 2017). According to Jardine et al. (2005), field-scale experiments have shown severe capacity degradation of piles under high-level and two-way cyclic loading. Cyclic stability diagrams, which can be obtained through in situ loading tests or small-scale models, are required to evaluate shaft friction degradation (Puech and Garnier, 2017). Therefore, cyclic forces should be considered in the design.

If piles are not well designed, single geotechnical and structural pile failure may occur, causing inappropriate differential settlement, or even foundation collapse. Eurocode 7 (EN 1997-1, 2004) highlights the importance of static pile load tests in the design of piles under static axial loading due to the great uncertainty about the pile behavior. However, in case of complex loadings, such as cyclic loading, the use of load tests should be replaced by very cautious design calculations values.

\section{Geotechnical design: Brazil}

The geotechnical design of onshore wind turbine foundations in Brazil usually use international guidelines including: Guidelines for design of Wind Turbines by DNV/Ris $\varnothing$ (2002); Guideline for the Certification of wind turbines by Germanischer Lloyd (2010); Wind turbines - part 1: Design requirements by IEC 61400-1 (2005); Eurocode 7 - Geotechnical 
design (EN 1997-1, 2004; EN 1997-2, 2007); Eurocode 2: Design of concrete buildings (EN 1992-1-1, 2004); and foundation design guides from the wind turbines manufactures. The Brazilian standards are used as well, such as the ABNT NBR 6122 (2010) Design and construction of foundations, ABNT NBR 6118 (2014) Design of structural concrete, ABNT NBR 8681 (2004) Actions and safety of structures and ABNT NBR 15421 (2006) Design of seismic resistant structures.

Foundation loads are usually obtained from the wind turbine manufacturer technical report. The main three loading scenarios are extreme, serviceability and fatigue loads in operation and non-operation conditions. The load combinations and factor of safety are based on the Brazilian standards (ABNT NBR 8681, 2004) and the international guides (DNV/Ris $\varnothing$, 2002; IEC 61400-1, 2005; Germanischer Lloyd, 2010).

\section{a) Shallow foundations geotechnical design: Brazil}

Several issues are addressed on the geotechnical design of shallow foundations including foundation stability against sliding and overturning; differential settlement; consolidation settlements; degradation of soil stiffness due to cyclic loading; rotational stiffness. Scour and erosion are usually not considered since the foundation is sufficiently embedded into subsoil. Additionally, a "no gap" verification under operational load is often performed to guarantee that all foundation area remains attached to the soil.

These issues are assessed using elastic and resistance parameters, which are mainly estimated via empiric correlations based on the geological and geotechnical description. The cohesion and friction angle of the soils are usually estimated via $\mathrm{N}_{\text {SPT }}$ values as proposed by Terzaghi and Peck (1948), Wolf (1989), Teixeira (1966) and Godoy and Teixeira (1996). However, these empiric correlations usually show a large variation in the results. Geophysical methods, when performed, provide an estimative of elastic parameters for small strain values, which are especially important to dynamic analyses.

The foundation stability against sliding and overturning are usually determined based on the classical approach and the failure surfaces analyzed using limiting equilibrium methods through FEMs. These numerical methods consider a linear elastic model under monotonic loading. The bearing capacity of the soil is evaluated using the analytical Terzaghi (1943), Hansen (1961) equations. Teixeira (1966) method, which is based on $\mathrm{N}_{\text {SPT }}$ values, is used as well. A factor of safety (FOS) of 3.0 is applied to obtain the admissible bearing stress.

The "Guidelines for design of Wind Turbines" by DNV/RisØ (2002) is usually used to verify foundation stiffness. Most projects considered the foundation supported by linear 
spring. The initial, or maximum, shear modulus is estimated based on the soil proprieties, over consolidation ratio, average confining effective stress and relative density (DNV/Ris $\varnothing$, 2002).

As the wind action imposes a dynamic loading, the dynamic shear modulus depends on the initial shear modulus and the shear strain $(\gamma)$, typically around 10-3 (DNV/Risø, 2002). This dynamic shear modulus can also be obtained through cross-hole tests. The vertical, horizontal, rotational and torsional stiffness are hence obtained. These stiffness values are then compared with the required values provided by the wind turbine manufacturer.

In order to evaluate the foundation settlement and stress distribution, FEMs are usually used. For rock anchored foundations, FEMs are also used to evaluate the anchor's loads, foundation settlement and rotational stiffness.

\section{b) Deep foundations geotechnical design: Brazil}

The onshore wind turbines deep foundations have almost the same geotechnical issues of a shallow foundation: foundation stability against sliding and overturning; differential settlement; rotational stiffness. However, the cyclic degradation of the pile load capacity is not regarded in Brazil, at least for the data acquired.

In order to distribute the load through the group of piles, FEMs are used. The piles are usually modeled as linear springs whose stiffness are determined using analytical and empirical methods. The principle of superposition of efforts is often used to assess the pile axial loads in a simple manner. The soil reaction below the pile cap is usually disregarded.

The piles are designed to resist four types of efforts: axial compression; axial tension; lateral loading; and axial compression-bending or axial tension-bending. Different approaches are used to determine these resistances depending on the pile type. However, piles are mainly designed to support axial loading. Usually, the axial tension capacity is estimated as $70 \%$ of the shaft capacity under axial compression.

Several empirical Brazilian methods, based on the $\mathrm{N}_{\text {SPT }}$ values, are used to determine the axial load capacity. The axial load capacity of root piles is based on the Cabral (1986) and Brasfond (1991) methods. The axial load capacity of driven piles is based on the Aoki and Velloso (1975) and Teixeira (1996) methods. The axial load capacity of continuous flight auger piles is based on the Aoki and Velloso (1975), Décourt and Quaresma $(1978,1982)$ and Antunes and Cabral (1996) methods. All these methods were already extensively used for buildings in Brazil. For the lateral and bending loadings, the piles are designed using FEMs. 


\subsubsection{Geotechnical investigation}

Geotechnical investigation: worldwide

The geotechnical investigation aims to gather relevant knowledge about the site subsoil conditions and properties. The geotechnical investigation should normally be performed in phases, such as preliminary investigations, design investigations and controlling and monitoring, depending on the questions raised during planning, design and construction phases (EN 1997-2, 2007). The amount of investigation depends on the complexity of the structure, loading, subsoil, and the acceptable level of risk of the structure (EN 1997-2, 2007).

The preliminary investigation includes desk studies of the geotechnical and geological information, including reports of previous investigations in the vicinity, aerial photos, topography maps, hydrogeology, field reconnaissance, geophysical survey, by means of seismic methods, consideration of construction experience in the vicinity. The design investigation comprises the main geotechnical investigations, including in situ testing and sampling of the ground for laboratory testing. Particularly to wind energy geotechnical investigation, the parameters required for the foundation design are typically collected by a combination of intrusive borings into the soil and bedrock, soil sampling, Standard Penetration Test (SPT), Cone Penetrometer Test (CPT) and geophysical testing (Tinjum and Christensen, 2010). The laboratory testing program depends on the soil types encountered in the profile but may include the strength and consolidation properties of soil, thermal properties and chemical compatibility testing. (Tinjum and Christensen, 2010). The control investigation consists of inspections performed during the construction phase to check if the subsoil conditions match those assumed in the design.

The most commons in situ testing methods used for the wind turbines foundation design are the CPT and vane test, according to the DNV/Ris $\varnothing$ (2002). According to Ntambakwa et al. (2016), "CPT soundings are commonly used either as a primary exploration method or to supplement traditional borings". In the current wind energy geotechnical investigation practice, a minimum of one boring or CPT at each wind turbine location is specified (Tinjum and Christensen, 2010; ASCE/AWEA, 2011). Additional exploration may also be required if initial data indicate a high potential for subsurface variability (Ntambakwa et al., 2016).

The strength and deformability of granular soils are typically based on correlations with the SPT blow counts or CPT cone resistance (Tinjum and Christensen, 2010). According to EN 1997-2 (2007), there is a wide empirical experience in the use of SPT for sandy soils, even though the results should be considered as only a rough approximation. For clayey soils, 
the SPT should be restricted to a qualitative evaluation of the soil profile or to a qualitative estimation of the strength properties, unless the clayey soil is under well-known local conditions (EN 1997-2, 2007).

For shallow foundations, exploration should be performed at least a minimum depth equal to the foundation diameter. For deep foundations, exploration should be performed at least the maximum anticipated foundation's depth, plus an additional 20\% (ASCE/AWEA, 2011). If the bedrock is encountered, conventional rock coring techniques are used. Ntambakwa et al. (2016) suggest extending rock coring a minimum of 3 to 5 meters into the rock formation if bedrock is encountered near the project foundation depth. Flat Plate Dilatometer (DMT), Pressuremeter Test (PMT) and vane shear testing are also used in a geotechnical investigation of wind sites (Ntambakwa et al., 2016). Appropriate laboratory investigations should be performed to provide a reliable estimation of geotechnical soil parameters (Ntambakwa et al., 2016); however, triaxial and direct shear tests are rarely performed (Tinjum and Christensen, 2010).

Surface geophysical methods, refraction microtremor, CPT seismic and seismic dilatometer are usually used to assess the seismic wave velocities (Tinjum and Christensen, 2010). According to Ntambakwa et al. (2016), seismic exploration testing such as Spectral Analysis of Surface Waves (SASW), Multi-Channel Analysis of Surface Waves (MASW), Refraction MicroTremor (ReMi) and downhole methods such as Seismic CPT should be performed at a minimum of $10 \%$ to $20 \%$ of wind turbines sites. Based on the shear and compression wave velocity profiles, the shear modulus of the soil are evaluated; hence foundation settlement and dynamic stiffness are determined. In the United States current practice, the shear modulus is typically obtained from CPT seismic or surface geophysical methods (Tinjum and Christensen, 2010).

The soil investigation report should contain statements on the ground with strata, disturbances and inclusions, groundwater conditions, soil and rock properties and parameter and boundaries of the investigated areas (Germanischer Lloyd, 2010). The groundwater level should consider seasonal fluctuations as well as long-term ground water levels (ASCE/AWEA, 2011). This report must provide site-specific soil parameters for the design of onshore wind turbine foundations (Tinjum and Christensen, 2010).

\section{Geotechnical investigation: Brazil}

In Brazil, most of the geotechnical design is based on SPTs combined to Rock Core Drilling tests. One in situ test is performed per wind turbine site. The geotechnical 
investigation sometimes includes laboratory tests, such as particle-size analysis, california bearing ratio, Atterberg limits and soil compaction tests. Rarely, geophysical methods are conducted, such as the MASW, crosshole and down hole methods, seismic refraction or reflection and electro-resistivity methods. More advanced in situ investigations, such as CPT, PMT and DMT, are not conducted - at least for the sample acquired. The consideration of water level on geotechnical design depends on the site situation, weather, soil proprieties, and so forth.

Static, or monotonic, load tests are often performed to assess the foundation bearing capacity and integrity. For shallow foundations, the plate load tests are often conducted once per foundation. For deep foundations, the dynamic and static load tests are conducted for at least one pile per wind turbine foundation or respecting the minimum number of load tests established by the Brazilian standard ABNT NBR 6122 (2010). The low strain impact integrity tests (PITs), when performed, are used to assess piles integrities.

\subsubsection{Conclusions}

The geotechnical design of onshore wind turbine foundations in Brazil is mainly performed based on international literature. Classical approach and subgrade reaction modulus are often used to determine foundation area and embedment depth. Additionally, Finite Elements Methods with simple linear-elastic models are used to assess foundation response. Usually, conservative assumptions of the dynamic shear modulus are performed. For deep foundations, piles are mainly designed for axial monotonic loading through empiric correlations.

The geotechnical design of onshore wind turbine foundations requires greater advances, especially when comparing the current Brazilian practice to the state-of-knowledge. For example, it is already possible to use Finite Element Methods with more complex models, such as the hardening soil model with small strain stiffness, and perform cyclic and dynamic analysis. For deep foundations, the effects of cyclic axial loading should be considered. For example, continuous flight auger piles must be cautiously designed due to the likelihood of low toe resistance. The low toe resistance and shaft friction degradation may lead to single piles geotechnical failure which may lead to foundation collapse.

Advanced design methods, however, require a suitable geotechnical investigation. Brazilian geotechnical investigation is mainly based on standard penetration tests. Hence, further investigation is required. More advanced in situ testing, such as penetrometer and cone penetration test, geophysical testing and laboratory testing should provide an appropriate level 
of geotechnical information. The geotechnical investigation should shift towards progressive stages of investigation, depending on the subsoil complexity, in turn of a single series of standard penetration tests.

The recent development of wind projects in Brazil, in association with the lack of national guidelines and standards, resulted in a primitive geotechnical design and investigation. Further national studies are required to assure the optimum design, performance and lifespan of onshore wind turbine foundations in Brazil. 


\section{LITERATURE REVIEW: SOIL-STRUCTURE INTERFACE}

A brief literature review which was not fully described in Chapters 4 and 5, is presented. This review details the key factors that influence the soil-solid interface behavior and strength under monotonic (Subsection 3.1) and cyclic (Subsection 3.2) loading.

\subsection{Soil-Structure Interface under Monotonic Loading}

The soil-structure interface has a primary importance on the performance of several geotechnical systems, including canal liners, deep foundations, landfills, leach ponds, microtunneling, retaining structures and slope stability (Dejong et al., 2000). In addition, the soilsolid interface mechanisms have a high importance on in-situ tests, such as SPT and CPT, and laboratory tests, such as interface shear and torsional shear. However, the difficulty in predicting the soil-structure interface response has limited the reliability of geotechnical design and performance (DeJong and Westgate, 2009).

Semi-empirical methods are usually used to estimate pile shaft resistance through insitu tests, such as SPT or CPT. Another approach is to determine the value of interface friction angle through interface shear tests, ensuring that the surface structural characteristics and the confinement condition are compatible with those experienced in the field (Jardine et al., 1993; Reddy et al., 2000). Lehane et al. (1993) and Reddy et al. (2000) compared the results from laboratory interface tests with model piles in sand. These authors concluded that the interface shear tests can be used to estimate the shaft capacity of piles.

The factors that affect interface behavior and strength have been primary researched through interface shear tests, such as simple shear and direct shear. However, the results obtained in these tests cannot be directly used to the geotechnical design or practice; they need to be corrected by adjustment factors. For example, Paikowsky et al. (1995) concluded that the physical boundaries set forth by the shear box itself resulted in a significant influence on the interface strength and behavior. Dejong and Frost (2002) indicated that appropriate engineering judgment must be conducted since several issues are involved, such as subsoil variability, stress state, surface roughness and so forth. Nevertheless, these authors pointed out that while almost all factors can be controlled or measured in the laboratory tests, relatively few can be controlled on the field.

Over the recent decades, extensive efforts have been made to achieve the complete understanding of soil-solid interface response. One of the pioneers of these studies Potyondy (1961) evaluated the interface strength between soils and construction materials, including 
wood, concrete and steel, through a series of Interface Direct Shear Tests (IDST). This author indicated four major factors that affect the interface strength: the soil moisture content; the composition of the soil; the surface roughness; and the intensity of the normal load.

Currently, the literature has reached a consensus regarding the key factors that have a major effect on the interface response. These key factors are the soil properties, particle characteristics, confinement condition, surface structural characteristics, soil moisture content, and temperature. The next subsections will seek to summarize the state of the knowledge of these factors.

\subsubsection{Surface structural characteristics}

\section{Surface texture}

The surface roughness of common construction materials, such as wood, steel, concrete and geomembranes, have a wide range of characteristics which directly affect the interface response (Dejong et al., 2000). Initially, researchers were limited to a qualitative evaluation of the surface (Potyondy 1961, Brumund and Leonards 1973). As pointed out by Dejong and Frost (2002), the development of automated profiling devices enabled the quantification of the surface characteristics. There are currently several types of surface measurement techniques to quantify the surface texture instead of over single profiles (ASME B46.1, 2009).

The ASME B46.1 (2009) standard defines the surface texture as the composite of certain deviations that are typical of the real surfaces. This surface texture includes roughness, described as the finner spaced irregularities, and waviness, defined as the more widely spaced component of the surface texture (Figure 3.1).

The roughness average, which is one of the most accepted parameter for quantifying the surface roughness, is defined as "the arithmetic average of the absolute values of the profile height $(Z)$ deviations recorded within the evaluation length $(L)$ and measured from the mean line" (Equation 3.1) (ASME, 2009). For evaluation of an area $\left(\mathrm{A}_{e}\right)$, the average roughness is determined based on a Cartesian coordinates XY (Equation 3.2).

$$
\begin{gathered}
R_{a}=\frac{1}{L} \int_{0}^{L}|Z(x)| d x \\
R_{a}=\frac{1}{A_{e}} \int_{0}^{L y} \int_{0}^{L x}|Z(x, y)| d x d y
\end{gathered}
$$




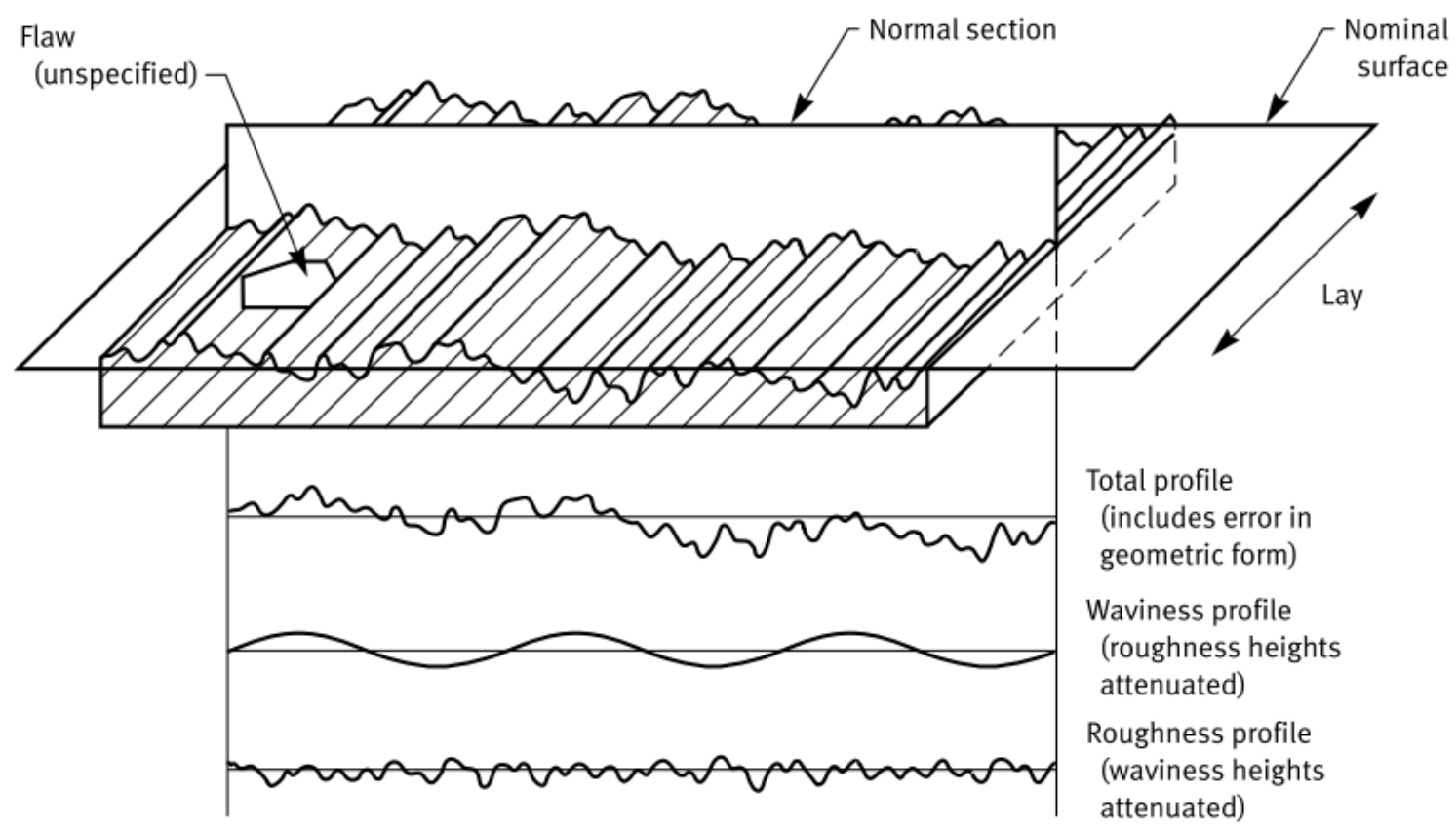

Figure 3.1: Schematic diagram of the surface texture (ASME, 2009).

Through sand-steel interface simple shear tests, Uesugi and Kishida (1986a; 1986b) quantified the role of the surface roughness on the interface strength. These authors proposed the normalized roughness parameter afterward they had identified the relationship between surface roughness and average sand particle diameter $\left(\mathrm{D}_{50}\right)$. The normalized roughness parameter $\left(R_{n}\right)$ is defined by Equation 3.3.

$$
R_{n}=\frac{R_{\max }\left(L=D_{50}\right)}{D_{50}}
$$

Where $R_{\max }$ is the relative height between the highest peak and the lowest valley along the surface profile over a sample length equal to average particle size $\left(\mathrm{D}_{50}\right)$.

Using the normalized roughness parameter, Uesugi and Kishida (1986b) found a bilinear relationship (Figure 3.2). In the left-part of this relationship, there is a linear ratio between interface strength and normalized roughness until a critical roughness value is reached. At this point, the shear plane is transferred from the interface to the adjacent soil and a constant coefficient of friction state is established (Brumund and Leonards, 1973; Uesugi and Kishida, 1986a, 1986b; Uesugi et al., 1988; Paikowsky et al., 1995; Dejong and Frost, 2002; Porcino et al., 2003; Dietz and Lings, 2006; Mortara et al., 2007; DeJong and Westgate, 2009; Chen et al., 2015; Di Donna et al., 2015; Feligha et al., 2016). 


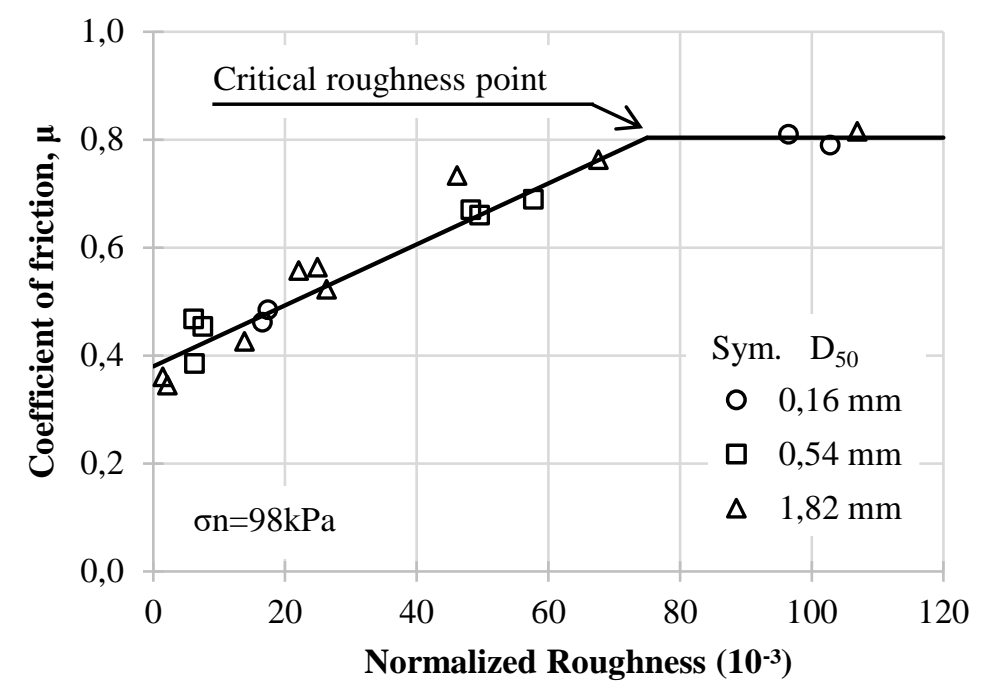

Figure 3.2: Normalized roughness versus friction coefficient between the very angular Seto sand and steel interface. After Uesugi and Kishida, 1986a.

For a sand-concrete interface, Uesugi et al. (1990) observed that the critical roughness point occurred around $10 \%$ of the mean particle diameter, resulting in an interface friction angle larger than $95 \%$ of the sand friction angle. Paikowsky et al. (1995) formally defined three different categories based on the normalized roughness concept: smooth, for $\mathrm{R}_{\mathrm{n}}<0.02$; intermediate, for $0,02<\mathrm{R}_{\mathrm{n}}<0.5$; and rough, for $\mathrm{R}_{\mathrm{n}}>0.5$.

The surface roughness has great influence on the soil particles interface behavior as well. Uesugi et al. (1988) observed that, along a smooth interface, sand particles slipped on the surface without large deformation of the sand mass. Along a rough interface, it was observed shear zone distortion and that sand particles slipped, rooled and moved up and down along the interface. DeJong and Westgate (2009) quantified a particle slippage of approximately $30 \%$ and up to nearly $100 \%$ to rough and smooth interfaces, respectively.

Concerning the stress-strain interface behavior, many studies converge about the role of surface roughness. For an interface between sand and smooth surface, many studies observed a strain hardening behavior regardless of the relative density as minimal normal displacement took place (Uesugi et al., 1988; Uesugi et al., 1990; Paikowsky et al., 1995; Tabucanon et al., 1995; Fakharian and Evgin, 1996; Gómez et al., 2008). As the surface roughness increased, several researchers noticed a more pronounced strain-softening behavior on the stress-displacement curve (Paikowsky et al., 1995; Tabucanon et al., 1995; Fakharian and Evgin, 1996; Porcino et al., 2003; Dietz and Lings, 2006; Mortara et al., 2007; Chen et al., 2015; Di Donna et al., 2015). Additionally, it was noticed that contraction shifts to dilation as the roughness increases (Paikowsky et al., 1995; Porcino et al., 2003; Dietz and 
Lings, 2006; DeJong and Westgate, 2009; Tehrani et al., 2016). Tehrani et al. (2016) performed instrumented model piles tests under axial loading and noticed that as the pile roughness is increased, greater displacements and strains were observed in the soil adjacent to the pile. When a pile is axially loaded in the field or an interface shear test is performed, a narrow shear band is formed next to the interface. The development of this shear band will be discussed at subsection 3.1.3.

For plastic soils, the stress-strain interface behavior is a complex issue. Canakci et al. (2016) observed a strain hardening behavior for an organic soil regardless of the surface roughness. Chen et al. (2015) evaluated the effect of surface roughness on the red clayconcrete interface shear behavior; they noticed that shear dilation is likely to occur on rougher interfaces under lower confining pressure. For a steel-cohesive soil interface, such as high plasticity clay or silt, Feligha et al. (2016) noticed three different failure modes as function of the surface roughness: full sliding at the interface; shear failure (or deformation) within the soil; and (3) a mixed behavior. Nevertheless, more comprehensive studies are necessary to achieve the understanding of the interface response between plastic soils and solid surfaces.

All of these studies mentioned so far have been extensively evaluated the interface strength and behavior for surfaces textures that included only surface roughness. Since roughness may be considered superimposed on a wavy surface, the waviness component of the surface texture was neglected. Alternative studies suggest that is possible to mobilize an interface strength higher than the soil's internal strength (Irsyam and Hryciw, 1991; Frost and DeJong, 2005; Chu and Yin, 2006; Martinez and Frost, 2017). These authors noticed that the overall interface strength is composed of two components: friction and passive resistance.

Irsyam and Hryciw (1991) performed a series of sand-steel interface direct shear tests with rigid ribbed inclusions. For larger ribs spacing, the soil passive resistance is fully mobilized and the failure surface exhibits a pronounced curvature (Figure 3.3). For small ribs spacings, the failure surface plane occurs parallel to the solid surface as the grains will be constricted on the intrarib zones. Irsyam and Hryciw (1991) concluded that for maximum interface strength the optimum rib spacing is $10 \mathrm{H}_{\mathrm{r}}$ for loose sand and $13 \mathrm{H}_{\mathrm{r}}$ for dense sand, where $\mathrm{H}_{\mathrm{r}}$ is the rib height. Martinez and Frost (2017) conducted a series of laboratory tests analyzing the mechanical response of sand-solid interfaces when considering the effects of interface clogging (Figure 3.4). The results indicated the interface strength with cloggingprone asperities or small ribs spacing was due to soil-soil friction, while structured interfaces had high interface strength due to the additional passive resistance. 


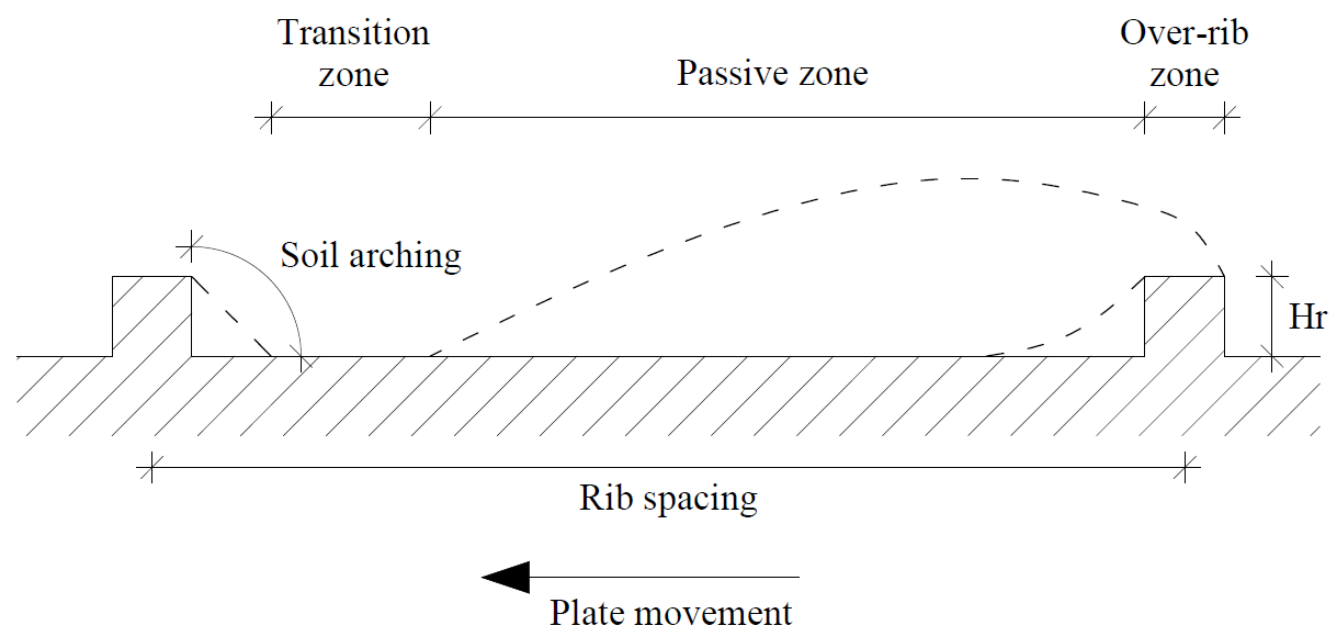

Figure 3.3: Intrarib zones for large rib spacing. After Irsyam and Hryciw (1991).

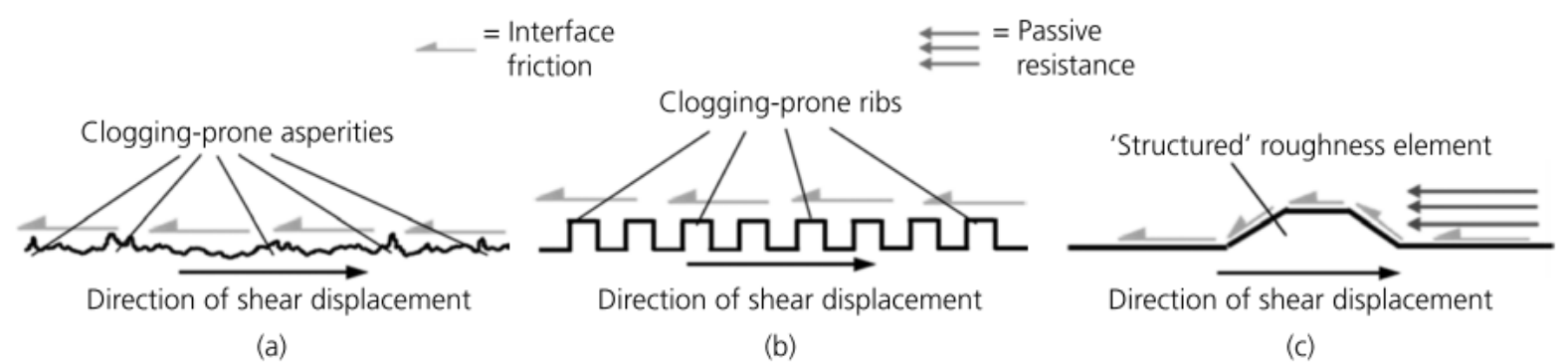

Figure 3.4: Load-transfer mechanisms during shear against surfaces of (a) random, (b) ribbed and (c) structured form (Martinez and Frost, 2017).

\section{Surface hardness}

The effects of surface hardness were first indicated by Potyondy (1961) who observed that the soil particles were pressed into the wood during shearing; and thus, interface strength increased. Surface hardness affects the interface behavior and strength primary by changing the mode of particles movements and by surface plowing. Several researchers concluded that the surface hardness had a great importance for softer construction materials, such as geomembranes, while for high surface hardness materials this effect was less significant (Dove and Frost, 1999; Dejong et al., 2000; Frost et al., 2002). Uesugi et al. (1990) noticed that the concrete strength had an insignificant effect on the friction coefficient value.

For softer geomaterial, as the normal stress increased, the interface strength initially decreased because the actual stress per particle decreased as a result of the larger number of particles and surface contacting the surface (Dove and Frost, 1999). At a critical stress, the total surface of contact reaches a maximum value and particle movement starts to involve plowing. Plowing causes surface damage as a consequence of forcing the particles to 
penetrate the surface and displace material from the surface during translation, increasing interface strength (Dejong et al., 2000).

Frost et al. (2002) noted a coupled effect of the surface roughness and hardness on the interface strength. These authors identified that the interface friction was more sensitive at low initial values of surface roughness and hardness. For high surface hardness values, changes in the surface roughness value resulted in minimal effects on the interface strength.

\subsubsection{Particle Characteristics}

The particle angularity and particle hardness have an important role on the interface response. For example, increasing the structural surface roughness have a similar effect to increase the particle surface roughness and angularity (DeJong and Westgate, 2009). Brumund and Leonards (1973) concluded that the interface strength increases with the angularity and surface roughness of granular particles.

Smooth subrounded particles trend to develop large rotations during shearing due to the low degree of particle interlocking. On the other hand, angular particles have a high degree of interlocking, increasing the interface strength (DeJong and Westgate, 2009). However, angular particles are more susceptibility to breakage during shearing (DeJong and Westgate, 2009). DeJong and Westgate (2009) noticed a secondary effect of the particle breakage depending on particle hardness, stress levels and total interface displacement.

Canakci et al. (2016) noticed that the shape of sand particles immersed in an organic soil (sand content less than 40\%) had not affected the interface strength. Further investigation is needed in order to evaluate the complete role of particle characteristics on the interface behavior and strength, especially for plastic soils.

\subsubsection{Soil Properties}

Many researchers studied the effect of soil properties on the interface behavior and strength. For granular particles-solid interfaces, the effects of the coefficient of uniformity $\left(C_{u}\right)$, coefficient of curvature $\left(C_{c}\right)$, mean particle diameter $\left(D_{50}\right)$ and relative density $\left(D_{r}\right)$ have been extensively studied (Uesugi and Kishida, 1986b; Uesugi et al., 1990; Jardine et al., 1993;

Fakharian and Evgin, 1996; Fioravante et al., 1999; Reddy et al., 2000; Porcino et al., 2003; DeJong and Westgate, 2009; Tiwari and Al-Adhadh, 2014).

The relationship between the average particle size $\left(D_{50}\right)$ of sandy soils and the interface strength were noted by several researchers (Uesugi and Kishida, 1986a; Uesugi et al., 1990; Paikowsky et al., 1995; Fioravante et al., 1999; Porcino et al., 2003; Frost and 
DeJong, 2005; Gómez et al., 2008; DeJong and Westgate, 2009). As show in Figure 3.5, the coefficient of friction decreased as the average particle size increased (Uesugi and Kishida, 1986b; Jardine et al., 1993; Dietz and Lings, 2006). Uesugi and Kishida (1986b) noticed that the peak interface friction coefficient of medium relative density sands is lower than high relative density sands (Figure 3.6). Several studies observed that dense sand specimens sheared against rough surfaces had high peak interface strength (Paikowsky et al., 1995; Fakharian and Evgin, 1996; DeJong and Westgate, 2009; Taha and Fall, 2013; Tiwari and AlAdhadh, 2014). In addition, dilation was less pronounced in the soil-solid interface than the soil-soil friction, resulting in an inferior soil-solid peak interface strength for the same increase in the relative density (Lehane et al., 1993; Tiwari and Al-Adhadh, 2014).

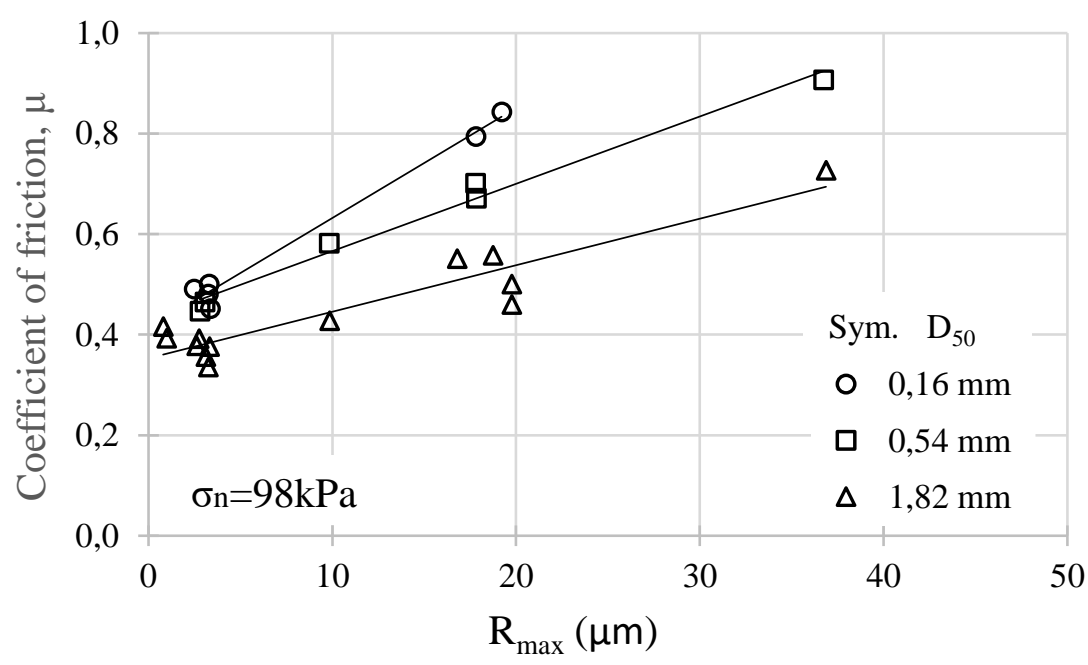

Figure 3.5: Surface roughness versus friction coefficient between the angular Fujigawa sand and steel interface. After Uesugi and Kishida, 1986b.

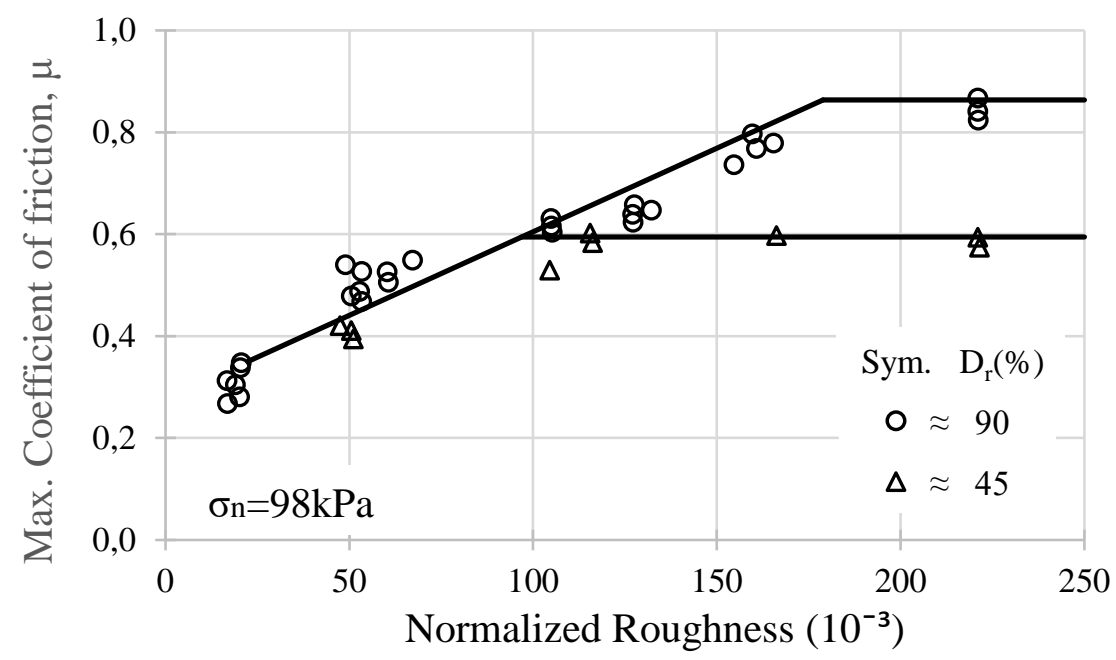

Figure 3.6: Normalized roughness versus maximum friction coefficient between the subrounded Toyoura sand and steel interface. After Uesugi and Kishida, 1986 b. 
Several authors observed that the postpeak interface friction angle not depended on the initial relative density (Uesugi and Kishida, 1986b; Jardine et al., 1993; Lehane et al., 1993; Fakharian and Evgin, 1996; Reddy et al., 2000; Porcino et al., 2003; Dietz and Lings, 2006). Dietz and Lings (2006) proposed a simplified model of interface behavior based on peak and postpeak interface friction angles $\left(\delta_{\mathrm{p}}{ }_{\mathrm{p}}, \delta_{\mathrm{pp}}\right)$ and peak interface dilation angle $\left(\xi_{\mathrm{p}}\right)$, as proposed by Bolton (1986) for sands (Equation 3.4).

$$
\delta_{p}^{\prime}=\delta_{p p}^{\prime}+0.75 \xi_{p}
$$

Regarding the stress-displacement interface behavior, Fakharian and Evgin (1996) noticed that loose and dense sand specimens sheared agaisnt a rough surface exhibit a strain hardening and strain softening behaviors, respectvely. For a smooth surface, these authors noticed a strain hardening behavior, regardless of the initial relative density.

DeJong and Westgate (2009) conducted a series of interface direct shear tests using Particle Image Velocimetry (PIV) in order to track particles movements. These authors concluded that granular particles adjacent to the structural surface must move away from the surface for sliding and particle rearrangement occur. DeJong et al. (2003) noticed there was a significant difference between the true dilation rate within the shear zone and the global dilation. DeJong and Westgate (2009) also investigated the volume behavior in dense and loose specimens. Dense specimens trend initially to contract and then dilate near the interface. Loose specimens was dilative along the interface shear zone and contractile above this zone.

The shear zone which occurs adjacent to the structural surface is influenced by several factors, such as relative density, confinement conditions, particle characteristics and surface structural characteristics. DeJong et al. (2003) indicated that "the interface shear zone thickness increases rapidly with initial interface displacement and then increases gradually with subsequent displacement". DeJong and Westgate (2009) noticed a dilation zone thickness ranging from of about $1 \mathrm{D}_{50}$ for loose specimens up to a maximum of $12 \mathrm{D}_{50}$ for dense specimens. Fioravante et al. (1999) noticed that this dilation zone thickness was approximately between $2 \mathrm{D}_{50}$ to $10 \mathrm{D}_{50}$. Uesugi et al. (1988) observed that the shear zone thickness was about $5 \mathrm{D}_{50}$ for rough surfaces. Tehrani et al. (2016) concluded the average shear zone thickness ranged from 3.2 $\mathrm{D}_{50}$ to $4.2 \mathrm{D}_{50}$ for rough model piles, whereas no shear zone was observed for smooth model piles.

These results suggest that the development of this narrow shear zone is affected by many factors, explaining the divergence on those values. DeJong and Westgate (2009) 
concluded that the shear zone thickness increases with relative density, particle angularity, and surface roughness, while it decreases with confinement conditions and particle hardness.

\subsubsection{Confinement Conditions}

DeJong and Westgate (2009) studied the effects of confinement conditions on the soilstructure interface through two parameters: the normal stress $(\sigma)$ and the normal stiffness $(\mathrm{k})$. For nonhorizontal interfaces, such as pile-soil interface, the normal stress is associated to the lateral earth pressure coefficient. These authors indicated that the normal stiffness couple the change in normal stress with the changes in soil volume $\left(\delta_{\mathrm{v}}\right)$ during shear (Equation 3.5). Boulon and Foray (1986) studied the elastic cavity expansion theory. These authors proposed that the normal stiffness can be determinate as a function of the soil shear modulus $\left(G_{\max }\right)$ and the pile radius (Equation 3.6). For laboratory test, three conditions can be applied according to the normal stiffness value. Soil-solid interface strength is bounded by a unique strength envelope, corresponding to the condition of maximum obliquity (Figure 3.7).

$$
\begin{gathered}
\sigma=\sigma_{i}-k \delta_{v} \\
\mathrm{k}=\frac{2 G_{\max }}{\mathrm{r}}
\end{gathered}
$$

- Constant Normal Load (CNL) $\rightarrow \mathrm{k}=0$;

- Constant Normal Stiffness (CNS) $\rightarrow \mathrm{k}>0$;

- Constant volume (CV) $\rightarrow \mathrm{k}=\infty$.

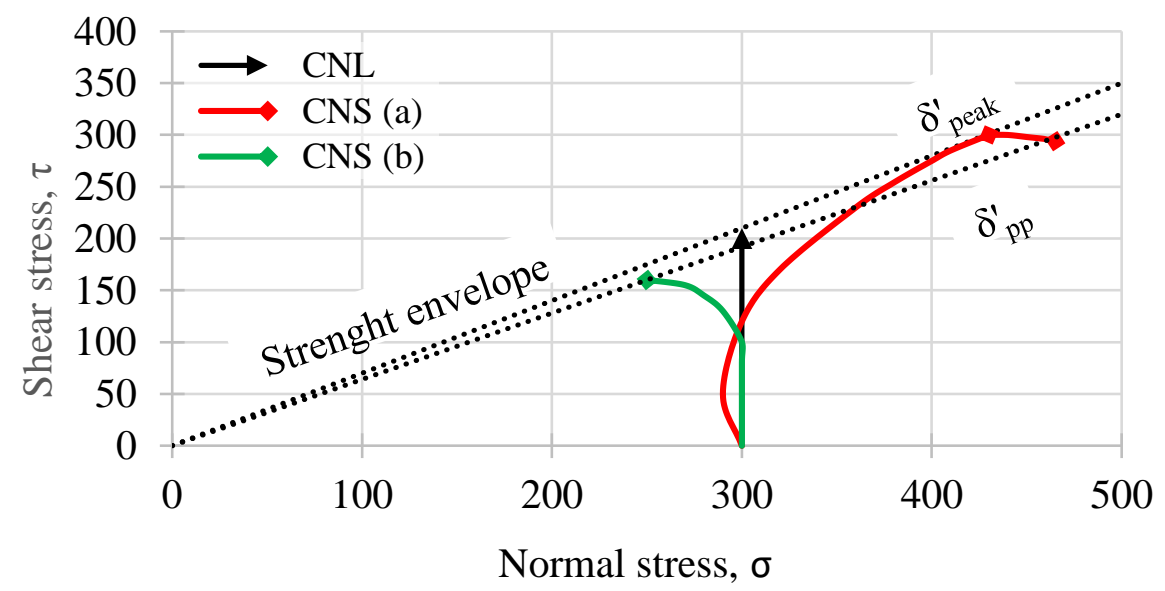

Figure 3.7: Strength envelope obtained through CNL and CNS tests with (a) dense sand-rough interface and (b) loose sand-smooth interface. 


\section{Constant Normal Stress}

Several authors noticed an increase in the interface strength as the normal stress increased (Gómez et al., 2008; Tiwari and Al-Adhadh, 2014; Chen et al., 2015; Canakci et al., 2016). As the confining stress increases, the interface dilation decreased and the soil mass became more contractile (Jardine et al., 1993; Tabucanon et al., 1995; Dietz and Lings, 2006; DeJong and Westgate, 2009; Di Donna et al., 2015; Tehrani et al., 2016). Intense particle rearrangement occured within a smaller shear zone thickness and there was an increase in the displacement required to reach the peak shear strength. As the normal stress increased, these authors noticed that the stress-displacement behavior changed from strain softening to strain hardening, reducing the difference between peak and postpeak interface strength.

Several authors concluded that the interface strength envelope can be described by a Mohr-Coulomb failure criterion (Jardine et al., 1993; Paikowsky et al., 1995; Chu and Yin, 2006; Dietz and Lings, 2006; DeJong and Westgate, 2009; Taha and Fall, 2013; Chen et al., 2015; Canakci et al., 2016).

\section{Constant Normal Stiffness}

The constant normal stiffness condition establishes a normal stress reaction to a normal displacement variation. Through interface direct shear tests under constant normal stiffness condition, many studies showed that dense specimens sheared against rough surfaces exhibited an increase in the current normal stress resulted from dilation, followed by an increase in the shear stress (Fioravante et al., 1999; Porcino et al., 2003; Di Donna et al., 2015). In other words, the tendency of the soil mass to dilate is resisted by the elastic reaction of the adjacent soil and the increase in the interface strength is only due to the increase in the normal stress. For loose soil specimens and smooth surfaces, the normal stress is reduced during shearing due to the contractile behavior, followed by a reduction in the shear stress (Fioravante et al., 1999; and Porcino et al., 2003). As the normal stress increases, a considerable increase in shear stress and a reduction in the peak stress ratio is observed (DeJong and Westgate, 2009).

DeJong and Westgate (2009) noticed a relatively small influence of the normal stiffness on the trends of percent slip, shear and dilation zones thickness. Porcino et al. (2003) noticed that the particle breakage can be enhanced by CNS condition and become more evident in the residual phase of the test due to the increase in the current normal stress. 


\subsubsection{Soil Moisture Content}

Several researchers studied the effects of soil moisture content on the interface response (Potyondy, 1961; Kim and O’Neill, 1998; Chu and Yin, 2006; Miller and Hamid, 2006; Gómez et al., 2008; Hamid and Miller, 2009; Taha and Fall, 2013; Tiwari and AlAdhadh, 2014; Hossain and Yin, 2014; Borana et al., 2016; Canakci et al., 2016; Liang et al., 2016). For example, Gómez et al. (2008) and Tiwari and Al-Adhadh (2014) noticed that sandsolid interface exhibited similar pattern in the stress-displacement behavior for dry and saturated specimens. However, dry soil conditions exhibited higher interface strength compared to the saturated soil (Tiwari and Al-Adhadh, 2014). Taha and Fall (2013) and Canakci et al. (2016) evaluated the interface behavior and strength for different water contents for a marine clay and an organic soil, respectively. Kim and O’Neill (1998) related the effects of seasonal moisture content changes in the soil on the shaft friction capacity of a drilled shaft.

When the structural surface is in contact with an unsaturated soil, Hamid and Miller (2009) referred this contact zone as an "unsaturated interface". Miller and Hamid (2006) proposed to extend the unsaturated failure envelopes used for soils (Fredlund et al., 1978; Vanapalli et al., 1996). Miller and Hamid (2006) suggested the validation through laboratory experiments of the linear and nonlinear interface strength envelopes (Equations 3.7 and 3.8).

$$
\begin{gathered}
\tau=\mathrm{c}^{\prime}+\left(\sigma-\mathrm{u}_{\mathrm{a}}\right) \tan \delta^{\prime}+\left(\mathrm{u}_{\mathrm{a}}-u_{w}\right) \tan \delta^{\mathrm{b}} \\
\tau=\mathrm{c}^{\prime}+\left(\sigma-\mathrm{u}_{\mathrm{a}}\right) \tan \delta^{\prime}+\left(\mathrm{u}_{\mathrm{a}}-u_{w}\right)\left(\frac{\theta-\theta_{r}}{\theta_{s}-\theta_{r}}\right) \tan \delta^{\prime}
\end{gathered}
$$

Where $\tau$ is the shear strength; c' is the effective cohesion; $\delta$ ' is the effective interface friction angle; $\sigma$ is the normal stress; $u_{\mathrm{a}}$ is the pore-air pressure; $\mathrm{u}_{\mathrm{w}}$ is the pore-water pressure; $\left(u_{a}-u_{w}\right)$ is the matric suction; $\theta$ is the current volumetric water content; $\theta_{r}$ is the residual volumetric water content; and $\theta_{\mathrm{s}}$ is the saturated volumetric water content.

Several studies performed unsaturated interface direct shear tests using the axis translation technique to apply the matric suction in the soil. These studies validated the use of Equations 3.7 and 3.8 for describing the unsaturated interface strength (Miller and Hamid, 2006; Hamid and Miller, 2009; Hossain and Yin, 2014; Borana et al., 2016). These authors concluded that the interface strength increases with matric suction. Hamid and Miller (2009) observed that both linear and nonlinear failure envelopes provide a reasonable model for 
unsaturated soils and interfaces. Several authors noticed that the angle which indicates the rate of increase in interface shear strength relative to matric suction $\left(\delta^{\mathrm{b}}\right)$ decreased nonlinearly with the matric suction (Hossain and Yin, 2014; Borana et al., 2016). Borana et al. (2016) observed a nearly linear increase of interface strength with matric suction until the air entry value of the soil.

\subsubsection{Temperature}

Di Donna et al. (2015) conducted a serie of interface direct shear tests between sandconcrete and clay-concrete interfaces with a temperature range from $20^{\circ} \mathrm{C}$ to $60^{\circ} \mathrm{C}$. Results indicated that sand-concrete interface response is not affected by temperature changes, even for test with cyclic loading. On the other hand, clay-concrete interface response changed at different temperatures due to the thermally induced overconsolidation effect. As temperature increased, the clay-concrete interface strength increased and slower cyclic degradation was observed. On the other hand, Yavari et al. (2016) concluded that the effect of temperature on the clay-concrete interface strength is negligible and the increase of the shear strength is related to thermal consolidation effect.

For temperatures below $0{ }^{\circ} \mathrm{C}$, Liu et al. (2014) studied the mechanical behavior of frozen silty clay-concrete interface. Contrarily, as the temperature is reduced, the interface strength increased. In addition, the water content of the specimens was found to influence the shear strength of the frozen soil-concrete interface.

\subsection{Soil-Structure Interface under Cyclic Loading}

Several geotechnical structures, such as offshore structures, transmission towers and wind turbine foundations, are subjected to cyclic loading resulted from wind, waves, machine operation, and earthquakes. Therefore, several studies are conducted on the soil-structure interface under cyclic loading. Cyclic axial loaded for piles can geotechnical fail even at low load levels due to the shaft friction degradation, also referred to as skin friction fatigue (Lee and Poulos, 1991, 1992). One of the pioneers of these studies Poulos $(1988,1989)$ performed small-scale laboratory tests and numerical analysis of piles under cyclic axial loading. Poulos $(1988,1989)$ identified four keys factors that affect the shaft friction degradation: the cyclic amplitude; number of cycles; soil type; and pile type. Poulos (1989) proposed the degradation factor concept to quantify the post-cyclic degradation (Equation 3.9). 


$$
D_{\tau}=\frac{\text { shaft friction after cyclic loading }}{\text { shaft friction in monotonic loading }}
$$

Several authors have described this friction degradation phenomenon as a consequence of the global contraction response of the soil adjacent to the interface, which is followed by a decrease in the confining stress (Poulos, 1989; Airey et al., 1992; Tabucanon et al., 1995; Fakharian and Evgin, 1997; DeJong et al., 2003; Gavin and O'Kelly, 2007; Mortara et al., 2007; Liu et al., 2012; Li et al., 2012; Bekki et al., 2013; Di Donna et al., 2015; Pra-ai and Boulon, 2016). This phenomenon requires especial attention for friction piles as the radial effective stress is most affected, while the pile base resistance remains almost constant (Gavin and O'Kelly, 2007). Shaft friction degradation depend on several factors, including surface structural characteristics, normal stiffness, soil relative density, soil characteristics, initial normal stress, and cyclic amplitude with the number of cycles.

For plastic soils, Di Donna et al. (2015) stated "the degradation phenomenon is less significant because of the reduced volumetric cyclic contraction of the interface with respect to the case of sand". Poulos (1988) compared two hypothetical cases of a driven pile in normally consolidated clay and a grouted pile in cemented calcareous sediment. The results indicated a more severe shaft friction degradation of the pile in calcareous sand deposit. Limited data has been published for clay-solid interface under cyclic loading. Therefore, the next subsections will present a summary of these key factors essentially for granular soils.

\subsubsection{Confinement Conditions}

\section{Constant Normal Load Condition}

Many researchers performed cyclic interface shear tests under CNL conditions (Uesugi et al., 1989; Uesugi et al., 1990; Airey et al., 1992; Fakharian and Evgin, 1996; Oumarou and Evgin, 2005; Mortara et al., 2007; Pra-ai and Boulon, 2016). Uesugi et al. (1989) observed that the friction coefficient under cyclic loading converged to a value close to the residual shear stress developed under monotonic loading. Airey et al. (1992) noticed that the maximum shear stress attained in each cycle remains practically constant. For lower amplitudes values, Fakharian and Evgin (1996) and Mortara et al. (2007) noticed that the interface strength increased after cycling due to a shear zone densification. Uesugi et al. (1990) noticed that particle crushing into the shear zone increased the normalized roughness; and as consequence, the interface strength increased. 
Studies also described this degradation phenomenon as a result of an increase in the amount of sliding at the interface, resulting in a decrease of interface friction angle (Uesugi et al., 1989; Uesugi and Kishida, 1991; Fakharian and Evgin, 1997; Oumarou and Evgin, 2005; Liu et al., 2012). For example, Oumarou and Evgin (2005) noticed that the amount of slip increased with cycling and this amount was larger for dense specimens. For a dense sand-steel interface, Fakharian and Evgin (1997) observed that the accumulation of sliding displacement with cycling plays a major role in the degradation of the interface strength.

\section{Constant Normal Stiffness Condition}

Several authors stated that the constant normal stiffness boundary condition replicates the actual field condition of piles and it can be used to understand the subsequent loss of shaft capacity reported for model and full-scale piles during cycling (Tabucanon et al., 1995; Chin and Poulos, 1996; Fakharian and Evgin, 1997; DeJong et al., 2003; Mortara et al., 2007; Jardine and Standing, 2012; Liu et al., 2012; Pra-ai and Boulon, 2016). Many studies noticed that the shear stress attained in each cycle rapidly decreased, resulted from the decrease of the normal stress (Airey et al., 1992; Tabucanon et al., 1995; Fakharian and Evgin, 1997; DeJong et al., 2003; Mortara et al., 2007; Liu et al., 2012; Pra-ai and Boulon, 2016). Figure 3.8 exhibits the shear stress $\left(\tau_{\mathrm{n}}\right)$ achieved at a $\mathrm{n}^{\text {th }}$ displacement reversal and at the first displacement reversal $\left(\tau_{1}\right)$ to define the degradation factor (Mortara et al., 2007), which is similar of those proposed by early authors (Poulos, 1989; Airey et al., 1992).
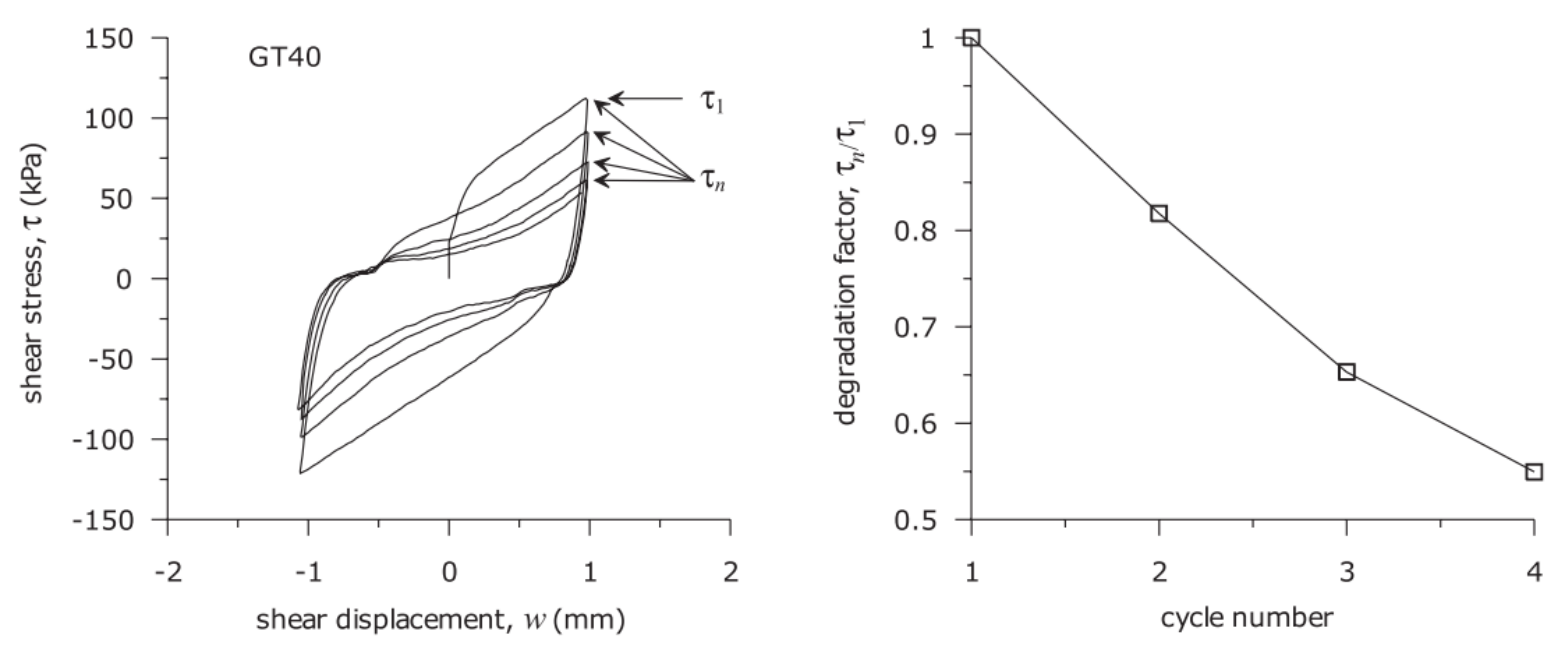

Figure 3.8: Graphical interpretation of cyclic degradation factor for cyclic interface direct shear test under CNS condition (Mortara et al., 2007). 
Many authors observed that shaft friction degradation phenomenon increased as the constant normal stiffness increased (Poulos, 1988; Tabucanon et al., 1995; Fakharian and Evgin, 1997; Mortara et al., 2007; Liu et al., 2012; Pra-ai and Boulon, 2016). For achieving practical results, cyclic interface shear tests should be conducted under a confinement condition that match the field condition (Jardine et al., 2005; Aghakouchak et al., 2015). However, these authors claim that $\mathrm{CV}$ condition $(\mathrm{k}=\infty)$ can provide a simple and conservative upper bound prediction of cyclic effect (i.e., undrained condition).

Concerning the volumetric behavior, all these authors observed a volumetric cyclic contraction of soil adjacent to the interface at a decreasing rate with cycling (Uesugi et al., 1990; Airey et al., 1992; Tabucanon et al., 1995; Fakharian and Evgin, 1996, 1997; DeJong et al., 2003; Oumarou and Evgin, 2005; Mortara et al., 2007; Liu et al., 2012; Pra-ai and Boulon, 2016). A few of them indicated that the volumetric cyclic contraction was greater for loose specimens than dense specimens (Uesugi et al., 1990; Tabucanon et al., 1995; Oumarou and Evgin, 2005; Pra-ai and Boulon, 2016). DeJong et al. (2003) noticed the magnitude of contraction generally exceed the magnitude of dilation in each cycle, resulting in net contraction per cycle.

\subsubsection{Surface structural characteristics}

For a sand-smooth solid interface, Mortara et al. (2007) noticed no phases of dilation. For a sand-rough solid interface, these authors noticed that the strong dilative behavior resulted in the "butterfly wing" pattern (Figure 3.9), and the cumulative net contraction produced greater friction degradation. However, in the post-cyclic stage, only the sand-rough solid interface "recovered part of the shear and normal stresses degraded in the cyclic phase as a result of its dilative features" (Mortara et al., 2007). As shown in Figure 3.9, the coulomb failure criterion is appropriate to describe the friction degradation phenomenon (Airey et al., 1992; Lehane et al., 1993; Fakharian and Evgin, 1997; Mortara et al., 2007; Jardine and Standing, 2012; Tsuha et al., 2012; Di Donna et al., 2015).

Specifically for piles, Lee and Poulos $(1991,1992)$ noticed that grouted piles have greater shaft friction capacity in calcareous sand than driven piles. However, these authors concluded that grouted piles are more susceptible to shaft friction degradation (Lee and Poulos, 1991, 1992). Many studies pointed out that the installation procedure is a key point to understand the pile behavior under cyclic loading (Lee and Poulos, 1991, 1992; Aghakouchak et al., 2015; Blanc and Thorel, 2016). 

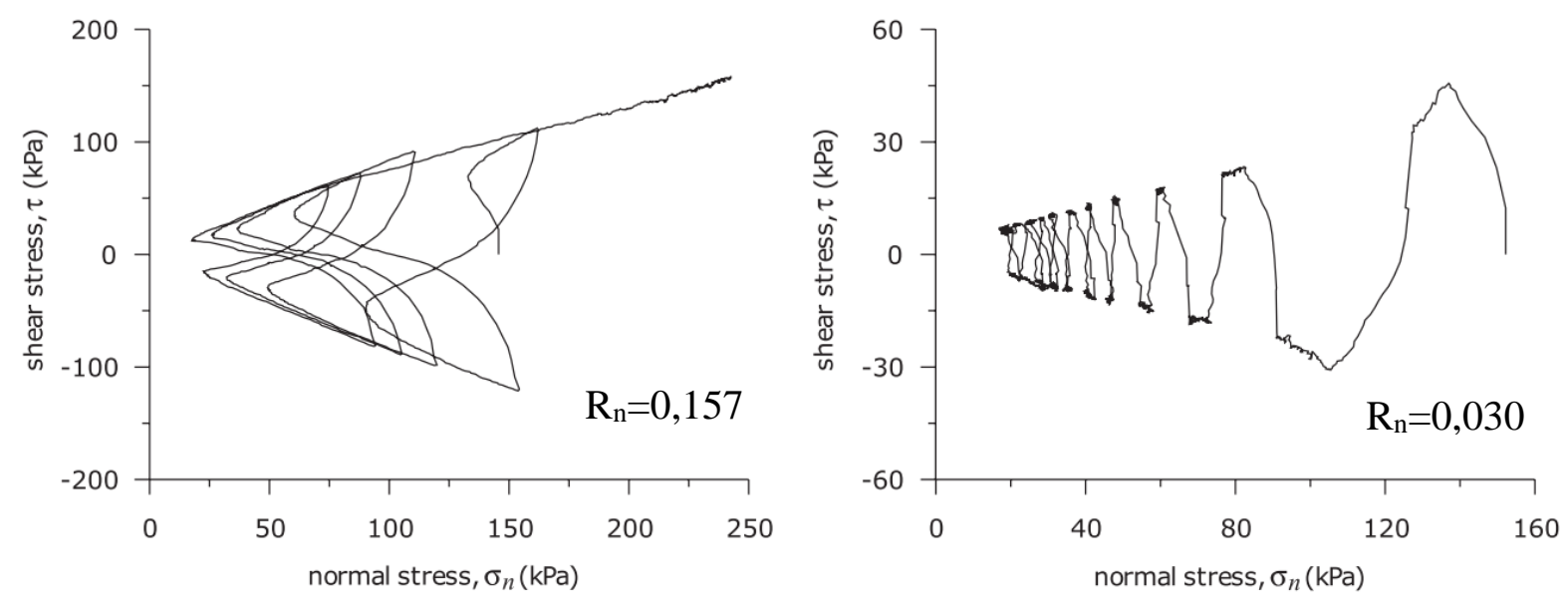

Figure 3.9: Effect of normalized roughness on the interface cyclic response. (Mortara et al., 2007).

\subsubsection{Particle Characteristics and Soil Properties}

In early studies, Poulos $(1988,1989)$ noticed the shaft friction degradation is more severe in calcareous sands than in silica sands due to the greater compressibility of the calcareous sand. In addition, calcareous sands have a high void ratio and are more susceptible to particle crushing (Lee and Poulos, 1991). DeJong et al. (2003) noticed a notable increase in the slip percentage with cycling for calcareous sands due to the particle rearrangement enabled by particle crushing adjacent to the interface.

Fakharian and Evgin (1997) indicated that this degradation phenomenon depends on the compressibility of the sand mass, but can occur even with silica sands. The shaft friction degradation is associated with a contraction in a highly constrained interface shear zone (Jardine and Standing, 2012). Through PIV analyses of cyclic interface direct shear tests, DeJong et al. (2003) noticed three distinct regions of deformation: slip between the interface and the shear zone; the shear zone itself; and a region above the shear zone that undergoes horizontal compression against the end walls of the apparatus. DeJong et al. (2003) also described the effect of different particle characteristics:

- For angular carbonate sand, there was larger shear zone thickness and particle crushing adjacent to the interface, which accelerated the friction degradation when compared to silica sands.

- For subrounded silica sand-rough steel interface, it was observed that the shear zone thickness increased with cycling, from around $5 \mathrm{D}_{50}$ to $8 \mathrm{D}_{50}$. However, the shear zone thickness tends to be smaller for lightly cemented sands and significantly larger for angular calcareous sands. 
- For a cemented soil, slip between the structural surface and soil appears more favorable than further decementation of the intact material away from the interface.

Using undrained cyclic triaxial tests in sand specimens, Aghakouchak et al. (2015) evaluated the effect of stress history on the cyclic degradation. Over-consolidated sand specimens experienced no cyclic degradation, with a slight increase in the shear strength. In contrast, these authors noticed large cyclic degradation in normally consolidated samples.

The friction degradation is greater for loose sands than dense sand specimens (Tabucanon et al., 1995; Pra-ai and Boulon, 2016). Greater shaft friction degradation can be expected for a pile placed in loose sand, "unless the normal stiffness is relatively low, as might be the case for large pile diameters" (Tabucanon et al., 1995).

\subsubsection{Amplitude, Frequency and Number of cycles}

As the number of cycles and cyclic amplitude increased, several studies noticed the increase in the friction degradation; and most of this degradation occurs in the first few cycles, but it continues at a decreasing rate (Poulos, 1989; Lee and Poulos, 1991; Tabucanon et al., 1995; Chin and Poulos, 1996; Fakharian and Evgin, 1997; Gavin and O'Kelly, 2007; Mortara et al., 2007; Liu et al., 2012; Tsuha et al., 2012; Li et al., 2012; Aghakouchak et al., 2015; Blanc and Thorel, 2016; Pra-ai and Boulon, 2016). These authors performed cyclic experimental tests with displacement-controlled amplitude or load-controlled amplitude. However, by reason of experimental duration, most of the studies performed cyclic interface tests with a limited number of cycles (e.g., Uesugi et al., 1989; Fakharian and Evgin, 1996, 1997; Mortara et al., 2007; Blanc and Thorel, 2016).

Specifically for piles, Lee and Poulos $(1991,1992)$ and Chin and Poulos (1996) noticed that the shaft friction degradation becomes insensitive to pile diameter when normalized by cycle slip displacement, $\rho_{c s}$ (i.e., the difference between the cyclic displacement amplitude and the displacement required to develop full shaft capacity) (Figure 3.10). This normalized cyclic slip displacement model was found to be the more appropriate model governing shaft friction degradation under cyclic loading conditions for grouted piles (Lee and Poulos, 1992) and jacked piles (Chin and Poulos, 1996) in calcareous sands.

Few authors suggest there is a threshold of maximum possible degradation for the pile-soil interface (Chin and Poulos, 1996; Liu et al., 2012). Other studies suggest that normal and shear stress would continue to decrease until very close to zero, with no evidence of a threshold (Tabucanon et al., 1995). However, a few authors performed experimental investigations with a large number of cycles (>1.000 cycles) (Jardine and Standing, 2012; 
Tsuha et al., 2012; Bekki et al., 2013; Aghakouchak et al., 2015; Pra-ai and Boulon, 2016). Aghakouchak et al. (2015) pointed out that making reliable predictions over thousands of cycles still remains a challenge.

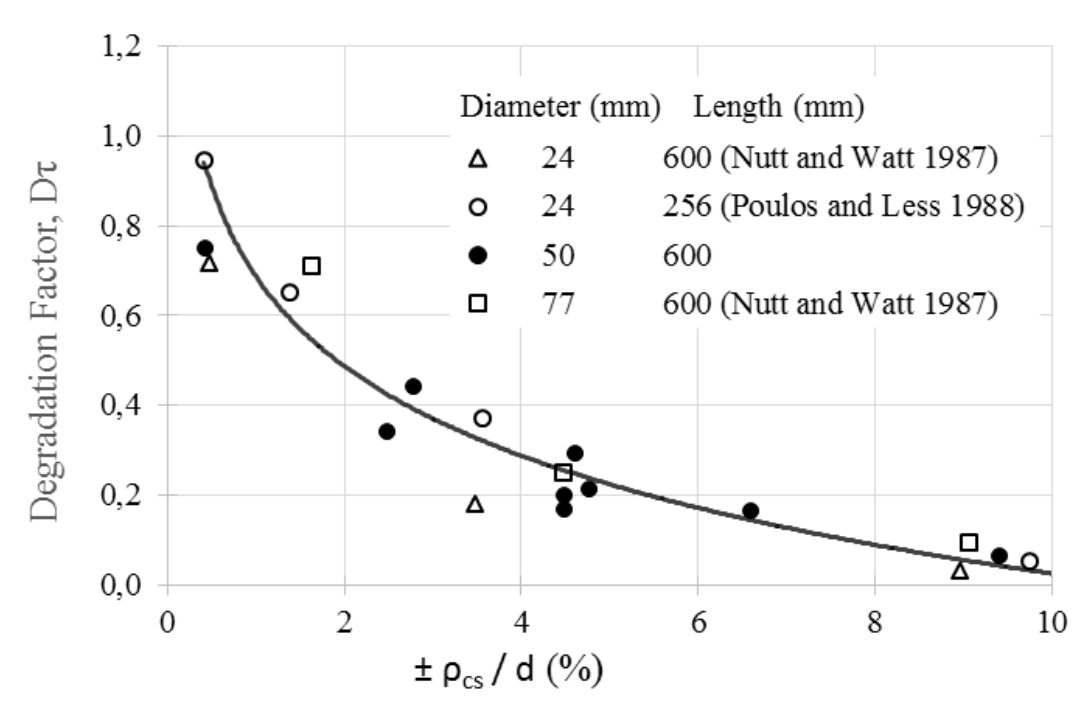

Figure 3.10: Effect of normalized cyclic slip displacement on the degradation factor of different pile diameters (Lee and Poulos, 1991).

Cyclic amplitude and frequency of cyclic axial loaded piles are often presented in terms of frequency (f), the mean load $\left(\mathrm{Q}_{\text {mean }}\right)$ and the cyclic amplitude $\left(\mathrm{Q}_{\text {cyclic }}\right)$ (Figure 3.11). Usually, a sinusoidal form of loading is used in experimental investigations (Jardine and Standing, 2012; Tsuha et al., 2012; Aghakouchak et al., 2015). Poulos (1988) proposed a cyclic stability diagram for cyclic axially loaded piles in which three regions are defined: unstable; metastable; and stable.

The stable zone can lead to shaft capacity gains due to a low-level cycling (Jardine and Standing, 2012; Tsuha et al., 2012; Aghakouchak et al., 2015). Tsuha et al. (2012) noticed the densification of the shear zone enhanced dilation under post-cycle loading. Several authors described one thousand cycles as an upper limit for a cyclic axial loaded pile be considered stable (Poulos, 1989; Jardine and Standing, 2012; Tsuha et al., 2012).

In opposite, high-level cyclic loading can significantly impact the pile shaft capacity, leading to an unstable zone (Jardine and Standing, 2012; Tsuha et al., 2012; Aghakouchak et al., 2015). Tsuha et al. (2012) noticed an inelastic contractive behavior in the soil mass, resulting in the drop of the mean shear stress. 
The metastable zone is related to excessive displacements accumulation, while increase or decrease in the shaft capacity is possible. Tsuha et al. (2012) observed a markedly plastic behavior concentrated in the interface shear zone.

Blanc and Thorel (2016) evaluated the cyclic behavior of piles using centrifuge tests with different load-amplitude sequences. These authors concluded that the order of cyclic sequences affects the shaft friction degradation, resulting in larger degradation scenario for cyclic amplitudes been continuously increased.

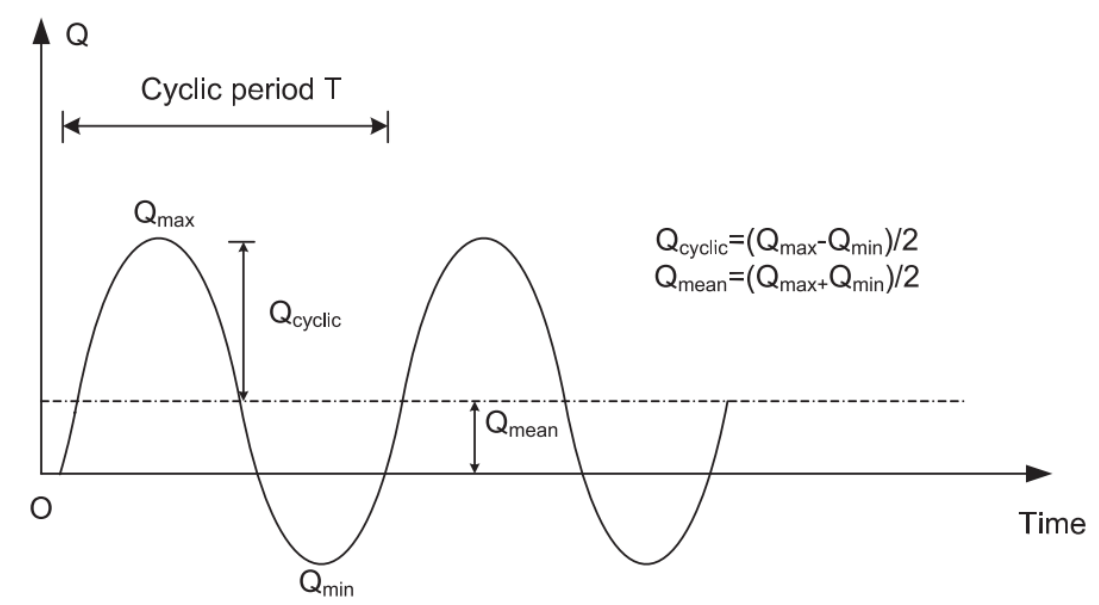

Figure 3.11: Definition of cyclic loading parameters for both field and laboratory model tests.

(Tsuha et al., 2012).

\subsubsection{Particle crushing}

Particle crushing plays an important role on the cyclic interface response. The volumetric contraction with cycling can be explained, at least in part, by particle crushing (Tabucanon et al., 1995) which occurs at the interface (Uesugi et al., 1989; Uesugi et al., 1990; DeJong et al., 2003; Pra-ai and Boulon, 2016). Several studies noticed that particle crushing is enchased by sand type (grain size distribution, grain shape and grain strength) and normal stress (Uesugi et al., 1989; Uesugi et al., 1990; DeJong et al., 2003; Pra-ai and Boulon, 2016). Blanc and Thorel (2016) and Pra-ai and Boulon (2016) pointed out that the surface roughness can contribute to the particle crushing. Additionally, the magnitude of cyclic amplitude and initial relative density can affect particle crushing, especially for dense specimens (Pra-ai and Boulon, 2016).

DeJong et al. (2003) observed severe particle crushing within the shear zone due to the low hardness and higher degree of interlocking of angular calcareous sands. Pra-ai and Boulon (2016) noticed that particle crushing increased the amount of finer particles sizes. 


\subsection{Conclusions}

A literature review of the soil-solid interface under monotonic and cyclic loading was conducted to comprehend the current state-of-knowledge. The key factors that influence the soil-solid interface behavior and strength were presented, including surface structural characteristics, confinement conditions, soil properties and so forth. Under cyclic loading, the cyclic amplitude and number of cycles have great influence on the interface response.

This section had a major role to support the experimental investigations developed in Chapters 4 and 5. 


\section{SAND-CONCRETE INTERFACE BEHAVIOR AND STRENGTH}

Sand-concrete interface was chosen to be the main focus of this research because it is an interface commonly found in the Brazilian onshore wind turbine deep foundations, as aforementioned in chapter 2 . This section is mainly composed of two subsections.

The first subsection presents the results of an experimental investigation on the sandconcrete interface behavior and strength under monotonic loading. The effects of surface structural characteristics, initial relative density, sand mean diameter and confinement condition were analyzed. This subsection composed an article which was accepted for publication on the Soils and Foundations Journal.

The second subsection presents a literature review of sand-concrete interface strength values for analyzing the effects of other conditions, such as particle morphology and sand gradation. In this review, the experimental results obtained in the first part were included in the analysis. It composed an article which was presented at the XIX Brazilian Conference of Soil Mechanics (2018).

\subsection{Sand-concrete interface: experimental investigation}

\subsubsection{Introduction}

Soil-structure interactions are of primary importance to the performance of various geotechnical systems. This interaction occurs through a contact zone that is referred to as the soil-solid interface. The enhancement in interface behavior and strength can improve the constructability and performance of deep foundations by either minimizing the interface friction during pile jacking or maximizing load transfer via skin friction (Frost and DeJong, 2005). However, the difficulty of predicting interface behavior and strength has limited its reliability in geotechnical design and performance (DeJong and Westgate, 2009).

Over recent decades, extensive efforts have been made to achieve a complete understanding of soil-solid interface behavior and strength (e.g., Potyondy, 1961; Oumarou and Evgin, 2005; Chen et al., 2015). The literature has currently reached a consensus regarding the key factors that have a major effect on the interface, which include soil properties (e.g., Tiwari and Al-Adhadh, 2014; Canakci et al., 2016; Feligha et al., 2016), particle characteristics (e.g., Uesugi and Kishida, 1986a, 1986b; DeJong and Westgate, 2009), confinement conditions (e.g., Reddy et al., Sastry, 2000; Dietz and Lings, 2006), surface structural characteristics (e.g., Brumund and Leonards, 1973; Paikowsky et al., 1995; Taha and Fall, 2013), soil moisture content (e.g., Miller and Hamid, 2006; Hamid and Miller, 2009; 
Hossain and Yin, 2014; Borana et al., 2016) and temperature (e.g., Liu et al., 2014; Yavari et al., 2016).

The surface structural characteristics, or solid surface characteristics, have two main aspects, i.e., surface texture and surface hardness, which directly affect the interface behavior and strength (Frost and al., 2002). According to ASME B46.1 (2009), surface texture is composed of surface roughness, which is defined by finely spaced irregularities, and surface waviness, which is defined by more widely spaced components. As proposed by Uesugi and Kishida (1986b), several researchers have established a bilinear relationship between roughness (normalized by the mean sand diameter) and interface strength (e.g., Paikowsky et al. 1995; Dejong and Frost, 2002). In these studies, interface strength was limited by sand strength. Alternative studies regarding the sand-steel interface suggest that interface strength can be higher than internal soil strength by superimposing surface roughness onto surface waviness (Irsyam and Hryciw, 1991; Frost and DeJong, 2005; Martinez and Frost, 2017; Samanta et al., 2018b). For soil-concrete interfaces, Chu and Yin (2006) and Qian et al. (2017) evaluated the role of waviness for a completely decomposed granite-concrete interface and a silty sand-concrete interface under constant normal load conditions. Additionally, surface waviness is frequently normalized by the mean diameter of sand or added to normalized roughness, which may lead to a conceptual conflict despite the valuable results (e.g., Su et al., 2018; Samanta et al., 2018b, Martinez and Frost, 2017).

Regarding surface hardness, smooth concrete surfaces have been identified as hard surfaces (Frost et al., 2002); thus, the effect of surface plowing on interface behavior and strength has not been evaluated. Some researchers have simulated rough concrete surfaces by producing a rough steel surface or gluing sand particles onto a steel surface (e.g., Tabucanon et al., 1995; Samanta et al., 2018a); however, surface plowing aspects have not been investigated at the sand-concrete interface.

Concerning confinement conditions, experimental investigations are usually conducted under constant normal load (CNL) conditions. Alternatively, studies at the sand-solid interface under constant normal stiffness (CNS) conditions, which might be the case for deep foundations, have been performed less frequently (Tabucanon et al., 1995; Porcino et al., 2003; Wang et al., 2017). Specifically for sand-concrete interfaces, even fewer experimental investigations have been carried out under CNS conditions (Di Donna et al., 2016).

As previously mentioned, several studies have conducted experimental investigations using both sand-steel (Evgin and Fakharian, 1996; Dietz and Lings, 2006; Ho et al., 2011; Tehrani et al., 2016) and sand-concrete (Uesugi et al., 1990; Gómez et al., 2008; Di Donna et 
al., 2016) interfaces to evaluate the influence of the surface structural characteristics on interface behavior and strength. However, mainly flat smooth concrete surfaces, made by pouring concrete against steel or plywood counterfaces, have been tested. Therefore, the effects of surface waviness at the sand-concrete interface have not been quantified, especially under CNS conditions. Additionally, the effects surface plowing on concrete surfaces have not been identified to date.

The results and conclusions herein advance the predictions for sand-concrete interface behavior and strength through a new experimental methodology to reproduce the sandconcrete interface. Three extreme surface texture scenarios, including smooth-driven piles, rough-grouted piles and rough-wavy omega screw piles, were used to cover the spectrum of concrete pile-sand interfaces. Using interface direct shear tests (IDSTs), the roles of the surface structural characteristics and the confinement condition were investigated. The results can be directly applied to improve the design and performance of several geotechnical systems, such as deep foundations. Surface plowing was assessed with the following three approaches: image analysis, laser scanning, and extended multifocal micrographs.

\subsubsection{Experimental methodology}

\section{Test setup and material}

For the present study, a large direct shear apparatus was modified to perform IDSTs with a shear area of $200 \times 200 \mathrm{~mm}$ (Fig. 4.1a). This apparatus used two electromechanical force actuators to control the normal and shear forces. The vertical and horizontal loads were measured by two load cells, and the vertical and horizontal displacements were measured by two linear variable differential transformers (LVDT). Both CNL and CNS tests were performed using this apparatus.

The lower part of the shear box of the direct shear apparatus was modified to accommodate a concrete slab of $200 \times 300 \times 63 \mathrm{~mm}$. The modified direct shear apparatus was designed to produce a constant soil-solid interface friction throughout testing. A gap of 0.5 $\mathrm{mm}$ or $2.0 \mathrm{~mm}$ (depending on the mean diameter of the sand particles) was arranged by placing steel foils between the lower and upper parts of the shear box. Hence, the contact between the upper shear box and the concrete surface was obviated. The soil sample had an area of $200 \times 200 \mathrm{~mm}$ and a height of $40 \mathrm{~mm}$. Figure $4.1 \mathrm{~b}$ shows a schematic diagram of the sand-concrete IDSTs performed. 
(a)

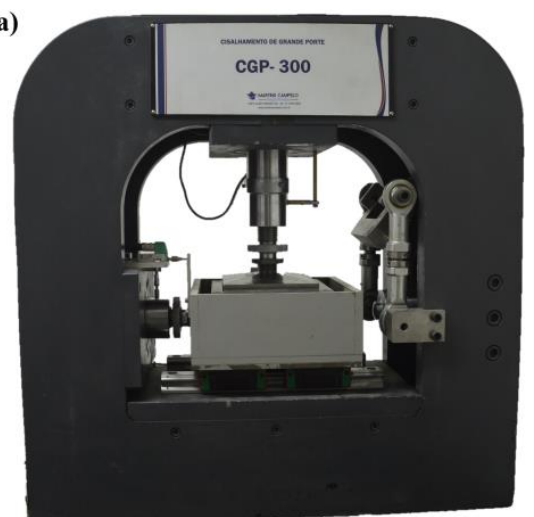

(b)

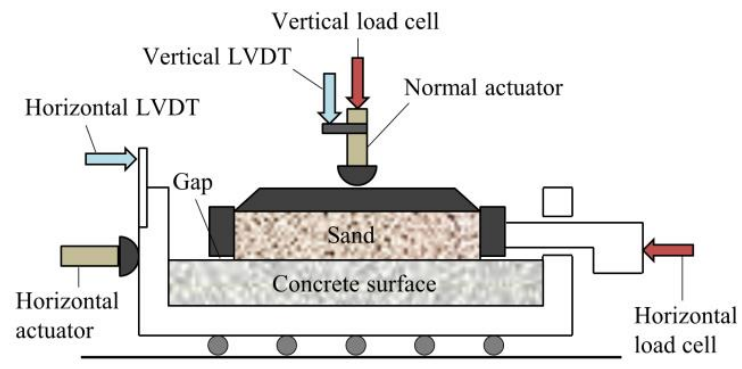

Figure 4.1: Experimental setup: (a) large direct shear apparatus and (b) schematic diagram of the sand-concrete IDSTs.

Two poorly graded Tietê Brazilian standard silica sands were used in this research. These sands are used as reference materials by the Brazilian laboratories to perform physicomechanical tests of Portland cement, and they have a specific production control scheme in addition to several technical and laboratory qualification requirements. Table 4.1 presents the properties of the very coarse sand (SP\#16) and the fine sand (SP\#100) used in the experimental program. The mineralogy of both sands is predominantly quartz, which represents more than $95 \%$ of the sand mass, with some feldspar and minor contents of other minerals. Fig. 4.2 shows the morphological aspects of the SP\#16 and SP\#100 particles. The particles have an angular shape and a slenderness of approximately 1.40 .

Table 4.1: Grain size, packing, particle and strength properties of the tested sands.

\begin{tabular}{lcc}
\hline Parameter & SP\#16 & SP\#100 \\
\hline $\mathrm{Gs}$ & 2.63 & 2.61 \\
$\mathrm{D}_{50}[\mathrm{~mm}]$ & 1.73 & 0.24 \\
$\mathrm{C}_{\mathrm{u}}$ & 1.40 & 1.60 \\
$\mathrm{C}_{\mathrm{c}}{ }^{a}$ & 0.96 & 0.96 \\
$\mathrm{e}_{\max }{ }^{b}$ & 0.834 & 0.970 \\
$\mathrm{e}_{\min }{ }^{b}$ & 0.742 & 0.743 \\
$\varphi_{\text {peak }}\left(\mathrm{D}_{\mathrm{r}} 70 \%\right)[\mathrm{deg}]$ & 39.9 & 35.8 \\
$\varphi_{\text {post-peak }}\left(\mathrm{D}_{\mathrm{r}} 70 \%\right)[\mathrm{deg}]$ & 34.0 & 30.9 \\
$\varphi_{\text {post-peak }}\left(\mathrm{D}_{\mathrm{r}} 30 \%\right)[\mathrm{deg}]$ & 34.2 & - \\
Mean aspect ratio $^{c, e}$ & 1.395 & 1.427 \\
Mean form factor $^{d, e}$ & 0.829 & 0.801 \\
\hline
\end{tabular}

${ }^{\mathrm{a}}$ ASTM D4254 (2016); ${ }^{\mathrm{b}}$ ASTM D4253 (2016); ${ }^{\mathrm{c}}$ aspect ratio= length/width; ${ }^{\mathrm{d}}$ form factor= 4 $\pi$ area / perimeter ${ }^{2} ;{ }^{\text {e }}$ dynamic image analysis method prescribed by ISO 13322-2 (2006). 

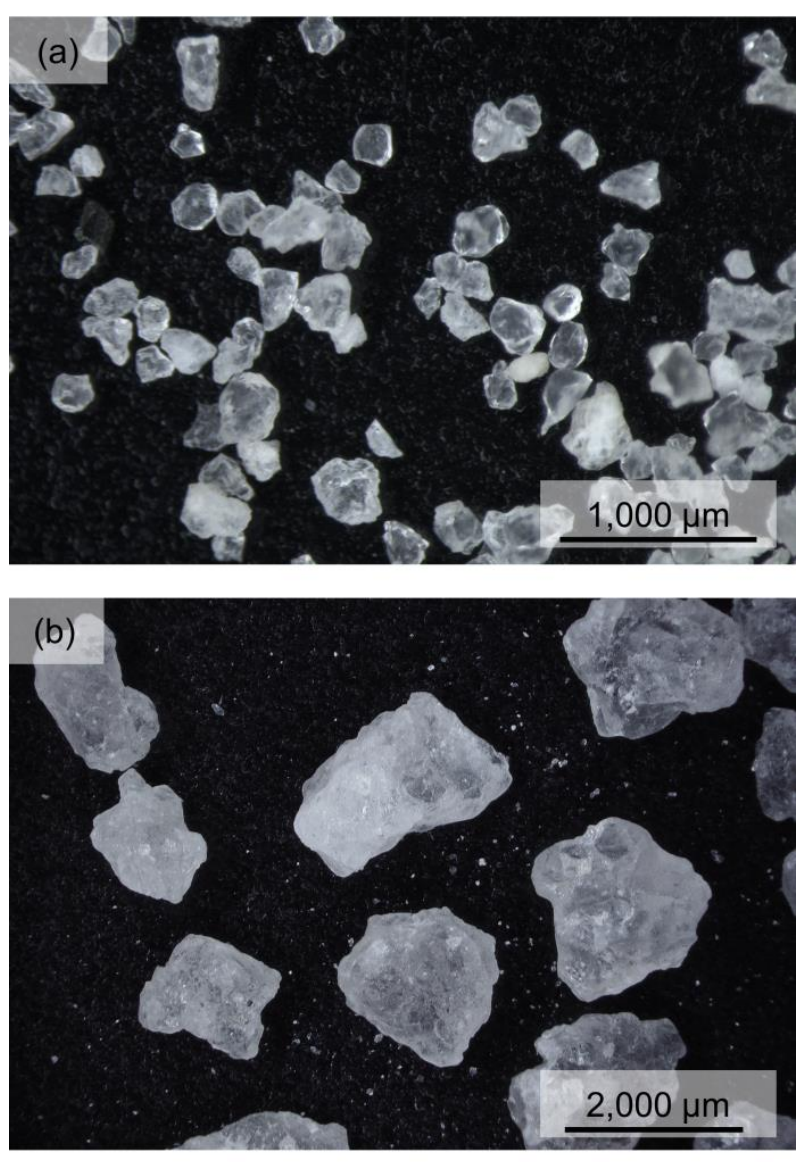

Figure 4.2: Micrographs of the sand particles: (a) SP\#100; and (b) SP\#16.

The concrete element of the sand-concrete system consisted of a cement mortar, which was fabricated in the laboratory by mixing Portland cement of high initial strength, two types of sand, water and superplasticizers. Table 4.2 displays the cement mortar mix design. This mix design was chosen for two reasons: its fluidity (as usually requested for piles) and its high initial strength (to optimize the experimental program schedule). The cement mortar had an average uniaxial compressive strength of $30.4 \mathrm{MPa}$ after 7 days. Additionally, a Silver Schmidt Hammer was used to evaluate the hardness of the flat smooth concrete surface (ASTM C805, 2013). An average rebound coefficient, "Q"-value, of 40.1 was acquired.

Table 4.2: Cement mortar mix design.

\begin{tabular}{lc}
\hline Parameter & Value \\
\hline Water/cement ratio & 0.45 \\
Cement/aggregate ratio & 1.50 \\
Cement/fine sand ratio & 0.75 \\
Cement/medium sand ratio & 0.75 \\
Superplasticizers (\% of cement) & 0.10 \\
\hline
\end{tabular}




\section{Structural surface design and evaluation}

The pile-soil system was replicated by fabricating smooth, rough and rough-wavy concrete surfaces. Smooth concrete surfaces (SCSs) were prepared by pouring concrete against a flat steel surface to simulate driven precast pile surfaces. Rough concrete surfaces (RCSs) were fabricated by pouring concrete against a flat surface of sand to replicate grouted pile surfaces, such as continuous flight auger pile surfaces. Rough-wavy concrete surfaces (RWCSs) were made by pouring concrete against a wavy surface of sand to replicate omega screw pile surfaces.

Seven types of concrete surface textures were fabricated (Fig. 4.3). The SCSs were made by pouring concrete against a flat steel surface, and the RCSs were made by pouring concrete against flat SP\#16 (RCS1) and SP\#100 (RCS2) sand surfaces. The four types of RWCSs were made by pouring concrete against a SP\#16 surface with single wave profile heights of $2.5 \mathrm{~mm}$ (RWCS1), $5.0 \mathrm{~mm}$ (RWCS2), $7.5 \mathrm{~mm}$ (RWCS3) and $10.0 \mathrm{~mm}$ (RWCS4). These RWCSs were designed to investigate the role of surface waviness on sand-concrete interface strength and behavior. These surface wave profile heights are commonly noticed in actual foundations. Additionally, a maximum surface wave profile height of $10.0 \mathrm{~mm}$ was established due to the shear box size.

Fig. 4.4 shows the fabrication methodology of RCS1 and the RWCSs. A purpose-built half container was used. Loose sand was placed in the lower part of the half container. A steel slab and vibrating table were used to impose a flat or a specific wave profile onto the sand surface. Later, a cement mortar was poured into the upper part of the purpose-built half container. Thus, the cement mortar penetrated into the sand voids to create an isotropic sandy-concrete surface. Due to the difficulty of applying the same procedure for RCS2, the SP\#100 particles were pluviated onto the fluid flat cement mortar surface with a sieve. All concrete slabs were cured for 7 days.

Three approaches were used to evaluate aspects related to surface texture and surface plowing. The seven types of concrete surface textures were evaluated with a Design ScanArm 2.0 (DSA, manufactured by Faro Technologies, Lake Mary, United States, 2018), which creates high-resolution point clouds. The maximum permissible error of the DSA is 0.075 $\mathrm{mm}$, and the minimum point spacing is $0.040 \mathrm{~mm}$. Polyworks software (InnovMetric Software, 2014) was used to perform cloud alignments and measurements. The surfaces textures were assessed before and after the IDST under a CNL of $100 \mathrm{kPa}$ to evaluate the effect of shearing on surface texture. 

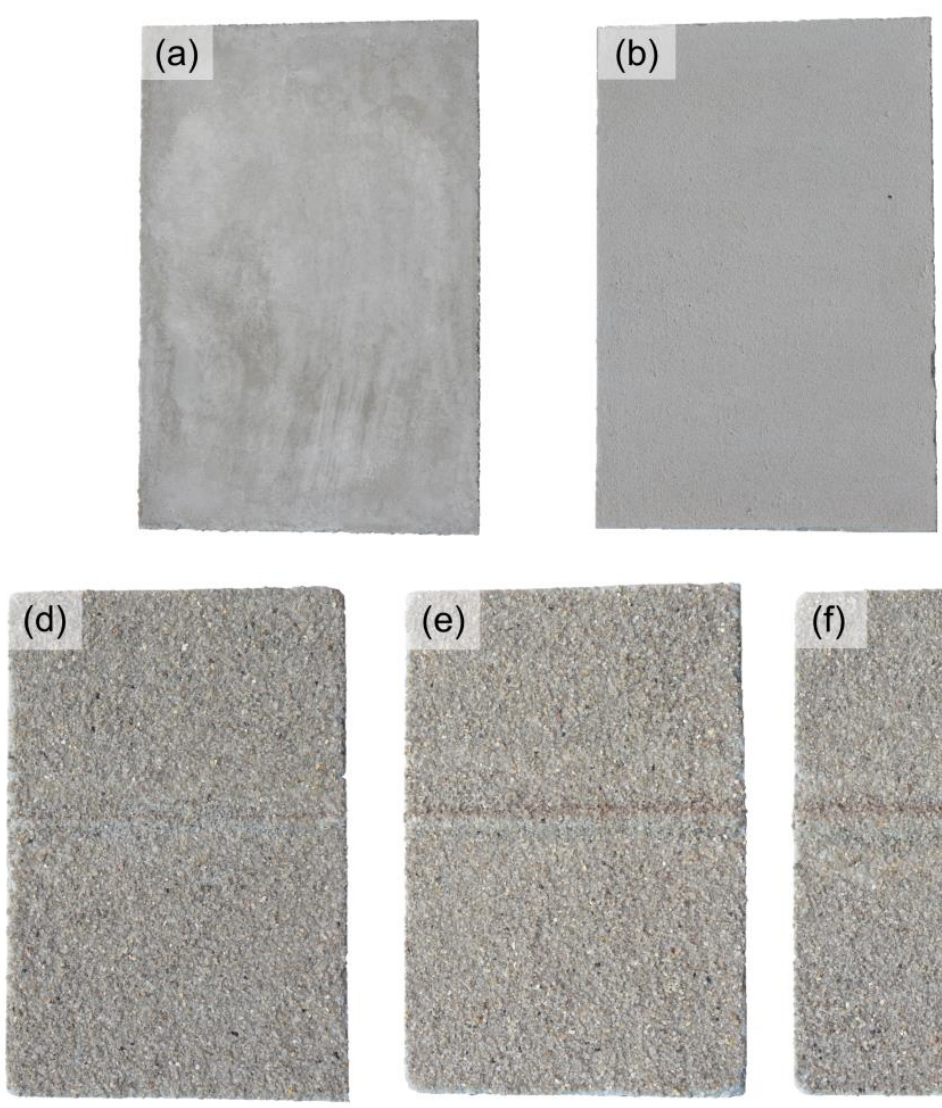

(e)

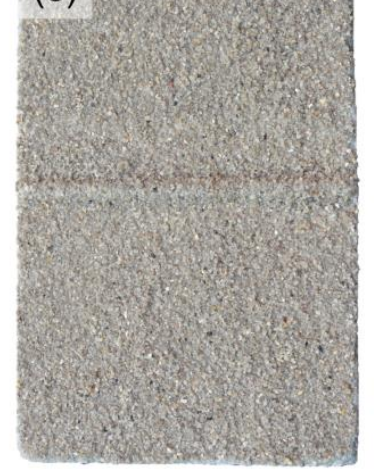

(f)

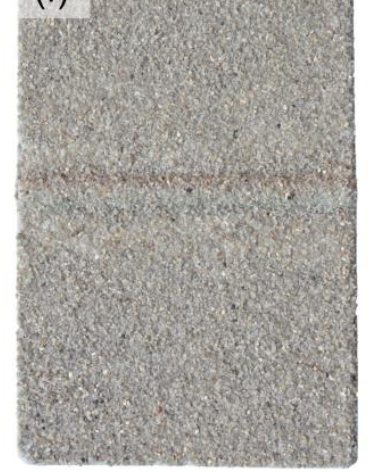

(c)

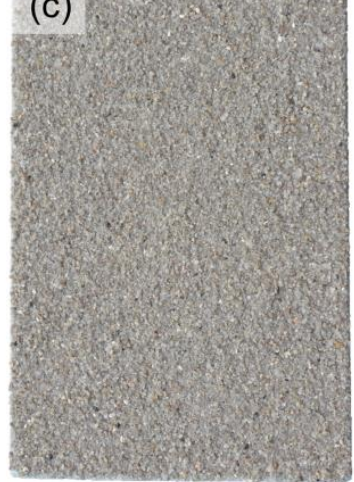

Figure 4.3: Orthogonal photographs of the seven types of manufactured concrete surface textures: (a) SCS; (b) RCS2; (c) RCS1; (d) RWCS1; (e) RWCS2; (f) RWCS3; and (g)

RWCS4. The concrete slabs had a width of $20 \mathrm{~cm}$ and a length of $30 \mathrm{~cm}$.

To evaluate surface roughness, a perfect flat plane was aligned to the surface point cloud using a best-fit command. For the RWCSs, a perfect plane with a single wave of varied height, according to the surface texture, was best fitted to the surface point cloud. The average roughness $(\mathrm{Ra})$ was determined as the average of the absolute values of the measured height deviations from the mean plane (ASME B46.1, 2009). Maximum roughness, which was determined as the maximum peak and valley height of the surface asperities, was normalized by the mean sand diameter to obtain the normalized roughness $(\mathrm{Rn})$.

In the second approach, image analyses were carried out using ImageJ software (Rasband, 2018) to evaluate the effect of the confinement condition before and after the IDST of surface plowing on the RCS1. Enhanced contrast and sharpening techniques were used to highlight the concrete surface (as opposed to the sand particles). After image processing, the red-green-blue (RGB) bands from 175 to 250 were selected to identify the authentic concrete surface color. However, due to the overlaying of RGB bands between the concrete surface and the sand particles, only areas greater than $0.15 \mathrm{~cm}^{2}$ were selected for analysis. 
The third approach used the extended multifocal micrographs of SCS, RCS1 and RCS2 before and after the IDST under a $100 \mathrm{kPa}$ CNL to observe the finest aspects of the surface. To perform multifocal imaging, it was necessary to focus on the lowest and highest elements of the surface. Then, it was possible to measure the height between the surface valleys and peaks before and after the IDST.

(a)

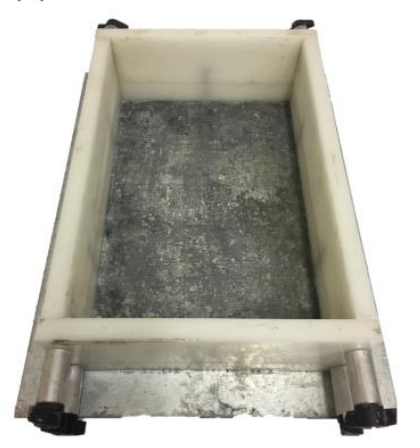

(d)

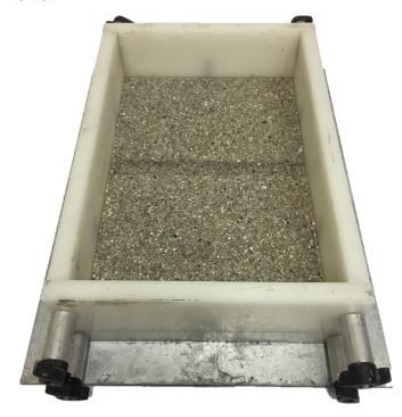

(b)

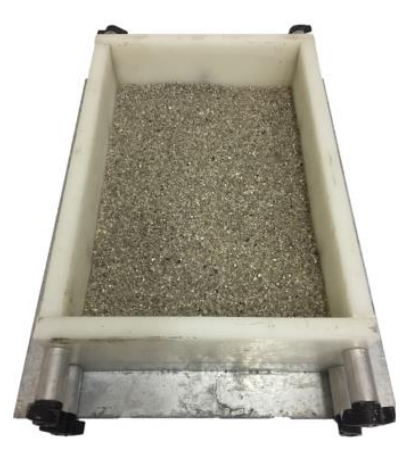

(e)

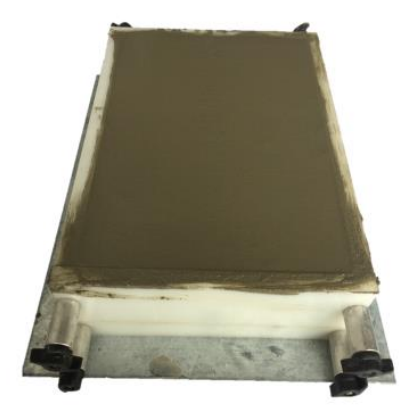

(c)

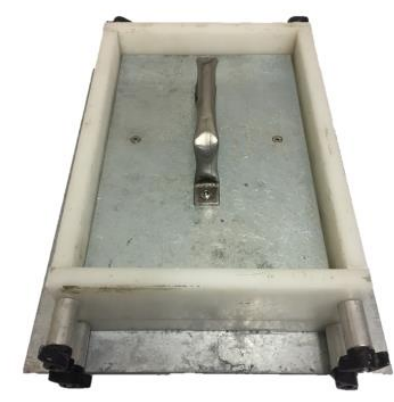

(f)

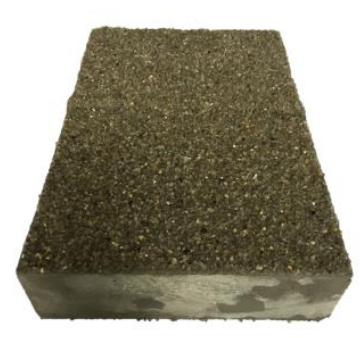

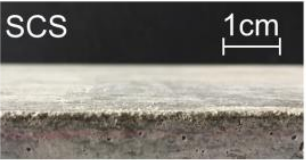
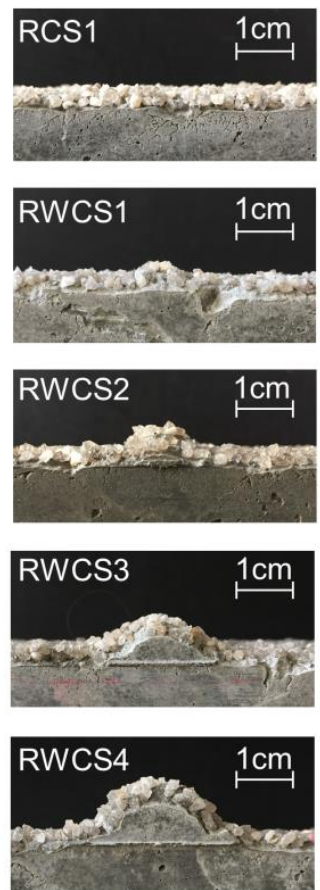

Figure 4.4: RCS1 and RWCS fabrication methodology: (a) proposed half container, (b) loose sand placement, (c) sand consolidation with the desired waviness profile, (d) sandy surface after consolidation, (e) fluid cement mortar placement and (f) RCS1 slab after 7 days of curing. On the right, the following surface profiles are shown: SCS, RCS1, RWCS1, RWCS2, RWCS3, and RWCS4.

\section{Experimental program}

The experimental program investigated the effects of the following variables: (i) surface structural characteristics, including the surface texture and surface plowing, (ii) relative density, and (iii) confinement conditions. The IDSTs were performed following the subsequent procedures: the concrete specimen was placed into the lower part of the shear box after being cured for 7 days; dense or loose sand specimens were prepared by placing a known mass of sand into the upper part of the shear box until a specified specimen height was 
achieved; and the sand was consolidated and then sheared monotonically under a CNL or a CNS condition with a horizontal displacement rate of $0.5 \mathrm{~mm} / \mathrm{min}$. This shear rate was established based on the available literature regarding experimental sand-solid interface direct shear tests. The sign convention for volumetric change was defined as negative for dilation and positive for contraction. The data acquisition rate was set at $1.0 \mathrm{~Hz}$, and the maximum shear displacement was limited to $18 \mathrm{~mm}$ due to the direct shear box modifications. Dense specimens were prepared with a relative density of $70 \%$, while loose specimens were prepared with a relative density of 30\%. The standard ASTM D3080 (2011) was used as a general guideline for the direct shear testing of soils under consolidated drained conditions.

A total of 48 IDSTs were performed under dry conditions. The specifications of all tests are listed in Table 4.3. All the IDSTs were performed using virgin concrete surfaces. The initial normal stresses, namely, 50, 100, and $250 \mathrm{kPa}$, were selected to range the normal effective stress that acts on the pile-soil system for most common geotechnical applications. Similarly, the chosen values of normal stiffness were 150,450 , and $900 \mathrm{kPa} / \mathrm{mm}$, which were applied to the IDSTs under CNS conditions. Although estimating the in situ normal stiffness is complex, Boulon and Foray (1986) related this stiffness to the shear modulus and diameter based on the elastic cavity expansion theory in an elastic material. To estimate the shear modulus, several authors proposed an empirical approach with a nonlinear shear modulus of sand with depth (Seed and Idriss, 1970; Hardin and Drnevich, 1972; Oztoprak and Bolton, 2013).

Table 4.3: List of tests performed.

\begin{tabular}{|c|c|c|c|c|c|c|c|}
\hline \multirow{3}{*}{$\begin{array}{l}\text { Sand } \\
\text { type }\end{array}$} & \multirow{3}{*}{ Concrete surface type ${ }^{a}$} & \multirow{3}{*}{ Reference $^{b}$} & \multirow{3}{*}{$\mathrm{D}_{\mathrm{r}}{ }^{c}$} & \multirow{2}{*}{$\mathrm{CNL}^{d}$} & \multicolumn{3}{|c|}{$\mathrm{CNS}^{e}$} \\
\hline & & & & & $150 \mathrm{kPa} / \mathrm{mm}$ & $450 \mathrm{kPa} / \mathrm{mm}$ & $900 \mathrm{kPa} / \mathrm{mm}$ \\
\hline & & & & Normal stress $(\mathrm{kPa})$ & \multicolumn{3}{|c|}{ Initial normal stress $(\mathrm{kPa})$} \\
\hline \multirow{6}{*}{ SP\#16 } & Smooth & SCS & 70 & 50,100 and 250 & 100 & 100 and 250 & 100 and 250 \\
\hline & Rough SP\#16 & $\mathrm{RCS} 1$ & 70 & 50,100 and 250 & 100 & 100 and 250 & 100 and 250 \\
\hline & Rough + Waviness of $2.5 \mathrm{~mm}$ & RWCS1 & 70 & 100 & & 100 & 250 \\
\hline & Rough + Waviness of $5.0 \mathrm{~mm}$ & RWCS2 & 70 & 100 & & 100 & 250 \\
\hline & Rough + Waviness of $7.5 \mathrm{~mm}$ & RWCS3 & 70 & 50,100 and 250 & 100 & 100 and 250 & 100 and 250 \\
\hline & Rough + Waviness of $10.0 \mathrm{~mm}$ & RWCS4 & 70 & 100 & & 100 & 250 \\
\hline \multirow{2}{*}{ SP\#100 } & Smooth & SCS & 70 & 100 & & 100 & 250 \\
\hline & Rough SP\#100 & RCS2 & 70 & 100 & & 100 & 250 \\
\hline \multirow{3}{*}{ SP\#16 } & Smooth & SCS & 30 & 100 & & 100 & 250 \\
\hline & Rough SP\#16 & RCS1 & 30 & 100 & & 100 & 250 \\
\hline & Rough + Waviness of $7.5 \mathrm{~mm}$ & RWCS3 & 30 & 100 & & 100 & 250 \\
\hline
\end{tabular}

Note: ${ }^{\mathrm{a}}$ relative description of the surface texture; ${ }^{\mathrm{b}}$ surface type abbreviation; ${ }^{\mathrm{c}}$ relative density $(\%) ;{ }^{\mathrm{d}}$ constant normal load condition; ${ }^{\mathrm{e}}$ constant normal stiffness condition. 


\section{Stiffness}

In order to simulate soil-pile interface, experimental test must be conducted under confinement conditions near field conditions. Equation 3.5 shows the reliance of the initial normal stress and normal stiffness to estimate the current normal stress.

Initial normal stress can be determined based on earth pressure coefficient and depth. Through tests on instrumented pile models under axial loading, Tehrani et al. (2016) concluded the average value of the lateral earth pressure coefficient increases with increasing soil density and pile surface roughness. In addition, these authors noticed that these coefficients for a real pile in dilative soil are higher than the at-rest earth pressure coefficient.

Estimate the in situ normal stiffness is a complex issue since it depends on several factors, such as pile diameter and shear modulus which also depends on the confining pressure, strain amplitude and void ratio. Many authors assume a non-linear shear modulus of sand with depth. Through experimental tests, Seed and Idriss (1970) have developed an empirical formulation to estimate the shear modulus at zero shearing strain amplitude $\left(\mathrm{G}_{\max }\right)$ of sandy soils (Equation 4.1).

$$
G_{\max }=1000 \cdot J \cdot p^{\prime 0,5}
$$

Where: $\mathrm{J}$ is a dimensionless number which depends on the relative density of the sand; and $p^{\prime}$ is the average effective stress. Guidelines for Design of Wind Turbines of DNV/Ris $\varnothing$ (2002) recommends $\mathrm{J}$ equal to 8 and 16 for loose and very dense sand, respectively. Hardin and Drnevich (1972) have also proposed an empirical approach based on the soil void ratio (Equation 4.2).

In addition, Oztoprak and Bolton (2013) have proposed an empirical formulation based on the atmospheric pressure $\left(\mathrm{p}_{\mathrm{a}}\right)$ and soil void ratio (Equation 4.3). The parameters $\mathrm{A}(\curlyvee)$ and $\mathrm{m}(\Upsilon)$ depend on the strain level $(\Upsilon)$. Assuming a small strain level, it is possible to approximate $\mathrm{G}$ to $\mathrm{G}_{\max }$.

$$
\begin{aligned}
G_{\text {max }} & =3230 \cdot \frac{(2,973-e)^{2}}{1+e} \cdot p^{0,5} \\
G & =\frac{A(\gamma) \cdot p_{a}}{(1+e)^{3}} \cdot\left(\frac{p^{\prime}}{p_{a}}\right)^{m(\gamma)}
\end{aligned}
$$


An analytical analysis of shear modulus with depth was performed in order to show the application of Equations 4.1, 4.2 and 4.3 (Fig. 4.5). In addition, Equation 4.1 was used to determine the stiffness according to depth for three different diameters (Fig. 4.6).
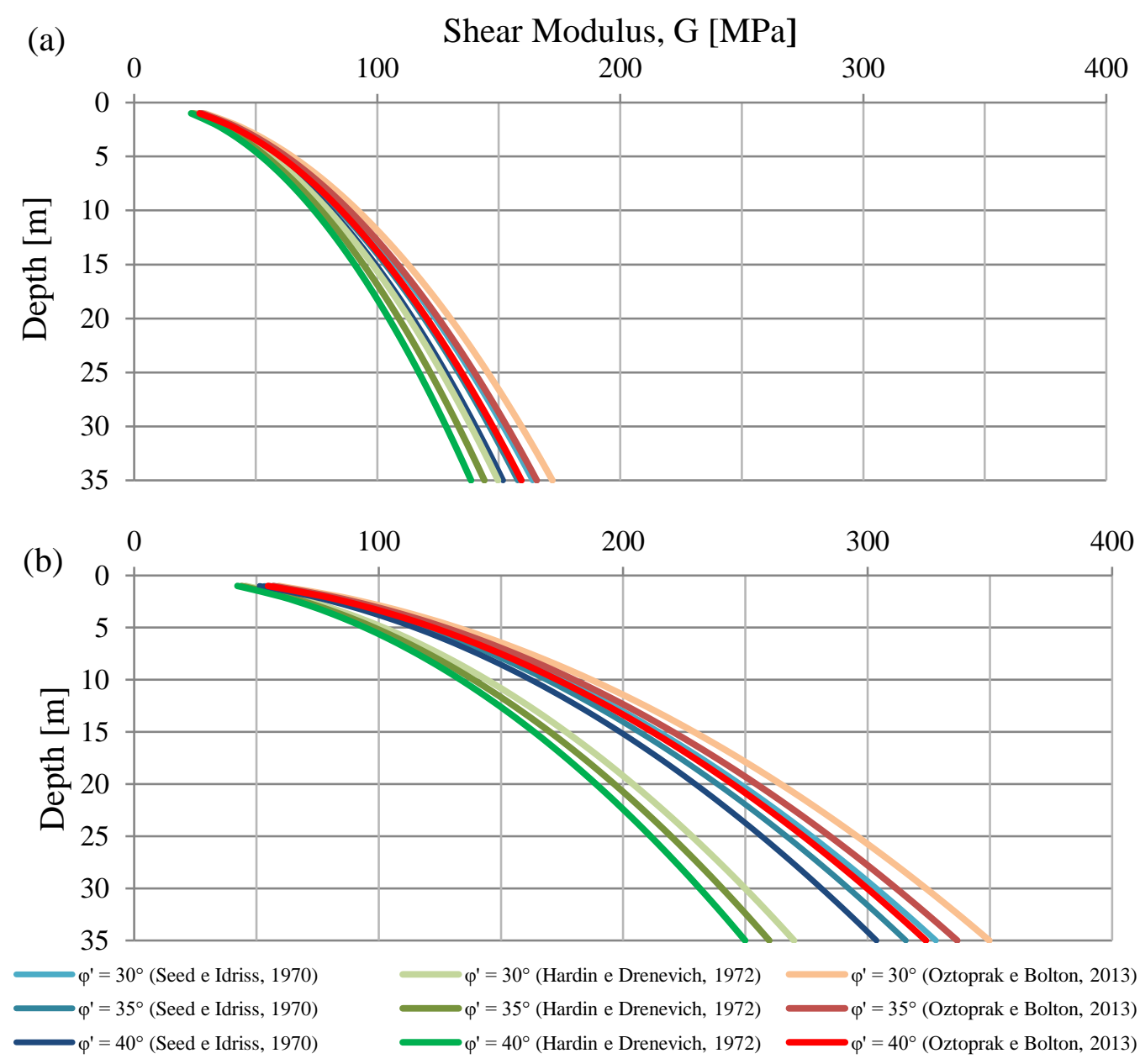

Figure 4.5: Shear modulus according to depth for several friction angles and different relative densities: (a) loose sand ( $e=0,9$ and $\mathrm{J}=8$ ) and (b) dense sand ( $\mathrm{e}=0,5$ and $\mathrm{J}=16$ ).

According to Oztoprak and Bolton (2013), the shear modulus should always be measured in situ if possible. Through instrumented piles tests in sand, it was observed that the radial effective stress strongly depend on the vertical distance from pile tip (Lehane et al., 1993; Gavin and O'Kelly, 2007) and the sand relative density (Lehane et al., 1993). In addition, the shaft capacity measured in tension was lower than in compression due to the effects of principal stress rotation in the sand mass and interface slip dilation (formation of a shear zone) (Lehane et al., 1993; Gavin and O’Kelly, 2007). Reddy et al. (2000) noticed the effects of interface slip dilation phenomena for small diameter piles. Also, these authors emphasize the effects of pile installation method on the radial effective stress. 
(a)
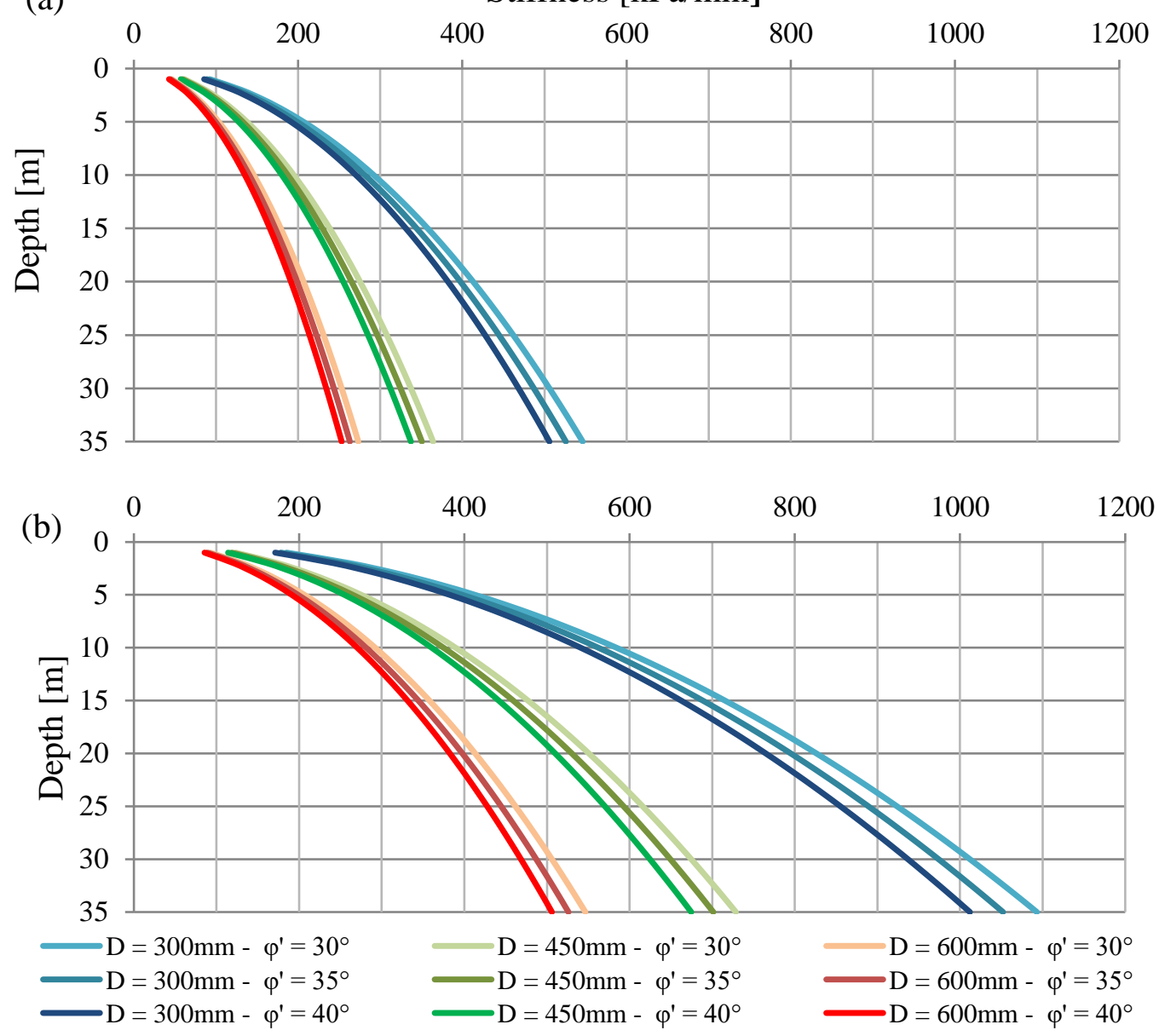

Figure 4.6: Stiffness versus depth for several pile diameters, friction angles and relative densities: (a) loose sand and (b) dense sand (Equations 3.6 and 4.1).

\subsubsection{Results}

The effects of the surface structural characteristics, which include surface roughness, surface waviness and surface plowing; relative density and confinement conditions are analyzed in the following sections. A summary of the test results is presented in Table 4.4. This table documents the interface strength envelopes and the interfacial-to-internal friction angle ratios for the seven types of surface textures tested. A linear strength envelope was demonstrated to fit well in all cases.

Additionally, Table 4.4 shows the average and normalized roughness values. The SCSs had an average roughness of $0.006 \mathrm{~mm}$ and a maximum roughness of $0.088 \mathrm{~mm}$, which corresponds to normalized roughness values of 0.366 and 0.051 for the SP\#100 and SP\#16 sand particles, respectively. The RCSs exhibited average roughness values of $0.049 \mathrm{~mm}$ and $0.418 \mathrm{~mm}$ for the SP\#100 and SP\#16 sand particles, respectively. The RCSs also had maximum roughness values of $0.598 \mathrm{~mm}$ and $4.812 \mathrm{~mm}$ corresponding to a normalized roughness values of 2.492 and 2.781 for the SP\#100 and SP\#16 sand particles, respectively. 
Because RCS1 and the RWCSs were made by pouring concrete against a SP\#16 sand surface, the average roughness was measured as the mean average roughness of these surfaces, and thus, an average roughness of $0.418 \mathrm{~mm}$ was obtained with a standard deviation of $0.021 \mathrm{~mm}$. The maximum roughness was approximately 12 times greater than the average roughness.

Table 4.4: Summary of the tests results.

\begin{tabular}{llllllllllll}
\hline $\begin{array}{c}\text { Sand } \\
\text { type }\end{array}$ & $\begin{array}{c}\text { Surface } \\
\text { type }\end{array}$ & $\mathrm{N}^{a}$ & $\mathrm{R}_{\mathrm{a}}{ }^{b}$ & $\mathrm{R}_{\max }{ }^{c}$ & $\mathrm{R}_{\mathrm{n}}{ }^{d}$ & $\mathrm{~W}^{e}$ & $\mathrm{D}_{\mathrm{R}}{ }^{f}$ & $\delta_{\mathrm{p}}$ & $\left(\frac{\delta}{\varphi}\right)_{p}$ & $\delta_{\mathrm{pp}}$ & $\left(\frac{\delta}{\varphi}\right)_{p p}$ \\
\hline & $\mathrm{SCS}$ & 8 & 0.006 & 0.088 & 0.051 & - & 70 & 35.1 & 0.88 & 30.7 & 0.90 \\
& RCS1 & 8 & 0.418 & 4.812 & 2.781 & - & 70 & 38.4 & 0.96 & 32.3 & 0.95 \\
& RWCS1 & 3 & 0.418 & 4.812 & 2.781 & 2.50 & 70 & 41.1 & 1.03 & 34.4 & 1.01 \\
SP\#16 & RWCS2 & 3 & 0.418 & 4.812 & 2.781 & 5.00 & 70 & 40.5 & 1.02 & 36.0 & 1.06 \\
& RWCS3 & 8 & 0.418 & 4.812 & 2.781 & 7.50 & 70 & 42.3 & 1.06 & 38.2 & 1.12 \\
& RWCS4 & 3 & 0.418 & 4.812 & 2.781 & 10.00 & 70 & 45.7 & 1.15 & 39.8 & 1.17 \\
\hline \multirow{2}{*}{ SP\#100 } & SCS & 3 & 0.006 & 0.088 & 0.366 & - & 70 & 32.1 & 0.90 & 27.5 & 0.89 \\
& RCS2 & 3 & 0.049 & 0.598 & 2.492 & - & 70 & 34.9 & 0.97 & 29.7 & 0.96 \\
\hline \multirow{2}{*}{ SP\#16 } & RCS1 & 3 & 0.006 & 0.088 & 0.051 & - & 30 & 32.5 & 0.95 & 30.5 & 0.89 \\
& RWCS3 & 3 & 0.418 & 4.812 & 2.781 & - & 30 & 32.8 & 0.96 & 31.9 & 0.93 \\
\hline NOtes & RCS & 0.418 & 4.812 & 2.781 & 7.50 & 30 & 38.8 & 1.13 & 38.8 & 1.13 \\
\hline
\end{tabular}

Notes: ${ }^{a}$ number of IDSTs performed; ${ }^{b}$ average roughness $(\mathrm{mm}) ;{ }^{\mathrm{c}}$ maximum roughness $(\mathrm{mm}) ;{ }^{\mathrm{d}}$ normalized roughness; ${ }^{\mathrm{e}}$ waviness $(\mathrm{mm}) ;{ }^{\mathrm{f}}$ relative density $(\%)$.

\section{Surface roughness}

The role of surface roughness is analyzed by comparing two extreme scenarios of pile surface, SCSs and RCSs, in terms of normalized roughness. The typically observed trends of the sand-sand friction and sand-concrete interface response are plotted in Fig. 4.7a and b. The SP\#16 sand sheared against SCS had the lowest normalized roughness $(\mathrm{Rn}=0.051)$, and it generated $67 \mathrm{kPa}$ and $63 \mathrm{kPa}$ of peak and post-peak shear stresses, respectively (Fig. 4.7a). Dilation was noticed (maximum normal displacement $=-0.35 \mathrm{~mm}$ ) following initial contraction (Fig. 4.7b). The SP\#100 sand sheared against SCS had a higher normalized roughness $(\mathrm{Rn}=0.366)$ than the $\mathrm{SP \# 16}$ sand sheared against SCS, and it developed a more pronounced post-peak softening, with $62 \mathrm{kPa}$ and $51 \mathrm{kPa}$ of peak and post-peak shear stresses, respectively (Fig. 4.7a). There was no significant variation in volume (maximum normal displacement $=-0.03 \mathrm{~mm}$ ) (Fig. $4.7 \mathrm{~b}$ ). The RCSs exhibited a normalized roughness of 2.492 and 2.781 for the SP\#100 and SP\#16 sands, respectively. The RCSs exhibited more pronounced post-peak softening and generated higher peak and post-peak shear stresses than SCSs. Dilation following an initial contraction was observed as well. The maximum shear 
stress and normal displacement (dilation) achieved for the SP\#16 sand sheared against RCS was $84 \mathrm{kPa}$ and $-1.65 \mathrm{~mm}$, respectively (Fig. 4.7a and b). For the SP\#100 sand sheared against RCS, the maximum shear stress and normal displacement (dilation) attained was 72 $\mathrm{kPa}$ and $-0.55 \mathrm{~mm}$, respectively (Fig. 4.7a and b).

The shear stresses and the volumetric behavior of the sand-concrete interface were similar to the sand-sand response. The shear stress developed while testing the RCSs was limited to sand shear stress, while the IDSTs on the SCSs developed lower values. In terms of volumetric behavior, pure sand shearing showed a larger amount of dilation than RCS, which showed a larger amount than SCS (Fig. 4.7b). The relationship between the sand-sand friction and sand-concrete interface response explains the lower shear stress and dilation observed for SP\#100 sand sheared against SCS in comparison with SP\#16 sand sheared against SCS, despite the higher normalized roughness value.

The peak and post-peak interfacial-to-internal friction angle ratios obtained are presented in Fig. 4.7c, which considered all IDST results (Table 4.4). The peak and post-peak interfacial-to-internal friction angle ratios ranged from $88 \%$ to $90 \%$ for SCSs (Fig. 4.7c). The angular shape of the sand particles increases the relative roughness of the sand-concrete interface, thus resulting in greater interfacial-to-internal friction angle ratios. The interfacialto-internal friction angle ratios of the RCSs ranged from approximately 95\% to 97\% (Fig. 4.7c). Those values indicate that perfect sand-sand friction did not occur, as the interface strength was inferior to the surrounding sand strength.

The effect of surface roughness on the interface response is also captured through the IDSTs for SP\#16 and SP\#100 sheared against the SCSs and RCSs under several confinement conditions (Fig. 4.8a-h). Almost all IDST results showed an initial contraction that is followed by a dilation, which resulted in the development of higher normal and shear stresses under the CNS condition. SP\#100 sand sheared against SCS, however, exhibited minimal normal displacement and almost no increase in the normal and shear stresses under the CNS condition (Fig. 4.8d).

Due the greater normalized roughness, the IDSTs on the RCS generated higher peak and post-peak shear strengths for the same confinement conditions. This greater shear resistance was the result of the higher values of interface friction angle and the higher normal stresses developed under the CNS conditions; the mean sand diameter directly influenced the amount of normal and shear stress developed under the CNS condition as well. The increase in the normal and shear stresses were significantly different for SP\#16 (Fig. 4.8b and f) and SP\#100 (Fig. 4.8d and h) sands, which clearly shows the importance of sand behavior on 
interface strength under the CNS condition. Fig. 4.8a and e show significant variability in the stress ratio during shearing, especially in the first few millimeters of the shear displacement of the RCS. This variability could be associated with the amount of dilation depending on the normal stress and mean sand diameter. The manufacturing process of the RCSs could be another factor, as the RCSs exhibited greater surface roughness variability than SCSs.
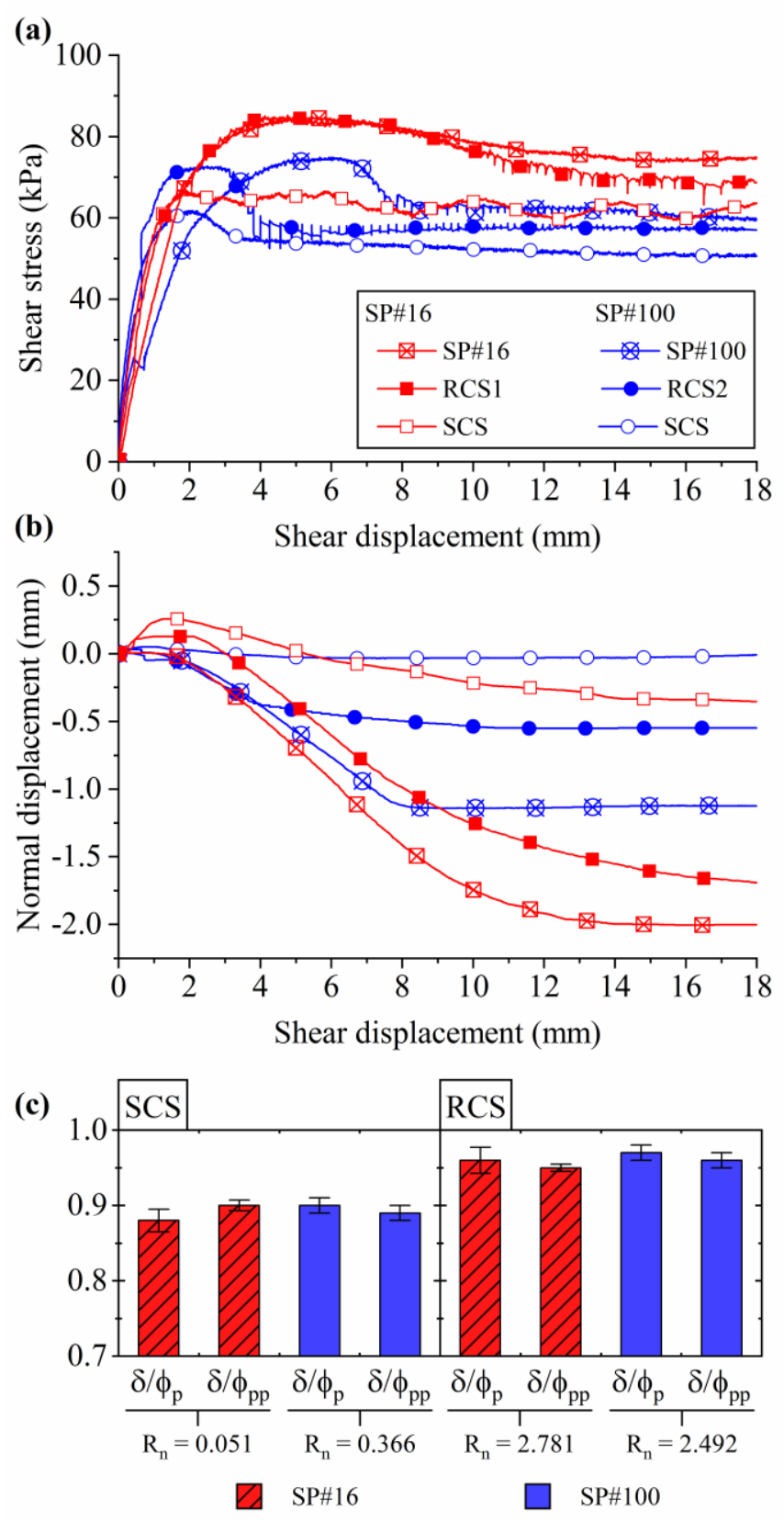

Figure 4.7: Effect of normalized roughness on the interface behavior and strength of dense SP\#16 and SP\#100 sand specimens sheared against SCSs and RCSs: (a) shear stress versus shear displacement; (b) normal displacement versus shear displacement; and (c) bar chart of all interfacial-to-internal friction angle ratios obtained (Table 4.4). Additionally, the results of the SP\#16 and SP\#100 sands are shown. 

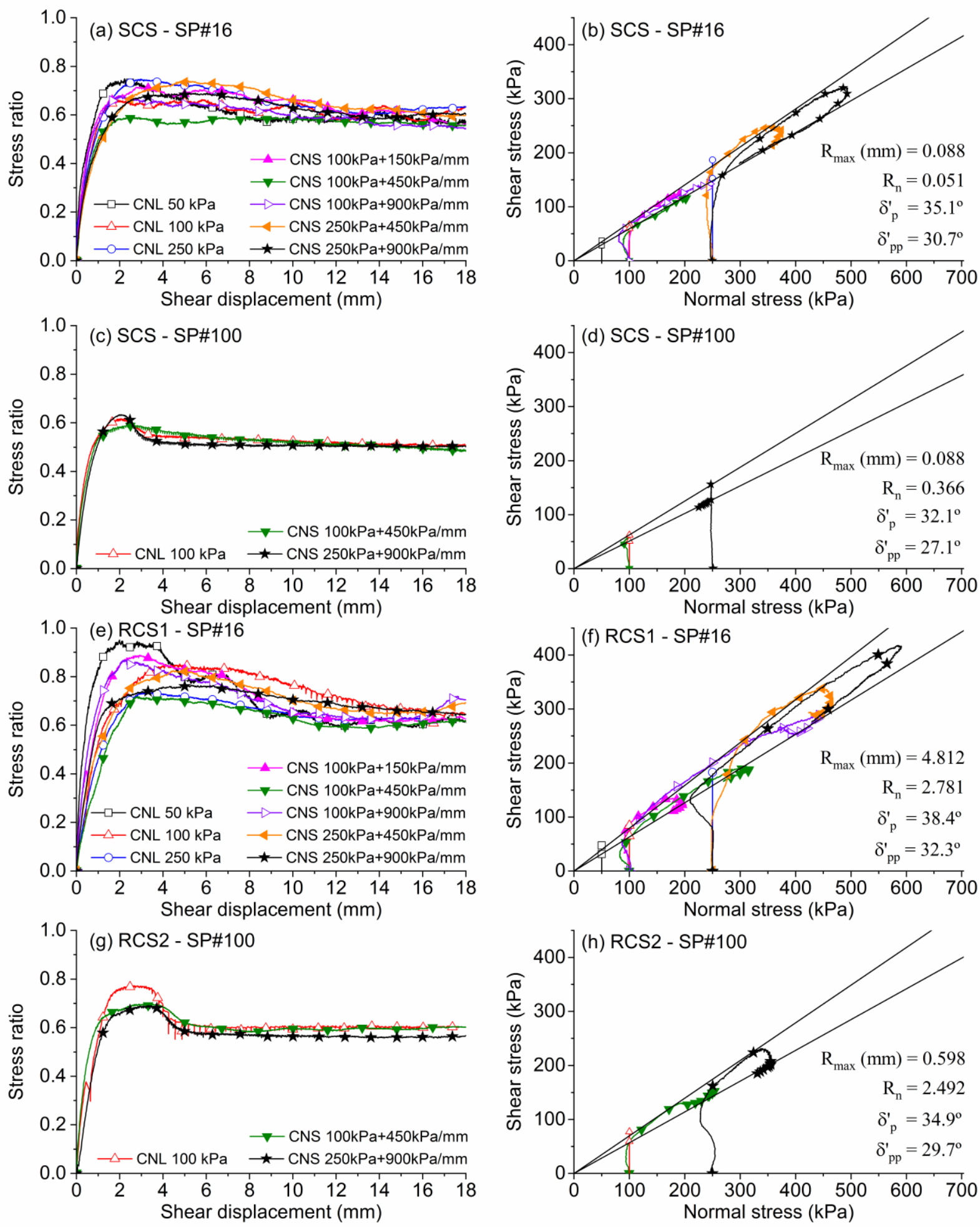

Figure 4.8: Influence of surface roughness at the sand-concrete interface: SCS sheared against (a, b) SP\#16 sand and (c, d) SP\#100 sand; and RCS sheared against (e, f) SP\#16 sand and (g, h) SP\#100 sand. 


\section{Surface waviness}

Surface texture is composed of finely spaced irregularities and widely spaced elevations, which are referred to as surface waviness. The response of dense SP\#16 sand specimens sheared against the RWCSs is plotted in Fig. 4.9. The IDSTs on the RWCSs typically developed dilation. Under the CNS condition, an increase in the current normal stress and, consequently, the shear stress, were observed. As surface waviness increased, higher stress ratios were developed and the peak and post-peak shear stresses were increased. However, a significant variability in the stress ratios was measured, especially for the first few millimeters of shear displacement (Fig. 4.9a,c,e and g). Additionally, the IDSTs on the RWCSs under high normal stress values led directly to a post-peak state (Fig. 4.9b,d,f and h). The interfacial-to-internal friction angle ratio developed a " $\delta>\varphi$ condition". This increase in the interface strength of the RWCSs can be associated with two strength components: friction and passive. This higher interfacial-to-internal friction angle ratio can be used to maximize the performance of geotechnical systems, such as load transfer through the skin friction of piles.

However, many IDSTs on the RWCSs showed an unexpected increase in stress ratio (Fig. 4.9a,c,e and g), in which the stresses did not follow the expected strength envelopes (Fig. 4.9b,d,f and h). This issue developed due to an experimental boundary effect. A failure surface, which was theoretically and experimentally investigated by Irsyam and Hryciw (1991), applied a compression force against the opposite side of the upper shear box, as passive strength was mobilized during testing (Fig. 4.10a). The influence of wave height and normal stress on this boundary effect is exhibited in Fig. 4.10b. As normal stress and wave height increased, the boundary effect appeared and a smaller shear displacement was required to develop it. This boundary effect could be prevented by using a larger shear box, a smaller wave height or a lower normal stress. Despite this boundary effect, as surface waviness increased, the results clearly show an increase in stress ratio and apparent friction angle. The increase in the apparent friction angle according to wave height is plotted in Fig. 4.11a. Both the peak and post-peak apparent friction angles increased almost linearly with surface waviness for the range of wave heights investigated.

A suitable way to assess the effect of waviness on interface strength is through the normalized waviness, i.e., the wave height divided by the distance between adjacent waves. Fig. $4.11 \mathrm{~b}$ shows the increase in the peak and post-peak interfacial-to-internal friction angle ratios as normalized waviness increased. The post-peak interfacial-to-internal friction angle 
ratio had a higher rate of increase than the peak interfacial-to-internal friction angle ratio. For clarity, a wave spacing equal to a shear box length of $200 \mathrm{~mm}$ was considered.
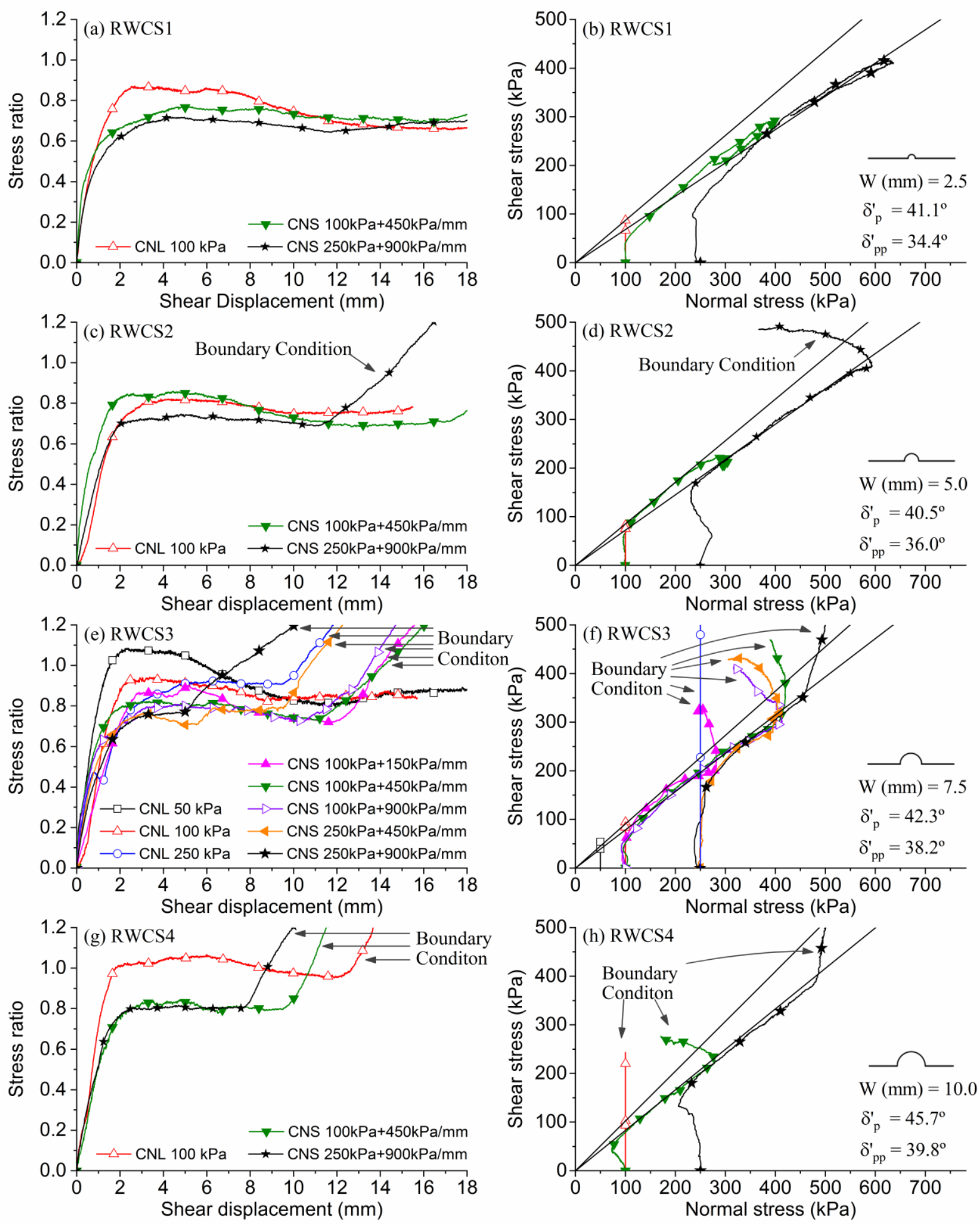

Figure 4.9: Stress ratio-displacement curves and stress path for SP\#16 sheared against several rough-wave concrete surfaces: (a, b) RWCS1; (c, d) RWCS2; (e, f) RWCS3; and (g, h)

RWCS4. 


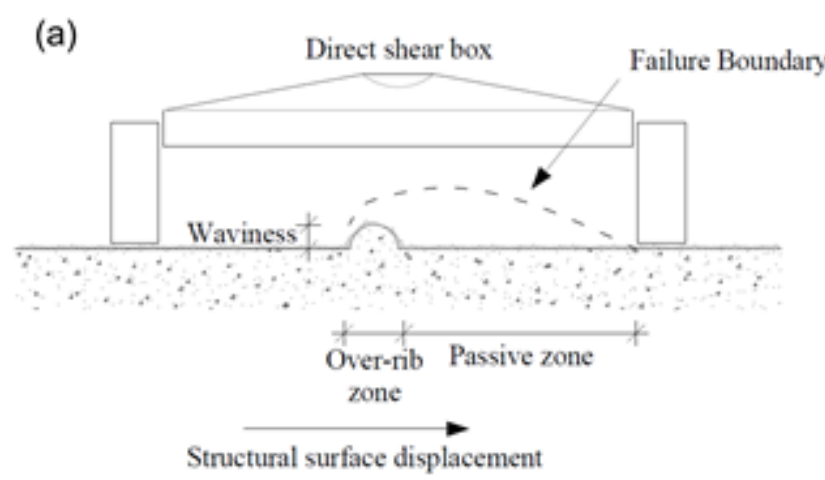

(b)

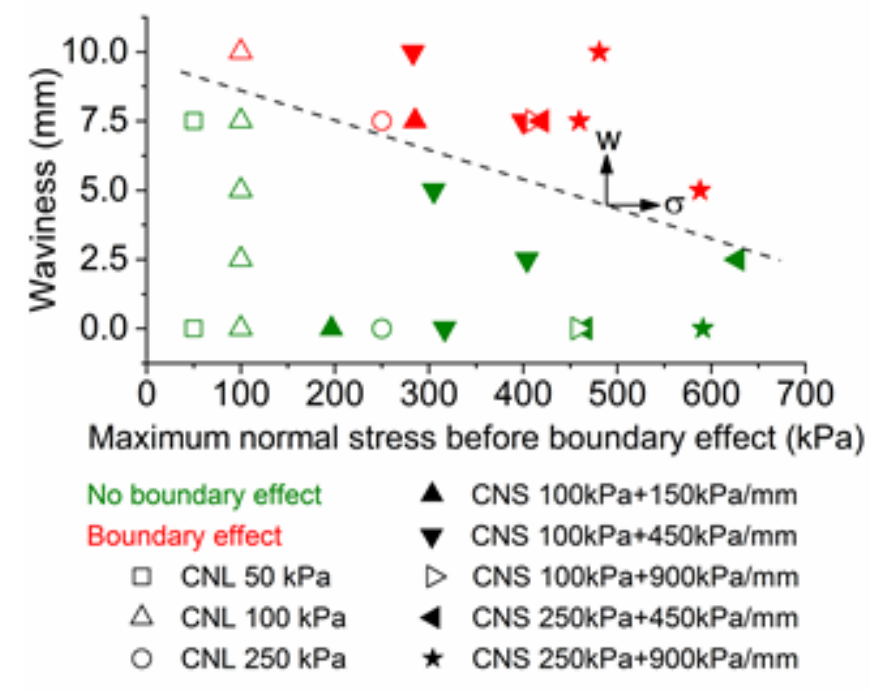

Figure 4.10: Boundary effect developed during testing: (a) schematic view of the passive strength mobilized during the IDSTs; (b) surface waviness versus maximum normal stress before the boundary effect for all IDSTs of the RWCSs.

Fig. 4.12 presents a conceptual nonlinear regression of the post-peak interfacial-tointernal friction angle ratio according to normalized roughness and normalized waviness. For a normalized waviness of zero, a maximum interfacial-to-internal friction angle ratio of 0.952 was used according to the RCS1 interface results (Fig. 4.11b). Additionally, a minimum interfacial-to-internal friction angle ratio of 0.780 was used based on several studies, including the results obtained herein, of the median interface strength between angular sands and SCSs (Brumund and Leonards, 1973; Uesugi et al., 1990; Gómez et al., 2008; Tiwari and Al-Adhadh, 2014). For low normalized waviness values (ranging 0.00 to 0.05 ), a linear increase of the interfacial-to-internal friction angle ratio was obtained (Fig. 4.12). Parallel nonlinear curves were considered, as no literature was currently available; however, the curvature and amplitude are expected to decrease as the normalized waviness increases. According to Irsyam and Hryciw (1991), the maximum interface strength is achieved when the rib spacing is approximately 10 times the wave height, which is equivalent to a 
normalized waviness of 0.10 . If the normalized waviness increases beyond this point, interface strength decreases, thus inhibiting passive resistance. For example, Samanta et al. (2018b) and Su et al. (2018) used normalized waviness values of 0.25 and 0.50 , respectively, and these authors achieved interfacial-to-internal friction angle ratios under 1.0. Different from the results presented herein, these studies were focused on the performance of the sandsteel interface with triangular- and square-spaced ribs. From a practical viewpoint, the concept of normalized roughness has to be coupled with normalized waviness to estimate the interface strength, especially for concrete structures cast in situ, foe which a marked waviness profile is expected.

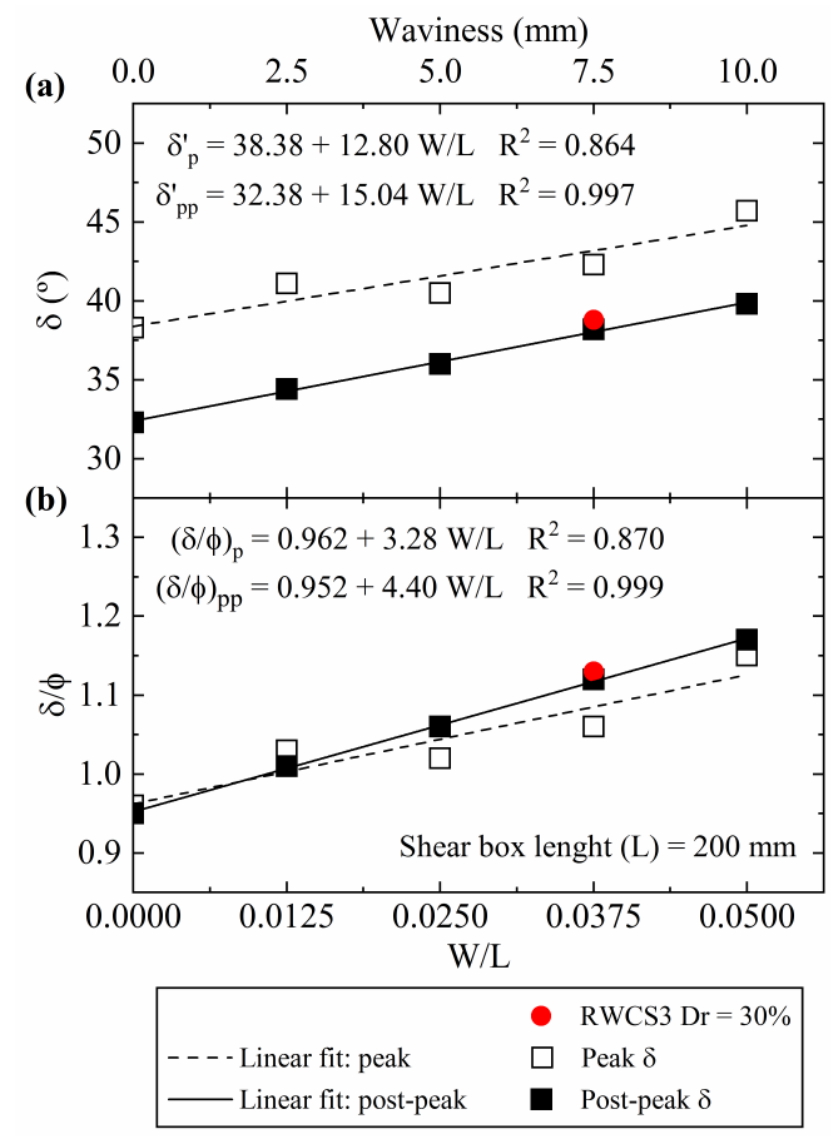

Figure 4.11: Effect of surface waviness on the (a) peak and post-peak apparent friction angle and (b) on the peak and post-peak interfacial-to-internal friction angle ratios. Results of the IDSTs on the RCS and RWCSs sheared against SP\#16 sand specimens. 


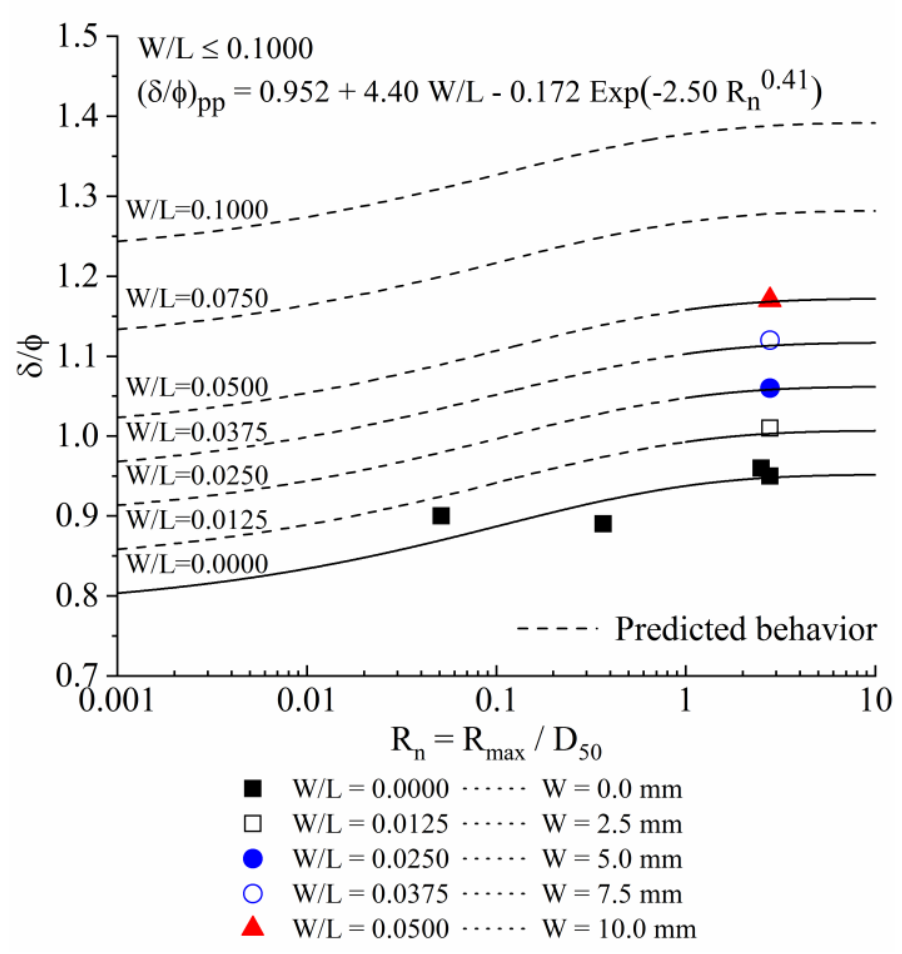

Figure 4.12: Conceptual model of the interface strength according to the normalized roughness and normalized waviness. Results from the IDSTs on the RCS and RWCSs sheared against dense SP\#16 sand specimens.

\section{Surface plowing}

A visual inspection of the RCSs and RWCSs before and after the IDST showed surface plowing was performed, as the sand particles were detached from the surface during shear displacement. To confirm these observations, three approaches were used. The first approach used image analysis to quantify the influence of the confinement conditions on RCS1. As shown in Figure 4.13, the IDST clearly damaged the surface, as the exposed concrete areas increased after testing. This effect could be captured for all normal loads, including the $50 \mathrm{kPa} C N L$ condition. An increase in the initial normal stress and imposed stiffness increased the exposed concrete areas of RCS1 (Fig. 4.13). Quantitatively, the higher peak shear stresses developed under various confinement conditions resulted in greater surface plowing (Fig. 4.14). However, as peak shear stress increased, a nonlinear increase in the exposed concrete areas was observed; thus, the limit value of the range of peak shear stress was investigated. No significant relationship between the stress ratio and the percentage of exposed concrete areas greater than $0.15 \%$ was verified. 
(a)

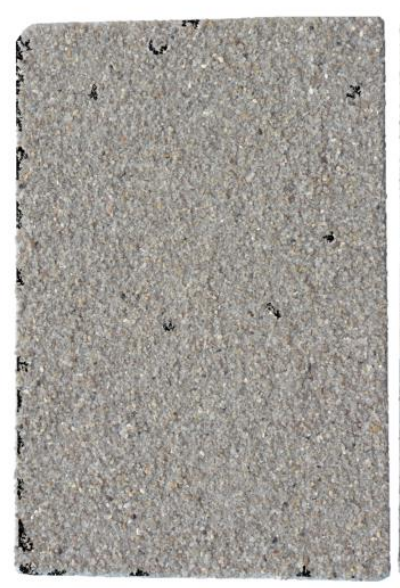

(b)

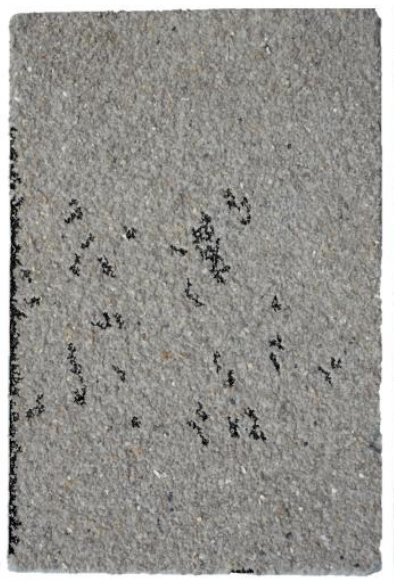

(c)

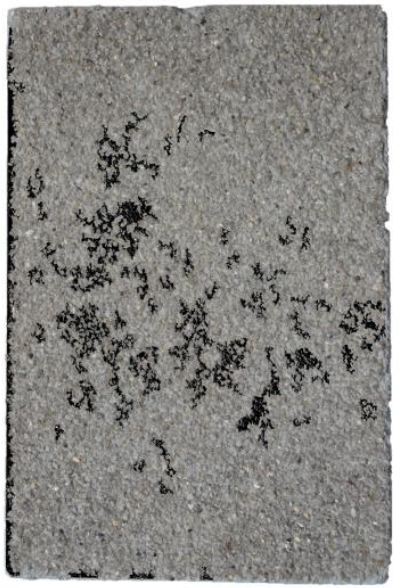

(d)

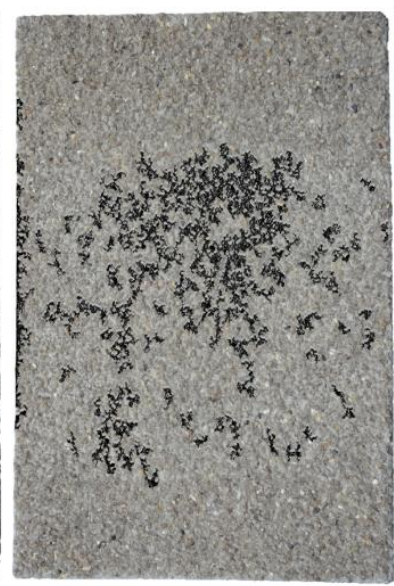

Figure 4.13: RCS1 exposed concrete areas greater than $0.15 \mathrm{~cm}^{2}$ captured by image analysis: (a) before IDST; (b) after IDST under CNL $50 \mathrm{kPa}$; (c) after IDST under CNL $100 \mathrm{kPa}$; (d) after IDST under CNS $100 \mathrm{kPa}+900 \mathrm{kPa} / \mathrm{mm}$. The concrete slabs have a width of $20 \mathrm{~cm}$ and a length of $30 \mathrm{~cm}$.

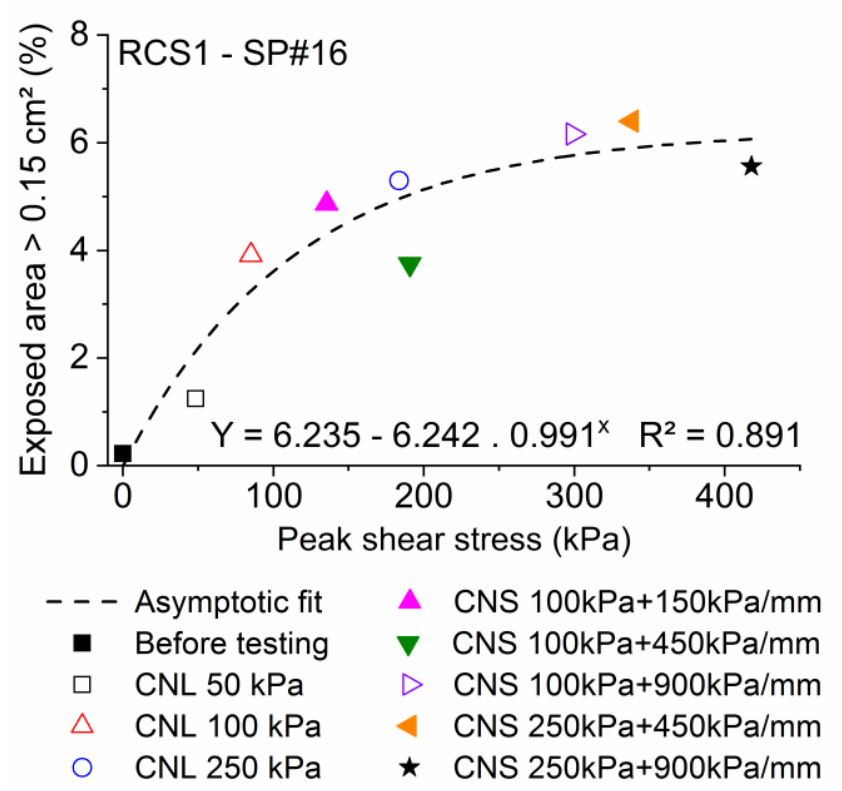

Figure 4.14: Effect of the confinement conditions on the surface damage of RCS1 sheared against the SP\#16 dense specimens captured by image analysis.

In the second approach, RCS1 and the RWCSs were scanned with DSA before and after the IDST under a $100 \mathrm{kPa}$ CNL to evaluate the effect of surface waviness on surface plowing. As shown in Figure 4.15, the surface textures changed after testing. A more evident impact was observed for flat RCS1, while RWCS4 concentrated this change at the top part of the waviness. Surface roughness was modified after the IDST under a $100 \mathrm{kPa}$ CNL on RCS1 and the RWCSs, as shown in Figure 4.16. An asymptotic curve demonstrated a satisfactory fit with an asymptote established at 100.00 of the average roughness ratio. The RCS1 and RWCS 
of $2.5 \mathrm{~mm}$ and $5.0 \mathrm{~mm}$ reduced the average roughness values after the IDST. RCS1 exhibited an average roughness of $81.65 \%$ of the initial value after the IDST. However, depending on the confinement condition, this average roughness value can be modified (Fig. 4.14). RWCS3 and RWCS4 showed no significant change in the average roughness after the IDST. With greater surface wave heights, the trend of the average roughness remained almost unchanged. The increase in surface waviness and consequently, passive strength, led to less surface plowing, probably because the shear zone moved away from the interface (Fig. 4.10a).
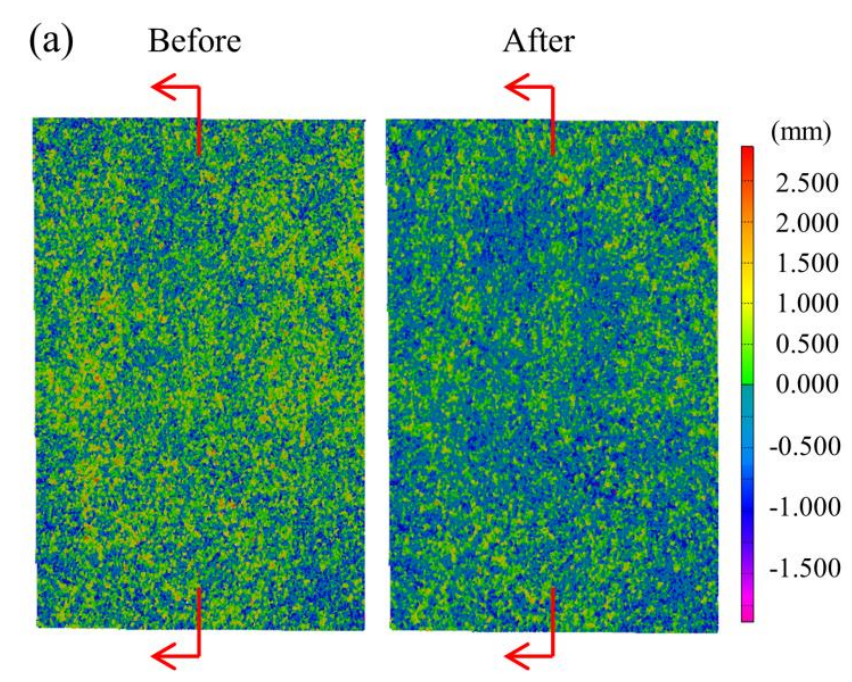

(b)
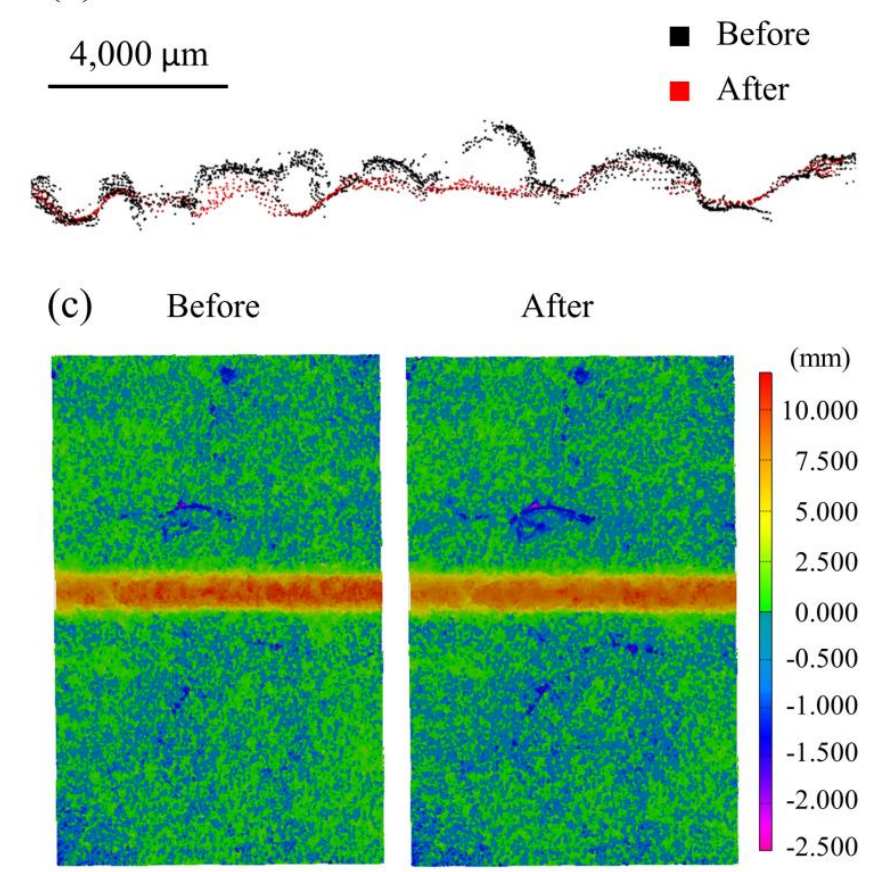

Figure 4.15: Surface texture before and after the IDST under a $100 \mathrm{kPa}$ CNL by DSA measurements for (a) RCS1 and (c) RWCS4. (b) A segment of the point cloud section with a width of $0.7 \mathrm{~mm}$ shows surface plowing after the IDST of RCS1 (a). The surface images have a width of $20 \mathrm{~cm}$ and a length of $30 \mathrm{~cm}$. 


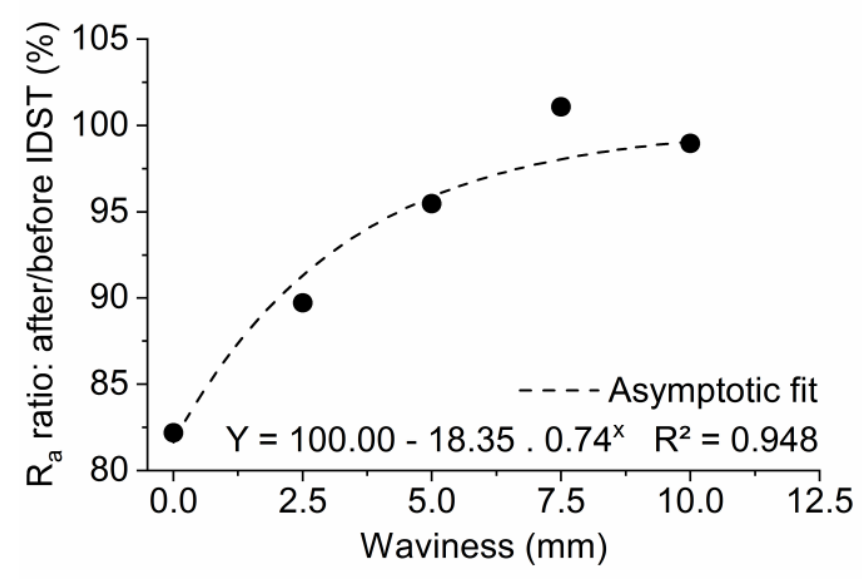

Figure 4.16: Effect of surface plowing on the average roughness of the IDST under a $100 \mathrm{kPa}$ CNL. Results from RCS1 and RWCSs sheared against the SP\#16 dense specimens.

The third approach used micrographs of SCS, RCS1 and RCS2 to observe surface plowing of the most finely spaced irregularities. Figure 4.17 displays micrographs before and after the IDST under a $100 \mathrm{kPa}$ CNL. For SCS, some microscopic irregularities were removed from the surface and a few scratches could be identified. For RCS, many SP\#16 and SP\#100 particles detached from the surface. This behavior could be evidence that weak bonds between sand particles and concrete tend to break during shearing. However, strong bonds remained unbroken (or at least no signs of damage could be identified). Additionally, the heights between the peaks and valleys changed after the IDSTs for RCS1, while this was not verified for RCS2. 
Before IDST under $100 \mathrm{kPa}$ CNL

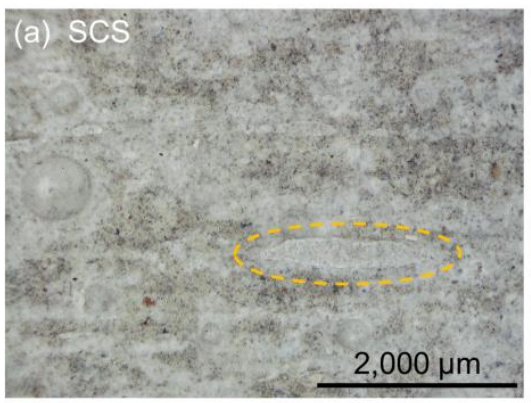

After IDST under $100 \mathrm{kPa}$ CNL
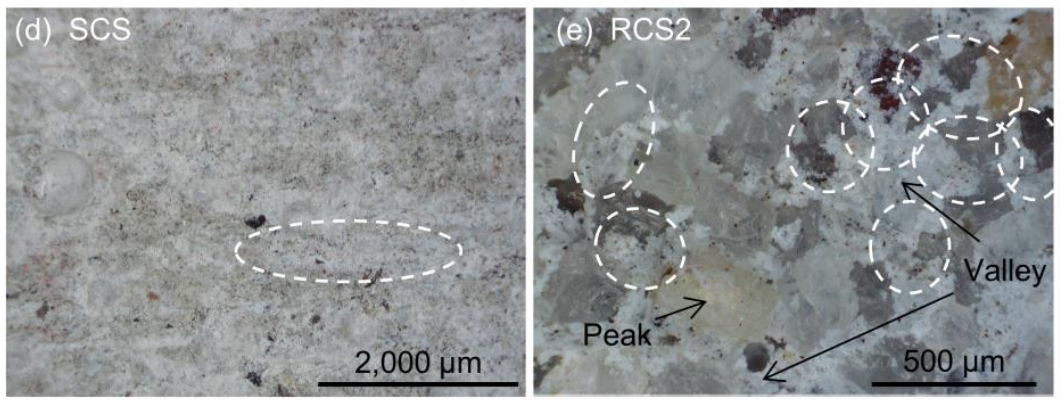

$\Delta Z_{\text {(peak - valley) }}=0.30 \mathrm{~mm} \approx 1.65 \mathrm{D}_{50}$

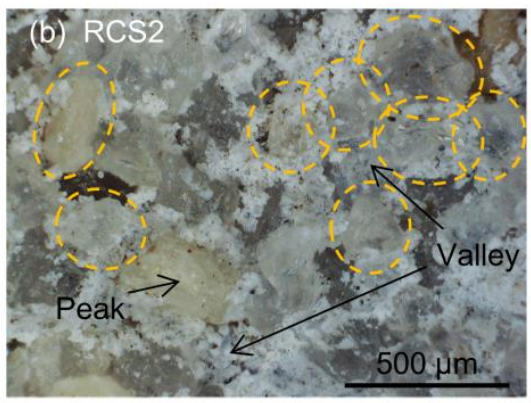

$\Delta Z_{\text {(peak - valley) }}=0.30 \mathrm{~mm} \approx 1.65 \mathrm{D}_{50}$

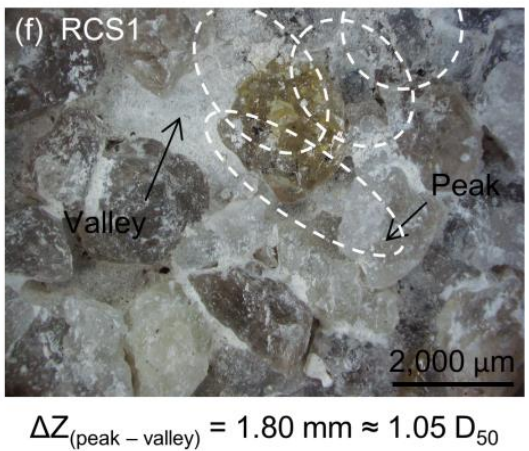

Figure 4.17: Extended multifocal micrographs before and after the IDST under a $100 \mathrm{kPa}$ CNL for SCS (a, d), RCS2 (b, e) and RCS1 (c, f).

\section{Effect of the relative density}

The influence of the relative density of dense and loose SP\#16 specimens sheared against SCS, RCS1 and RWCS3 is plotted in Fig. 4.18. In terms of stress ratio, dense specimens showed a pronounced strain-softening behavior while loose specimens had a strain-hardening behavior (Fig. 4.18a-c), especially for RCSs. The bar chart of the peak and post-peak interface friction angles clearly shows that the post-peak interface friction angles were independent of the initial relative density, regardless of surface texture. The peak interface friction angles of dense sand specimens were significantly higher those of loose sand specimens, especially for RCS1 and RWCS3. This peak interface friction angle difference was less remarkable for the IDSTs on SCSs, which is expected, as a less pronounced dilation difference is observed between loose and dense sand specimens sheared against SCSs (Fig. $4.18 \mathrm{~g}-\mathrm{i})$.

Fig. 4.18d-f captured the effect of relative density on interface strength and behavior through shear stress-displacement curves. The relative density had a very significant effect on the IDSTs under the CNS conditions (Fig. 4.18d-f). Due to the rotation of the upper part of the shear box, grain leakage was more considerable in specimens with low relative density, and a reduction in the post-peak shear stress was thus developed (Fig. 4.18d-i). Despite this 
effect, the imposed stiffness had a significant impact when comparing the dense and loose specimens sheared against RCS1 and RWCS3 results. For example, loose sand specimens sheared against RCS1 and RWCS3 achieved lower shear stresses than SCSs (Fig. 4.18d-f). For SCS sheared against the loose and dense SP\#16 specimens, the impact of relative density under the CNS condition was less pronounced (Fig. 4.18d).
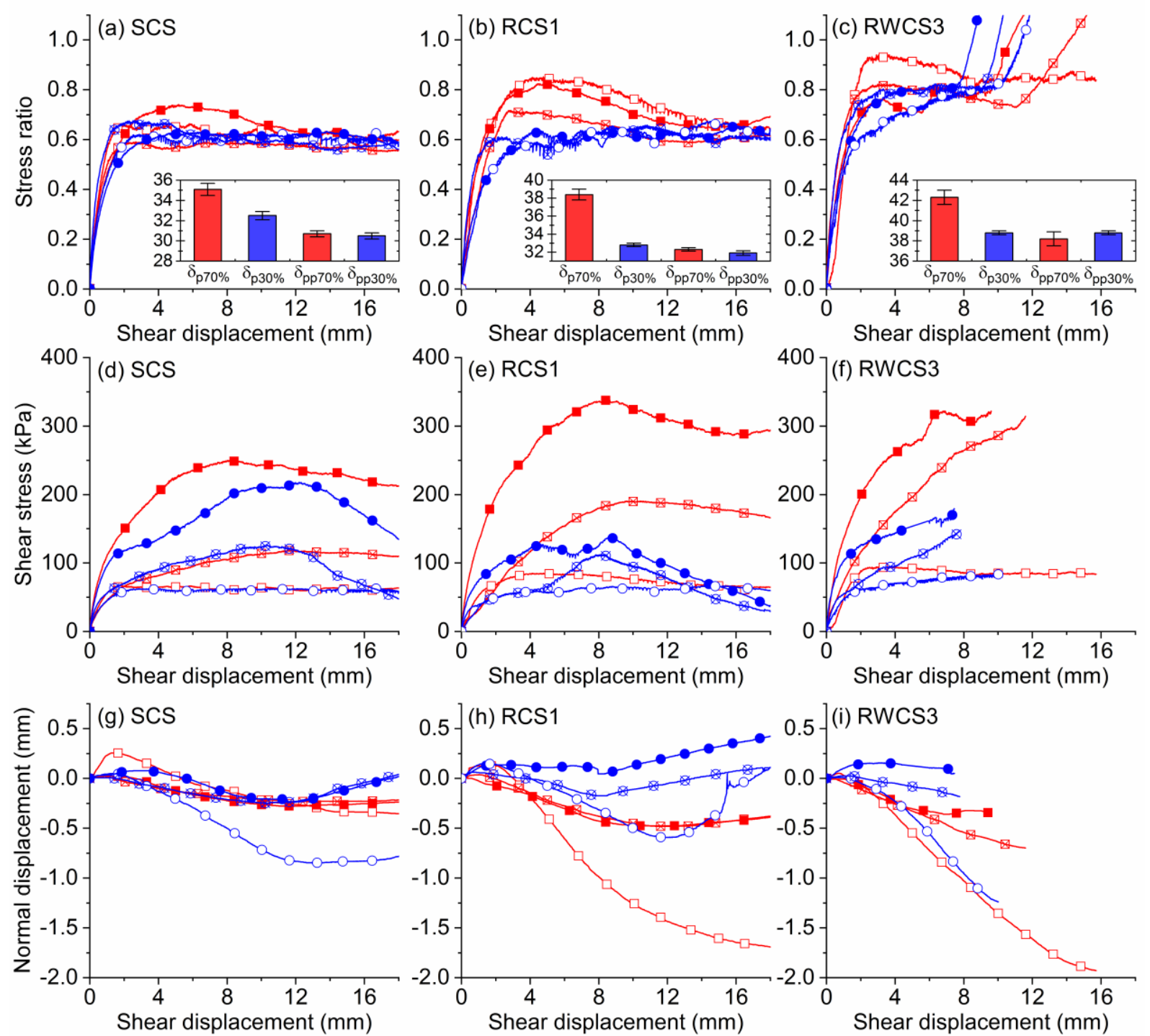

Relative density of 70\%: $-\square \mathrm{CNL} 100 \mathrm{kPa} \longrightarrow \mathrm{CNS} 100 \mathrm{kPa}+450 \mathrm{kPa} / \mathrm{mm} \longrightarrow \mathrm{CNS} 250 \mathrm{kPa}+450 \mathrm{kPa} / \mathrm{mm}$ Relative density of 30\%: — - CNL $100 \mathrm{kPa}$ CNS $100 \mathrm{kPa}+450 \mathrm{kPa} / \mathrm{mm} \longrightarrow \mathrm{CNS} 250 \mathrm{kPa}+450 \mathrm{kPa} / \mathrm{mm}$

Figure 4.18: Influence of relative density on interface behavior and strength. Results from IDSTs of SP\#16 sheared against: (a, d, g) SCS; (b, e, h) RCS; and (c, f, i) RWCS3. A bar chart of the peak and post-peak interface friction angles obtained in all the IDSTs is shown (a, $\mathrm{b}, \mathrm{c})$.

Fig. 4.19 displays the effects of initial relative density on the peak and post-peak interfacial-to-internal friction angle ratios for SCS, RCS1 and RWCS3. It was noticed that 
the post-peak interfacial-to-internal friction angle ratio is independent of relative density, regardless of surface texture. However, the peak interfacial-to-internal friction angle ratio increased as the relative density decreased, especially for SCS and RWCS3. The reason for this result is that the sand peak friction angle is more sensitive to relative density than peak interface friction angle (i.e., the rate of increase of the sand peak friction angle is relatively higher than that of the interface peak friction angle due the larger amount of dilation).

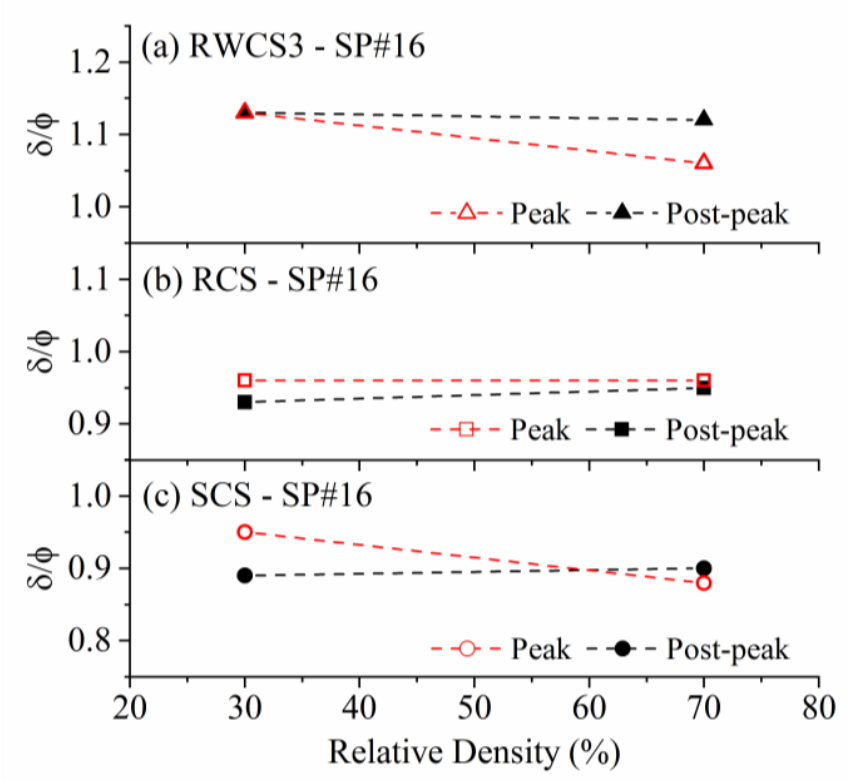

Figure 4.19: Effect of initial relative density on the peak and post-peak interfacial-to-internal friction angle ratios. Results of IDSTs on SP\#16 sand sheared against (a) RWCS3, (b) RCS1 and (c) SCS.

\section{Effect of confinement conditions}

Interface strength and behavior is significantly influenced by the confinement condition. Fig. 4.20a and d show the effect of the increase of normal stress for IDSTs on dense SP \#16 sand specimens sheared against SCS, RCS1 and RWCS3. The increase in the normal stress resulted in an increase in the shear stress, while the stress ratio remained unaltered, as previously mentioned. Additionally, the soil mass was less dilative as the normal stress increased, regardless of the surface texture (Fig. 4.20d).

Fig. 4.20b,c,e and f show the effect of the imposed stiffness for IDSTs on the dense SP\#16 sand specimens sheared against SCS, RCS1 and RWCS3. The dilative behavior of the interface led to an increase in the current normal stress and, consequently, an increase in the shear stress. Additionally, higher shear displacements were required to achieve the peak shear stress (Fig. 4.20b and c). For example, the IDSTs under CNS conditions developed a peak 
shear stress for 8 to $11 \mathrm{~mm}$ of shear displacement, while the IDSTs under CNL conditions exhibited values of approximately 2 to $3 \mathrm{~mm}$. In the final part of shear displacement, grain leakage was observed due to the rotation of the upper shear box, especially for the IDSTs under the CNS condition with $250 \mathrm{kPa}$ of initial normal stress (Fig. 4.20c). Thus, the decrease in the post-peak shear stress in the IDSTs under CNS conditions was due to the reduction in soil volume and, consequently, the current normal stress. Under realistic conditions, the pile surrounding soil could be considered a confined system and minimal post-peak volume change would occur. Despite these changes in stress-displacement behavior, the stress ratio versus displacement curves remained unchanged.
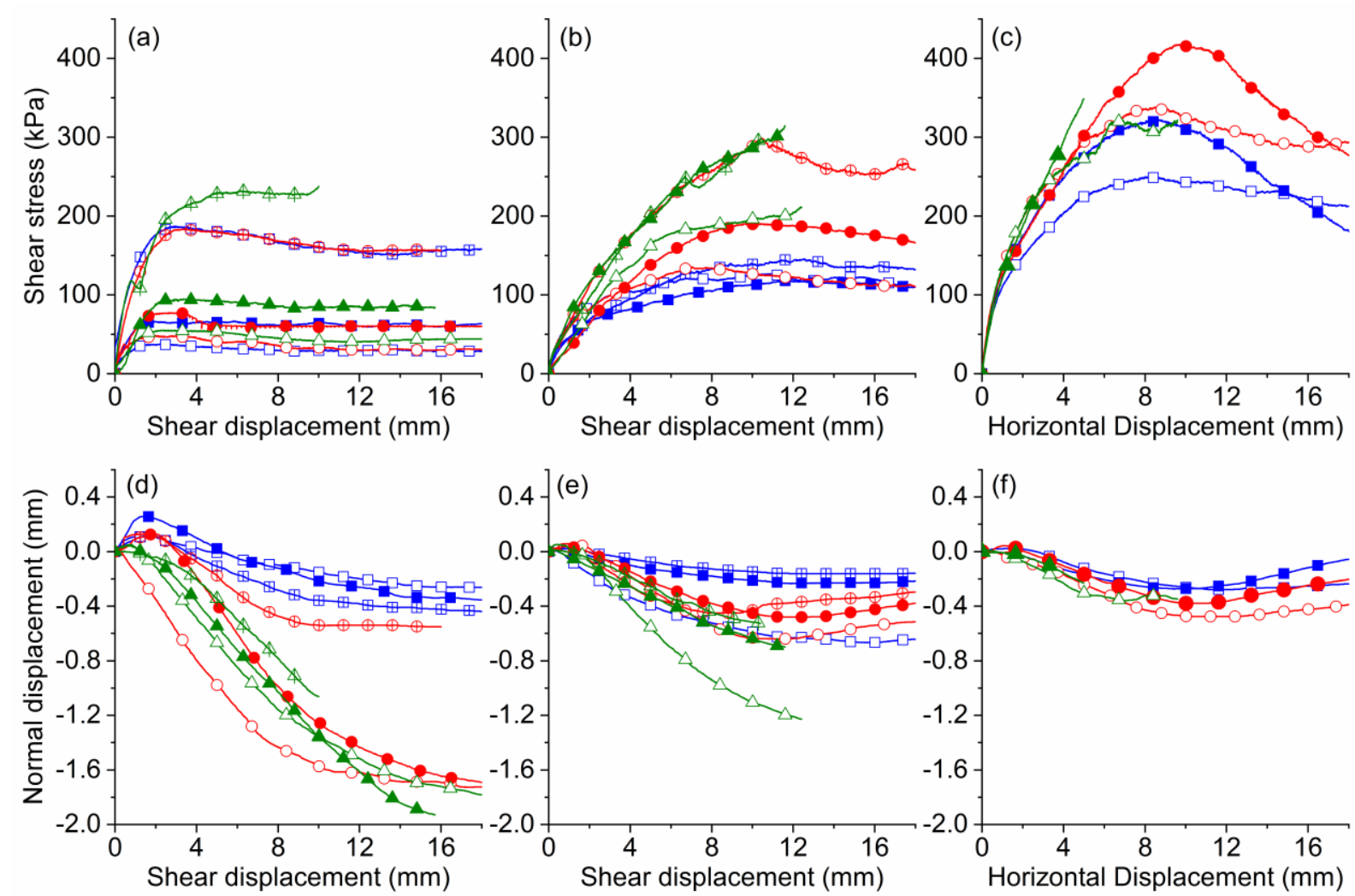

(a, d) SCS RCS RWCS3

$\rightarrow-\multimap-\triangle C \mathrm{CNL} 50 \mathrm{kPa}$

$\rightarrow-\longrightarrow-\mathrm{CNL} 100 \mathrm{kPa}$

(b, e) SCS RCS RWCS3

$\neg-\multimap-\backsim$ CNS $100 \mathrm{kPa}+150 \mathrm{kPa} / \mathrm{mm}$

$\because-\backsim$ CNS $100 \mathrm{kPa}+450 \mathrm{kPa} / \mathrm{mm}$

$\rightarrow-\rightarrow-$ CNS $100 \mathrm{kPa}+900 \mathrm{kPa} / \mathrm{mm}$ (c, f) SCS RCS RWCS3

$\neg-\multimap-\backsim$ CNS $250 \mathrm{kPa}+450 \mathrm{kPa} / \mathrm{mm}$ $\rightarrow-\longrightarrow$ CNS $250 \mathrm{kPa}+900 \mathrm{kPa} / \mathrm{mm}$

Figure 4.20: Effect of the confinement condition on the IDSTs of dense SP\#16 sand specimens sheared against SCS, RCS and RWCS3: (a, d) CNL condition; (b, e) CNS condition with a $100 \mathrm{kPa}$ initial normal stress; and (c, f) CNS condition with a $250 \mathrm{kPa}$ initial normal stress.

As the stiffness and initial normal stress increased, a smaller amount of dilation was observed, as greater resistance to normal displacement was imposed (Fig. 4.20e and f). In addition, the increase in stiffness had a more significant impact depending on the surface 
texture. For example, minimal shear stress change was observed for SCS as stiffness increased, while a significant increase was observed for RCS1 and RWCS3. Clearly, there is a relationship between the volumetric behavior observed in the IDSTs under the $100 \mathrm{kPa} C N L$ conditions (Fig. 4.20d) and the increase in the normal and shear stresses under CNS conditions (Fig. 4.20b).

Under CNL conditions, the sand-concrete interface friction angle can be directly applied in engineering practice to predict the interface shear strength. However, under CNS conditions, the interface strength is influenced by normal stress variation according to the interface volumetric behavior. This volumetric behavior can be a function of several variables, such as surface roughness, surface waviness, mean sand diameter, initial relative density and confinement condition. To assess this effect, the normalized normal stress variation, i.e., the difference between the maximum and initial normal stresses $(\Delta \sigma)$ developed during the IDST divided by the initial normal stress $(\sigma i)$, was analyzed. The IDST results indicated that, as stiffness, mean sand diameter, normalized roughness and relative density increased, the normalized normal stress variation increased (Fig. 4.21), while as the initial normal stress increased, the normalized normal stress variation decreased (Fig. 4.21d). Regarding the effect of surface waviness, no significant trend was observed on the normalized normal stress variation (Table 4.5). The normalized normal stress variation values obtained for RWCSs were similar to those of RCS1, especially under high levels of initial normal stress or stiffness. Under a low confinement condition, such as $100 \mathrm{kPa}$ of initial normal stress and stiffness of 150 or $450 \mathrm{kPa} / \mathrm{mm}$, a narrow spread of the normalized normal stress variation values was observed. Although the maximum normal stress was not achieved in all cases due to the boundary effect, the maximum normal stress value was estimated based on the results obtained before this boundary effect. 

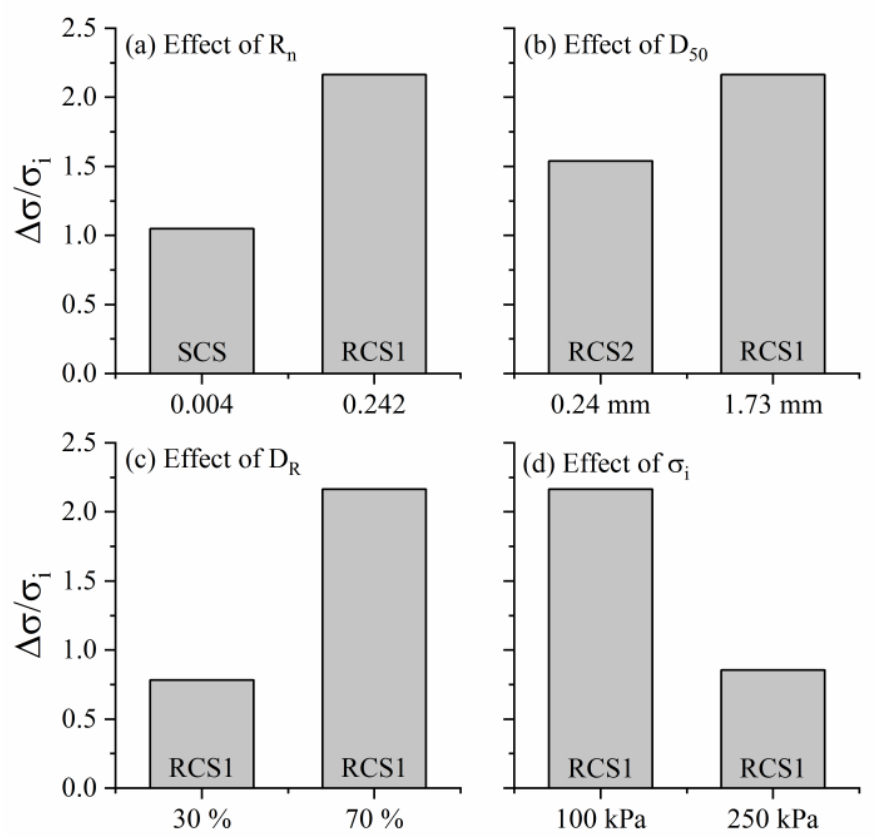

Figure 4.21: Effect of (a) normalized roughness, (b) mean sand diameter, (c) relative density and (d) initial normal stress on normalized normal stress variation. Results of IDSTs under a

CNS condition of: (a) dense SP\#16 specimens sheared against SCS and RCS1; (b) dense SP\#16 and SP\#100 specimens sheared against RCS2 and RCS1; (c) loose and dense SP\#16 specimens sheared against RCS1; and (d) dense SP\#16 specimens sheared against RCS1 under $100 \mathrm{kPa}$ and $250 \mathrm{kPa}$ of initial normal stress.

Table 4.5: The effect of surface waviness on the results of normalized normal stress variation values from dense SP\#16 sand specimens sheared against RCS1 and RWCS.

\begin{tabular}{cccccccc}
\hline$\sigma_{\mathrm{i}}$ & $\mathrm{k}$ & $\mathrm{D}_{\mathrm{r}}$ & \multicolumn{5}{c}{ Waviness $(\mathrm{mm})$} \\
\cline { 4 - 8 } $\mathrm{kPa}$ & $\mathrm{kPa} / \mathrm{mm}$ & $\%$ & 0.0 & 2.5 & 5.0 & 7.5 & 10.0 \\
\hline 100 & 150 & & 0.96 & & & 1.82 & \\
100 & 450 & & 2.17 & 3.01 & 2.04 & 3.20 & 2.40 \\
100 & 900 & & 3.61 & & & 3.55 & \\
250 & 450 & & 0.86 & & & 0.92 & \\
250 & 900 & 70 & 1.36 & 1.55 & 1.44 & 1.52 & 1.40 \\
\hline 100 & 450 & 30 & 0.78 & & & 1.20 & \\
250 & 900 & & -0.08 & & & -0.06 & \\
\hline
\end{tabular}

Based on these effects, a multiple regression was developed to assess the effects of the normalized normal stress variation on the IDSTs under the CNS condition. This empirical regression was based on the results obtained herein and several sand-solid interface results under the CNS condition (Tabucanon et al., 1995; Evgin and Fakharian, 1996; Ghionna and Mortara, 2002; Porcino et al., 2003). Eq. 4.4 to 4.7 link normalized normal stress variation to initial normal stress, stiffness, initial relative density, normalized roughness and mean sand diameter. Surface waviness was disregarded because no significant trend was observed, as previously mentioned. This model was demonstrated to be suitable to assess the normalized 
normal stress variation, as shown in Fig. 4.22a. These equations should be used for sand-steel or sand-concrete interfaces with an initial normal stress under $300 \mathrm{kPa}$ and a stiffness under $1,000 \mathrm{kPa} / \mathrm{mm}$.

$$
\begin{gathered}
\frac{\Delta \sigma}{\sigma_{i}}=\alpha k \\
\alpha=f\left(\sigma_{i}, R_{n}, D_{50}\right)=\zeta-\lambda \ln \sigma_{i} \\
\zeta=-0.000794+0.00195 D_{R} \ln \left(48,184 R_{n}\right)+0.00533 D_{R} \ln \left(D_{50}\right) \\
\lambda=-0.0000849+0.000317 D_{R} \ln \left(48,184 R_{n}\right)+0.000866 D_{R} \ln \left(D_{50}\right)
\end{gathered}
$$

There was good linear agreement between the normalized normal stress variation and the stiffness for several cases (Fig. 4.22b). RCS and RWCS showed a higher rate of increase of normalized normal stress variation than SCS. The rates of increase of normalized normal stress variation were higher for SP\#16 sands than for SP\#100 sands. However, the rate of increase of normalized normal stress with stiffness markedly depended on initial normal stress (Eq. 4.5). The effect of initial normal stress on normalized normal stress variation also depended on normalized roughness, relative density and mean sand diameter (Eqs. 4.6 and 4.7).

A few practical results can be addressed. Fine sands would develop lower values of normalized normal stress variation than coarse sand deposits. The test results for SP\#100 sands indicated that this value ranged from 0 (for dense sand sheared against SCS) to 1.54 (for dense sand sheared against RCS with low initial normal stress). Coarse sands would develop higher values of normalized normal stress variation. Tests results on SP\#16 sands exhibited a normalized normal stress variation range of 0 (for loose sand and high initial normal stress) to 3.61 (for dense sand sheared against RCS with low initial normal stress). Therefore, the role of the mean sand diameter has to be linked with surface roughness, initial normal stress and relative density.

Near the surface, high normalized normal stress variation values are expected because of the low initial normal stress, especially in dense sand deposits. For loose deposits, SCS would achieve similar shear stresses as RCS because it is less sensitive to the relative density reduction. For greater depths, lower values of normalized normal stress variation values are expected because of the high initial normal stress condition and nonlinear increase of stiffness with depth. RCS would profit from greater friction than SCS, especially in dense coarse sand 
deposits. For fine sand deposits or loose sand, a less pronounced difference is expected. RWCSs would have a similar soil elastic response of RCS because no significant effect was observed on the normalized normal stress variation, regardless of the depth.
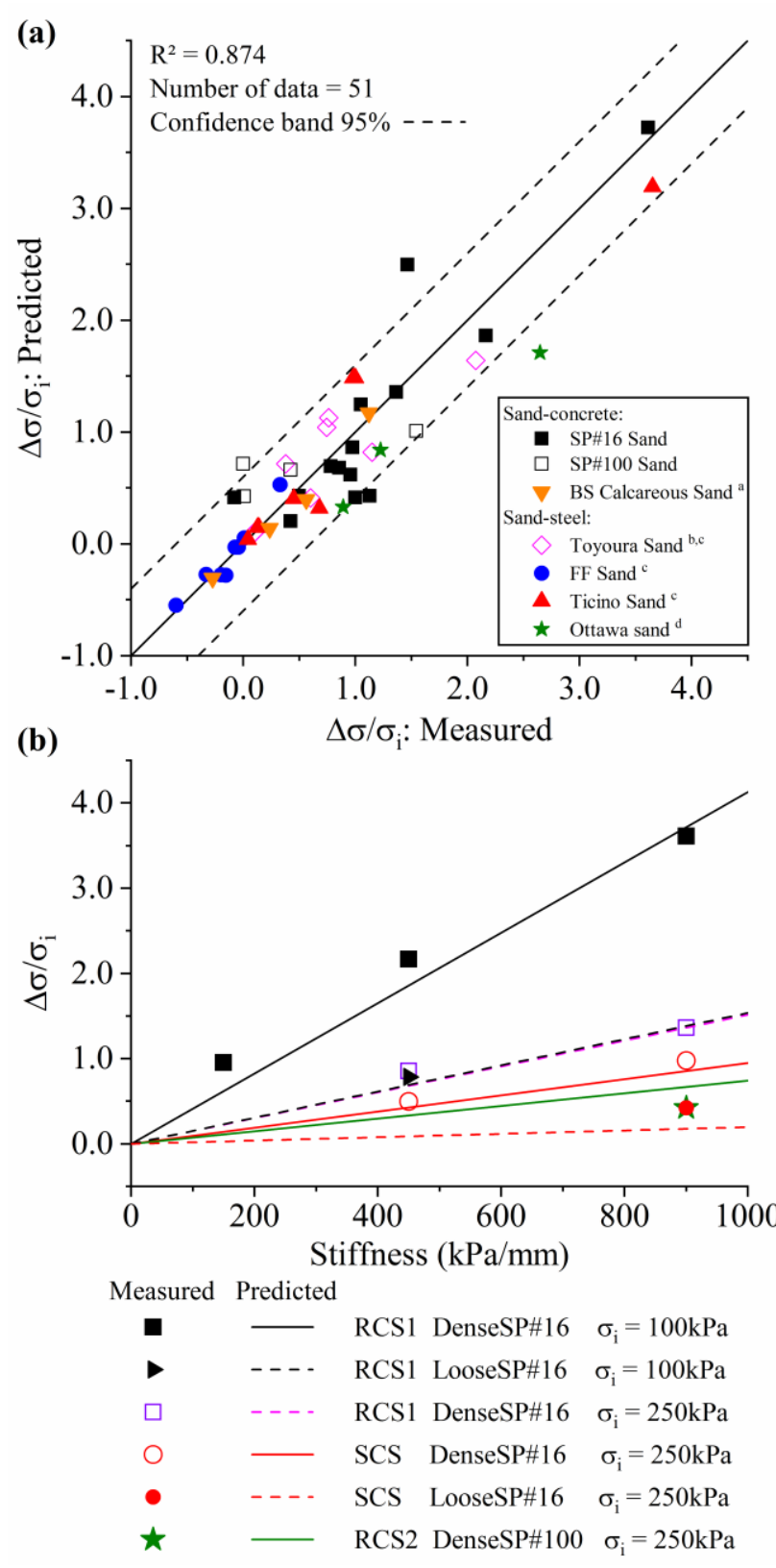

Figure 4.22: Multiple regression of normalized normal stress variation: (a) measured versus predicted; (b) examples of model prediction for several conditions. Notes: ${ }^{a}$ Tabucanon et al., 1995; ${ }^{\mathrm{b}}$ Ghionna and Mortara, 2002; ${ }^{\mathrm{c}}$ Porcino et al., 2003; and ${ }^{\mathrm{d}}$ Evgin and Fakharian, 1996.

\subsubsection{Conclusions}

A new experimental methodology to reproduce a sand-concrete interface was conducted. Sand-concrete IDSTs under CNL and CNS conditions were performed to evaluate the influence of surface structural characteristics on the interface strength and behavior. An 
investigation into the effects of surface texture, surface plowing, relative density and confinement condition at the sand-concrete interface was performed. The following conclusions were drawn.

Two extreme scenarios of pile surface roughness, SCSs and RCSs, were analyzed. The IDSTs on SCSs exhibited high values of interfacial-to-internal friction angle ratios, ranging $88 \%$ to $90 \%$. The angular shape of the sand particles led to a greater relative roughness of the sand-concrete system and resulted in greater interfacial-to-internal friction angle ratios. RCSs exhibited more pronounced post-peak softening and a larger amount of dilation and generated higher shear stresses due to the higher interface friction angle values and higher normal stress developed under CNS conditions. However, the interface strength was still inferior to the surrounding sand strength.

A higher sand-concrete interface strength was achieved as surface waviness increased, reaching interfacial-to-internal friction angle ratios greater than 1.0. A nonlinear conceptual regression of the interfacial-to-internal friction angle ratio was proposed according to normalized roughness and normalized waviness. The interfacial-to-internal friction angle ratio tends to increase as the normalized waviness increases until an optimal value; thereafter, the interfacial-to-internal friction angle ratio tends to decrease.

The surface plowing results imply that a mixed shear plane at the sand-concrete interface developed as the sand particles were detached from the surface. This mixed shear plane is composed of internal sand failure and weak bond failures between sand particles and concrete. The practical significance of the acknowledgment of surface plowing on the concrete surface is as follows: concrete surfaces are susceptible to surface plowing under interface shearing, surface plowing increases with the normal and shear stresses, surface plowing inhibits the interface friction angle to achieve the surrounding sand friction angle, surface plowing modifies the concrete surface roughness, and surface plowing can be suppressed with surface waviness.

Under the CNL condition, the sand-concrete interface friction angle can be directly applied in engineering practice to predict the interface shear strength. However, under CNS conditions, the interface strength is directly influenced by normal stress variation according to the interface volumetric behavior. In this case, the interface shear strength mainly depends on the current normal stress, which in turn significantly depends on the initial normal stress, stiffness, surface roughness, mean sand diameter and relative density. A multiple regression was proposed to assess the effects of the normalized normal stress variation to consider these variables. The surface waviness did not have a significant effect on the normalized normal 
stress variation. Therefore, the rough-wavy concrete piles are expected to achieve higher interface strength due the higher $\delta / \sigma$ ratio, and not due to the greater elastic response of the surrounding soil.

\subsection{Sand-concrete interface strength: a review}

\subsubsection{Introduction}

Sand-concrete IDSTs were performed to evaluate the role of surface structural characteristics, confinement conditions, sand mean diameter and relative density. In order to assess sand-concrete interface strength for others conditions, a literature review of interfacialto-internal friction angle ratios was conducted. This is essential considering the several variables involved including surface roughness, sand properties, particle characteristics, relative density and so forth.

Sand-concrete interface strength is usually defined by a Coulomb failure criterion (Lehane et al., 1993) (Equation 4.8). The sand-concrete interface friction angle is usually estimated as two-thirds of the sand friction angle, as commonly established for retaining walls (Ilori et al., 2017). However, several studies indicated that this value can be considered underestimated for the sand-concrete interface strength (Tiwari and Al-Adhadh, 2014). The use of two-thirds as the interfacial-to-internal friction angle ratio for the sand-concrete interface could be considered in favor of safety for the case of static axial loaded piles, or against, for the case of negative skin friction of piles.

$$
\tau=\sigma \tan \delta
$$

Where: $\tau$ is the shear stress developed; $\sigma$ is the normal stress; and $\delta$ is the interface friction angle.

An international literature review of experimental interface shear results was undertaken, and data of interfacial-to-internal friction angle ratios $(\delta / \varphi)$ of the sand-concrete interface was acquired. Additionally, the sand-concrete IDSTs performed in the last subsection were used to complement the database. Key aspects of sand-concrete interface strength were analyzed including surface roughness, sand properties, particle morphology, and relative density. 


\subsubsection{Materials}

Eight international studies were used to conduct this research (Table 4.6), besides the IDST results obtained in the last subsection. These experimental studies conducted IDSTs on the sand-concrete interface, besides Uesugi et al. (1990) and Brumund and Leonards (1973) who had performed interface simple shear tests and interface tests with a special apparatus, respectively. A few studies on the sand-concrete interface were not incorporated to the database because they were based on the interface between sand and rough steel surface or between sand and sand particles glued onto a steel surface (e.g., Tabucanon et al., 1995).

Several information were acquired from these studies, such as: interfacial-to-internal friction angle ratio; the Unified Soil Classification System (USCS) (ASTM D2487, 2017); relative density (Dr); sand mean diameter $\left(D_{50}\right)$; particle morphology; surface roughness; number of interface shear tests performed; and test condition, dry or saturated.

Table 4.6: The references used.

\begin{tabular}{cl}
\hline Reference & \multicolumn{1}{c}{ Study } \\
\hline 1 & Potyondy (1961) \\
2 & Brumund and Leonards (1973) \\
3 & Uesugi, Kishida and Uchikawa (1990) \\
4 & DeJong et al. (2002) \\
5 & Frost et al. (2000) \\
6 & Gómez et al. (2008) \\
7 & Tiwari and Al-Adhadh (2014) \\
8 & Di Donna, Ferrari and Laloui (2015) \\
\hline
\end{tabular}

\subsubsection{Methodology}

The analyses investigated the effects of the following variables: (i) surface roughness; (ii) sand mean diameter; (iii) relative density; (iv) particle morphology; and (iv) USCS. Analyses were conducted considering the number of interface shear tests performed. When this number was not specified, it was considered a number of three interface tests.

Regarding the surface roughness, the studies diverged in the characterization of surface roughness. Therefore, the surface roughness was divided in three conditions: smooth, when it was made by pouring concrete against a flat steel, periglass or wood surface; median; and rough, when it was made by pouring concrete against a rough surface. Quantitatively, the surface roughness was classified according to the normalized roughness value. As proposed by Paikowsky et al. (1995): smooth surface when the surface roughness was less than 0.05 of 
the sand mean diameter; median surface when the surface roughness was between 0.05 and 0.10 of the sand mean diameter; and rough surface when the surface roughness was larger than 0.10 of the sand mean diameter.

In addition, compactness of the sand specimen was qualitatively classified as: loose when the relative density was less than $33 \%$; medium when the relative density was between $33 \%$ and $66 \%$; and dense when the relative density was higher than $66 \%$.

\subsubsection{Results}

Table 4.7 display the data acquired of sand-concrete interface shear tests. Additionally, the experimental results obtained in the last subsection were included.

Box plots were used to analyze the influence of each parameter. This graphically depict displays the dispersion in samples of population without a statistical distribution assumption. The spread, skewness and outliers in the data can be evaluated. First (25\%), second (median) and third (75\%) quartiles are displayed, as well as the mean value. Outliers were considered when data values were not in the range of the 1.5 interquartile range (IQR). The IQR was defined as the difference between the first and third quartiles.

Due to the limited amount of data, a few box plots ought to be analyzed meticulously. In addition, no significant difference was observed between dry and saturated interfacial-tointernal friction angle ratios. Therefore, the results presented herein refer to dry condition only. 
Table 4.7: Interfacial-to-internal friction angle ratios obtained from nine different references.

\begin{tabular}{|c|c|c|c|c|c|c|c|c|c|}
\hline \multirow[t]{2}{*}{ Ref. $^{a}$} & \multirow{2}{*}{$\begin{array}{c}\text { Sand } \\
\text { ASTM }\end{array}$} & \multirow[t]{2}{*}{$\mathbf{D}_{\mathbf{5 0}}{ }^{b}$} & \multirow{2}{*}{$\begin{array}{l}\text { Particles } \\
\text { Morphology }\end{array}$} & \multirow[t]{2}{*}{$\mathbf{D r}^{c}$} & \multirow[t]{2}{*}{ Roughness } & \multicolumn{4}{|c|}{$\begin{array}{c}\begin{array}{c}\text { Interfacial-to-internal friction } \\
\text { angle ratio }\end{array} \\
\end{array}$} \\
\hline & & & & & & $\mathbf{N}^{d}$ & Dry & $\mathbf{N}^{d}$ & $\overline{\text { Saturated }}$ \\
\hline \multirow{2}{*}{1} & \multirow{2}{*}{ SW } & \multirow{2}{*}{0.58} & & \multirow{2}{*}{66} & Smooth & $*$ & 0,89 & $*$ & 0,90 \\
\hline & & & & & Rough & $*$ & 0,98 & & \\
\hline \multirow{4}{*}{2} & \multirow{2}{*}{ SP } & \multirow{2}{*}{0.72} & \multirow{2}{*}{ Rounded } & \multirow{2}{*}{90} & Smooth & 34 & 0,71 & & \\
\hline & & & & & Rough & 32 & 0,95 & & \\
\hline & \multirow{2}{*}{ SP } & \multirow{2}{*}{0.21} & \multirow{2}{*}{ Angular } & \multirow{2}{*}{90} & Smooth & 32 & 0,90 & & \\
\hline & & & & & Rough & 4 & 1,00 & & \\
\hline \multirow{10}{*}{3} & \multirow{5}{*}{ SW } & & & 50 & Median & 9 & 0,80 & & \\
\hline & & & & & Rough & 7 & 0,87 & & \\
\hline & & 0.18 & Sub-rounded & & Rough & 4 & 0,95 & & \\
\hline & & & & 95 & Rough & 2 & 0,96 & & \\
\hline & & & & & Rough & 6 & 1,00 & & \\
\hline & SW & 019 & Anoular & 90 & Median & 4 & 0,90 & & \\
\hline & $\mathrm{SW}$ & 0.19 & Angular & 90 & Rough & 4 & 1,00 & & \\
\hline & & & & & Smooth & 4 & 0,66 & & \\
\hline & SW & 1.8 & Angular & 90 & Median & 4 & 0,84 & & \\
\hline & & & & & Rough & 1 & 1,00 & & \\
\hline$A$ & CW & 0.72 & Sub-rounded & 80 & Rough & $*$ & 0,95 & & \\
\hline 4 & $\mathrm{SW}$ & 0.62 & Angular & 80 & Rough & $*$ & 0,88 & & \\
\hline & $\mathrm{SP}$ & 0.7 & & 80 & Smooth & 4 & 0,74 & & \\
\hline 5 & SP & 051 & Sub_rounded & 75 & Smooth & 4 & 0,86 & & \\
\hline 5 & $\mathrm{SP}$ & 0.31 & Sub-rounded & 49 & Smooth & 4 & 0,71 & & \\
\hline & SP & 0.41 & Sub-angular & 80 & Smooth & 4 & 0,79 & & \\
\hline & & & & 14 & Smooth & 4 & 0,82 & 4 & 0,88 \\
\hline & & & & 40 & Smooth & 4 & 0,62 & 4 & 0,68 \\
\hline & SW & 0.85 & Angular & 68 & Smooth & 4 & 0,74 & 4 & 0,72 \\
\hline 6 & & & & 95 & Smooth & 4 & 0,71 & 4 & 0,69 \\
\hline & SP & 0.55 & Sub-rounded & 10 & Smooth & & & 4 & 0,94 \\
\hline & SM & 0.6 & & 10 & Smooth & & & 4 & 0,91 \\
\hline & SP-SM & 0.52 & & 10 & Smooth & & & 4 & 0,97 \\
\hline & & & & & Smooth & 3 & 0.77 & & \\
\hline 7 & SP & 0.5 & & $>66$ & Medium & 15 & 0.8 & & \\
\hline & & & & & Rough & 11 & 0.87 & & \\
\hline & SP & 12 & Sub_rounded & 80 & Medium & 5 & 0.82 & & \\
\hline 8 & $\mathrm{SP}$ & 1.2 & Sub-rounded & 50 & Medium & 5 & 0.92 & & \\
\hline & SP & 023 & Sub-rounded & 80 & Rough & 5 & 0.86 & & \\
\hline & & & & 50 & Rough & 5 & 0.86 & & \\
\hline & SP & 024 & Sub anoulor & 70 & Smooth & 3 & 0.81 & & \\
\hline & $\mathrm{SP}$ & 0.24 & Sub-angular & 70 & Rough & 3 & 0.89 & & \\
\hline 0 & SP & 173 & Sub_anoular & 70 & Smooth & 8 & 0.92 & & \\
\hline 9 & $\mathrm{SP}$ & 1.13 & suo-angular & 70 & Rough & 8 & 0.96 & & \\
\hline & SP & 173 & Sub-anoular & 30 & Smooth & 3 & 0.89 & & \\
\hline & & & & 30 & Rough & 3 & 0.93 & & \\
\hline
\end{tabular}

Notes: ${ }^{a}$ reference abbreviation; ${ }^{b}$ sand mean diameter in $\mathrm{mm} ;{ }^{c}$ relative density in $\%$; ${ }^{d}$ number of interface shear tests performed; and * not specified. 
Figure 4.23 shows the influence of the surface roughness on the $\delta / \varphi$ ratio. The increase of surface roughness led to an increase in the $\delta / \varphi$. The minimum $\delta / \varphi$ ratio obtained was of 0.62 for the smooth concrete surface. The maximum $\delta / \varphi$ ratio obtained was of 1.00 for the rough concrete surface. The median $\delta / \varphi$ ratios observed were: 0.78 for the smooth concrete surface; 0.87 for the median concrete surface; and 0.95 for the rough concrete surface. Moreover, the results showed that the smooth concrete surfaces have a greater spread of the $\delta / \varphi$ ratio. The data from the IDSTs performed in the last subsection showed a good accordance with the published data.

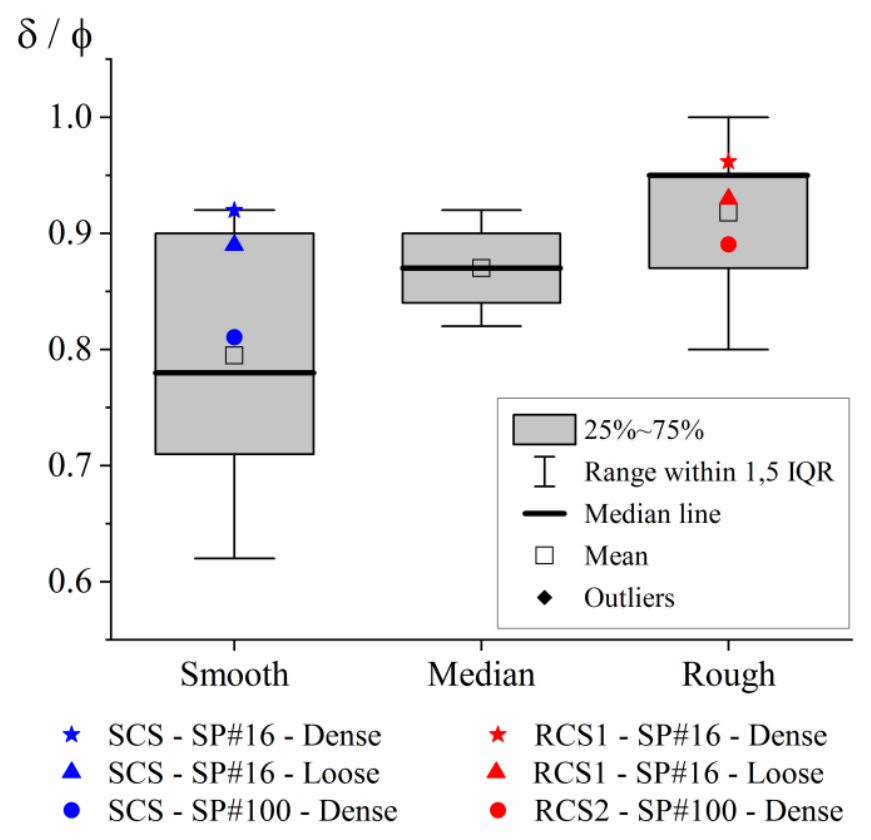

Figure 4.23: The effect of the surface roughness on the sand-concrete interfacial-to-internal friction angle ratios for dry conditions.

The sand mean diameter had values ranging from 0.18 to $1.8 \mathrm{~mm}$, which correspond to fine to very coarse sands. Figure 4.24 shows that no significant relationship between the $\delta / \varphi$ ratio and the sand mean diameter was verified for the medium and rough concrete surfaces. Nevertheless, for the smooth concrete surfaces, the fine sands had higher $\delta / \varphi$ ratios than the medium to very coarse sands. Since there is a relationship between the surface roughness and the sand mean diameter, defined as normalized roughness, the sand mean diameter has an indirect influence on the $\delta / \varphi$ ratio. However, for sand mean diameters higher than $0.75 \mathrm{~mm}$, no influence on the $\delta / \varphi$ ratio was observed. 


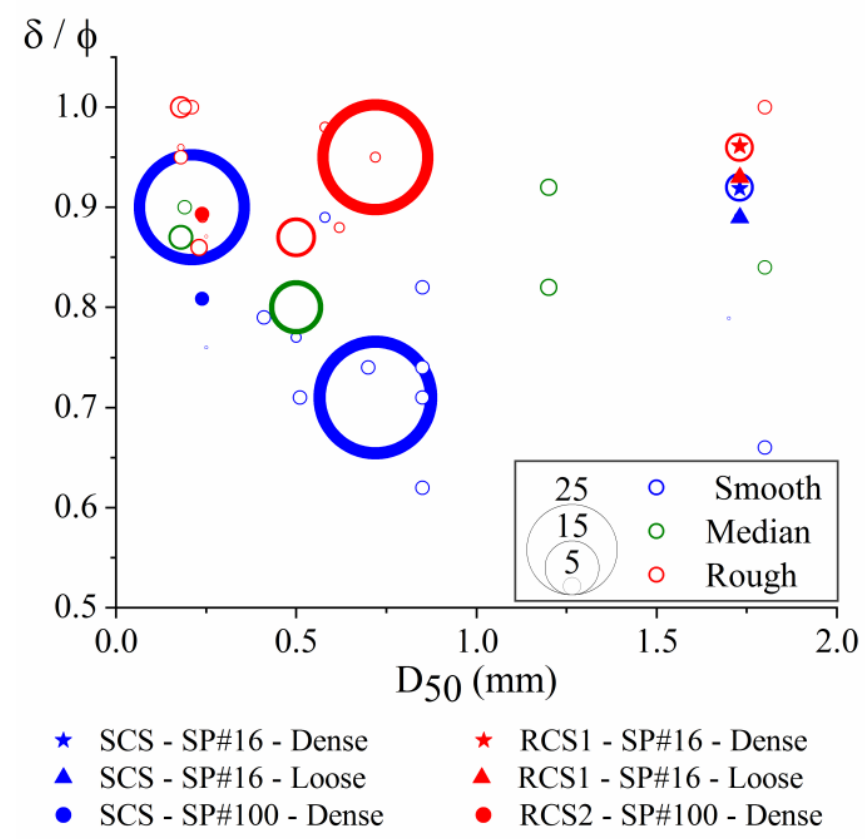

Figure 4.24: Effect of the sand mean diameter on the sand-concrete interfacial-to-internal friction angle ratios for dry conditions. The circle size indicates the number of interface shear tests performed.

Particle morphology had great influence on the $\delta / \varphi$ ratio, especially for SCSs (Figure 4.25). The angular sand particles trend to have larger $\delta / \varphi$ ratios than the rounded sand particles. For the SCSs, sub-angular to angular particles had a median $\delta / \varphi$ ratio of 0.90 , while the sub-rounded to rounded particles had a median $\delta / \varphi$ ratio of 0.71 . This difference was less significant for the RCS in which the sub-angular to angular particles had a median $\delta / \varphi$ ratio of 0.96 , while the sub-rounded to rounded particles had a median $\delta / \varphi$ ratio of 0.95 . Additionally, sub-angular to angular particles had a higher statistical distribution than the sub-rounded to rounded for the RCS. When considering the particle morphology, the data from the IDSTs performed in the last subsection showed a great accordance with the published data. 


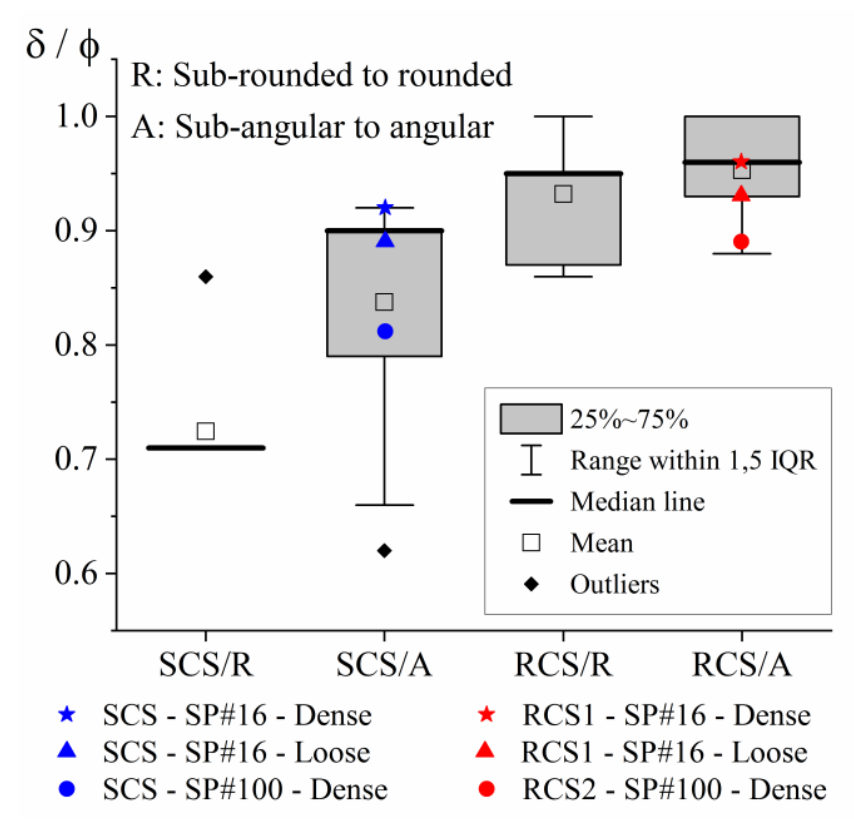

Figure 4.25: The effect of the particle morphology on the sand-concrete interfacial-to-internal friction angle ratio for the smooth and rough concrete surfaces under dry conditions.

The influence of sand compactness on the $\delta / \varphi$ ratio is plotted in Figure 4.26. Few data of the $\delta / \varphi$ ratios for loose sand specimens, especially for the medium and rough concrete surfaces, was obtained. Hence, the statistical distribution for these conditions had to be carefully analyzed. For the RCSs, the medium compactness obtained a smaller median than loose and dense specimens. For the SCSs, the median values had a noticeable difference depending on the initial compactness, despite of the high statistical dispersion. It was not possible to verify the effect of the sand mean diameter and particle morphology on the $\delta / \varphi$ ratio for different compactness condition, especially for SCS, due to the amount of data (Figure 4.27).

The statistical distribution demonstrated that an unequivocal influence of the sand initial compactness on the $\delta / \varphi$ ratios could not be verified. In addition, the median values obtained were affected by the size of the sample. These results are in good agreement with the literature. According to Dietz and Lings (2006), the peak interface friction angle trend to increase with the increase of the sand relative density, similar to sand-sand shearing. Additionally, several authors concluded that the post-peak interface friction angle do not depend on the initial compactness (Fakharian and Evgin, 1996; Porcino et al., 2003). 


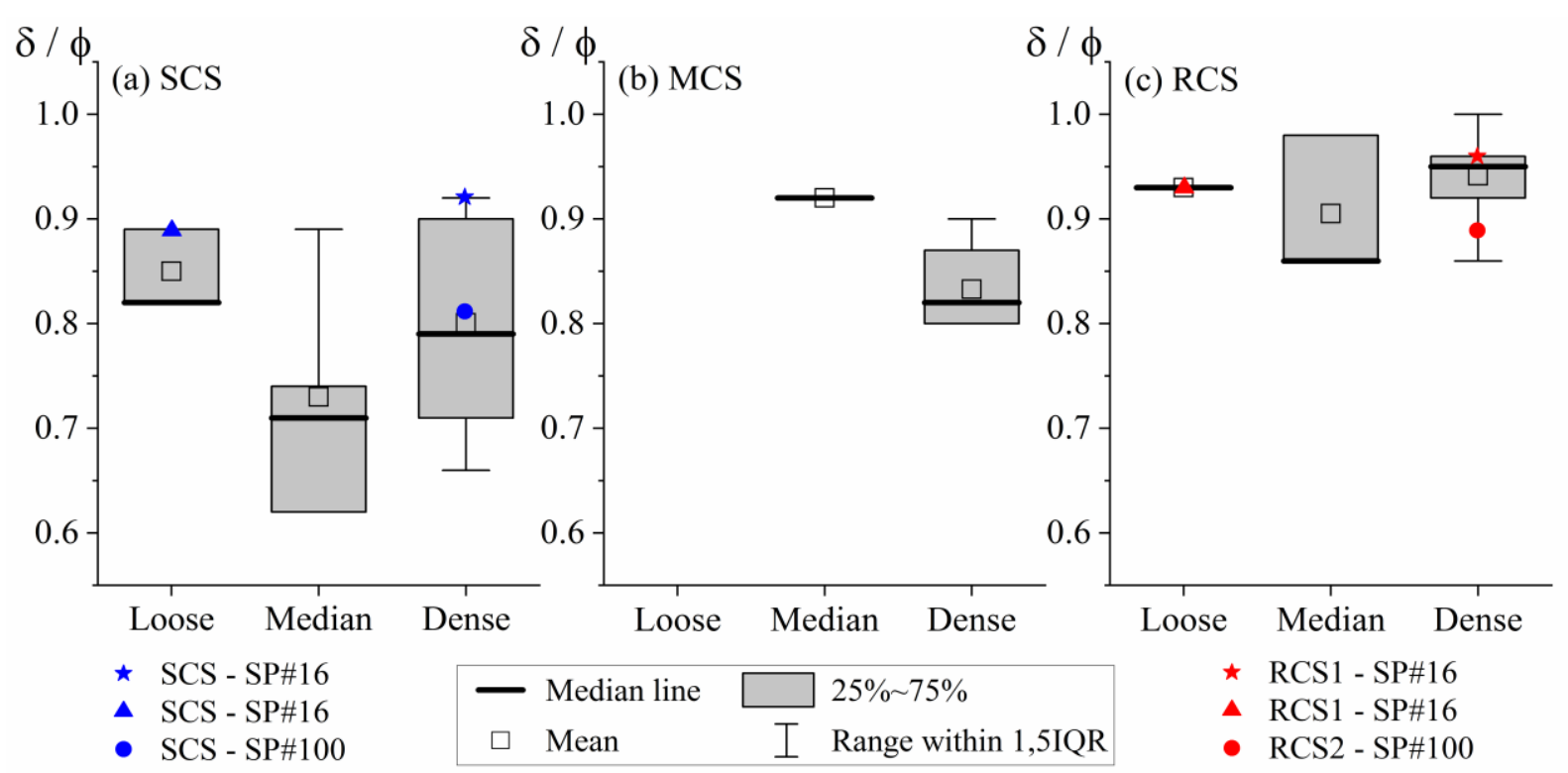

Figure 4.26: The effect of the sand compactness on the sand-concrete interfacial-to-internal friction angle ratio for dry conditions and for each surface roughness: (a) smooth; (b) median; and (c) rough.
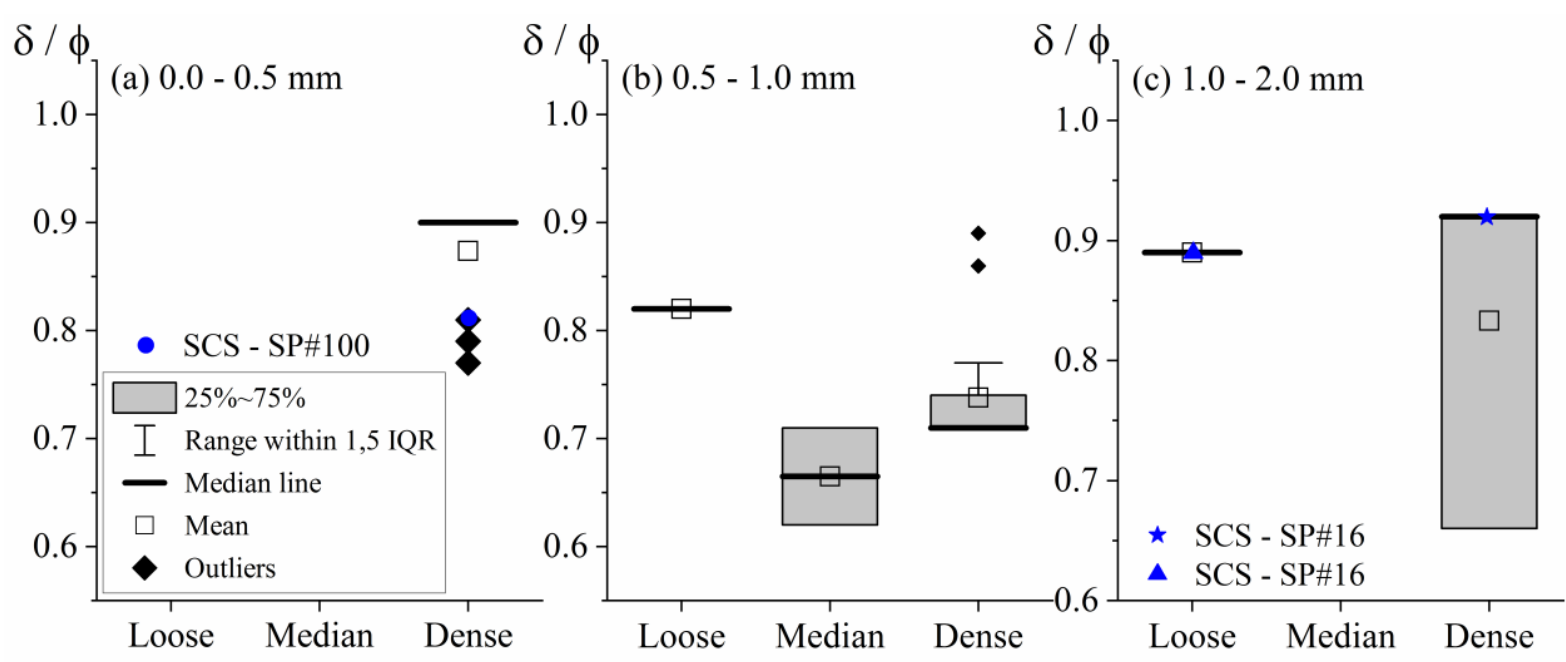

Figure 4.27: The effect of the sand compactness on the sand-concrete interfacial-to-internal friction angle ratio for dry conditions with different sand mean diameter range sheared against a SCS: (a) 0.0 to $0.5 \mathrm{~mm}$; (b) 0.5 to $1.0 \mathrm{~mm}$; and (c) 1.0 to $2.0 \mathrm{~mm}$.

Figure 4.28 shows the influence of the sand gradation on the $\delta / \varphi$ ratio for the smooth and rough concrete surfaces. For the SCSs, the poorly graded sands had a median $\delta / \varphi$ ratio of 0.81 , while the well-graded had a median $\delta / \varphi$ ratio of 0.71 . For the RCSs, the well-graded had a median $\delta / \varphi$ ratio of 0.98 , while the poorly graded sands had a median $\delta / \varphi$ ratio of 0.95 . A more narrow statistical distribution was obtained for the RCS, while the smooth concrete surface had a more spread distribution. This is expected since particle morphology and sand mean diameter have greater effect on the $\delta / \varphi$ ratio for the SCS. However, an analysis of the 
combined influence of particle morphology, sand mean diameter and sand gradation could not be performed due to the sample size. The data from the sand-concrete IDSTs performed in the last subsection showed a great accordance with the published data for poorly graded sands.

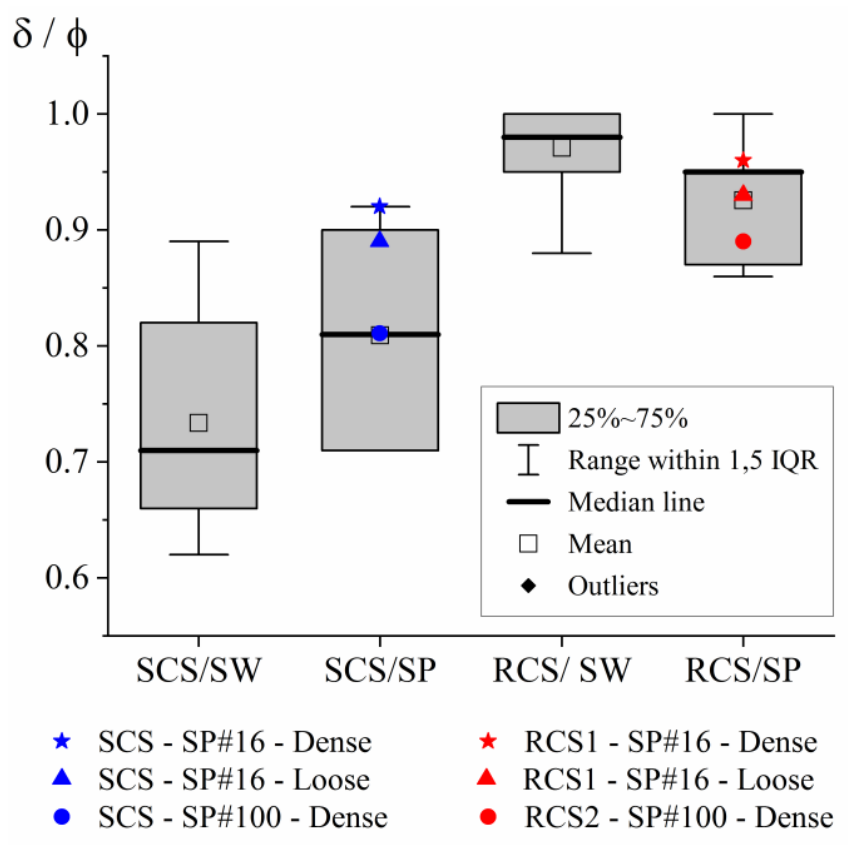

Figure 4.28: The effect of the sand gradation on the sand-concrete interfacial-to-internal friction angle ratio for dry conditions.

\subsubsection{Conclusions}

The analyses showed great accordance between the published data and the IDSTs performed in the last subsection, especially when considering the surface roughness, particle morphology and sand gradation. The effects of the surface roughness, sand mean diameter, relative density, particle morphology and USCS on the sand-concrete interfacial-to-internal friction angle ratio were investigated. Limited data have been published face the several factors involved on the sand-concrete interfacial-to-internal friction angle ratio. Thus, more experimental investigations on the sand-concrete interface strength are appropriate in order to consolidate the following conclusions.

It was observed that the sand-concrete interfacial-to-internal friction angle ratio increased as surface roughness was increased. For rough concrete surfaces, it can be expected that the interface strength will be close to the own sand strength, especially for well-graded angular sands. For smooth concrete surfaces, the interfacial-to-internal friction angle ratio ranged from 0.62 to 0.92 , depending on several factors, such as particle morphology, sand gradation and sand mean diameter. 
No significant relationship between the $\delta / \varphi$ ratio and sand mean diameter was found for the median and rough concrete surfaces. For smooth concrete surfaces, the fine sands had higher $\delta / \varphi$ ratios than the medium to very coarse sands. Moreover, the angular particles had higher $\delta / \varphi$ ratios than the rounded particles, especially for the smooth concrete surface.

The influence of the sand initial compactness on the $\delta / \varphi$ ratios could not verified. Moreover, the influence of the sand graduation was evaluated. A difference on the $\delta / \varphi$ ratio between well-graded and poorly graded sands was observed, especially for smooth concrete surfaces. The poorly graded sands exhibited higher $\delta / \varphi$ ratios than the well-graded sands for the smooth concrete surface.

Finally, several aspects have to be considered in order to predict the interfacial-tointernal friction angle ratio of the sand-concrete interface. The proper design and performance of geotechnical systems should rely on more realistic interfacial-to-internal friction angle ratios. 


\section{CYCLIC SAND-SOLID INTERFACE RESPONSE}

Sand-concrete and sand-steel cyclic interface direct shear tests were performed to assess the shaft friction degradation. A new approach based on increasing cyclic amplitude is proposed to overcome the conventional method based on constant cyclic amplitudes. Further attention is given to the sand-concrete interface because it is the typical interface case of the onshore wind turbine deep foundations in Brazil. This chapter was recently submitted to a high-impact journal, and it is currently under review.

\subsection{A new approach to the design of cyclic axial loaded piles}

\subsubsection{Introduction}

Piles under cyclic axial loading are subjected to shaft friction degradation (Poulos 1988 and 1989; Lee and Poulos, 1991 and 1992). Several authors have described this friction degradation phenomenon as a consequence of the global contraction response of the soil adjacent to the pile, which is followed by a decrease in the confining stress (e.g., Airey et al., 1992; Gavin and O'Kelly, 2007). Experimental investigations have reached a consensus regarding the key factors that affect shaft friction degradation, including surface roughness (e.g., Mortara et al., 2007; Tehrani et al., 2016), confinement conditions (e.g., Fakharian and Evgin, 1996 and 1997; Liu et al., 2012; Bekki et al., 2013), relative soil density (e.g., Uesugi et al., 1990; Oumarou and Evgin, 2005), soil characteristics (e.g., Uesugi et al., 1989; Di Donna et al., 2016), particle crushing (e.g., Pra-ai and Boulon, 2016; Yang et al., 2010; Ho et al., 2011), load sequence (e.g., Blanc and Thorel, 2016), and cyclic amplitude (e.g., Chin and Poulos, 1996; Tsuha et al., 2012; Li et al., 2012; Aghakouchak et al., 2015). Several experimental approaches have been used by these authors, such as ring shear tests, simple shear tests, direct shear tests, calibration chamber tests, centrifuge tests and field tests. However, these studies were mainly interested in cyclic responses under constant displacement-controlled or load-controlled amplitudes.

In geotechnical engineering practice, cyclic stability diagrams are widely used to describe the shaft friction degradation of piles under cyclic axial loading. Field and experimental tests are usually performed to evaluate the number of cycles until failure under a constant cyclic amplitude (CCA). Through this approach, cyclic failure can either occur quickly or not at all. From a practical viewpoint, the cyclic test times are unpredictable, which makes these tests difficult to plan and realize. As several tests are required to develop one cyclic stability diagram, these investigations are often expensive and time consuming. To 
overcome this issue, a new approach based on increasing cyclic amplitudes (ICAs) is proposed. The potential benefits of this approach are the time predictability, the failure at certain critical cyclic amplitudes, the effects of low-level cyclic loading effects and the relationship between CCAs and ICAs.

The current paper investigated the main aspects concerning the ICA approach in comparison with the conventional CCA approach. Hence, the main scope of this study was to establish a relationship between the conventional cyclic design method and the new proposed approach. Several one-way and two-way cyclic interface direct shear tests (CIDSTs) were perfomed under constant normal stiffness (CNS) conditions. The constant stiffness boundary replicates the actual field condition of piles and can thus be used to understand the subsequent loss of shaft capacity reported for model and full-scale piles during cycling (e.g., Tabucanon et al., 1995; DeJong et al., 2003; Jardine and Standing, 2012). The cyclic responses of sandsteel and sand-concrete interfaces were explored under constant and increasing cyclic loadcontrolled amplitudes. Sand-steel and sand-concrete interfaces reproduced field conditions similar to grouted piles, steel-driven piles and concrete-driven piles embedded in sand, which are commonly found in onshore and offshore deep foundations. The results of this experimental investigation were used to develop a simple cumulative damage model that is capable of predicting cyclic interfacial failure. This new approach has two immediate leverages to geotechnical engineering practice: it can significantly reduce the number of tests required because the model parameters can be easily estimated, and it can be effortlessly applied in other experimental and field investigations.

\subsubsection{Experimental materials and methods}

Fine poorly graded Tietê Brazilian standard silica sand was used in this research (Fig. 5.1a). This angular quartz sand had a mean diameter of $0.24 \mathrm{~mm}$. Smooth concrete surfaces (SCSs) were prepared by pouring concrete against a flat steel surface. Rough concrete surfaces (RCSs) were fabricated by pluviating sand onto the flat fluid cement mortar with a sieve. The cement mortar was fabricated in the laboratory by mixing Portland cement of high initial strength, with two types of sand, water and a superplasticizer. The cement mortar had an average uniaxial compressive strength of $30.4 \mathrm{MPa}$ after 7 days. The steel surface (SS) was an SAE J403-1045 high carbon steel without surface treatment. A Design ScanArm 2.0 (Faro Technologies, 2018) and a confocal laser scanning microscope were used to evaluate the surface roughness of the concrete and steel, respectively. Figure 5.1b shows the SS, SCS and 
RCS and a topographical section of each surface. Further details about the experimental materials are presented in subsection 4.1.

A two-way direct shear apparatus was modified to perform the CIDSTs (Fig. 5.1c). The apparatus had the lower part of the shear box modified to provide constant friction on the soil-solid interface throughout testing. A gap of approximately $0.15 \mathrm{~mm}$ was arranged between the lower and upper parts of the shear box to avoid grain leakage during testing. Therefore, the contact between the upper shear box and the solid surface was obviated. The steel and concrete slabs had dimensions of $164 \mathrm{~mm} \times 100 \mathrm{~mm} \times 32 \mathrm{~mm}$, while the soil sample had a $100 \mathrm{~mm} \times 100 \mathrm{~mm}$ area and a $22 \mathrm{~mm}$ height. Figure 5.1d displays a schematic diagram of the sand-solid CIDST.
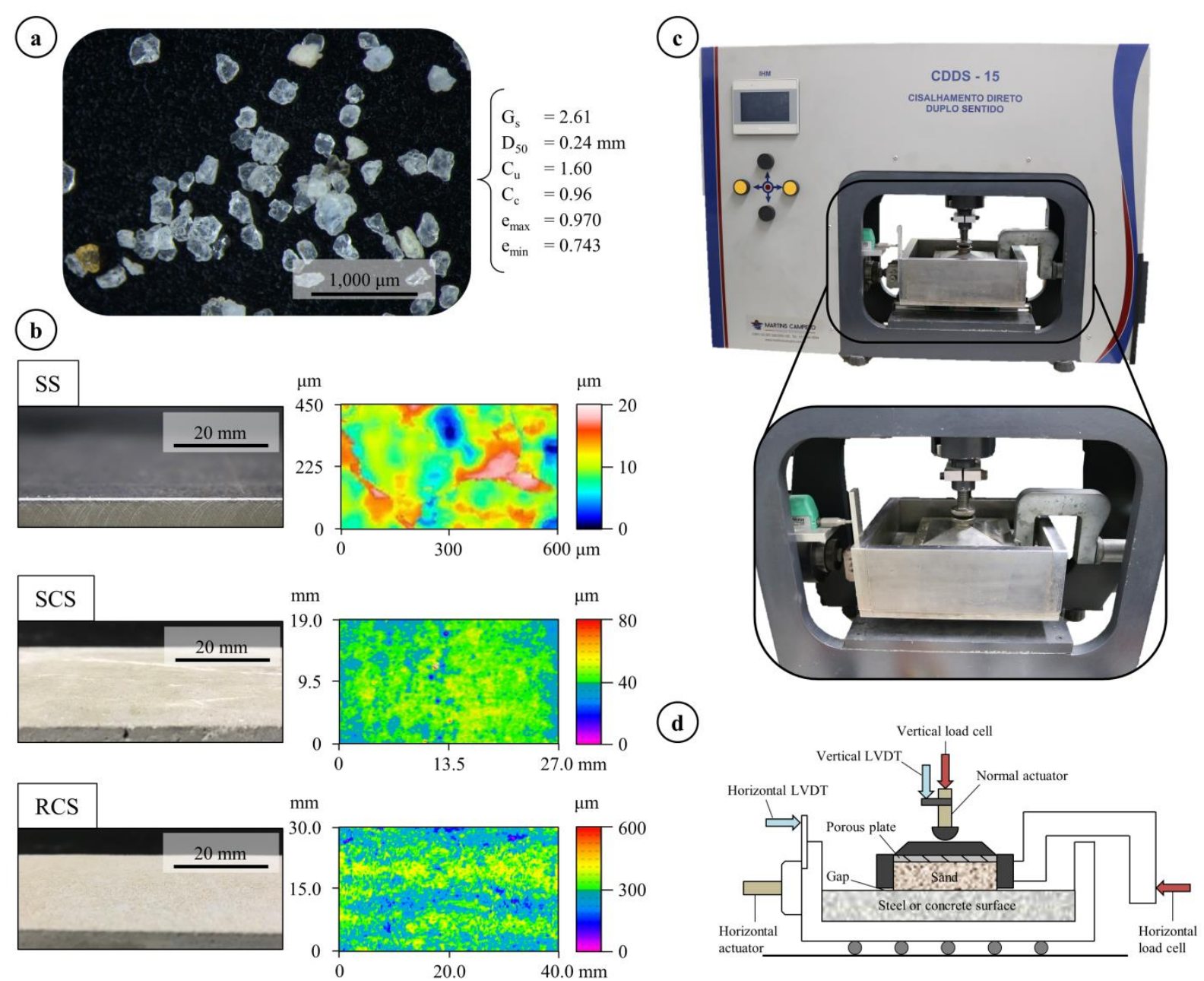

Figure 5.1: Experimental methodology: (a) micrograph of the fine poorly graded Brazilian standard silica sand; (b) steel and concrete surfaces and their 3D surface models; (c) the twoway direct shear apparatus; and (d) a schematic diagram of the sand-solid CIDST. 
The experimental programme investigated the friction degradation phenomenon of the sand-solid interface under ICAs and CCAs. A total of 12 monotonic IDSTs and 24 loadcontrolled CIDSTs were performed under CNS conditions. Table 1 summarizes the test programme of the CIDSTs. This table illustrates the range of tested parameters, including the normalized roughness $\left(\mathrm{R}_{\mathrm{n}}\right)$, normalized mean shear stress $\left(\tau_{\operatorname{mean}} / \tau_{\max \text { static }}\right)$, cycles per stage $\left(\mathrm{N}_{\mathrm{s}}\right)$, and stiffness $(\mathrm{k})$. The CIDSTs under ICAs had a cyclic amplitude increase of 0.05 in each stage. The initial normal stress and stiffness were set at $100 \mathrm{kPa}$ and $450 \mathrm{kPa} / \mathrm{mm}$, respectively. These values reproduce an average normal effective stress that acts on a pile-soil system in common geotechnical applications. Two CIDSTs were performed with an initial normal stress and stiffness of $100 \mathrm{kPa}$ and $200 \mathrm{kPa} / \mathrm{mm}$, respectively, to evaluate the model efficacy to other confinement conditions. All specimens were prepared with a relative density of $70 \%$, and the shear displacement rate was set to $0.5 \mathrm{~mm} / \mathrm{min}$, which corresponded to an average frequency of 1 cycle per minute or $0.017 \mathrm{~Hz}$.

Figure 5.2a displays the cyclic stability diagram of the CIDSTs under ICA. Three constant normalized mean shear stresses of $0.10,0.30$ and 0.50 were established. Figure 5.2b and c shows an example of CIDSTs under ICAs and CCAs. For ICAs, several cyclic stages were performed until failure occured (Fig. 5.2b). The cyclic stage at failure was set for a new CIDST under CCA (i.e., the CIDSTs under CCAs were performed under the same cyclic amplitude as that corresponding to failure in the CIDSTs under ICAs) (Fig. 5.2c). The initial conditions of the CIDSTs include the initial normal stress $\left(\sigma_{i}\right)$, stiffness $(k)$ and mean shear stress $\left(\tau_{\text {mean }}\right)$. Under ICAs, the initial conditions also required the number of cycles per stage $\left(\mathrm{N}_{\mathrm{s}}\right)$ and cyclic amplitude increment in each stage $\left(\Delta \tau_{\mathrm{cyc}}\right)$. Under CCAs, the initial conditions also needed the cyclic amplitude $\left(\tau_{\text {cyc }}\right)$ (Fig. 5.2c). The results of the CIDSTs under ICAs comprised the total number of cycles $\left(\mathrm{N}_{\mathrm{t}, \mathrm{i}}\right)$, the number of cycles in the last cyclic stage $\left(\mathrm{N}_{\mathrm{f}}\right)$ and the cyclic amplitude at failure. The results of the CIDSTs under CCAs provided only the number of cycles to failure $\left(\mathrm{N}_{\mathrm{t}, \mathrm{c}}\right)$. 

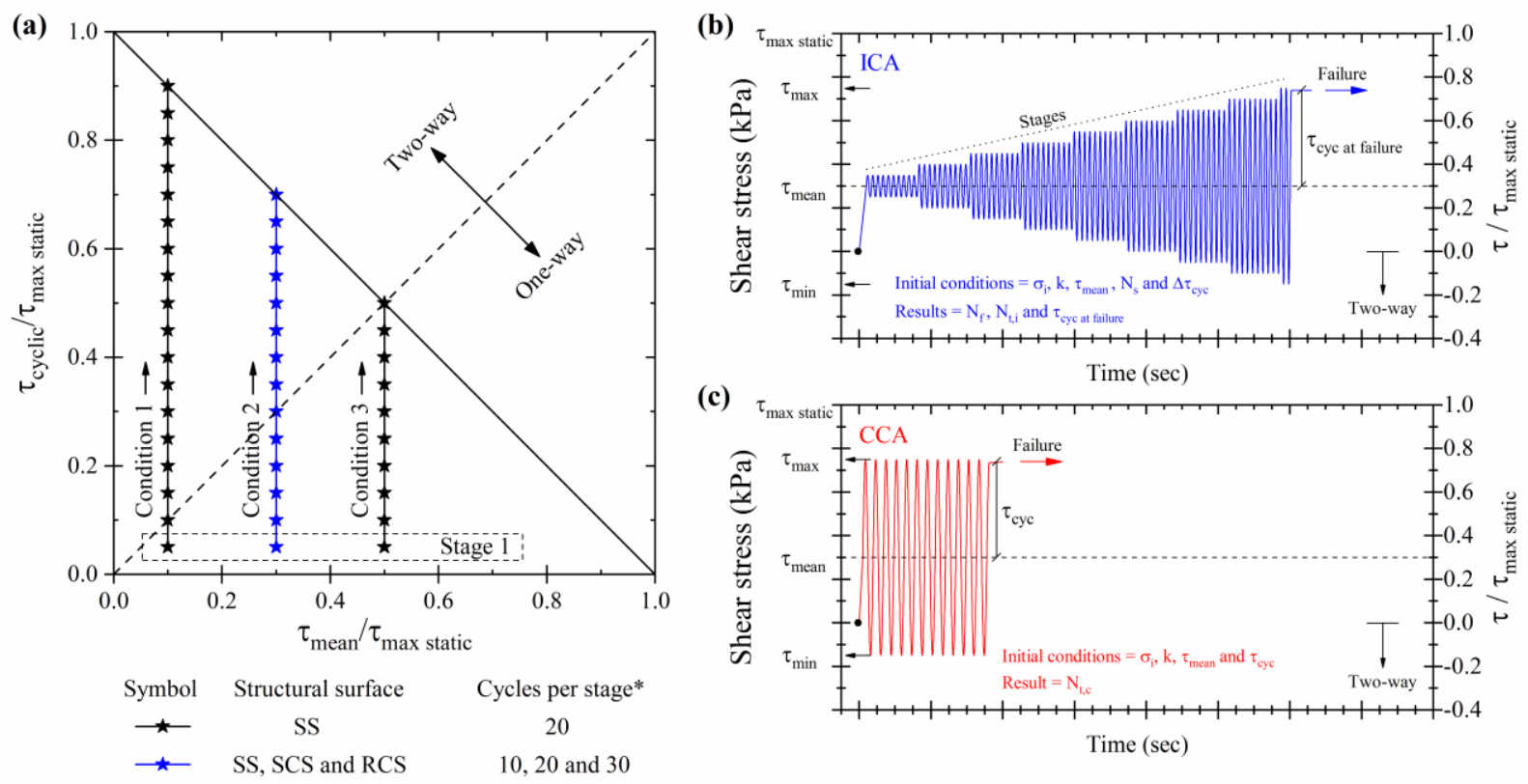

Figure 5.2: Experimental test methodology: (a) cyclic stability diagram of a sand-solid interface under ICAs; (b) a CIDST under ICA; and (c) a CIDST under CCA. Note: * Until failure occurs.

\subsubsection{Results}

Figure 5.3 shows the failure envelopes of the sand-sand friction and sand-solid interfaces. As the normalized roughness increased, higher interfacial friction angles were obtained. The shear strength of the RCSs was similar to that of the sand, while the post-peak friction angles of the SCSs and SSs were $87 \%$ and $84 \%$ of the post-peak friction angle of the sand, respectively. These high values of the interfacial-to-internal friction angle ratio $(\delta / \varphi)$ were expected due to the angular shape of the sand particles and the high normalized roughness values, which were greater than $9 \%$ of the mean sand diameter. In terms of the stress-displacement behaviour, the RCSs exhibited strain-softening behavior, whereas the SCSs exhibited less pronounced strain-softening behaviour. SSs had a strain-hardening interfacial response, and no clear peak strength was identified. Further details about the monotonic response of the sand-concrete interface are presented in subsection 4.1.

Figure 5.3 displays the response of the sand-solid interface under CNS conditions of $450 \mathrm{kPa} / \mathrm{mm}$. Under CNS conditions, the RCSs developed greater shear stress due to the increase in the normal stress as a consequence of the dilative behaviour. The SSs and SCSs did not exhibited significant volume variations, and as a result, the normal stress remained approximately constant. Under this CNS condition, the residual shear stress of the RCS was $100 \mathrm{kPa}$, whereas the residual shear stress of both the SS and the SCS was approximately 50 $\mathrm{kPa}$. 


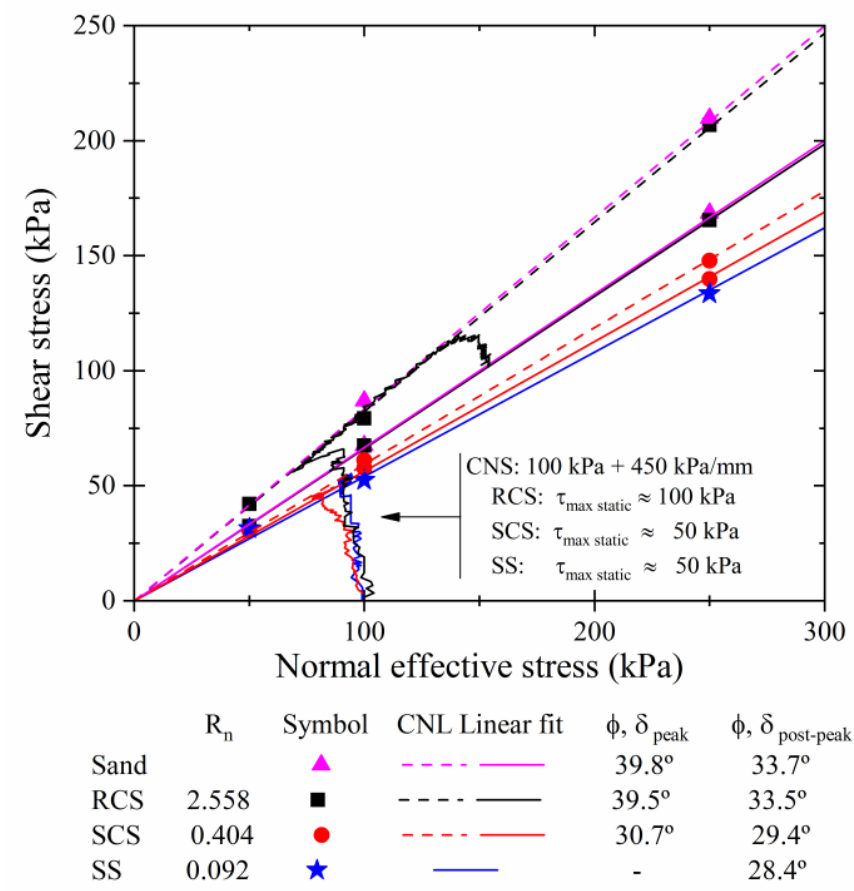

Figure 5.3: Monotonic responses of the sand-solid interfaces.

Table 5.1 summarizes the main test results of the CIDSTs under ICAs and CCAs. This table documents important values regarding the interfacial cyclic response, including the total number of cycles until failure $\left(\mathrm{N}_{\mathrm{t}}\right)$, number of cycles per stage $\left(\mathrm{N}_{\mathrm{s}}\right)$, number of cycles in the last cyclic stage $\left(\mathrm{N}_{\mathrm{f}}\right)$ and the final normalized cyclic amplitudes $\left(\tau_{\mathrm{cyc}} / \tau_{\mathrm{max}}\right.$ static $)$. As mentioned above, the CIDSTs under ICAs had a cyclic amplitude increase of 0.05 in each stage. 
Table 5.1: CIDST results under ICAs and CCAs.

\begin{tabular}{|c|c|c|c|c|c|c|c|c|c|c|}
\hline \multirow[b]{2}{*}{$\begin{array}{c}\text { Structural } \\
\text { surface }\end{array}$} & \multirow[b]{2}{*}{$\begin{array}{c}\text { CIDST } \\
\text { type }\end{array}$} & \multirow[b]{2}{*}{$\begin{array}{c}\text { Test } \\
\text { abbreviation }\end{array}$} & \multirow[b]{2}{*}{$\sigma_{\mathrm{i}} \mathrm{kPa}$} & \multirow[b]{2}{*}{$\begin{array}{c}\mathrm{k} \\
\mathrm{kPa} / \mathrm{mm} \\
\end{array}$} & \multirow[b]{2}{*}{$\begin{array}{c}\text { Constant } \\
\tau_{\text {mean }} / \tau_{\max \text { static }} \\
\end{array}$} & \multirow[b]{2}{*}{$\begin{array}{c}\text { Initial } \\
\tau_{\mathrm{cyc}} / \tau_{\max \text { static }} \\
\end{array}$} & \multirow[b]{2}{*}{$\mathrm{N}_{\mathrm{s}}$} & \multicolumn{3}{|c|}{ Failure } \\
\hline & & & & & & & & $\tau_{\text {cyc }} / \tau_{\text {max static }}$ & $\mathrm{N}_{\mathrm{f}}$ & $\mathrm{N}_{\mathrm{t}}$ \\
\hline \multirow{12}{*}{$\begin{array}{l}\quad \text { SSs } \\
\mathrm{R}_{\mathrm{a}}=0.002 \mathrm{~mm} \\
\mathrm{R}_{\max }=0.022 \mathrm{~mm} \\
\mathrm{R}_{\mathrm{n}}=0.092\end{array}$} & \multirow{6}{*}{ ICA } & SS-ICA-01 & 100 & 450 & 0.10 & 0.05 & 20 & 0.40 & 5 & 145 \\
\hline & & SS-ICA-02 & 100 & 450 & 0.30 & 0.05 & 10 & 0.50 & 2 & 92 \\
\hline & & SS-ICA-03 & 100 & 450 & 0.30 & 0.05 & 20 & 0.40 & 2 & 142 \\
\hline & & SS-ICA-04 & 100 & 450 & 0.30 & 0.05 & 30 & 0.35 & 26 & 206 \\
\hline & & SS-ICA-05 & 100 & 450 & 0.50 & 0.05 & 20 & 0.30 & 6 & 106 \\
\hline & & SS-ICA-06 & 100 & 200 & 0.30 & 0.05 & 20 & 0.60 & 1 & 221 \\
\hline & \multirow{6}{*}{ CCA } & SS-CCA-01 & 100 & 450 & 0.10 & 0.40 & - & 0.40 & - & 32 \\
\hline & & SS-CCA-02 & 100 & 450 & 0.30 & 0.50 & - & 0.50 & - & 5 \\
\hline & & SS-CCA-03 & 100 & 450 & 0.30 & 0.40 & - & 0.40 & - & 49 \\
\hline & & SS-CCA-04 & 100 & 450 & 0.30 & 0.35 & - & 0.35 & - & 83 \\
\hline & & SS-CCA-05 & 100 & 450 & 0.50 & 0.30 & - & 0.30 & - & 38 \\
\hline & & SS-CCA-06 & 100 & 200 & 0.30 & 0.60 & - & 0.60 & - & 34 \\
\hline \multirow{6}{*}{\begin{tabular}{l}
\multicolumn{1}{c}{ SCSs } \\
$\mathrm{R}_{\mathrm{a}}=0.005 \mathrm{~mm}$ \\
$\mathrm{R}_{\max }=0.097 \mathrm{~mm}$ \\
$\mathrm{R}_{\mathrm{n}}=0.404$
\end{tabular}} & \multirow{3}{*}{ ICA } & SCS-ICA-01 & 100 & 450 & 0.30 & 0.05 & 10 & 0.50 & 10 & 100 \\
\hline & & SCS-ICA-02 & 100 & 450 & 0.30 & 0.05 & 20 & 0.45 & 14 & 174 \\
\hline & & SCS-ICA-03 & 100 & 450 & 0.30 & 0.05 & 30 & 0.35 & 21 & 201 \\
\hline & \multirow{3}{*}{$\mathrm{CCA}$} & SCS-CCA-01 & 100 & 450 & 0.30 & 0.50 & - & 0.50 & - & 5 \\
\hline & & SCS-CCA-02 & 100 & 450 & 0.30 & 0.45 & - & 0.45 & - & 22 \\
\hline & & SCS-CCA-03 & 100 & 450 & 0.30 & 0.35 & - & 0.35 & - & 76 \\
\hline \multirow{6}{*}{$\begin{array}{l}\quad \text { RCSs } \\
\mathrm{R}_{\mathrm{a}}=0.052 \mathrm{~mm} \\
\mathrm{R}_{\max }=0.614 \mathrm{~mm} \\
\mathrm{R}_{\mathrm{n}}=2.558\end{array}$} & \multirow{3}{*}{ ICA } & RCS-ICA-01 & 100 & 450 & 0.30 & 0.05 & 10 & 0.50 & - & 94 \\
\hline & & RCS-ICA-02 & 100 & 450 & 0.30 & 0.05 & 20 & 0.45 & - & 165 \\
\hline & & RCS-ICA-03 & 100 & 450 & 0.30 & 0.05 & 30 & 0.45 & - & 242 \\
\hline & \multirow{3}{*}{ CCA } & RCS-CCA-01 & 100 & 450 & 0.30 & 0.50 & - & 0.50 & - & 3 \\
\hline & & RCS-CCA-02 & 100 & 450 & 0.30 & 0.45 & - & 0.45 & - & 7 \\
\hline & & RCS-CCA-03 & 100 & 450 & 0.30 & 0.35 & - & 0.35 & - & 37 \\
\hline
\end{tabular}

\section{Effect of low-level cycling}

Low-level cycling refers to low cyclic amplitude values that can lead to an increase in shaft capacity. In practice, low-level cycling is related to the stable zone of the cyclic stability diagram. The effect of low-level cycling on the interfacial response depended on the surface roughness (Fig. 5.4). The average number of cycles until failure occurs was approximately 160 cycles. The SCS had the highest number of cycles $\left(\mathrm{N}_{\mathrm{t}, \mathrm{i}}=174\right)$, whereas SS had the lowest values $\left(\mathrm{N}_{\mathrm{t}, \mathrm{i}}=142\right)$. These cycles took place before $1.2 \mathrm{~mm}$ of shear displacement for the RCS and $0.60 \mathrm{~mm}$ for the SS and SCS. The RCS and SCS achieved a shear stress at failure of 75.0 $\mathrm{kPa}$ and $37.5 \mathrm{kPa}$, respectively, which both correspond to a normalized cyclic amplitude of 0.45. SS exhibited a shear stress at failure of $35 \mathrm{kPa}$, which corresponds to a normalized cyclic amplitude of 0.40 .

Low-level cycling developed greater particle interlocking, especially in the RCS (Fig. 5.4d). For the SS, particle slippage remained the main mechanism of interfacial failure even 
after low-level cycling. Figure 5.4d shows that the maximum stress ratios exhibited by the RCS and SCS were 1.04 and 0.67 , which correspond to interfacial peak friction angles of $46.1^{\circ}$ and $33.8^{\circ}$, respectively (i.e., an increase of $16.7 \%$ and $10.1 \%$ from the static peak friction angle). The SS exhibited no peak friction angle despite low-level cycling. After failure occurred, the shear stresses moved towards the static post-peak shear stress value, regardless of the surface roughness (Fig. 5.4d).
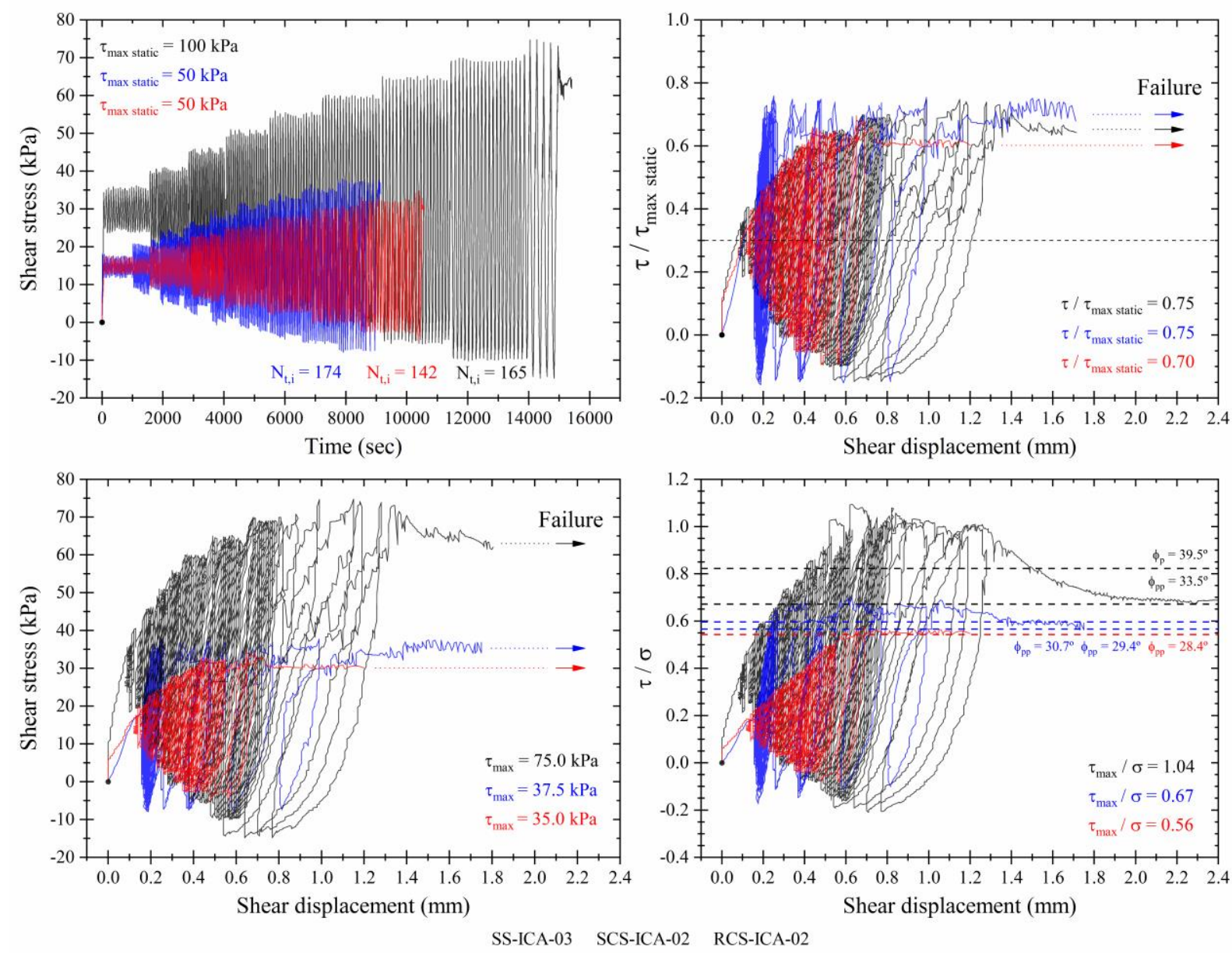

Figure 5.4: Effect of low-level cycling on the cyclic response of the sand-solid interface. The results of the CIDSTs under ICAs of 20 cycles per stage with a normalized mean shear stress of 0.30 .

\section{Cycling under constant and increasing amplitudes}

The cyclic responses of the sand-steel interface under ICAs and CCAs are plotted in Figure 5.5. Increasing the number of cycles per stage led to an increase in the total number of cycles, and in turn, the cyclic amplitude at failure decreased (Fig. 5.5a). Higher values of shear stress at failure were achieved as the total number of cycles decreased. Failure usually 
occurred after two-way cycling initiated. Cyclic failure of the sand-steel interface occured prior to a $0.6 \mathrm{~mm}$ shear displacement, regardless of the cyclic amplitude. The CIDSTs under CCAs obtained lower numbers of cycles to failure than the CIDSTs under ICAs (Fig. 5.5b). As the CCA increased, the number of cycles to failure decreased.
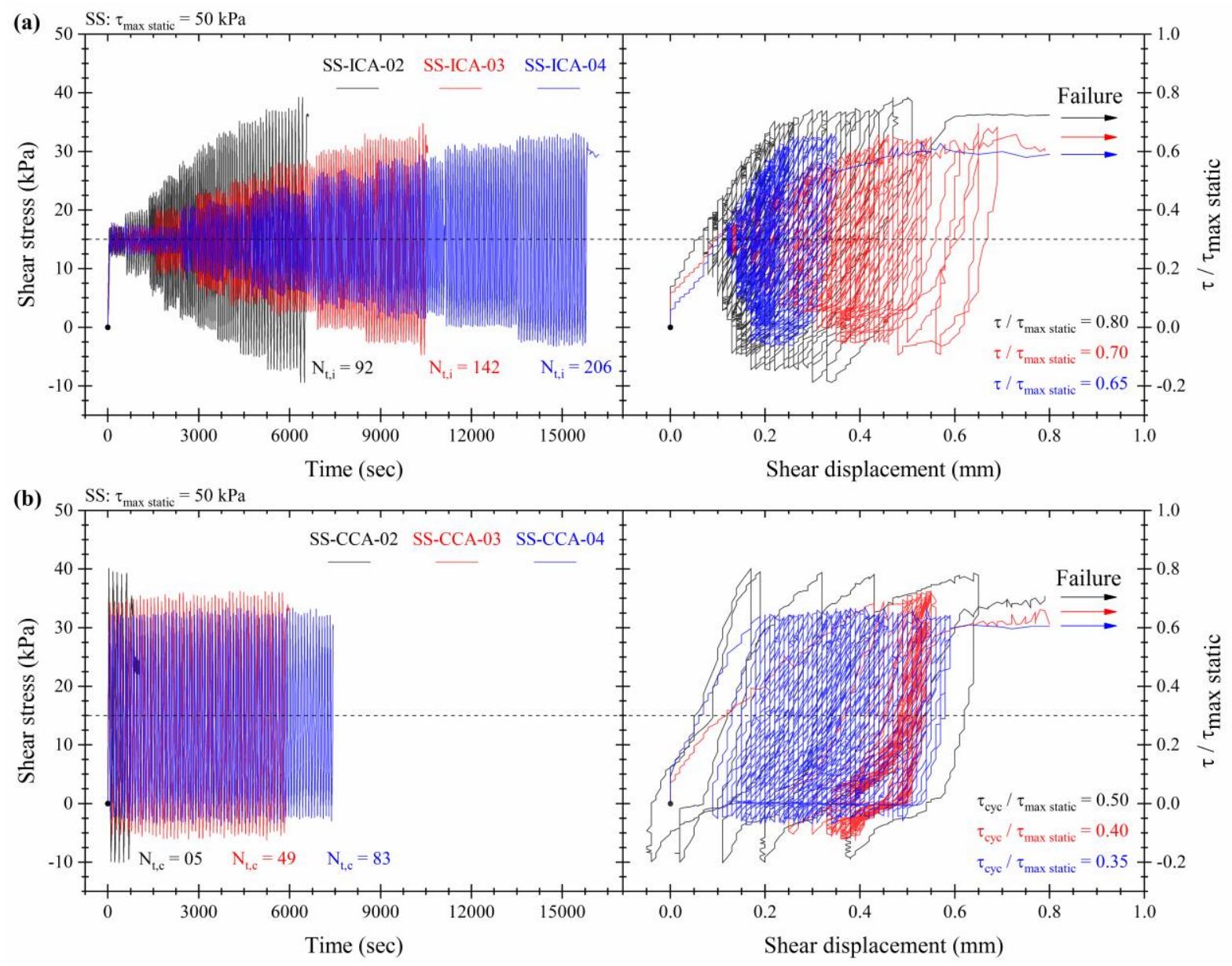

Figure 5.5: CIDSTs of the sand-steel interface under (a) ICAs and (b) CCAs with a normalized mean shear stress of 0.30 .

Figure 5.6 displays the cyclic response of the sand-smooth concrete interface, wherein similar trends to the cyclic response of the sand-steel interface were observed. The increase in the number of cycles per stage increased the total number of cycles and, in turn, the cyclic amplitude at failure decreased. Cyclic failure occurred prior to a $1.2 \mathrm{~mm}$ shear displacement, regardless of the cyclic amplitude. For ICAs, the total number of cycles of sand-smooth concrete interface was generally higher than that of the sand-steel interface. However, for CCAs, the number of cycles of the sand-smooth concrete interface was lower than that of the sand-steel interface. 

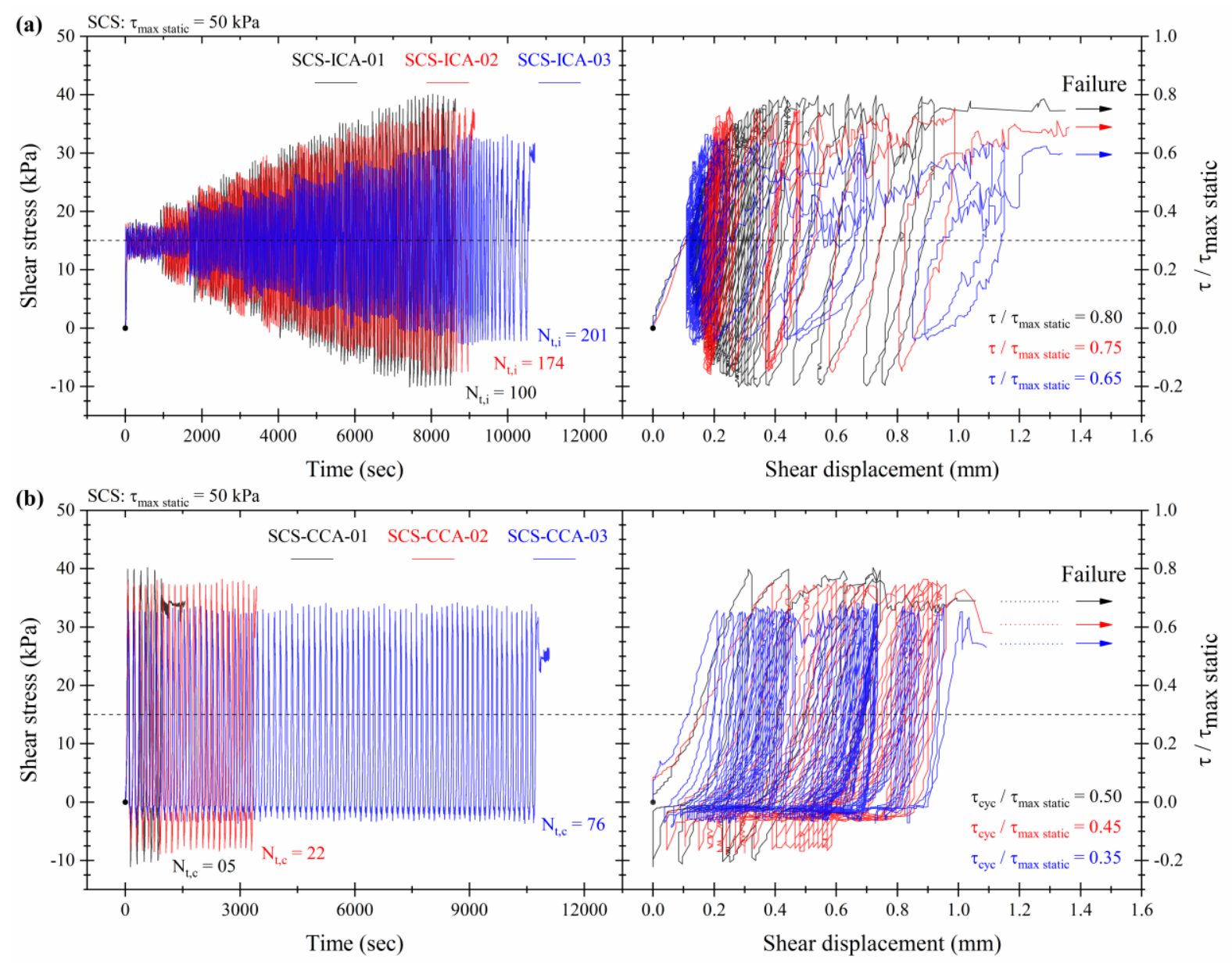

Figure 5.6: CIDSTs of the sand-smooth concrete interface under (a) ICAs and (b) CCAs with a normalized mean shear stress of 0.30 .

The cyclic response of the sand-rough concrete interface is plotted in Figure 5.7, where in similar trends to the cyclic responses of the sand-steel and sand-smooth concrete interfaces were observed. Under ICAs, the increase in the cycles per stage led to an increase in the total number of cycles, and in turn, the cyclic amplitude at failure decreased. Cyclic failure occurred prior to a $2 \mathrm{~mm}$ shear displacement, regardless of the cyclic amplitude. Under ICAs, the total number of cycles of the sand-rough concrete interface was higher than those of the sand-steel and sand-smooth concrete interfaces. For CCAs, the number of cycles of the sand-rough concrete interface was lower than those of the sand-steel and sand-smooth concrete interfaces. 

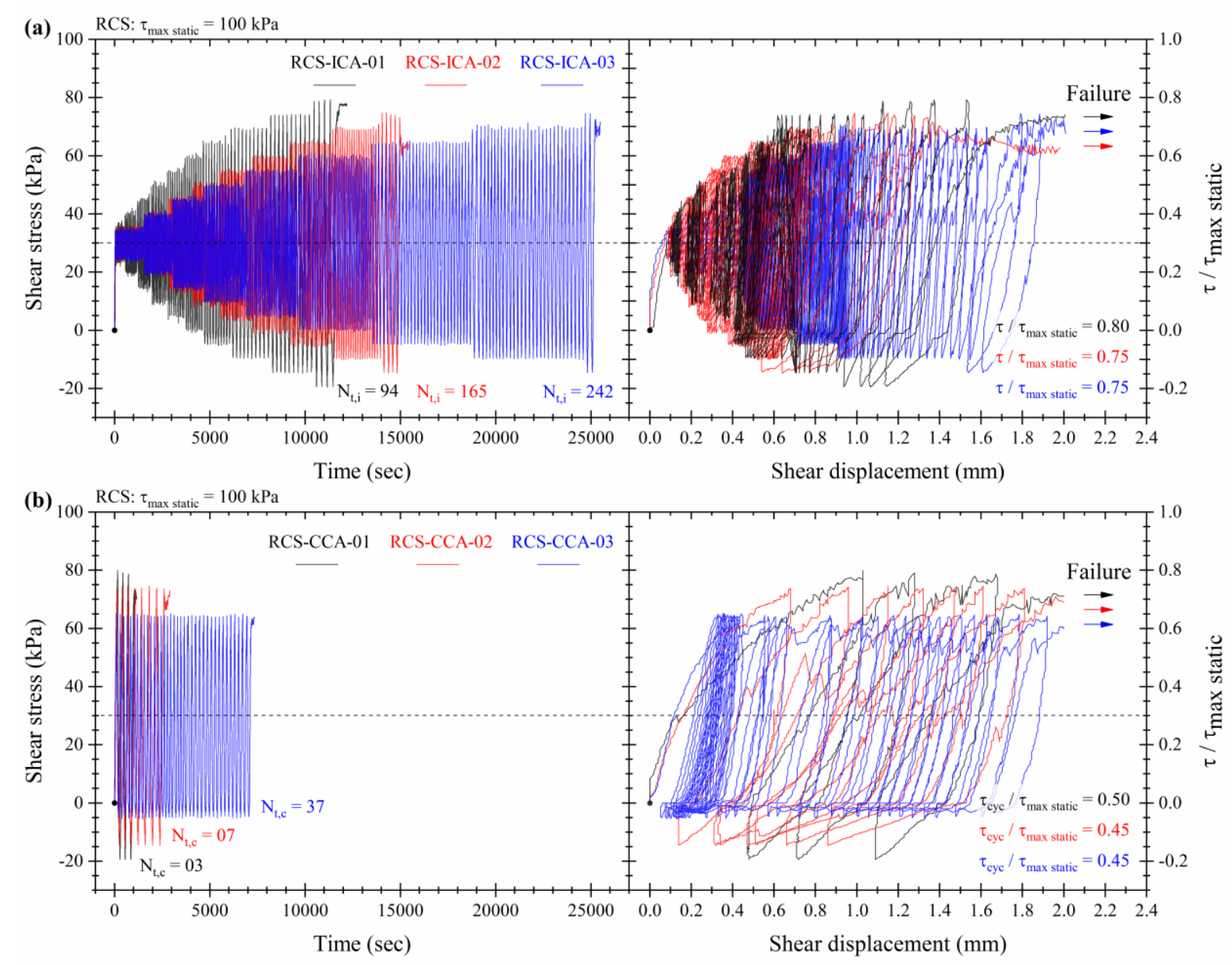

Figure 5.7: CIDSTs of the sand-rough concrete interface under (a) ICAs and (b) CCAs with a normalized mean shear stress of 0.30 .

\section{Cyclic stability diagrams}

The cyclic stability diagrams were developed based on the CIDST results (Table 1). Figure 5.8 shows these diagrams under ICAs (left column) and CCAs (right column) for the SSs, SCSs and RCSs. The cyclic stability diagrams of the sand-steel interface show that the linear fit was in good agreement with the experimental results (Fig. 5.8a). A linear fit was selected due to the limited data and practical applicability; however, nonlinear isolines would have a better fit than linear isolines because nonlinear isolines could better capture the effect of the normalized mean shear stress.

Similar trends were observed in the cyclic stability diagrams of the SSs, SCSs and RCSs. As the number of cycles per stage increased, the cyclic amplitude at failure decreased. The CIDSTs under CCAs obtained a lower number of cycles to failure than the CIDSTs under ICAs (Fig. 5.8). The cyclic stability diagrams clearly show that as the surface roughness increased, the number of cycles to failure increased for ICAs and decreased for CCAs. For example, SS-ICA-03 and SS-CCA-03 required 142 and 49 cycles to experience failure, 
respectively, whereas RCS-ICA-02 and RCS-CCA-02 required 165 and 7 cycles to experience failure, respectively (Table 1).

The cyclic stability diagrams were developed based on a power function relationship between the number of cycles and the cyclic amplitude at zero mean shear stress. This power function proved to fit well with the experimental results and literature data (Fig. 5.9). Eqs. 5.1 and 5.2 show the power functions used in this study.

$$
\begin{aligned}
& N_{t, i}=\alpha_{i}\left(\frac{\tau_{c y c}}{\tau_{\max \text { static }}}\right)^{-\beta_{i}} \\
& N_{t, c}=\alpha_{c}\left(\frac{\tau_{\text {cyc }}}{\tau_{\max \text { static }}}\right)^{-\beta_{c}}
\end{aligned}
$$

where $\mathrm{N}_{\mathrm{t}, \mathrm{i}}$ and $\mathrm{N}_{\mathrm{t}, \mathrm{c}}$ are the number of cycles to failure under ICAs and CCAs, respectively; $\tau_{\text {cyc }} / \tau_{\max \text { static }}$ is the normalized cyclic amplitude; and $\alpha_{\mathrm{i}}$ and $\beta_{\mathrm{i}}$ and $\alpha_{\mathrm{c}}$ and $\beta_{\mathrm{c}}$ are fitting parameters for ICAs and CCAs, respectively. A logarithmic relationship between $\alpha$ and $\beta$ was observed (Fig. 5.9). The simple, closed-form Eqs. 5.1 and 5.2 can be related to express the relationship between the number of cycles to failure under ICAs and CCAs, as shown in Eq. 5.3.

$$
\frac{N_{t, i}}{N_{t, c}}=\frac{\alpha_{i}}{\alpha_{c}}\left(\frac{\tau_{c y c}}{\tau_{\max \text { static }}}\right)^{\beta_{c}-\beta_{i}}
$$

Eq. 5.3 can provide a reasonable estimation of this relation when the number of cycles is less than 1,000 cycles. If the number of cycles considerably surpasses 1,000 cycles, Eq. 5.2 might become superior to Eq. 5.1, which will cause the values of Eq. 5.3 to become less than 1.0. The results indicated that the numerical difference of the $\beta$ parameter ranged from 1.9 to 2.1 , regardless of the test conditions. In most cases, an average $\beta$ parameter difference of 2.0 can successfully extended to other conditions. The $\alpha$ parameter relationship depended on the power function parameters (i.e., experimental results) which, in turn, relied on the interfacial characteristics and confinement conditions. 

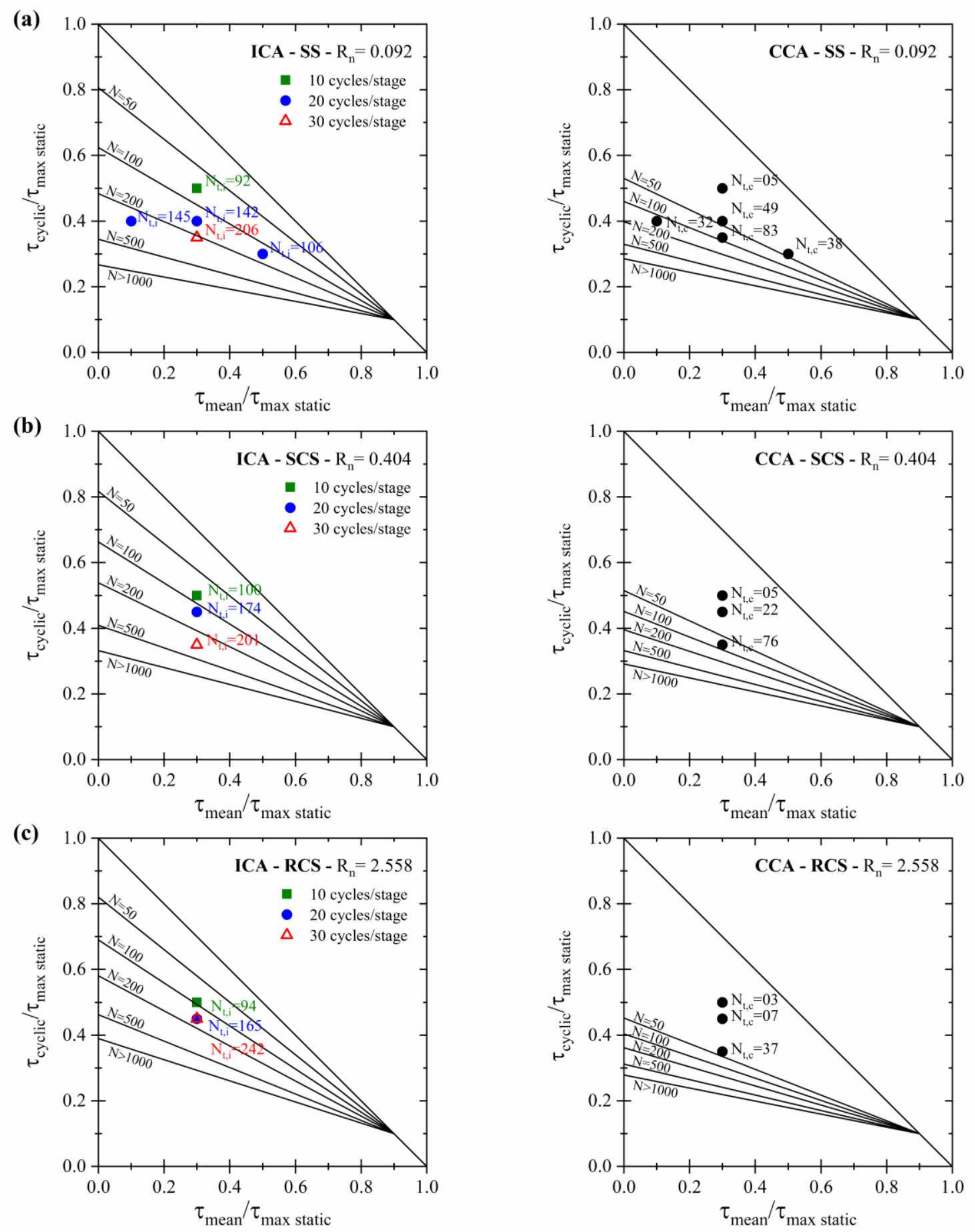

Figure 5.8: Cyclic stability diagrams under (left column) ICAs and (right column) CCAs for the (a) sand-steel interface, (b) sand-smooth concrete interface and (c) sand-rough concrete interface. 


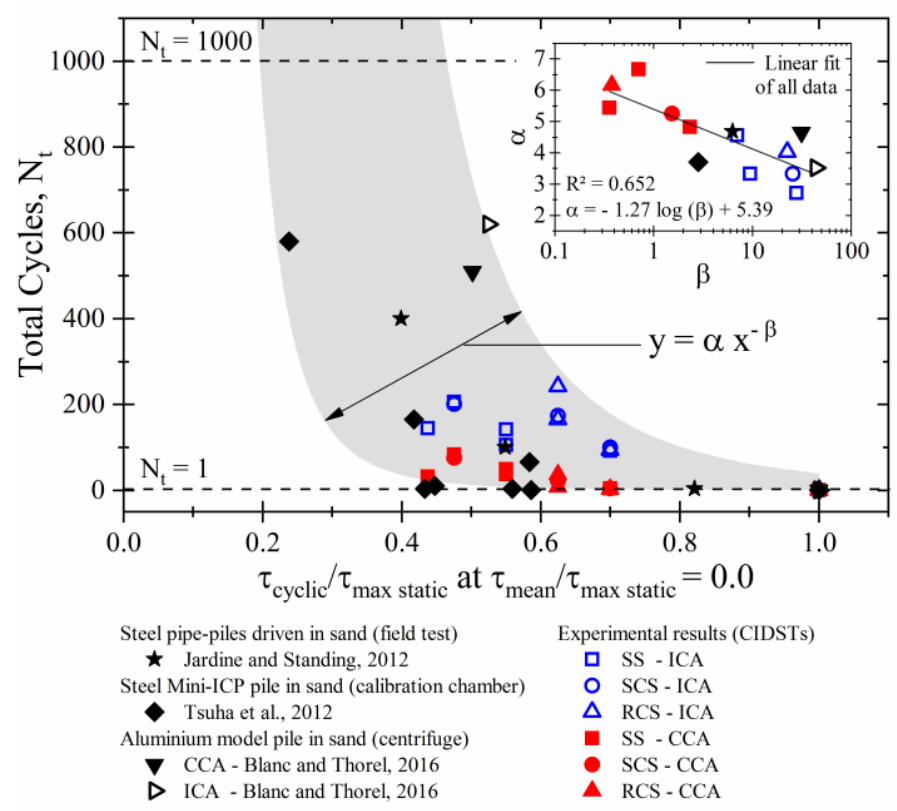

Figure 5.9: Power function relationship of the cyclic stability diagram of the sand-solid interfaces.

\section{Cumulative damage model}

The cumulative damage theory assumes that a series of cyclic loads develop permanent damage accumulation. Cumulative damage models are often used for fatigue life predictions. These models are commonly used for industrial materials and fracture mechanics. A nonlinear cumulative damage model was developed to relate the interfacial cyclic response under ICAs and CCAs. Eq. 5.4 shows the proposed simple cumulative damage model function. This function was based on the nonlinear modification of Palmgren-Miner's rule (Palmgren, 1924; Miner, 1945). The cumulative damage value equal to 1.0 expresses fatigue failure or, in this case, cyclic interfacial failure.

$$
D=\sum_{i=1,2, \cdots} \kappa\left(\frac{n_{i}}{N_{t, c, i}}\right)^{\eta}
$$

where $\mathrm{D}$ is the cumulative damage, $\mathrm{n}_{\mathrm{i}}$ is the number of cycles performed at a certain cyclic amplitude, $\mathrm{N}_{\mathrm{t}, \mathrm{c}, \mathrm{i}}$ is the number of cycles to failure under a CCA (Eq. 5.2) at certain cyclic amplitudes, and $\eta$ and $\kappa$ are model fitting parameters. These fitting parameters were back-analysed based on the experimental results and their derived power functions. As these parameters are directly based on the cyclic results, they consider all types of effects, such as the surface roughness, low-level cycling, confinement conditions, and relative density. Eqs. 
5.5 and 5.6 were used to determine these parameters in a simple manner. These equations showed the best fits and regression coefficients to the experimental data.

$$
\begin{gathered}
\eta=\frac{1}{\beta_{c}-\beta_{i}} \\
\kappa=\frac{1}{A-B e^{C}}
\end{gathered}
$$

where $\beta_{\mathrm{c}}$ and $\beta_{\mathrm{i}}$ are the fitting parameters of the power functions under CCAs and ICAs and A, B and C are as yet undetermined parameters. These model fitting parameters can be effortless determined. The $\eta$ parameter is mainly based on the exponential parameters of power functions under ICAs and CCAs. The $\kappa$ parameter depends on several factors; however, the $\kappa$ parameter can be back analysed based on a first cumulative damage estimation. Figure 5.10 captures the behaviour of $\eta$ and $\kappa$ model parameters.

Figure $5.10 \mathrm{a}$ shows the $\kappa$ parameter value according to the normalized roughness and number of cycles per stage. The A, B and C were effortlessly determined. The A and B parameters determine the minimum and maximum $\kappa$ parameter values, which depend on the normalized roughness value. In turn, the $\mathrm{C}$ parameter influenced the form of the curve and relied upon the number of cycles per stage. Based on the experimental results, the backanalysed $\kappa$ parameter ranged from 0.20 to 0.60 . As the cumulative damage value can significantly vary with a minor change in the number of cycles, a variation band of $20 \%$ was established. This variation band was defined according to the standard deviation of the obtained damage, as shown later in Fig. 5.11a. Figure 5.10a also shows that the $\kappa$ parameter value can range from 0.15 to 0.25 for low values of cycles per stage. As the number of cycles per stage increased, the $\kappa$ parameter value increased in a nonlinear manner. For high values of cycles per stage, the $\kappa$ parameter value can range from 0.30 to 0.75 depending on the surface roughness.

The $\eta$ parameter ranged from 0.48 to 0.51 , regardless of the normalized roughness (Fig. 5.10b). The number of cycles per stage did not have a significant effect. A value of 0.50 was defined for $\eta$, which showed good agreement with experimental results. 

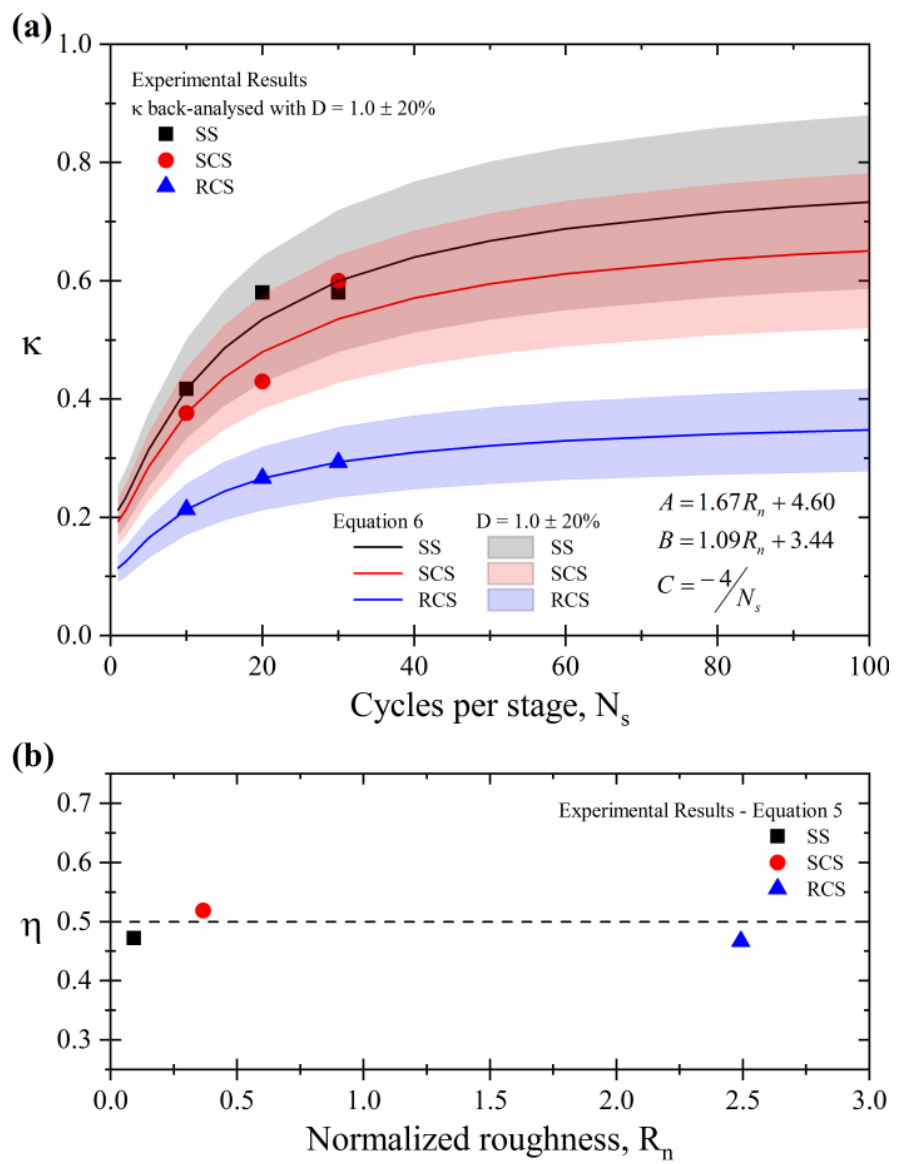

Figure 5.10: Cumulative damage model fitting parameters: (a) $\kappa$ fitting parameter and (b) $\eta$ fitting parameter.

The cumulative damage value had a considerable spread in the results, wherein the standard deviation was 0.206 (Fig. 5.11a). Minor variations in the number of cycles at this stage caused a significant spread in the results. This observation was confirmed when analysing the predicted versus experimental total number of cycles under ICAs (Fig. 5.11b).

The predicted total number of cycles corresponds to a cumulative damage value of 1.0. First, based on the power function (Eq. 5.2), the number of cycles to failure under CCAs was determined for several cyclic amplitudes. Second, based on the initial conditions (i.e., normalized roughness and cycles per stage), the cumulative damage model fitting parameters were determined (Eqs. 5.5 and 5.6). Finally, Eq. 5.4 was used to sum the damages caused by cyclic stages until the cumulative damage value reached 1.0. Another approach was to determine the number of cycles to failure under ICAs for a certain cyclic amplitude based on the power function (Eq. 5.1) and then determine the number of cycles per stage.

The cumulative damage model demonstrated great agreement with the experimental results (Fig. 5.12). According to the cumulative damage model and experimental results, the cyclic amplitude at failure produces the most severe damage to the cyclic response. The 
cumulative damage model accurately predicted the total number of cycles and cyclic amplitude at failure (Fig. 5.12). The observed spread in the cumulative damage value can be expected when examining several experimental and field investigations. Tests performed under the same conditions would probably have minor differences in the total number of cycles and cyclic amplitude at failure.
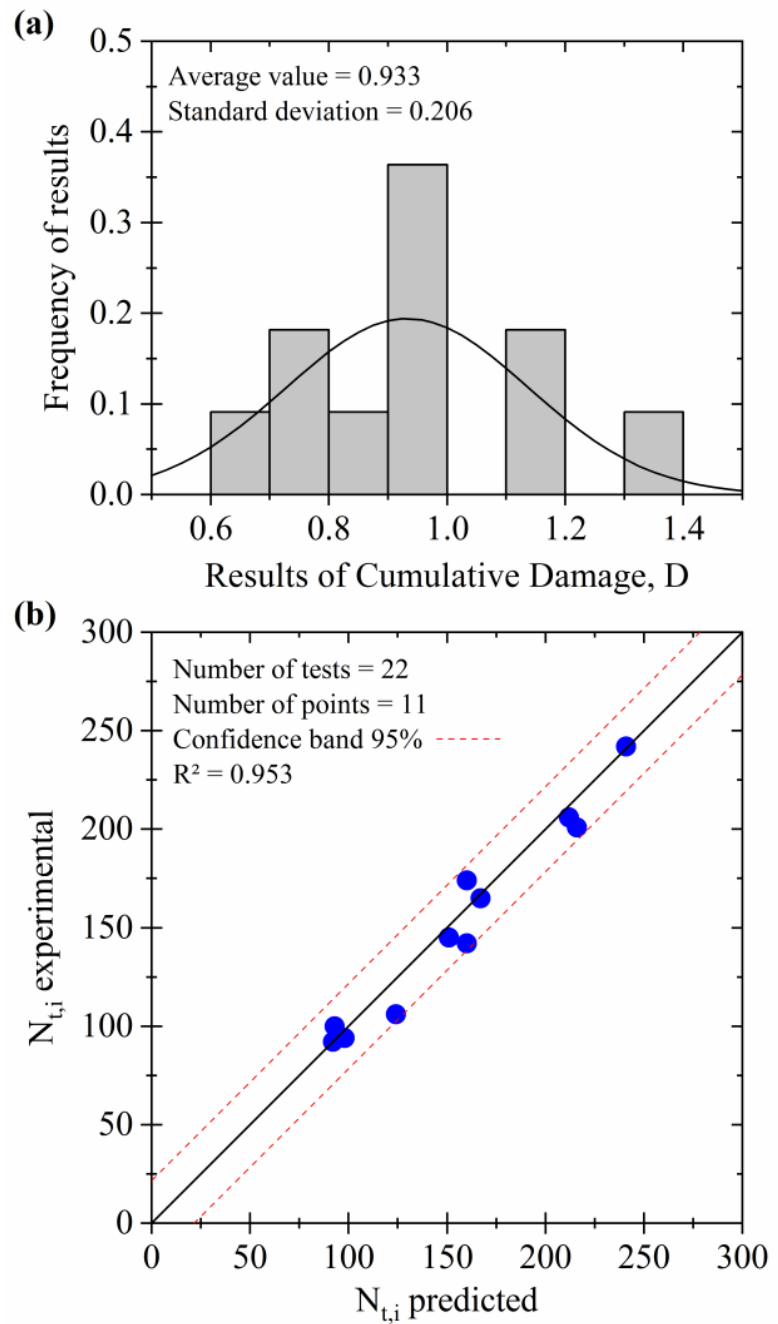

Figure 5.11: Cumulative damage model: (a) spread of cumulative damage results and (b) measured versus predicted total number of cycles. 
(a) SS

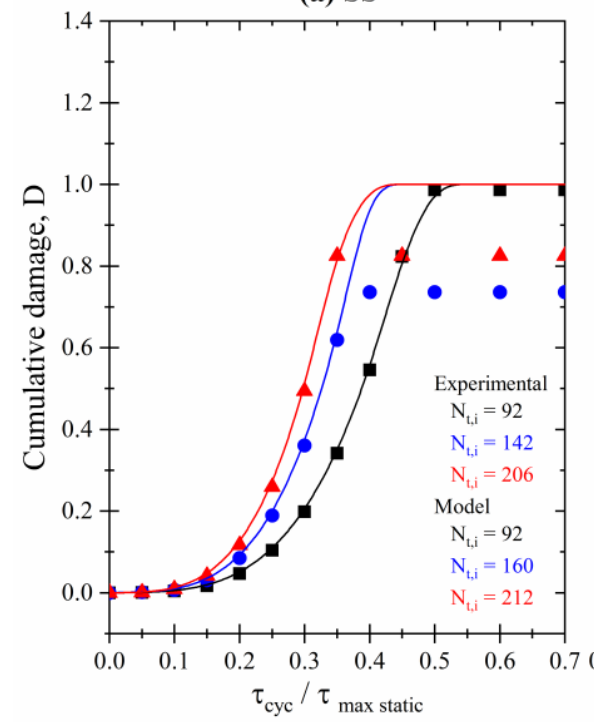

(b) SCS

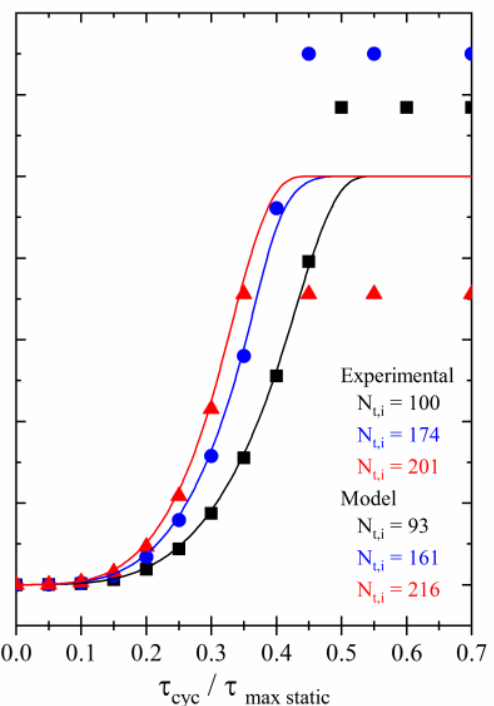

(c) RCS

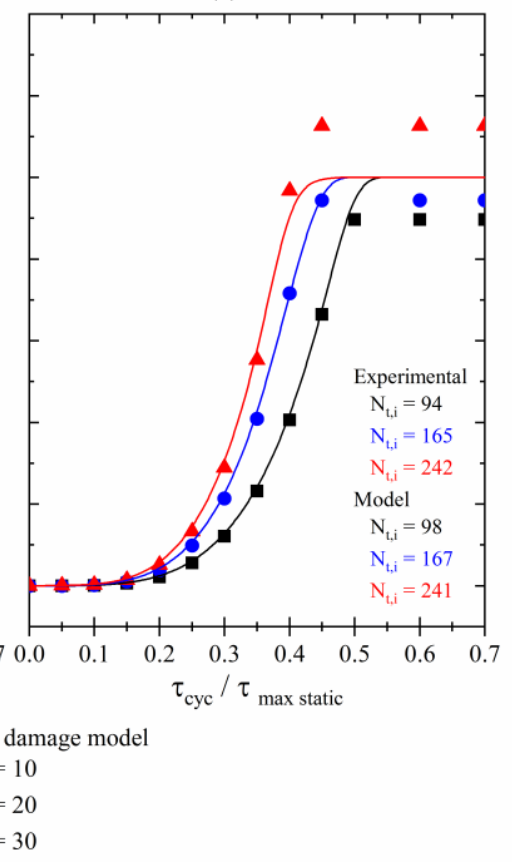

Figure 5.12: Cumulative damage model and experimental results considering a normalized mean shear stress of 0.30: (a) sand-steel interface, (b) sand-smooth concrete interface and (c) sand-rough concrete interface.

\section{Parametric analysis}

The effects of the surface roughness and cycles per stage were captured by the cumulative damage model (Fig. 5.13). Figure 5.13 shows the predicted behaviour of the model under three different numbers of cycles per stage-5, 40 and 100 cycles - for the three sand-solid interfaces. Regardless of the surface roughness, as the number of cycles per stage increased, the cycle amplitude at failure decreased and the total number of cycles increased.

As the surface roughness increased, the number of cycles to failure and the cyclic amplitude at failure increased (Fig. 5.13). However, for high rates of ICAs, only a minor difference was observed in the results. For example, for 5 cycles per stage, the total number of cycles for the RCS, SCS and SS ranged from 71 to 73 , and the final normalized cyclic amplitude was 0.75 . In turn, for 100 cycles per stage, the total number of cycles for the RCS, SCS and SS ranged from 700 to 811 , and the final normalized cyclic amplitudes were 0.45 , 0.40 and 0.35 , respectively.

This cumulative damage model accurately predicted the effects of low-level cycling on the interfacial cyclic response. As previously mentioned, low-level cycling resulted in increased grain interlocking, and consequently, the interfacial cyclic response improved. A few literature results have shown improved static strength after low-level cycling (i.e., lowlevel cycling resulted in decreased damage or increased energy). The present model does not 
directly consider this positive effect, as it would be difficult and non-conservative to use in engineering practice. The model, in turn, reproduced the effect of low-level cycling by mitigating damage at low cyclic amplitudes.

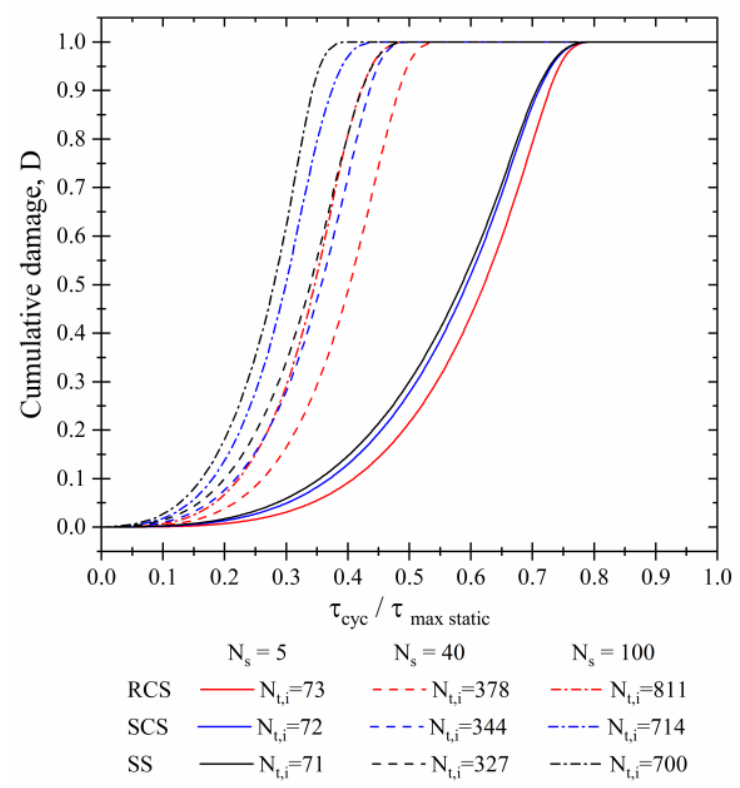

Figure 5.13: Cumulative damage model for different sand-solid interfaces and different numbers of cycles per stage.

\section{Comparison with other confinement conditions}

The confinement condition plays a major role in the magnitude of the shaft friction degradation of piles under cyclic axial loading. For example, under constant normal load conditions (i.e., a stiffness value of zero), minimal shaft friction degradation can be expected. The present methodology requires at least two cyclic load tests (i.e., one cyclic load test under ICA and one cyclic load test under CCA) to estimate the cyclic response under ICA. Based on these two results, the power functions can be estimated (Eqs. 5.1 and 5.2). Then, the cumulative damage model parameters can be determined (Eqs. 5.5 and 5.6). Finally, the cumulative damage model (Eq. 5.4) can be applied, and the cyclic stability diagrams can be constructed.

Thus, two sand-steel CIDSTs were performed under ICAs and CCAs. These CIDSTs were performed under CNS conditions with a stiffness of $200 \mathrm{kPa} / \mathrm{mm}$, an initial normal stress of $100 \mathrm{kPa}$ and a normalized mean shear stress of 0.30 . The CIDST under ICA was set to 20 cycles per stage. The results of these two CIDSTs are shown in Fig. 5.14a. For the CIDST under ICA, the total number of cycles and normalized cyclic amplitude at failure were 221 cycles and 0.55 , respectively. Under CCA, 34 cycles were required to achieve sand-steel 
interface failure (Fig. 5.14a). Afterwards, the results were fitted with power functions (Fig. 5.14b). The cumulative damage model was developed with $\eta$ and $\kappa$ parameter values of 0.50 and 0.53 , respectively. The $\kappa$ parameter was determined based on the $\mathrm{A}, \mathrm{B}$ and $\mathrm{C}$ values of Fig. 5.10 for a stiffness of $450 \mathrm{kPa} / \mathrm{mm}$. If the $\kappa$ parameter was back-analysed, a $\kappa$ value of 0.62 would be obtained to achieve a cumulative damage value of 1.0. However, these two value differences resulted in a $15 \%$ variation in the cumulative damage, which was considered within the expected spread (Fig. 5.11a). A great agreement between the model and experimental results was observed (Fig. 5.14c). Finally, the cyclic stability diagrams were developed for ICAs and CCAs, as plotted in Figure 5.14d and e, respectively.
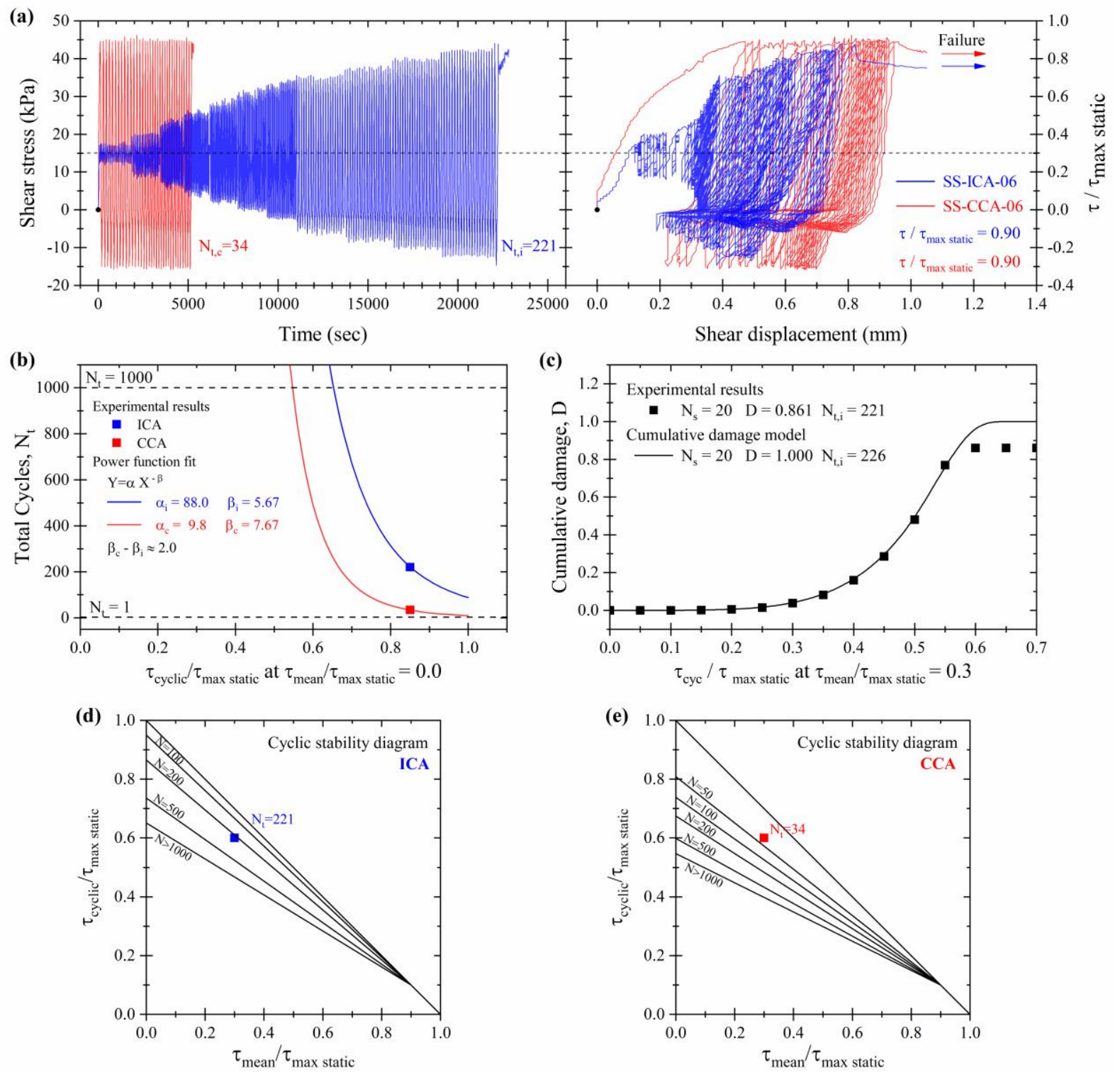

Figure 5.14: Response of the sand-steel interface under different confinement conditions: (a) results of the CIDSTs; (b) power functions; (c) cumulative damage model; and cyclic stability diagrams under (d) ICAs and (e) CCAs. 


\subsubsection{Conclusions}

This chapter established a relationship between the conventional cyclic design method and a new approach based on ICAs. The cyclic responses of sand-steel and sand-concrete interfaces were explored under constant and increasing cyclic load-controlled amplitudes. The sand-solid interface reproduced similar field conditions to grouted piles, steel-driven piles and concrete-driven piles embedded in sand. Several CIDSTs under CNS conditions were performed, and the main findings are listed below.

(a) Low-level cycling had a significant effect on the interfacial cyclic response. The sand-concrete interface had an increase in the peak stress ratio due to low-level cycling, especially for the sand-rough concrete interface. However, the sand-steel interface did not benefit from low-level cycling and exhibited no peak stress ratio. Low-level cycling can clearly promote particle interlocking, which enhances interfacial response.

(b) The interfacial cyclic responses of sand-steel, sand-smooth concrete and sandrough concrete exhibited similar trends under ICAs. As the number of cycles per stage increased, the normalized cycle amplitude at failure decreased, and the total number of cycles increased. However, the results were significantly affected by the surface roughness. Under ICAs, the total number of cycles to failure increased as the surface roughness increased. Under CCAs, the number of cycles to failure decreased as the surface roughness increased.

(c) A simple cumulative damage model was developed that related the cyclic tests under ICAs and CCAs. The cumulative damage model accurately predicted the total number of cycles and cyclic amplitude at failure. At least two cyclic load tests (i.e., one cyclic load test under ICA and one cyclic load test under CCA) must be performed to estimate the cumulative damage model parameters.

(d) The new approach provides additional insights into the interfacial cyclic response, such as the effect of previous cycles, the cyclic amplitude at failure, the number of cycles in the last stage of cycling and the displacement development throughout cycling.

The design of cyclic axial loaded piles is mostly based on CCA tests. Through this conventional method, cyclic failure can either occur quickly or not at all; hence, cyclic test times are unpredictable. Cyclic load tests under ICAs can overcome the conventional timeconsuming method and significantly reduce the number of tests required. From a practical viewpoint, this new approach can reduce the cost and duration of projects. 


\section{FINAL REMARKS}

This research sought to assess the shaft friction degradation of axially loaded piles in wind turbine deep foundations. Several issues related to the main objective of this study were addressed because onshore wind turbine foundations are an area of recent research, especially in Brazil. The following remarks highlighted the main breakthroughs.

Chapter 2 assesses key aspects regarding onshore wind turbine foundations worldwide and in Brazil. The main reason to explore this subject is that several authors consider onshore wind turbine foundations a well-understood topic; however, limited data from actual situations have been published, especially in developing countries where wind energy projects have recently started. Thus, a survey on Brazilian energy companies and foundation designers was conducted, and the first Brazilian database of wind turbine foundations was created. This database contains data from more than three thousand Brazilian wind turbine foundations. This chapter brought light to an area still seldom explored. New insights into the wind turbine foundations in Brazil were presented. For example, in Brazil, 43.3\% of wind turbines have shallow foundations, essentially concrete gravity, and $56.7 \%$ have deep foundations, mostly continuous flight auger piles. Worldwide, concrete gravity foundations are the most commonly used foundation type for onshore wind turbines. The foundation type was chosen according to the local foundation expertise and geotechnical conditions, which included soil type, water table level, soil layer resistance, the extent of porous soil layers and bedrock depth. Assessment of onshore wind turbine foundations could be used as a guidance, especially in Brazil, for new wind energy projects and for future researches in the area.

Approximately $70 \%$ of Brazilian wind turbine deep foundations used continuous flight auger piles, most of them embedded in sandy soils. Therefore, experimental investigations of the sand-concrete interface response under monotonic and cyclic loading are essential. A literature review of soil-solid interface response was presented in Chapter 3. This section provided essential information about the key factors affecting the interface response.

In Chapter 4, the sand-concrete interface response was assessed through monotonic interface direct shear tests under different confinement conditions. The role of surface structural characteristics, confinement condition, sand mean diameter, particle morphology, sand gradation and relative density were evaluated. A nonlinear conceptual model of the interfacial-to-internal friction angle ratio was proposed according to normalized roughness and normalized waviness. Additionally, a multiple regression was proposed to estimate the sand-concrete interface strength according to the constant normal stiffness. These results 
were essential to understand and to predict the sand-concrete interface response of concrete piles under static axial loading.

Chapter 5 explored the shaft friction degradation of cyclic axial loaded piles through sand-concrete and sand-steel cyclic interface direct shear tests. In geotechnical engineering practice, field and experimental tests are usually performed to evaluate the number of cycles until failure occurs under constant cyclic amplitude. According to this approach, cyclic failure can either occur quickly or not at all. From a practical viewpoint, the cyclic test times are unpredictable, which makes these tests difficult to plan and to perform. A new approach based on increasing cyclic amplitude is proposed to overcome the conventional method. A simple cumulative damage model established a relationship between the cyclic loaded tests under constant and increasing cyclic amplitudes. The new approach provides additional insights into the cyclic interfacial response, such as the effect of previous cycles, the cyclic amplitude at failure and the displacement development throughout cycling. This new approach can be effortlessly extended to other experimental and field investigations. From a practical viewpoint, this new approach can reduce the cost and duration of projects.

The author believes that this dissertation brought breakthroughs to the wind energy companies and to the geotechnical engineering community. However, further studies on onshore wind turbine foundations are still required, especially because wind energy has recently advanced in developing countries, such as Brazil. 


\section{REFERENCES}

Abhinav, K. A. and Saha, N. 2017. Stochastic response of jacket supported offshore wind turbines for varying soil parameters. Renewable Energy, 101: 550-564. doi: 10.1016/j.renene.2016.09.019.

ABNT. 2004. NBR 8681 - Actions and safety of structures. Brazilian Association of Technical Standards, Rio de Janeiro, 18 p.

ABNT. 2006. NBR 15421 - Design of seismic resistant structures. Brazilian Association of Technical Standards, Rio de Janeiro, 26 p.

ABNT. 2010. NBR 6122 - Design and construction of foundations. Brazilian Association of Technical Standards, Rio de Janeiro, 91 p.

ABNT. 2014. NBR 6118 - Design of structural concrete. Brazilian Association of Technical Standards, Rio de Janeiro, 238 p.

Aghakouchak, A., Sim, W.W., and Jardine, R.J. 2015. Stress-path laboratory tests to characterize the cyclic behaviour of piles driven in sands. Soils and Foundations, 55(5): 917-928. doi: 10.1016/j.sandf.2015.08.001.

Agora Energiewende. 2017. Future cost of onshore wind. Recent auction results, longterm outlook and implications for upcoming German auctions. Agora Energiewende, April, p. 32.

Airey, D.W., Al-Douri, R.H., and Poulos, H.G. 1992. Estimation of Pile Friction Degradation from Shearbox Tests. Geotechnical Testing Journal, 15(4): 388-392.

Andersen, L. V., Vahdatirad, M.J., Sichani, M.T., and Sørensen, J.D. 2012. Natural frequencies of wind turbines on monopile foundations in clayey soils-A probabilistic approach. Computers and Geotechnics, 43: 11 p. doi: 10.1016/j.compgeo.2012.01.010.

Antunes, W.R., and Cabral, D.A. 1996. Capacidade de carga de estacas hélice continua. Proceedings of SEFE, 3., São Paulo, 2: 105-109.

Antunes, W.R., Cabral, D.A. 2000. Sugestão para a Determinação da Capacidade de Carga de Estacas Escavadas Embutidas em Rocha. IV Seminário de Engenharia de Fundações Especiais - SEFE IV São Paulo, 1: 169-173.

Aquila, G., Pamplona, E.O., Queiroz, A.R., Junior, P.R., and Fonseca, M.N. 2017. An overview of incentive policies for the expansion of renewable energy generation in 
electricity power systems and the Brazilian experience. Renewable and Sustainable Energy Reviews, 70: 1090-1098. doi: 10.1016/j.rser.2016.12.013.

Aoki, N., and Velloso, D.A. 1975. An approximate method to estimate the bearing capacity of piles. Proceedings of Pan American CSMFE, 5., Buenos Aires, 1: 367376.

Aoki, N. 1987. Modelo simples de transferência de carga de estaca vertical sujeita a carga axial de compressão. Ciclo de palestras sobre Engenharia de Fundações, ABMS.

ASCE/AWEA. 2011. Recommended Practice for Compliance of Large Land-Based Wind Turbine Support Structures. 89p.

ASME B46.1. 2009. Surface texture: surface roughness, waviness, and lay. ASME standard B46.1. ASME, New York, NY.

ASTM. 2011. Direct shear test of soils under consolidated drained conditions. ASTM standard D3080. ASTM, West Conshohocken, PA. doi: 10.1520/D3080_D3080M-11.

ASTM. 2013. Standard test method for rebound number of hardened concrete. ASTM standard C805. ASTM, West Conshohocken, PA. doi: 10.1520/C0805_C0805M-13a.

ASTM. 2016. Standard test methods for maximum index density and unit weight of soils using vibratory table. ASTM standard D4253. ASTM, West Conshohocken, PA. doi: 10.1520/D4253-16.

ASTM. 2016. Standard test methods for minimum index density and unit weight of soils and calculation of relative density. ASTM standard D4254. ASTM, West Conshohocken, PA. doi: 10.1520/D4254-16.

ASTM. 2017. Standard Practice for Classification of Soils for Engineering Purposes (Unified Soil Classification System). ASTM standard D2487. ASTM, West Conshohocken, PA. doi: 10.1520/D2487-17.

Bekki, H., Canou, J., Tali, B., Dupla, J.-C., and Bouafia, A. 2013. Evolution of local friction along a model pile shaft in a calibration chamber for a large number of loading cycles. Comptes Rendus Mecanique, 341: 499-507. doi: 10.1016/j.crme.2012.11.012.

Berndt, M. L. 2015. Influence of concrete mix design on CO2 emissions for large wind turbine foundations. Renewable Energy. 83: 608-614. doi: 10.1016/j.renene.2015.05.002

Blanc, M., and Thorel, L. 2016. Effects of cyclic axial loading sequences on piles in sand. Géotechnique Letters, 6(2): 163-167. doi: 10.1680/jgele.15.00155. 
Borana, L., Yin, J.-H., Singh, D.N., and Shukla, S.K. 2016. Interface behaviour from suction-controlled direct shear test on completely decomposed granitic soil and steel surfaces. International Journal of Geomechanics, 16(6): 4016008. doi: 10.1061/(ASCE)GM.1943- 5622.0000658.

Brazilian Wind Energy Association. 2017. 2016 Annual Wind Power Generation Report. São Paulo, 17 p.

Brazilian Wind Energy Association .2018a. 2017 Annual Wind Power Generation Report. São Paulo, 28 p.

Brazilian Wind Energy Association. 2018b. Energia Eólica, Os bons ventos do Brasil: InfoVento no 6. p. 2.

Boulon, M., and Foray, P. 1986. Physical and numerical simulation of lateral shaft friction along offshore piles in sand. In Proceedings of the 3rd International Conference on Numerical Methods in Offshore Piling. Paris, France. pp. 127-148.

Brasfond. 1991. Catálogo técnico de fundações especiais: estaca raiz. São Paulo, 38p.

Brumund, W.F., and Leonards, G.A. 1973. Experimental study of static and dynamic friction between soil and typical construction materials. Journal of Testing and Evaluation, 1(2): 162-165.

Cabral, D.A. 1986. O uso da estaca raiz como fundação de obras normais. Proceedings of CBMSEF, 8., Porto Alegra, 6: 71-82.

Canakci, H., Hamed, M., Celik, F., Sidik, W., and Eviz, F. 2016. Friction characteristics of organic soil with construction materials. Soils and Foundations, 56(6): 965-972. doi: 10.1016/j.sandf.2016.11.002.

Casa dos Ventos. 2019. Photograph: Wind turbines in Ventos do Araripe III wind farm. Available from http:// http://casadosventos.com.br/en-us/projects/wind-farms [accessed 27 July 2019].

Chaussê, W. 2014. Artwork: Potencial eólico. In: Ibelli, R.C. Impostos atravancam o vento e solo. Available at: https://especiais.dcomercio.com.br/luz-energia-brasil/ (accessed 10 November 2018).

Chen, X., Zhang, J., Xiao, Y., and Li, J. 2015. Effect of roughness on shear behaviour of red clay - concrete interface in large-scale direct shear tests. Canadian Geotechnical Journal, 52(8): 1122-1135. doi: 10.1139/cgj-2014-0399.

Chin, J. T., and Poulos, H. G. 1996. Tests on model jacked piles in calcareous sand. Geotechnical Testing Journal, 19(2): 164-180. doi: 10.1520/GTJ10339J. 
Chu, L.M., and Yin, J.-H. 2006. Study on soil-cement grout interface shear strength of soil nailing by direct shear box testing method. Geomechanics and Geoengineering: An International Journal, 1(4): 259-273. doi: 10.1080/17486020601091742.

Coyle, H. M., and Reese, L. C. 1966. Load transfer for axially loaded piles in clay. Journal of soil mechanic and Foundation Division (ASCE), 92(SM2): 26 p.

Crawford, R. H. 2009. Life cycle energy and greenhouse emissions analysis of wind turbines and the effect of size on energy yield. Renewable and Sustainable Energy Reviews, 13(9): 2653-2660. doi: 10.1016/j.rser.2009.07.008.

Cresesb. 2001. Atlas do Potencial Eólico Brasileiro. Centro de Referência para as Energias Solar e Eólica Sérgio de S. Brito, Brasília, 44 p.

Décourt, L., and Quaresma, A.R. 1978. Capacidade de carga de estacas a partir de valores de SPT. Proceedings of CBMSEF, 6., Rio de Janeiro, 1: 45-53.

Décourt, L., and Quaresma, A.R. 1982. Como calcular (rapidamente) a capacidade de carga limite de uma estaca. A construção de São Paulo, nº 1800.

Dejong, J. T., Frost, J. D., and Sacs, M. 2000. Relating quantitative measures of surface roughness and hardness to to geomaterial interface strength. Proceedings of GeoEngineering. Sydney, Australia, 6 p.

DeJong, J. T., and Frost, J.D. 2002. A multisleeve friction attachment for the conepenetrometer. Geotechnical Testing Journal, 25(2): 111-127.

DeJong, J. T., Randolph, M. F., and White, D. J. 2003. Interface Load Transfer Degradation During Cyclic Loading: A Microscale Investigation. Soils and Foundations, 43(4): 81-93. doi: 10.3208/sandf.43.4_81.

DeJong, J. T., and Westgate, Z. J. 2009. Role of initial state, material properties, and confinement condition on local and global soil-structure interface behaviour. Journal of Geotechnical and Geoenvironmental Engineering, 135(11): 1646-1660. doi: 10.1061/(ASCE)1090-0241(2009)135:11(1646).

Dietz, M.S., and Lings, M.L. 2006. Postpeak strength of interfaces in a stress-dilatancy framework. Journal of Geotechnical and Geoenvironmental Engineering, 132(11): 1474-1484. doi: 10.1061/(ASCE)1090-0241(2006)132:11(1474).

Di Donna, A., Ferrari, A., and Laloui, L. 2016. Experimental investigations of the soilconcrete interface: physical mechanisms, cyclic mobilization and behaviour at different temperatures. Canadian Geotechnical Journal, 53(4): 659-672. doi: 10.1139/cgj-2015-0294. 
DNV/Ris $\varnothing$. 2002. Guidelines for design of wind turbines - Second Edition. Det Norske Veritas, Copenhagen, and Wind Energy Department, Ris $\varnothing$ National Laboratory. Denmark, 294 p.

Dove, J. E., and Frost, J. D. 1999. Peak friction behavior of smooth geomembrane-particle interfaces. Journal of Geotechnical and Geoenvironmental Engineering, 125(7): 544555.

EN 1992-1-1. 2004. Design of Concrete Buildings - Part 1-1: General rules and rules for buildings. Luxembourg, $186 \mathrm{p}$.

EN 1997-1. 2004. Eurocode 7: Geotechnical Design - Part 1: General rules. Luxembourg, $168 \mathrm{p}$.

EN 1997-2. 2007. Eurocode 7: Geotechnical Design - Part 2: Ground investigation and testing. Luxembourg, $196 \mathrm{p}$.

Enevoldsen, P. and Valentine, S. V. 2016. Do onshore and offshore wind farm development patterns differ?. Energy for Sustainable Development, 35: 41-51. doi: 10.1016/j.esd.2016.10.002.

EPE. 2018. Brazilian Energy Balance: year 2017. Energy Research Office. Rio de Janeiro, p. 294.

Evgin, E., and Fakharian, K. 1996. Effect of stress paths on the behaviour of sand-steel interfaces. Canadian Geotechnical Journal, 33(6): 853-865.

EWEA. 2011. Design limits and solutions for very large wind turbines: A 20 MW turbine is feasible. European Wind Energy Association, UpWind, Brussels, March: 108 p.

Fakharian, K., and Evgin, E. 1996. An automated apparatus for three-dimensional monotonic and cyclic testing of interfaces. Geotechnical Testing Journal, 19(1): 2231. doi: 10.1139/t96-116-336.

Fakharian, K. and Evgin, E. 1997. Cyclic Simple-Shear Behavior of Sand-Steel Interfaces Under Constant Normal Stiffness Condition. Journal of Geotechnical and Geoenvironmental Engineering, 123(12): 1096-1105.

Faro Technologies. 2018. Design ScanArm 2.0. Faro Technologies Incorporation. Lake Mary, Florida, United States. http://www.faro.com

Feligha, M., Hammoud, F., Belachia, M., and Nouaouria, M.S. 2016. Experimental investigation of frictional behaviour between cohesive soils and solid materials using direct shear apparatus. Geotechnical and Geological Engineering, 34(2): $567-$ 578. doi: 10.1007/s10706-015-9966-5. 
Ferreira, A.C.; Blasques, L.C.M.; and Pinho, J.T. 2014. Analysis about the evolution of the hired and installed capacity and of the costs of wind energy in brazil: from PROINFA to energy auctions. Revista Brasileira de Energia Solar, 5(1): 82-91.

Fioravante, V., Ghionna, V.N., Pedroni, S., and Porcino, D. 1999. A constant normal stiffness direct shear box for soil-soil interface. Rivista Italiana di Geotecnica, $16 \mathrm{p}$.

Frank, R.; Bauduin, C.; Driscoll, R.; Kavvadas, M.; Ovesen, N.K.; Orr, T.; Schuppener, N.; and Gulvanessian, H. 2005. Designers' Guide to EN 1997-1 Eurocode 7: Geotechnical Design - General Rules. January, p. 213.

Fredlund, D.G., Morgenstern, N.R., and Widger, R.A. 1978. The shear strength of unsaturated soils. Canadian Geotechnical Journal, 15(3): 313-321. doi: 10.1139/t78029.

Frost, J. D., DeJong, J. T., and Recalde, M. 2002. Shear failure behavior of granularcontinuum interfaces. Engineering Fracture Mechanics, 69: 2029-2048. doi: 10.1016/S0013-7944(02)00075-9.

Frost, J.D., and DeJong, J. T. 2005. In situ assessment of role of surface roughness on interface response. Journal of Geotechnical and Geoenvironmental Engineering, 131(4): 498-511. doi: 10.1061/(ASCE)1090-0241(2005)131:4(498).

Frost, J.D., and DeJong, J. T., and , M. 2002. Shear failure behaviour of granularcontinuum interfaces. Engineering Fracture Mechanics, 69: 2029-2048.

Gavin, K. G., and O'Kelly, B. C. 2007. Effect of Friction Fatigue on Pile Capacity in Dense Sand. Journal of Geotechnical and Geoenvironmental Engineering, 133(1): 6371. doi: 10.1061/(ASCE)1090-0241(2007)133.

Germanischer Lloyd. 2010. Guideline for the Certification of Wind Turbines. Hamburg, July, 384 p.

Ghionna, V. N. and Mortara, G. 2002. An elastoplastic model for sand-structure interface behavior. Géotechnique, 52(1): 41-50. doi: 10.1680/geot.2002.52.1.41.

Godoy, N. S., and Teixeira, A.T. 1996. Análise, Projeto e execução de Fundações rasas. Fundações: teoria e prática. São Paulo, chapter 7: 227-264.

Gómez, J.E., Filz, G.M., Ebeling, R.M., and Dove, J.E. 2008. Sand-to-concrete interface response to complex load paths in a large displacement shear box. Geotechnical Testing Journal, 31(4): 358-369.

Guezuraga, B., Zauner, R. and Pölz, W. 2012. Life cycle assessment of two different 2 MW class wind turbines. Renewable Energy. 37(1): 37-44. doi: 10.1016/j.renene.2011.05.008. 
GWEC and Brazilian Wind Energy Association. 2011. Analysis of the regulatory framework for wind power generation in Brazil. Global Wind Energy Council, Brussels, Belgium, 48 p.

GWEC. 2016. The Global Wind Energy Outlook - 2016. Global Wind Energy Council, Brussels, October, 44 p.

GWEC. 2017. Global Wind Statistics 2016. Global Wind Energy Council, Brussels, February, 4 p.

GWEC. 2018. Global Wind Statistics 2017. Global Wind Energy Council, Brussels, April, p. 4.

Hamid, T.B., and Miller, G.A. 2009. Shear strength of unsaturated soil interfaces. Canadian Geotechnical Journal, 46(5): 595-606. doi: 10.1139/T09-002.

Hansen, J.B. 1961. A general formula for bearing capacity. Danish Geoteknisk Institut, Copenhagen, Bulletin ${ }^{\circ} 11$.

Hardin, B. O., and Drnevich, V. P. 1972. Shear modulus and damping in soils: design equations and curves. Journal of the Soil Mechanics and Foundations Division, 98(SM7): 667-692. doi: 10.1017/S000748530002229X.

Hassanzadeh, M. 2012. Cracks in Onshore Wind Power Foundations: Causes and Consequences. Elforsk rapport. Stockholm, January, 68 p.

Hernández, C.V., Telsnig, T. and Pradas, A.P. 2017. JRC Wind Energy Status Report 2016 Edition. Luxembourg: Publications Office of the European Union, 62 p. doi:10.2760/332535.

Ho, T.Y.K., Jardine, R.J., and Anh-Minh, N. 2011. Large-displacement interface shear between steel and granular media. Géotechnique, 61(3): 221-234. doi: 10.1680/geot.8.P.086.

Horgan, C. 2013. Using energy payback time to optimise onshore and offshore wind turbine foundations. Renewable Energy, 53: 287-298. doi: 10.1016/j.renene.2012.10.044.

Hossain, Md. A., and Yin, J.-H. 2014. Dilatancy and strength of an unsaturated soilcement interface in direct shear tests. International Journal of Geomechanics, 15(5): 04014081. doi: 10.1061/(ASCE)GM.1943-5622.0000428.

International Electrotechnical Commission (IEC) 61400-1. 2005. Wind Turbines - Part 1: Design requirements. November, $90 \mathrm{p}$. 
IEA-ETSAP and IRENA. 2016. Wind power - technology Brief. International Energy Agency - Energy Technology Systems Analysis Programme, and International Renewable Energy Agency. March, 28 p. doi: 10.1049/ep.1976.0231.

IEC 61400-1. 2005. Wind Turbines - Part 1: Design requirement. International Electrotechnical Commission, p. 90.doi: 10.1615/AtoZ.w.wind_turbines.

Ilori, A.O., Udoh, N.E., and Umenge, J.I. 2017. Determination of soil shear properties on a soil to concrete interface using direct shear box apparatus. Geo-Engineering, 8(17), 14 p. doi: 10.1186/s40703-017-0055-x.

InnovMetric Software. 2014. Polyworks version, Quebec City. http://www.innovmetric.com

IRENA. 2016. The Power to Change: Solar and Wind Cost Reduction Potential to 2025. RenewableUK, June, p. 112.

IRENA. 2017. Renewable energy benefits: Leveraging local capacity for onshore wind. International Renewable Energy Agency, Abu Dhabi, 28 p.

Irsyam, M., and Hryciw, R.D. 1991. Friction and passive resistance in soil reinforced by plane ribbed inclusions. Géotechnique, 41(4): 485-498.

Ismael, N. F. 1982. Design of shallow rock-anchored foundations. Canadian Geotechnical Journal, 19(4): 463-471. doi: 10.1061/9780784403716.

ISO. 2006. Particle size analysis - image analysis methods - part 2: dynamic image analysis methods. International standard 13322-2. ISO, Geneva, Switzerland.

Jardine, R.J., Lehane, B.M., and Everton, S.J. 1993. Friction Coefficients for Piles in Sands and Silts. Offshore Site Investigation and Foundation Behaviour, 28: 661-677.

Jardine, R., Chow, F., Overy, R., and Standing, J. 2005. ICP Design Methods for Driven Piles in Sand and Clays. Thomas Telford, London, 105 p. doi: 10.1680/idmfdpisac.32729.

Jardine, R.J., and Standing, J.R. 2012. Field axial cyclic loading experiments on piles driven in sand. Soils and Foundations, 52(4): 723-736. doi: 10.1016/j.sandf.2012.07.012.

Kaldellis, J.K., Apostolou, D., Kapsali, M., and Kondili, E. 2016. Life cycle energy and carbon footprint of offshore wind energy. Comparison with onshore counterpart. Renewable Energy, 92: 543-556. doi: 10.1016/j.renene.2017.02.039.

Kim, M.H., and O’Neill, M.W. 1998. Side Shear Induced in Drilled Shaft by Suction Change. Journal of Geotechnical and Geoenvironmental Engineering, 124(8): 771780. doi: 10.1061/(ASCE)1090-0241(1998)124:8(771). 
Lang, P.J. 2012. Sensitivity of shallow wind turbine foundation design and soil response to geotechnical variance with construction cost implications. M.S. thesis, University of Wisconsin, Madison.

Lehane, B.M., Jardine, R.J., Bond, A.J., and Frank, R. 1993. Mechanisms of Shaft Friction in Sand From Instrumented Pile tests. Journal of Geotechnical Engineering, 119(1): $19-35$.

Lee, C.Y., and Poulos, H.G. 1991. Tests on Model Instrumented Grouted Piles in Offshore Calcareous Soil. Journal of Geotechnical Engineering, 117(11): 1738-1753. Lee, C.Y., and Poulos, H.G. 1992. Static and Cyclic Load Tests on Model Grouted Piles in Marine Calcareous Sediments. Geotechnical Engineering, 23: 5-27.

Li, Z., Bolton, M.D., and Haigh, S.K. 2012. Cyclic axial behaviour of piles and pile groups in sand. Canadian Geotechnical Journal, 49: 1074-1087. doi: 10.1139/t2012-070.

Liang, Y., Lu, X.-Z., Wang, J.-J., and Liu, M.-W. 2016. Experimental Study of Shear Behavior of Interfaces Between Crushed Sandstone-Mudstone Particle Mixture and Smooth Steel Plate. Soil Mechanics and Foundation Engineering, 53(3): 158165. doi: 10.1007/s11204-016-9380-x.

Liu, J.-W., Zhang, Z.-M., Yu, F., and Zhao, Y.-B. 2012. Estimation of friction fatigue for preformed piles based on constant normal stiffness shear test. Chinese Journal of Geotechinal Engineering, 34(4): 725-729.

Liu, J., Lv, P., Chui, Y., and Liu, J. 2014. Experimental study on direct shear behaviour of frozen soil-concrete interface. Cold Regions Science and Technology, 104105(August-September): 1-6. doi:10.1016/j.coldregions.2014.04.007.

Luna, D. 2018. Petrobrás vai gerar energia eólica no mar. O Estado de São Paulo. https://economia.estadao.com.br/noticias/geral,petrobras-vai-gerar-energia-eolica-nomar,70002412545. (accessed November 2018).

Martínez, E.; Sanz, F.; Pellegrini, S.; Jiménez, E.; and Blanco, J. 2009. Life-cycle assessment of a 2-MW rated power wind turbine: CML method. International Journal of Life Cycle Assessment, 14:52-63. doi: 10.1007/s11367-008-0033-9.

Martinez, A., and Frost, J.D. 2017. The influence of surface roughness form on the strength of sand-structure interfaces. Géotechnique Letters, 7(1): 104-111. doi: 10.1680/jgele.16.00169.

Miller, G.A., and Hamid, T.B. 2006. Interface direct shear testing of unsaturated soil. Geotechnical Testing Journal, 30(3): 1-10. 
Miner, M. 1945. Cumulative damage in fatigue. Journal if applied mechanics, 12(3): 159164.

Mohamed, W. and Austrell, P. E. 2017. A comparative study of three onshore wind turbine foundation solutions. Computers and Geotechnics, 94: 46-57. doi: 10.1016/j.compgeo.2017.08.022.

Morgan, K. and Ntambakwa, E. 2008. Wind Turbine Foundation Behavior and Design Considerations. AWEA WINDPOWER Conference, Houston, p. 14.

Mortara, G., Mangiola, A., and Ghionna, V.N. 2007. Cyclic shear stress degradation and post-cyclic behaviour from sand-steel interface direct shear tests. Canadian Geotechnical Journal, 44(7): 739-752. doi: 10.1139/t07-019.

Negro, V.; López-Gutiérrez, J.-S.; Esteban, M D.; and Matutano, C. 2014. Uncertainties in the design of support structures and foundations for offshore wind turbines. Renewable Energy, 63:125-132. doi: 10.1016/j.renene.2013.08.041.

Ntambakwa, E.; Yu, H.; Guzman, C.; and Rogers, M. 2016. Geotechnical Design Considerations for Onshore Wind Turbine Shallow Foundations. ASCE Geotechnical and Structural Engineering Congress 2016, pp. 1153-1165.

Oumarou, T.A., and Evgin, E. 2005. Cyclic behaviour of a sand-steel plate interface. Canadian Geotechnical Journal, 42(6): 1695-1704. doi: 10.1139/T05-083.

Oztoprak, S. and Bolton, M.D. 2013. Stiffness of sands through a laboratory test database. Géotechnique, 63(1): 54-70. doi: 10.1680/geot.10.P.078.

Paikowsky, S.G., Player, C.M., and Connors, P.J. 1995. A dual interface apparatus for testing unrestricted friction of soil along solid surfaces. Geotechnical Testing Journal, 18(2): 168-193.

Palmgren, A. 1924. Die Lebensdauer von Kugellagern (Life Length of Roller Bearings. In German).

Peikko. 2017. Online catalogue of projects by Peikko. Available from https://www.peikko.com/ [accessed 13 November 2017].

Pham, H. V.; Dias, D.; Miranda, T.; Cristelo, N.; and Araújo, N. 2018. 3D Numerical Modeling of Foundation Solutions for Wind Turbines. International Journal of Geomechanics, 18(12): p. 14. doi: 10.1061/(ASCE)GM.1943-5622.0001318.

Porcino, D., Fioravante, V., Ghionna, V.N., and Pedroni, S. 2003. Interface behaviour of sands from constant normal stiffness direct shear tests. Geotechnical Testing Journal, 26(3): 289-301. 
Potyondy, J.G. 1961. Skin friction between various soils and construction materials. Géotechnique, 11: 339-353.

Poulos, H.G., and Davis, E.H. 1980. Pile Foundation Analysis and Design. John Wiley and Sons Inc, 410 p. doi: 10.1016/0013-7952(84)90010-3.

Poulos, H.G. 1988. Cyclic Stability Diagram for Axially Loaded Piles. Journal of Geotechnical Engineering, 114(8): 877-895. doi: 10.1061/(ASCE)07339410(1988)114:8(877).

Poulos, H.G. 1989. Cyclic Axial Loading Analysis of Piles in Sand. Journal of Geotechnical Engineering, 115(6): 836-852.

Pra-ai, S. and Boulon, M. 2016. Soil-structure cyclic direct shear tests: a new interpretation of the direct shear experiment and its application to a series of cyclic tests. Acta Geotechnica, 12(1): 107-127. doi: 10.1007/s11440-016-0456-6.

Puech, A.; and Garnier, J. 2017. Design of piles under cyclic loading - SOLCYP Recommendations. ISTE Ltd and John Wiley \& Sons, Inc. 443 p.

Pytlik, R. 2016. Soil Fatigue due to cyclically loaded foundations. Thesis presented to the Luxembourg University, $219 \mathrm{p}$.

Qian, J.-G., Gao, Q., Xue, J.-F., Chen, H.-W., and Huang, M.-S. 2017. Soil and ribbed concrete slab interface modeling using large shear box and 3D FEM. Geomechanics and Engineering, 12(2): 295-312. doi: 10.12989/gae.2017.12.2.295.

Randolph, M.F., and Wroth, C.P. 1978. Analysis of deformation of vertically loaded piles. Journal of the Geotechnical Engineering Division, 104(GT12): 23p.

Rasband, W.S. 2018. ImageJ 1.52a. U. S. National Institutes of Health, Bethesda, Maryland, USA. https://imagej.nih.gov/ij.

Rebelo, C., Moura, A., Gervásio, H., Veljkovic, M., and Silva, L.S. 2014. Comparative life cycle assessment of tubular wind towers and foundations - Part 1: Structural design. Engineering Structures, 74: 292-299. doi: 10.1016/j.engstruct.2014.02.041.

Reddy, E.S., Chapman, D.N., and Sastry, V.V.R.N. 2000. Direct shear interface test for shaft capacity of piles in sand. Geotechnical Testing Journal, 23(2): 199-205.

Royal Academy of Engineering. 2014. Wind energy - Implication of large-scale deployment on the GB electricity system. London, April, 72 p.

Samanta, M., Punetha, P., and Sharma, M. 2018a. Effect of roughness on interface shear behaviour of sand with steel and concrete surface. Geomechanics and Engineering, 14(4): 387-398. doi: 10.12989/gae.2018.14.4.387. 
Samanta, M., Punetha, P., and Sharma, M. 2018b. Influence of surface texture on sand-steel interface strength response. Géotechnique Letters, 8(1): 40-48. doi: 10.1680/jgele.17.00135.

Seed, B.H. and Idriss, I.M. 1970. Soil modules and damping factors for dynamic response analyses. Earthquake Engineering Research Center, University of California, 48 p.

Shrestha, S. 2015. Design and Analysis of Design and Analysis of foundation for onshore tall wind turbines. M.S. thesis, Clemson University, 237 p.

Shrestha, S. and Ravichandran, N. 2016. Design and Analysis of Foundations for Onshore Tall Wind Turbines. Geo-Chicago 2016 GSP 270, pp. 217-226.

SIC. 2017. Online catalogue of projects by Stenger \& Ibsen Construction. Available from https://si-construction.com/ [accessed 13 November 2017].

Siemens. 2013. Photograph: Wind turbines in Anholt wind farm. Available from https://www.siemens.com/press/en/feature/2013/energy/2013-09-anholt.php [accessed 27 July 2019].

Souza, R.A., and Reis, J.H.C. 2008. Interação solo- Interação solo-estrutura para edifícios sobre fundações rasas. Acta Scientiarum Technology, 30(2): 161-171. doi: 10.4025/actascitechnol.v30i2.5467.

Su, L.-J.; Zhou, W.-H.; Chen, W.-B.; and Jie, X. 2018. Effects of relative roughness and mean particle size on the shear strength of sand-steel interface. Measurement, 122: $339-346$.

Svensson, H. 2010. Design of Foundations For Wind Turbines. M.S. thesis. Lund University. Sweden, p. 161.

Tabucanon, J.T., Airey, D.W., and Poulos, H.G. 1995. Pile skin friction in sands from constant normal stiffness tests. Geotechnical Testing Journal, 18(3): 350-364.

Taha, A., and Fall, M. 2013. Shear behaviour of sensitive marine clay-concrete interfaces. Journal of Geotechnical and Geoenvironmental Engineering, 139(4): 644-650. doi: 10.1061/(ASCE)GT.1943-5606.0000795.

Tehrani, F.S., Han, F., Salgado, R., Prezzi, M., Tovar, R.D., and Castro, A.G. 2016. Effect of surface roughness on the shaft resistance of non-displacement piles embedded in sand. Géotechnique, 66(5): 386-400. doi: 10.1680/jgeot.15.P.007.

Teixeira, A.H. 1966. Correlação entre capacidade de carga das argilas e a resistência à penetração. Proceedings of III Congresso Brasileiro de Mecânica dos Solos, Belo Horizonte, 1: 55-69.

Teixeira, A.H. 1996. Projeto e execução de fundações. Proceedings of SEFE, 3. São Paulo. 
Terzaghi, K. 1943. Theoretical soil mechanics. New York: John Wiley \& Sons.

Terzaghi, K., and Peck, R.B. 1948. Soil mechanics in engineering practice. New York: John Wiley \& Sons.

Tinjum, J. M. and Christensen, R. W. 2010. Chapter 2: Site investigation, characterization and assessment for wind turbine design and construction. In Wind Energy Systems: Optimising Design and Construction for Safe and Reliable Operation. Woodhead Publishing Limited, pp. 26-45. doi: 10.1533/9780857090638.1.28.

Tiwari, B., and Al-Adhadh, A.R. 2014. Influence of relative density on static soil-structure frictional resistance of dry and saturated sand. Geotechnical and Geological Engineering, 32(2): 411-427. doi: 10.1007/s10706-013-9723-6.

Tsuha, C.H.C., Foray, P.Y., Jardine, R.J., Yang, Z.X., Silva, M., and Rimoy, S. 2012. Behaviour of displacement piles in sand under cyclic axial loading. Soils and Foundations. 52(3): 393-410. doi: 10.1016/j.sandf.2012.05.002.

Uesugi, M., and Kishida, H. 1986a. Influential factors of friction between steel and dry sands. Soils and Foundations, 26(2): 33-46.

Uesugi, M., and Kishida, H. 1986b. Frictional resistance at yield between dry sand and mild steel. Soils and Foundations, 26(4): 139-149.

Uesugi, M., Kishida, H., and Tsubakihara, Y. 1988. Behavior of sand particles in sand-steel friction. Soils and Foundations, 28(1): 107-118. doi: http://dx.doi.org/10.3208/sandf1972.28.107.

Uesugi, M., Kishida, H., and Tsubakihara, Y. 1989. Friction between sand and steel under repeated loading. Soils and Foundations, 29(3): 127-137. doi: 10.1248/cpb.37.3229.

Uesugi, M., Kishida, H., and Uchikawa, Y. 1990. Friction between dry sand and concrete under monotonic and repeated loading. Soils and Foundations, 30(1): 115-128.

Uesugi, M. and Kishida, H. 1991. Discussion of "Cyclic axial loading analysis of piles in Sand" by Poulos. Journal of Geotechnical Engineering, 117(9): 1435-1437.

U.S. Department of Energy. 2017. Wind Technologies Market Report 2016. Office of Energy Efficiency and Renewable Energy, United States, August, 94 p.

Vanapalli, S.K., Fredlund, D.G., Pufahl, D.E., and Clifton, A.W. 1996. Model for the prediction of shear strength with respect to soil suction. Canadian Geotechnical Journal, 33: 379-392. doi: 10.1139/t96-060.

Vesic, A.S. 1977. Design of pile foundations. National Cooperative Highway Research Program, Synthesis Highway Practice Report, 42: 80 p. 
Wang, J., Liu, S., and Cheng, Y.P. 2017. On the role of normal boundary condition in interface shear test for the determination of skin friction along pile shaft. Canadian Geotechnical Journal, 54(9): 1245-1256. doi: 10.1139/cgj-2016-0312.

Wind Europe. 2017. Wind in power - 2016 European Statistics. Brussels, February, 24 p. doi: 10.1007/s10854-007-9177-9.

Wolf, T.F., 1989. Pile Capacity Prediction Using Parameter Functions. ASCE Geotechnical Special Publications, No 23: 96-106.

Yang, Z. X., Jardine, R. J., Zhu, B. T., Foray, P., and Tsuha, C. H. C., 2010. Sand grain crushing and interface shearing during displacement pile installation in sand. Géotechnique, 60(6): 469-482. doi: 10.1680/geot.2010.60.6.469.

Yavari, N., Tang, A.M., Pereira, J.-M., and Hassen, G. 2016. Effect of temperature on the shear strength of soils and soil-structure interface. Canadian Geotechnical Journal, 53(7): 1186-1194. doi: 10.1139/cgj-2015-0355.

Ziegler, L.; Gonzalez, E.; Rubert, T.; Smolka, U.; and Melero, J. J. 2018. Lifetime extension of onshore wind turbines: A review covering Germany, Spain, Denmark, and the UK. Renewable and Sustainable Energy Reviews, 82: 1261-1271. doi: 10.1016/j.rser.2017.09.100. 